U.S. A rmy Poast. Eng. Pees etr.TP

TP $80-2$

\title{
Energy Spectra
}

in

\section{Shallow U. S. Coastal Waters}

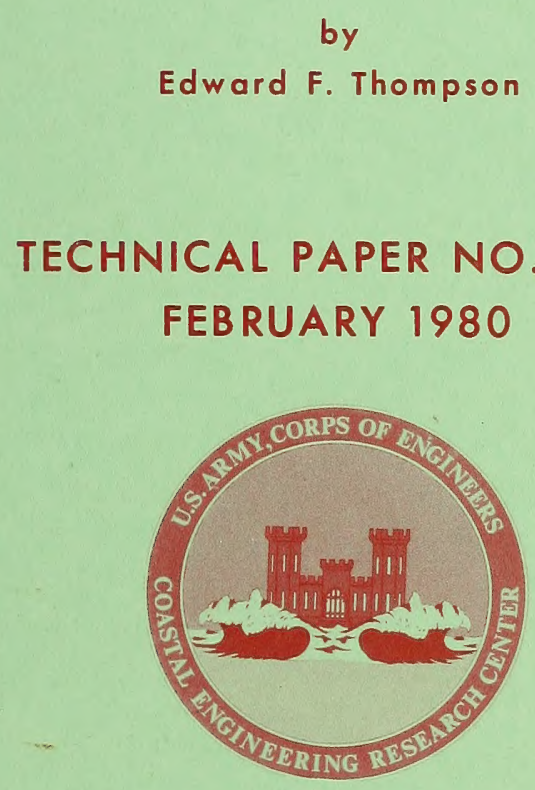

Approved for public release; distribution unlimited.

\section{U.S. ARMY, CORPS OF ENGINEERS COASTAL ENGINEERING "RESEARCH CENTER \\ Kingman Building \\ Fort Belvoir, Va. 22060}


Reprint or republication of any of this material shall give appropriate credit to the U.S. Army Coastal Engineering Research Center.

Limited free distribution within the United States of single copies of this publication has been made by this Center. Additional copies are available from:

\section{National Technical Information Service ATTN: Operations Division 5285 Port Royal Road \\ Springfield, Virginia 22161}

Contents of this report are not to be used for advertising, publication, or promotional purposes. Citation of trade names does not constitute an official endorsement or approval of the use of such commercial products.

The findings in this report are not to be construed as an official Department of the Army position unless so designated by other authorized documents. 


\begin{tabular}{|c|c|}
\hline REPORT DOCUMENTATION PAGE & $\begin{array}{l}\text { READ INSTRUCTIONS } \\
\text { BEFORE COMPLETING FORM }\end{array}$ \\
\hline 2. GOVT ACCESSION NO. & 3. RECIPIENT'S CATALOG NUMBER \\
\hline $\begin{array}{l}\text { 4. TITLE (and Subtitie) } \\
\text { ENERGY SPECTRA IN SHALLOW U.S. COASTAL WATERS }\end{array}$ & $\begin{array}{l}\text { 5. TYPE OF REPORT \& PERIOD COVERED } \\
\text { Technical Paper }\end{array}$ \\
\hline & 6. PERFORMING ORG. REPORT NUMBER \\
\hline $\begin{array}{l}\text { 7. AUTHOR(a) } \\
\text { Edward F. Thompson }\end{array}$ & 8. CONTRACT OR GRANT NUMBER( $(\theta)$ \\
\hline $\begin{array}{l}\text { 9. PERFORMING ORGANIZATION NAME AND ADDRESS } \\
\text { Department of the Army } \\
\text { Coastal Engineering Research Center (CERRE-CO) } \\
\text { Kingman Building, Fort Belvoir, Virginia 22060 }\end{array}$ & $\begin{array}{l}\text { 10. PROGRAM ELEMENT, PROJECT, TASK } \\
\text { AREA \& WORK UNIT NUMBERS } \\
\text { A } 31463\end{array}$ \\
\hline $\begin{array}{l}\text { 11. CONTROLLING OFFICE NAME AND ADDRESS } \\
\text { Department of the Army }\end{array}$ & $\begin{array}{l}\text { 12. REPORT DATE } \\
\text { February } 1980\end{array}$ \\
\hline $\begin{array}{l}\text { Coastal Engineering Research Center } \\
\text { Kingman Building, Fort Belvoir, Virginia } 22060\end{array}$ & $\begin{array}{l}\text { 13. NUMBER OF PAGES } \\
149\end{array}$ \\
\hline 14. MONITORING AGENCY NAME \& ADDRESS(It different from Controlling Office) & $\begin{array}{l}\text { 15. SECURITY CLASS. (of this roport) } \\
\text { UNCLASSIFIED }\end{array}$ \\
\hline & $\begin{array}{l}\text { 15a. DECLASSIFICATION/DOWNGRADING } \\
\text { SCHEDULE }\end{array}$ \\
\hline
\end{tabular}

Approved for public release; distribution unlimited.

17. DISTRIBUTION STATEMENT (of the abstract antored in Block 20, if difforent from Report)

18. SUPPLEMENTARY NOTES

19. KEY WORDS (Continue on reverse side If necessary and identlfy by block number)

Coastal engineering Spectral parameters Wave energy spectra
Wave gages

Waves

20. ABSTAACT (Continue en rovores ofide if mecoveary and tdentlty by block number)

Digital wave analyses for 3 to 12 months of data from each of $11 \mathrm{U} . \mathrm{S}$. coastal gages are summarized and discussed. Water depths at the gage sites were typically between 5 and 9 meters. The gage designs included step resistance, continuous wire, pressure, and accelerometer buoy. The analysis for each record included computation of the energy (or variance) spectrum and the distribution function of sea-surface elevations. Parameters of the spectrum and distribution function of sea-surface elevations were also computed. (continued) 
Spectra and parameters for the 24 highest energy cases from each gage location are presented individually. Spectra for all cases are grouped according to significant wave height and peak spectral period. Mean spectra and standard deviations about the mean are presented for most height-period groups. Parameters for all cases are summarized, including number of major spectral peaks, spectral-peakedness parameter, and third and fourth moments of the normalized distribution function of sea-surface elevations.

Multipeaked spectra are common at all locations. Mean spectra show evidence of systematic changes in shape as a function of significant height and peak spectral period. Values of the spectral-peakedness parameter range from about one to eight. The distribution functions of sea-surface elevations indicate a tendency for more extreme high values than low and for a more narrow distribution function than the Gaussian distribution. Observed characteristics are related to physical wave behavior and illustrated with three cases from cnoidal wave theory. Evidence is presented that the ratio of significant wave height to water depth does not exceed 0.55 in depths of 5 to 9 meters. 


\section{PREFACE}

This report provides coastal engineers and researchers with wave energy spectra and spectral parameters for nine shallow-water gage locations along the U.S. Atlantic, Pacific, gulf, and Great Lakes coasts. Insight is also provided on the physical meaning of shallowwater spectra, which are becoming increasingly important in coastal engineering work. The work was carried out under the waves and coastal flooding research program of the U.S. Army Coastal Engineering Research Center (CERC).

This report was prepared by Edward F. Thompson, Hydraulic Engineer, under the supervision of Dr. C.L. Vincent, Chief, Coastal Oceanography Branch, and his predecessor, Dr. D.L. Harris.

The guidance and constructive comments provided by Drs. Vincent and Harris are gratefully acknowledged. The computer program in Appendix D was developed by Dr. Harris. The assistance of D.G. Dumm in preparing some of the tables and figures is appreciated. Special appreciation is due the CERC Automatic Data Processing Office for outstanding support in producing the voluminous computer printouts and plots generated for this report.

Comments on this publication are invited.

Approved for publication in accordance with Public Law 166, 79th Congress, approved 31 July 1945, as supplemented by Public Law 172, 88 th Congress, approved 7 November 1963.

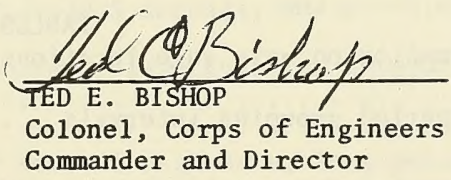


CONTENTS

Page

CONVERSION FACTORS, U.S. CUSTOMARY TO METRIC (SI) . . . . . 8

SYMBOLS AND DEFINITIONS. . . . . . . . . . . . 9 9

I INTRODUCTION .................... 11

II PHYSICAL CHARACTERISTICS OF SHALLOW-WATER OCEAN WAVES. • . 14

III WAVE GAGE DATA COLLECTION AND ANALYSIS . . . . . . . . 17

1. Collection. . . . . . . . . . . . . 17

2. Analysis................ . . . 19

IV SPECTRA, SPECTRAL SUMMARIES, AND SEA-SURFACE ELEVATION

DISTRIBUTION FUNCTION PARAMETERS . . . . . . . . . 31

1. High-Energy Wave Spectra. . . . . . . . . . 31

2. Mean Spectra. . . . . . . . . . . . . 32

3. Spectral and Sea-Surface Elevation Distribution

Function Parameters. . . . . . . . . 38

$\mathrm{V}$ CONCLUSIONS. . . . . . . . . . . . . 54

VI SUMMARY. . . . . . . . . . . . . . . 56

LITERATURE CITED ............... 58

APPENDIX

A INDIVIDUAL HIGH-ENERGY WAVE SPECTRAL PLOTS . . • . . • . 61

B MEAN SPECTRA GROUPED BY HEIGHT AND PERIOD . . . . . . . . . 95

C MEAN SPECTRA GROUPED BY HEIGHT, PERIOD AND WATER LEVEL • • 140

D DESCRIPTION OF COMPUTER ROUTINE SMOOTH FOR IDENTIFYING

MAJOR PEAKS AND VALLEYS IN AN IRREGULAR SIGNAL . . • . . 145

TABLES

1 Information on wave gage locations . . . . . . . . . . . 20

2 Peak period grouping intervals . . . . . . . . . . . . 25

3 Percentage of cases in each significant height group corresponding to number of major spectral peaks . . . . . . 42

4 Linear correlation between number of major spectral peaks, significant height and period corresponding to the highest peak.

5 Percentage of cases in each peak period group corresponding to number of major spectral peaks 


\section{CONTENTS}

\section{TABLES--Continued}

6 Correlation between spectral-peakedness parameter and other

Page wave parameters .................. 5

7 Mean $\mathrm{Q}_{p}$ values for each $\mathrm{H}_{s}-\mathrm{T}_{p}$.group. ......... 51

8 Statistics on skewness and kurtosis of distribution of seasurface elevations. . . . . . . . . . . . . . 51

\section{FIGURES}

1 CERC wave gage locations . . . . . . . . . . . . . 12

2 Wave profiles and energy spectra for several cnoidal wave cases. 15

3 Time history of significant wave height for three North Carolina gages during a large winter storm ..............

4 Aerial photo showing multiple wave trains along the southern

California coast 8 kilometers south of Port Hueneme on 29 March 1977.

5 Sequence of spectra computed at 6-hour intervals for Nags Head, North Carolina, beginning at 0642 e.s.t., 20 April 1969 . . .

6 Several individual spectra in the same $\mathrm{H}_{s}-\mathrm{T}_{p}$ group, Nags Head,

7 Technique for partitioning spectral energy and assigning the energy to major peaks

8 Comparison of two measured spectra from the North Atlantic

Ocean with $\mathrm{H}_{s}=3.3$ meters, $\mathrm{T}_{p}=10.5$ seconds, and $\varepsilon=0.61$.

9 Distribution function of sea-surface elevations for several idealized wave profiles

10 Dimensionless mean spectra for several high wave, long-period groups and for the cnodial wave shown in Figure 2, case 3 .

11 Section of pen-and-ink strip-chart record from Lake Worth, Florida, beginning at 0810 e.s.t., 20 February 1969.

12 Dimensionless mean spectra for several high wave, short-period groups at Nags Head, North Carolina.

13 Two pen-and-ink strip-chart records and corresponding spectra from Nags Head, North Carolina. 


\section{CONTENTS}

\section{FIGURES--Continued}

14 Third moment of the normalized distribution of spectral points

in each frequency band as a function of frequency and $\mathrm{H}_{8}$ for Nags Head, North Carolina ... . . . . . . . . . . . .

15 Fourth moment of the normalized distribution of spectral points in each frequency band as a function of frequency and $\mathrm{H}_{s}$ for Nags Head, North Carolina.

16a Comparison of mean spectra from different gage locations $\left(\mathrm{H}_{s}=30\right.$ to 61 centimeters; $\mathrm{T}_{p}=3$ to 4 seconds $)$.

$16 \mathrm{~b}$ Comparison of mean spectra from different gage locations $\left(\mathrm{H}_{s}=91\right.$ to 122 centimeters; $\mathrm{T}_{p}=11.6$ to 13.3 seconds $)$

17 Percentage of spectra versus number of major spectral peaks.

18 Pen-and-ink strip-chart records and corresponding spectra for some cases with five major spectral peaks . . . . . . . . . .

19 Fraction of spectra with at least one major secondary peak versus $T_{p}$.

20 Frequency of occurrence and average energy for secondary peaks as a function of secondary peak period at Nags Head, North Carolina.

21 Frequency of occurrence and average energy for secondary peaks as a function of secondary peak period at Huntington Beach, California.

22 Cumulative probability distribution functions for spectral peakedness.

23 Pen-and-ink strip-chart records for selected cases with high

$\mathrm{Q}_{p}$ values.

24 Cumulative probability distribution functions for skewness of sea-surface elevation distribution function . . . . . . . .

25 Cumulative probability distribution functions for kurtosis of sea-surface elevation distribution function at Atlantic and gulf coast locations.

26 Cumulative probability distribution functions for kurtosis of sea-surface elevation distribution function at Great Lakes and Pacific coast locations. 


\section{CONTENTS}

\section{FIGURES--Continued}

27 Mean skewness of sea-surface elevation distribution function as a function of $\mathrm{H}_{S}$ for ocean and gulf coast locations. . . 55

28 Mean skewness of sea-surface elevation distribution functions as a function of $\mathrm{H}_{S}$ for Great Lakes locations . . . . . . . 55 
U.S. customary units of measurement used in this report can be converted to metric (SI) units as follows:

\begin{tabular}{|c|c|c|}
\hline Multiply & by & To obtain \\
\hline $\begin{array}{l}\text { inches } \\
\text { square inches } \\
\text { cubic inches }\end{array}$ & $\begin{array}{l}25.4 \\
2.54 \\
6.452 \\
16.39\end{array}$ & $\begin{array}{l}\text { millimeters } \\
\text { centimeters } \\
\text { square centimeters } \\
\text { cubic centimeters }\end{array}$ \\
\hline $\begin{array}{l}\text { feet } \\
\text { square feet } \\
\text { cubic feet }\end{array}$ & $\begin{array}{l}30.48 \\
0.3048 \\
0.0929 \\
0.0283\end{array}$ & $\begin{array}{l}\text { centimeters } \\
\text { meters } \\
\text { square meters } \\
\text { cubic meters }\end{array}$ \\
\hline $\begin{array}{l}\text { yards } \\
\text { square yards } \\
\text { cubic yards }\end{array}$ & $\begin{array}{l}0.9144 \\
0.836 \\
0.7646\end{array}$ & $\begin{array}{l}\text { meters } \\
\text { square meters } \\
\text { cubic meters }\end{array}$ \\
\hline $\begin{array}{l}\text { miles } \\
\text { square miles }\end{array}$ & $\begin{array}{l}1.6093 \\
259.0\end{array}$ & $\begin{array}{r}\text { kilometers } \\
\text { hectares }\end{array}$ \\
\hline knots & 1.852 & kilometers per hour \\
\hline acres & 0.4047 & hectares \\
\hline foot-pounds & 1. 3558 & newton meters \\
\hline mil1ibars & $1.0197 \times 10^{-3}$ & kilograms per square centimeter \\
\hline ounces & 28.35 & grams \\
\hline pounds & $\begin{array}{r}453.6 \\
0.4536\end{array}$ & $\begin{array}{l}\text { grams } \\
\text { kilograms }\end{array}$ \\
\hline ton, long & 1.0160 & metric tons \\
\hline ton, short & 0.9072 & metric tons \\
\hline degrees (angle) & 0.01745 & radians \\
\hline Fahrenheit degrees & $5 / 9$ & Celsius degrees or Kelvins ${ }^{1}$ \\
\hline
\end{tabular}

${ }^{1}$ To obtain Celsius (C) temperature readings from Fahrenheit (F) readings, use formula: $C=(5 / 9)(F-32)$.

To obtain Kelvin (K) readings, use formula: $K=(5 / 9)_{4}(F-32)+273.15$. 


\section{SYMBOLS AND DEFINITIONS}

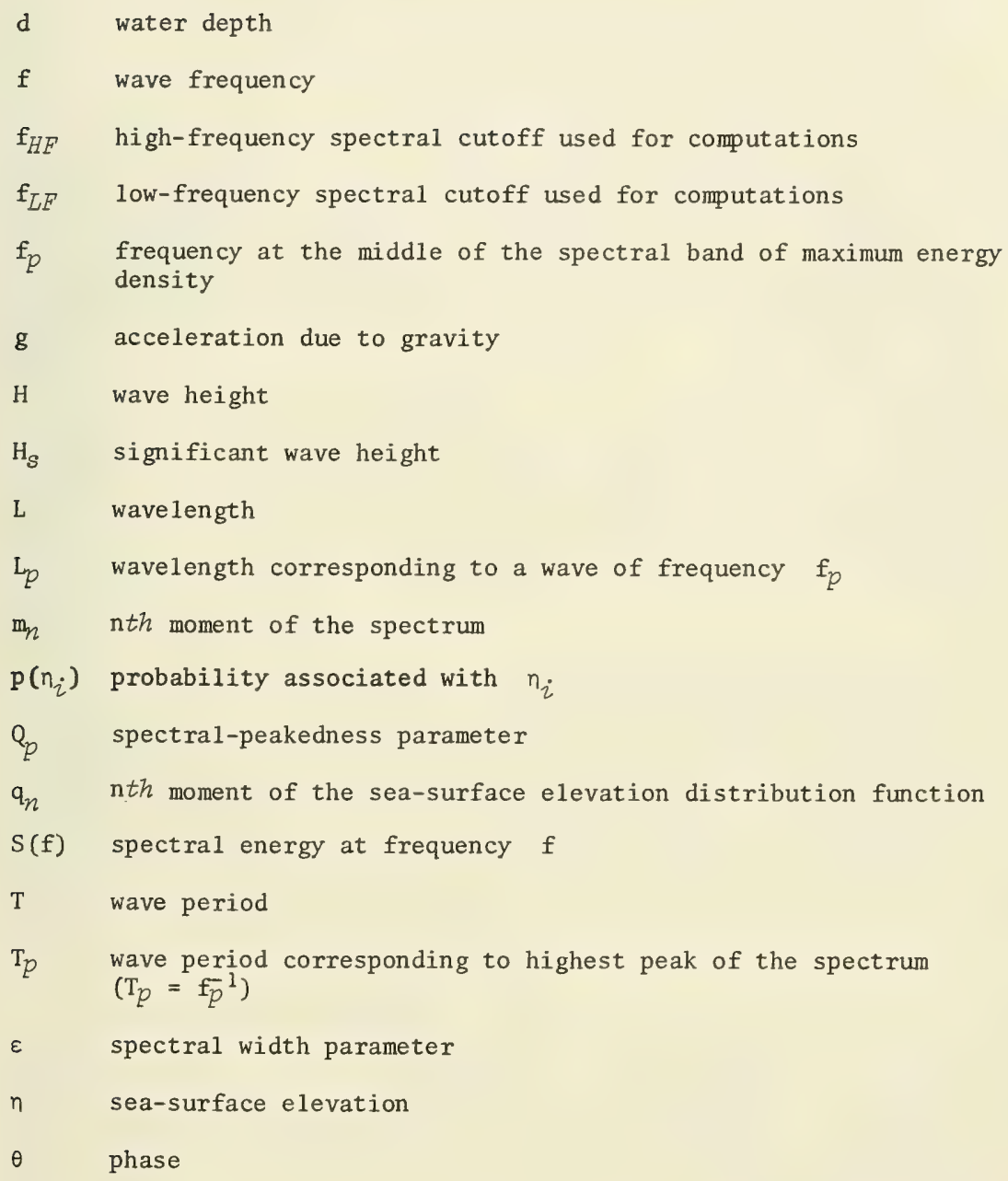





\title{
ENERGY SPECTRA IN SHALLOW U.S. COASTAL WATERS
}

\author{
by \\ Edward F. Thompson
}

\section{INTRODUCTION}

Wind-generated gravity waves, with periods ranging from 1 to 25 seconds, are a primary concerm in most coastal engineering work. Wind waves relate directly to such processes as longshore sand movement, onshoreoffshore sand movement, and forces exerted on coastal structures. Hence, wind waves must be considered in virtually all coastal engineering endeavors, especially in design and maintenance of harbors and exposed navigation channels and in shore protection efforts. Edmisten (1978) presents an extensive list of major applications for coastal wind wave data.

Coastal engineers and researchers have wrestled for decades with the difficult problem of how to reduce the complexity of ocean wind waves to simple, useful approximations. The most common approach has been to represent the dominant waves in a particular sea state with three simple parameters: significant wave height, significant wave period, and wave direction. The latter parameter is normally unavailable, especially with gage data; however, it can be estimated from wind and weather records for days of special interest.

Practical techniques are available for estimating significant height and period from a wave record. All of the accepted techniques produce reasonable estimates for significant height. However, estimates for significant period are generally more variable and their significance is often questionable. One of the best approaches to estimating significant or dominant period is to compute the distribution of wave energy as a function of frequency (frequency is the reciprocal of period) and use the wave period corresponding to the frequency of greatest energy density. This period has a clear dynamic significance. The distribution of wave energy as a function of frequency is commonly referred to as the wave energy spectmom.

Although significant height, period, and direction provide a useful approximation to many sea states, these simple parameters omit details of the sea state which can be important in some applications. For example, the simultaneous occurrence of several prominent wave trains with different wave periods and directions is an important consideration in relating coastal wave conditions to longshore sediment movement. Design of ships and flexible coastal structures, such as floating breakwaters and offshore platforms, requires special consideration of how much wave energy can be expected at frequencies near the resonant frequencies of the structure. Similarly, effective harbor design requires that resonant oscillations in the harbor be minimized. Since the effectiveness of floating breakwaters in attenuating wave energy depends on the wave frequency, floating breakwater designs should be formulated and evaluated with a knowledge of how wave energy is distributed with frequency. 
The preceding examples illustrate several applications in which more detailed specification of sea state is needed. Much of this additional needed detail is provided by the energy spectrum. Evolving technology and design techniques in most areas of coastal engineering are generating a similar need for engineers to acquire a more advanced understanding of sea state and its climate.

CERC (and its predecessor the Beach Erosion Board) has operated wave gages at numerous U.S. sites during the last 30 years and has acquired a volume of shallow-water coastal wave records matched by few other places in the world. Most of the gages were mounted on coastal piers in water depths of 4 to 6 meters. Significant wave heights and periods from many of the gages have been summarized by Thompson (1977). Although none of the gages was capable of sensing wave direction, an array of gages was used at one site to obtain direction estimates (Esteva, 1977).

This report presents spectra and spectral summaries for the selected CERC gage locations shown in Figure 1; it contains 264 high-energy spectra which mostly represent shallow-water wave conditions. These spectra are a significant addition to the existing published literature on shallow-water spectra. Field measurements continually show that individual spectra are quite erratic and variable. To identify general spectral characteristics, this report contains summaries of approximately 7,000 spectra and selected spectral parameters; summaries of parameters of the sea-surface elevation distribution function are also included.

The scope of this report is limited. Fewer than one-half of the CERC gages for which spectra are available are included. Gages were selected for optimum coverage of U.S. coasts and optimum accessibility of archived spectra. Only a fraction of the available spectra from each gage was considered. For most gages, the spectra represent one

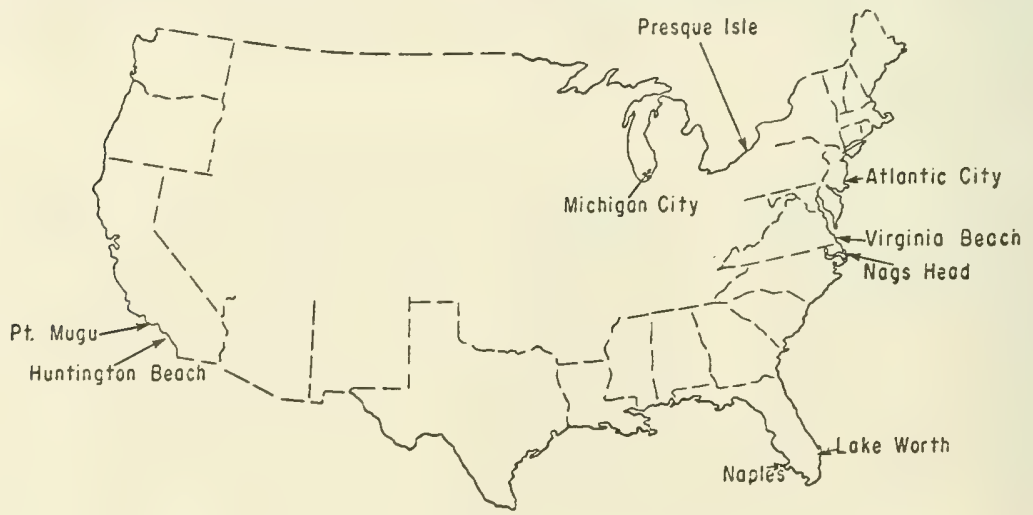

Figure 1. CERC wave gage locations. 
reasonably complete year of data. It seems doubtful that more extensive summaries would be worth the requisite cost and effort until techniques for interpreting and applying spectra are better established.

This report is intended to provide coastal engineers a better qualitative understanding of shallow-water waves and spectra as well as providing quantitative information for engineering use. Qualitatively, it provides:

(a) Perspective on how to interpret shallow-water wave energy spectra;

(b) numerous examples of high-energy, shallow-water field wave spectra from the U.S. Atlantic, Pacific, gulf, and Great Lakes coasts;

(c) evidence that the ratio of significant wave height to water depth never approaches the commonly used limit of 0.78 in the water depths considered; and

(d) perspective on the likelihood of relatively high individual waves occurring in succession in a sea state.

Quantitatively, the report provides the following information helpful to coastal engineers:

(a) Average spectra corresponding to the more common significant height and period combinations at each site;

(b) frequency of occurrence of sea states with major secondary wave trains;

(c) probability statistics for moments of the sea-surface elevation distribution function, which can be related to probabilities associated with instantaneous surface elevations above and below the local mean; and

(d) a computer program for identifying major peaks and valleys in an irregular signal; it has many potential applications including identification of major peaks in a spectrum and identification of meaningful crests and troughs in a time series of sea-surface elevation.

A brief discussion of the physical characteristics of shallow-water ocean waves is presented in Section II. Wave gage data collection, analysis, and summarization techniques are described in Section III which includes a discussion of the motivation for grouping spectra by both significant height and dominant period and computing average spectra. Spectra computed for several theoretical cases of cnoidal wave profiles are presented for perspective in interpreting field spectra. The choice, computation, and interpretation of spectral parameters and sea-surface elevation distribution function parameters are also discussed in Section III. 
The analyzed and summarized field wave spectra are discussed in Section IV which includes samples of spectra representing the highest measured wave conditions at each site, average spectra and summaries of parameters derived from the spectrum and the sea-surface elevation distribution function. Conclusions from the results in Section IV are provided in Section V. Major findings are summarized in Section VI. Numerous individual high-energy spectral plots are contained in Appendix A. Average spectra are included in Appendixes B and C.

\section{PHYSICAL CHARACTERISTICS OF SHALLOW-WATER OCEAN WAVES}

Wind waves change considerably when propagating from deep to shallow water. Consider a train of uniform waves moving toward shore with crests oriented parallel to the bottom contours. The wave height first decreases slightly and then increases continually as the waves move into progressively shallower water. The phase velocity, group velocity, and wavelength all decrease with decreasing water depth. Wave energy is generally reduced as waves propagate shoreward.

It appears contradictory that the wave height in a train of uniform waves moving shoreward increases while the energy decreases. Yet the two effects occur together mainly because the wave profile changes. The profile of a wave in deep water can usually be considered sinusoidal unless the waves are exceptionally high in relation to their wavelength. However, the profile of a steep wave in very shallow water is decidedly nonsinusoidal (Fig. 2). The troughs are broad and flat, and the crests are narrow and high. Deviation of the wave profile from sinusoidal becomes important when the relative water depth (ratio of water depth to wavelength) is less than 0.04 for wind waves with very low steepness (ratio of wave height to wavelength). Nonsinusoidal profiles also occur for relative depths greater than 0.04 when the wave steepness is greater than about 0.0015 ; i.e., for ratios of wave height to the product of gravitational acceleration times wave period squared greater than 0.00006 (U.S. Army, Corps of Engineers, Coastal Engineering Research Center, 1977, p. 2-35). For waves with very high steepness (greater than 0.0063 or height divided by $\mathrm{gT}^{2}$ greater than 0.001), nonsinusoidal profiles occur in all water depths.

Since phase velocity of an ocean wave decreases with decreasing water depth, a long wave crest approaching shore at an angle to the bottom contours has a nonuniform phase velocity along the crest. The velocity differences result in an apparent bending, or refracting, of the crest which decreases the angle between the crest and the bottom contours. Refraction can affect a wave when the relative water depth is less than one-half. Relative depths for the gages in this report range typically from 0.04 to 1. Hence, refraction has potentially affected many of the wave measurements considered in this study. Refraction can act to increase or decrease wave heights depending on wave period and direction and bottom contour orientation. Since most of the gages are sufficiently nearshore that large waves can move bottom sediment seaward of the gage, the bottom contour orientation affecting refraction can change with time. 
Cose 1
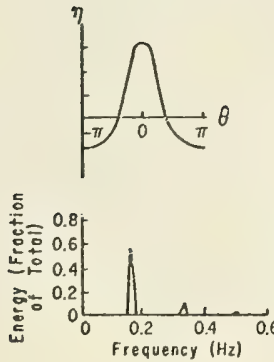

$T=6.0 \mathrm{~s}$

$\frac{H}{d}=0.572$

$d / g T^{2}=0.0142$

$\delta / L=0.129$

$\mathrm{a}_{1}=0$

$q_{2}=1.0$

$q_{3}=0.84$

$a_{4}=2.23$

$a_{p}=14.2$
Case 2
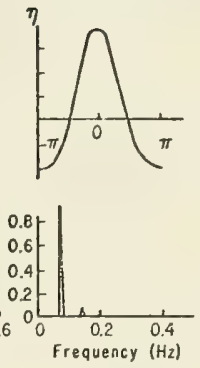

$14.0 \mathrm{~s}$

0.076

0.0026

0.052

0

1.0

0.51

1.89

13.2
Case 3
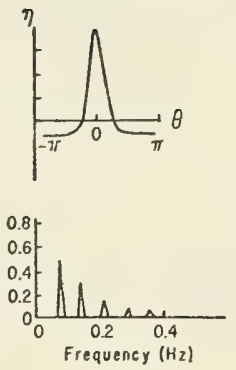

14.08

0.572

0.0026

0.046

0

1.0

2.02

5.82

6.8

Figure 2. Wave profiles and energy spectra for several cnoidal wave cases (record length: 512 seconds; spectral bandwidth: 0.00977 hertz).

Another very important phenomenon is wave breaking, which for monochromatic waves occurs in deep water approximately when the wave steepness exceeds 0.14 or in shallow water when the ratio of wave height to water depth exceeds 0.78. The heights of individual nearshore waves are actually quite variable but generally conform to a Rayleigh distribution (Thompson, 1974; Goda 1974; U.S. Army, Corps of Engineers, Coastal Engineering Research Center, 1977). Thus, 13.5 percent of the waves can be expected to be higher than the significant height and break farther seaward than a wave with the significant height. Breaking of a few very large waves does not visibly affect the significant height, but when the depth-induced breaking starts to affect many large waves, the significant height decreases. Quantitative predictions of the decrease in significant height as waves begin to break nearshore are given by Seelig and Ahrens (in preparation, 1980) for a variety of wave steepnesses and beach slopes. Their design curves, based on theory developed by Goda (1975), indicate that breaking can begin to affect significant height when the ratio of significant height to water depth is greatex than about 0.5. This general. observation is consistent with field wave gage data presented by Irie (1975). For a typical water depth at the gage of 5 meters, breaking might be expected to have affected all significant heights greater than about 2.5 meters. 
The large effect wave breaking can have on significant height measured at most of the CERC gages is shown in Figure 3 . The figure shows a time history of significant wave height for three Atlantic coast gages during a large winter storm. The standard Nags Head, North Carolina, gage is represented along with two staff gages on the new CERC Field Research Facility (FRF) pier 30 miles north of Nags Head. The FRF gage farthest seaward shows peak significant heights about 1 meter higher than the FRF gage 390 meters farther shoreward. During the peak of the storm, significant heights at the Nags Head gage drop well below heights at the seaward FRF gage. The figure suggests that breaking has a major influence on significant height at both the nearshore FRF gage and the Nags Head gage.

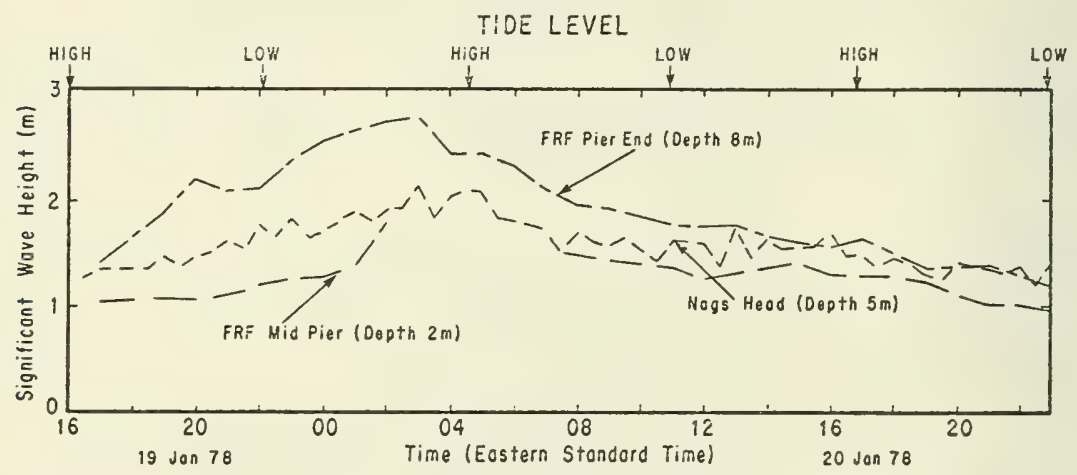

Figure 3. Time history of significant wave height for three North Carolina gages during a large winter storm.

For some of the gage sites included in this report, and perhaps for all except the accelerometer buoy sites, a sandbar was often seaward of the gage. The bar is a somewhat transient feature which can have a major influence on the waves by causing high waves to break before they arrive at the gages and by acting to reflect energy seaward or trap it between the bar and shore. Evidence presented by Wang and Yang (1976) indicates the bar acts mainly as an energy dissipator at low tide. At high tide for nonbreaking waves, the bar tends to reflect wave energy seaward during onshore winds and to trap wave energy between the bar and beach during offshore winds.

Since ocean waves in a sea state are never strictly uniform in either height or frequency, a sea state is conveniently characterized by the distribution of wave energy as a function of frequency (the spectrum). During active wave growth, most energy from the atmosphere is added at frequencies slightly higher than the dominant frequency. The energy is then redistributed by nonlinear transfers within the wave field to frequencies slightly lower than the dominant frequency and to very high frequencies where it is lost to breaking processes. These phenomena result in a gradual shift of the spectral peak to lower frequencies. 
For waves propagating outside the wave-generation area the non 1 inear energy transfer to low and very high frequency continues without the accompanying replenishment of energy at midfrequencies. Thus, swe11 waves are characterized by narrow spectra with peaks at low frequency.

There is evidence that the intensity of nonlinear energy transfer increases rapidly with decreasing water depth. The nonlinear transfer may also narrow the directional spread of energy in shallow-water waves (Herterich and Hasse1mann, in preparation, 1980).

Aerial photos of nearshore ocean waters indicate remarkable organization in the surface waves (Fig. 4); the photos also indicate that sea states dominated by a single visible wave train are relatively unusual. Photos typically show two or three apparently independent wave trains with different, we11-defined directions and wavelengths. The relative prominence of the trains often varies with proximity to shore due to frequency-dependent shoaling and refraction, and in some cases due to redistribution of energy with frequency by nonlinear interactions between trains.

For example, although a long swell wave train often dominates the breaker zone in photos taken along the southern California coast, the train is invisible two or three wavelengths seaward of the breaker zone. The swell waves are preferentially amplified nearshore. McClenan and Harris (1975) show several examples of this process occurring.

The swell waves are also refracted more completely than higher frequency waves so that at breaking they are often nearly parallel to the shore. The water particle velocity associated with low-frequency swell waves attenuates slowly with depth. High-frequency waves which have not been substantially refracted can travel into the swe11-created breaker zone with a large component of longshore motion; yet, their particle velocities attenuate rapidly with depth. Since Iongshore sediment movement requires both a mechanism for initiating sediment movement and a longshore drift to transport it, two concurrent wave trains may move sediment alongshore more effectively than either train acting alone.

The presence of a current near a gage site can alter the measured characteristics of waves. The longshore current in and near the breaker $z$ one affects some of the gage measurements in this report. Tidal currents and wind-generated currents may also affect the measurements. The Gulf Stream may affect deepwater waves approaching the U.S. Atlantic coast by steepening waves enough to cause breaking or, in special cases, by refracting the waves so that they never reach the shore (Kenyon, 1971). The rate of wave growth in the vicinity of the current may also be affected.

\section{WAVE GAGE DATA COLLECTION AND ANALYSIS}

\section{Collection.}

The wave gage data used in this report were collected as part of the CERC field wave data collection program from 11 gages at the 9 locations 


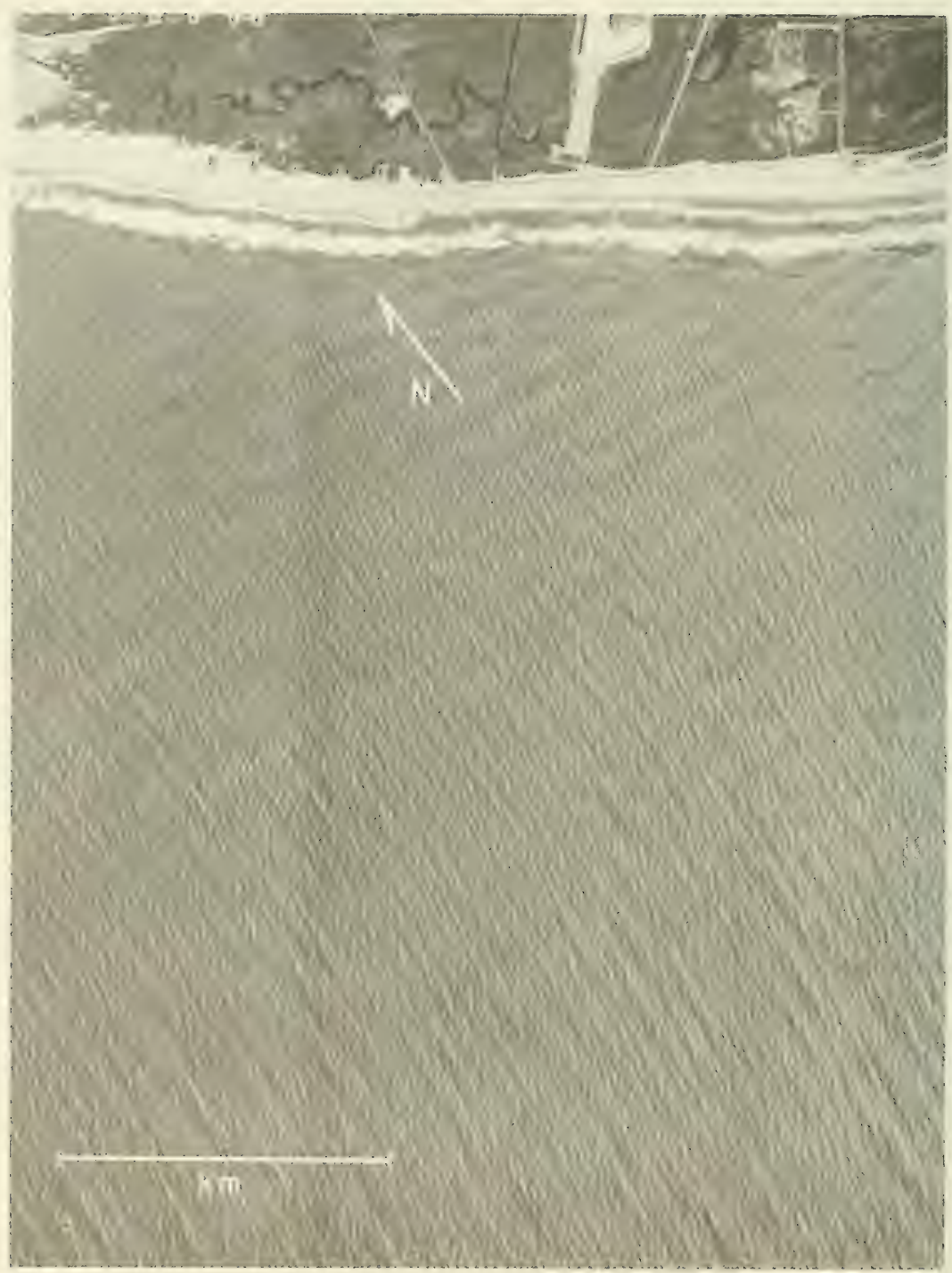

Figure 4. Aerial photo showing multiple wave trains along the southern California coast 8 kilometers south of Port Hueneme on 29 March 1977 (courtesy of National Aeronautics and Space Administration). 
shown in Figure 1. Table 1 gives some details of the gage locations, gage types, and water depth at the gages. The gage designs and characteristics are described in detail by Thompson (1977), and for the Great Lakes accelerometer buoy installations in Thompson (1978).

The continuous-wire staff gage (manufactured by the Baylor Company, Houston, Texas) is the more accurate sensor because the gage directly senses surface waves and it interferes very little with waves being measured. The continuous-wire gage and the pressure gage (fabricated at CERC) give comparable surface wave height estimates when the pressuregage record is compensated for the depth-dependent attenuation of the dynamic component of pressure due to surface waves. Suitably compensated pressure-gage spectra are also comparable to continuous-wire gage spectra except at high frequencies (Esteva and Harris, 1970).

The accelerometer-buoy gage or Waverider (manufactured by Datawe11, Haarlem, the Netherlands) gives wave heights and spectra which are reasonably comparable to those given by the continuous-wire gage for frequencies between 0.065 and 0.5 hertz, including virtually all important frequencies in the Great Lakes (Pitt, Driver, and Ewing, 1978). The step-resistance staff gage (fabricated at CERC) has been shown to have a consistent bias toward high wave heights (Esteva and Harris, 1970). Significant height estimates from the step-resistance gage may be 30 centimeters too high during low wave conditions and 20 percent too high during high wave conditions. Aside from the tendency for overestimating wave height and energy, Esteva and Harris show evidence that spectra for step-resistance gage records are reasonably consistent with continuous-wire gage spectra.

Time series of sea-surface elevation from staff gages, subsurface pressure from pressure gages, and double-integrated sea-surface vertical acceleration from buoy gages were transmitted by telephone line to the CERC laboratory and used to generate pen-and-ink, strip-chart records and digital records on computer-compatible, seven-track magnetic tape. Digital records are 20 minutes long. A digital record from a single station contains data points at 0.25 -second intervals giving a total of 4,800 data points per location per 20-minute record. Further details of CERC field wave data collection procedures are given in Thompson (1974, 1977).

\section{Analysis.}

a. Spectral Analysis. The digital field wave gage records were analyzed by the CERC routine analysis system (Thompson, 1977). One record per 6 hours is routinely analyzed; however, one record per 2 hours was analyzed for some of the Great Lakes data. The routine ana1ysis times are chosen to approximately coincide with synoptic times $(0100,0700,1300$, and 1900 e.s.t.). The procedure includes editing each 20-minute time series to eliminate data points which are obviously bad, computing and testing the distribution function of the edited data points, and computing the variance or energy spectrum for the time series 


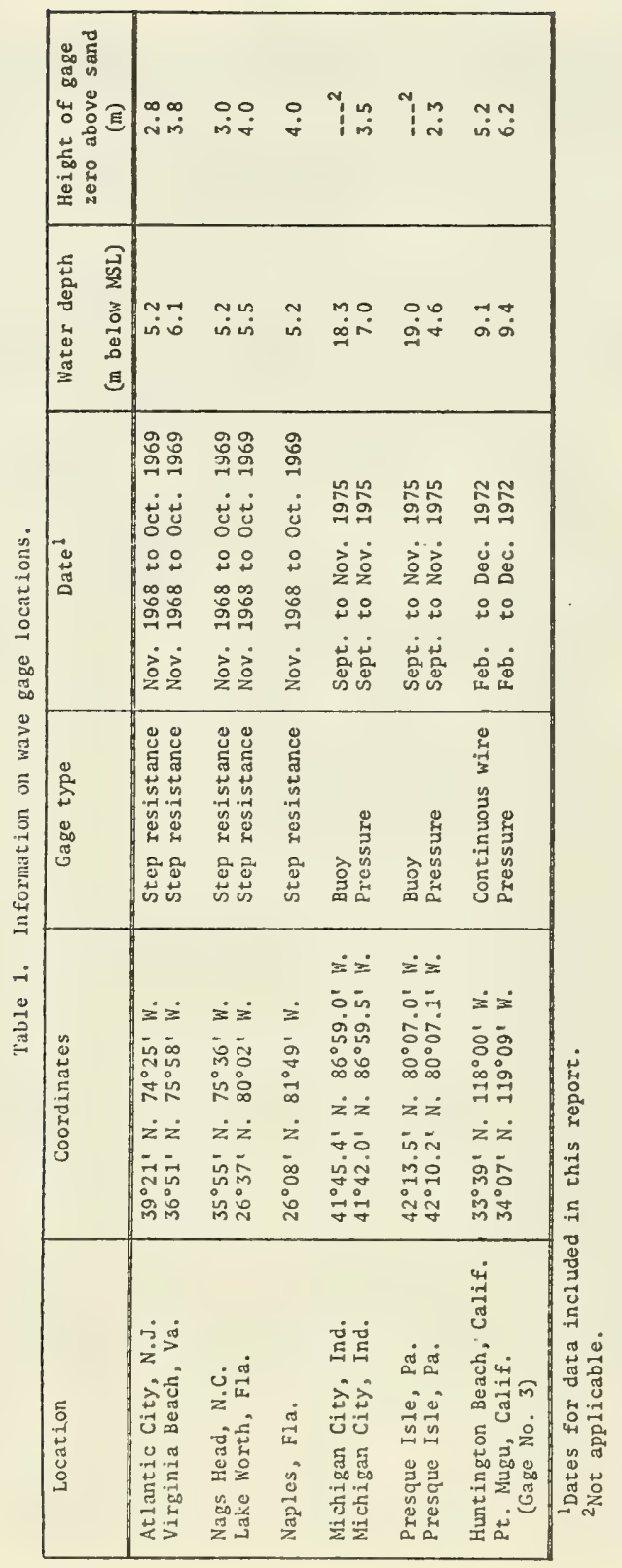


smoothed with a cosine bell data window. The spectrum is computed with a fast Fourier transform (FFT) algorithm applied to 4,096 data points (17-minute and 4-second record).

The spectral analysis procedure assigns a fraction of the total variance of the record to each of 1,024 frequencies, or frequency lines. It is difficult to deal with such finely resolved spectra. To gain statistical stability, groups of 11 successive lines in each spectrum are combined into bands. The resultant band width is 0.01074 hertz over the full range of frequencies considered ( 0.03 to 1.00 hertz). The uniform spectral resolution over the frequency range gives a nonuniform resolution in wave period. Significant height is estimated as four times the square root of the total variance assigned to wave frequencies of interest, usually 0.03 to 1.00 hertz.

The frequency-dependent responses of some of the gage types required some special treatment of the spectra. Accelerometer-buoy gage spectra were terminated at the high-frequency end at 0.5 hertz. A special lowfrequency bound of about 0.065 hertz on the spectrum would have been appropriate but was not used because energy at frequencies between that and the low-frequency cutoff for other gage types (0.03 hertz) was insignificant in the Great Lakes buoy records.

Pressure-gage records were compensated for hydrodynamic attenuation of the pressure signal with depth by multiplying the energy in each spectral band by a frequency-dependent factor. The compensation factor becomes very large at high frequencies where the small pressure signal is often obscured by noise. Hence, it is necessary to terminate the high-frequency end of pressure-gage spectra at a frequency below the standard 1-hertz cutoff for staff gages. The high-frequency cutoff used for the Michigan City and Presque Isle pressure gages is 0.33 hertz. The cutoff for the Pt. Mugu pressure gage is 0.31 hertz. A11 spectral energy assigned to frequencies above the cutoffs was omitted from both the spectrum and the significant height estimate. The neglected energy is unimportant during high wave conditions, but it can increase significant height by as much as 0.5 meter during low recorded wave conditions. The latter effect is often partially balanced by slight overcompensation of the high-frequency energy retained in the spectrum.

\section{b. Spectral Summarization.}

(1) Averaging. Individual shallow-water ocean wave energy spectra are quite irregular and can change substantially and somewhat erratically with time (see Fig. 5). Because of these problems, it is difficult to identify typical spectra for each wave gage site. However, it is desirable to condense the masses of individual spectra into a more concise form.

At this time, no completely satisfactory technique is in use for isolating and summarizing general characteristics of field spectra. One 


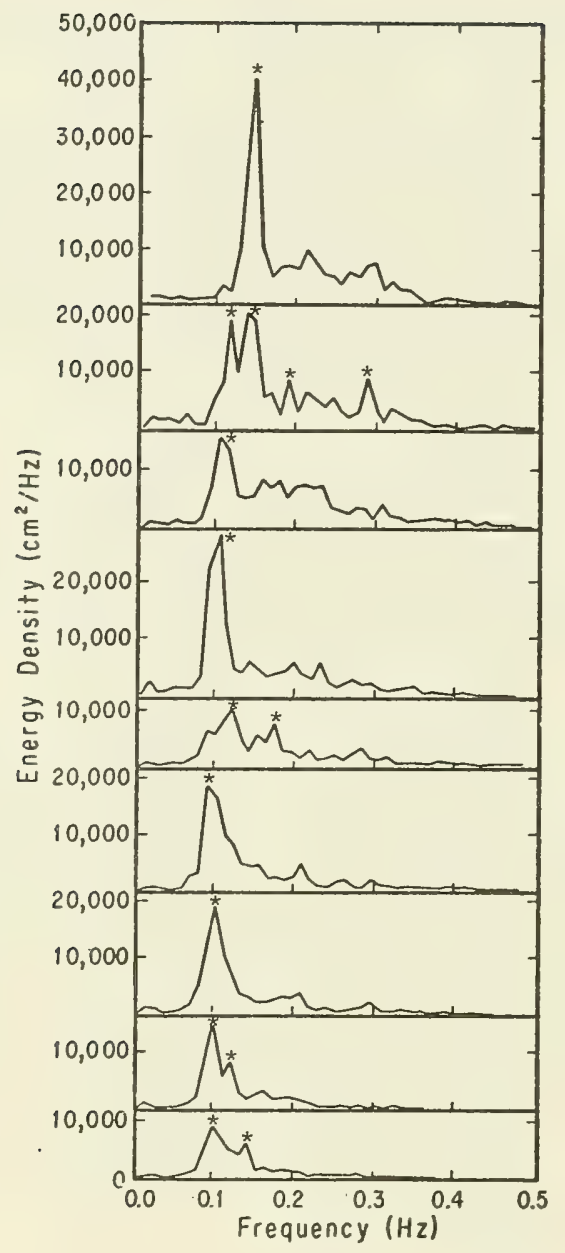

Figure 5. Sequence of spectra computed at 6-hour intervals for Nags Head, North Carolina, beginning at 0642 e.s.t., 20 April 1969. $\mathrm{H}_{S}$ is 190 centimeters for the top spectrum decreasing to 97 centimeters for the bottom spectrum. Major spectral peaks are marked with asterisks. 
common approach is to compute spectral statistics which are often based on moments of the spectrum, where the nth spectral moment, $m_{n}$, is defined as

$$
m_{n}=\int_{0}^{\infty} S(f) f^{n} d f
$$

where $f$ is the frequency and $S(f)$ the spectral energy at frequency $f$. This approach is used in many cases because it is the only tractable way to deal with large numbers of spectra. However, some of these spectral statistical parameters have disadvantages which will be discussed later. A relatively new and promising approach to spectral parameterization involves the use of eigenfunctions (Vincent and Resio, 1977).

Another approach to the problem of how to characterize and summarize ocean wave spectra has been used in conjunction with ship-response prediction. Hoffman (1974) organized deepwater spectra into 10 groups from a site in the North Atlantic according to significant height. For each group, the mean and standard deviation of spectral energy in each band were computed. The average energy of the one-third highest and one-third lowest values in each band was also computed. The importance of accounting for variability of spectral shape when predicting shipbending moment responses was demonstrated.

An averaging procedure for summarizing deepwater spectra from a site in the North Atlantic was also used by Gospodnetic and Miles (1974). Spectra were grouped according to both significant wave height and average wave period. The average spectra were made dimensionless to facilitate comparison of spectral shapes. Although most of the variations were removed by using the dimensionless format, it was concluded that even the dimensionless spectra vary systemmatically with both height and period.

In very shallow water, spectral characteristics would be expected to have a pronounced systematic relationship to both significant height and dominant spectral period, although the relationship would be somewhat obscured when major secondary wave trains exist. Wave height is important because high waves lead to wave breaking in shallow water. Thus, any reasonable attempt to compute average spectra at a shallow-water location must include stratification of the spectra according to wave height or energy.

The extent of wave shoaling is specified by the relative water depth, $\mathrm{d} / \mathrm{L}_{\mathrm{p}}$, which is directly related to the dominant wave period. Waves in very shallow water assume a nonsinusoidal profile which gives rise to spectra with peaks at multiples of the dominant frequency. An example of the profile and spectrum for several cnoidal wave cases is shown in Figure 2; another example is an aerial photo spectrum pair in McClenan and Harris (1975, p. 63-64). Because of such systematic effects on the shallow-water spectrum, spectra should also be stratified by $d / L_{p}$ or by a characteristic wave period. 
Deviations of the wave profile from sinusoidal occur even in deep water for very steep waves as discussed previously. Spectra for such waves can also be expected to show energy at multiples of the dominant frequency. In such cases the spectral form is related to both wave height and period.

Because of expected systematic influences of wave height and period on the shallow-water spectrum, spectra in this study were grouped into sets by both significant height and period corresponding to the highest spectral peak. Significant height and peak period are convenient because they are comparable to height and period parameters used extensively in past nonspectral wave analyses.

Despite the grouping, major differences between individual spectral shapes in each set can still occur. Differences between spectra at one location for several cases in which the significant height and peak period were near the annual means are shown in Figure 6. The differences in spectral shape between individual spectra in a set were greater than the differences in the mean spectrum between sets in this study and in Hoffman's (1974) study. However, any systematic characteristics of each set should emerge in the mean spectrum and standard deviation if the number of samples is sufficient. This does not imply that the mean spectra necessarily represent characteristics.

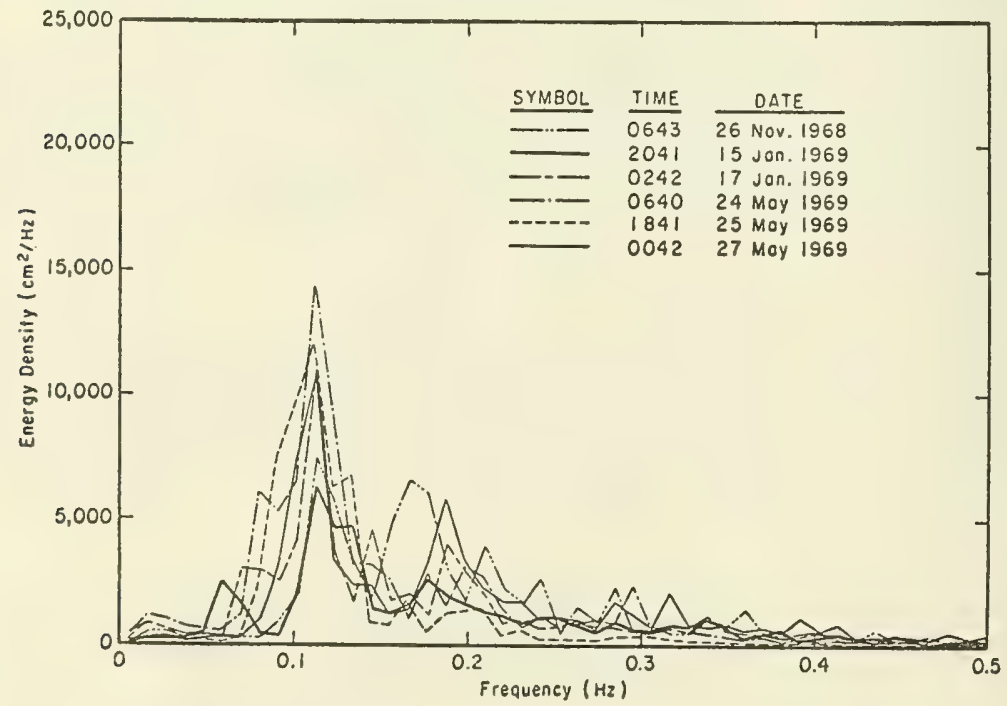

Figure 6. Several individual spectra in the same $\mathrm{H}_{s}-\mathrm{T}_{p}$ group $\left(\mathrm{H}_{s}=91\right.$ to 122 centimeters; $\mathrm{T}_{p}=8.5$ to 9.3 seconds $)$, Nags Head, North Carolina. 
Spectra were grouped by 30 -centimeter intervals of significant height and by variable intervals of peak period (Table 2). Variable period intervals were needed because energy is computed for nonuniform period bands (but uniform frequency bands) in the CERC spectral analysis program. Selection of longer period intervals was necessary so that each interval encompasses only one spectral band. If the intervals had included more than one spectral band, the averaging procedure would tend to produce an unrepresentatively low and broad peak in the average spectrum.

Table 2. Peak period grouping intervals.

\begin{tabular}{|c|c|c|c|}
\hline Period interval & $\begin{array}{c}\text { Frequency bands } \\
\text { in interval } \\
\text { (No.) }\end{array}$ & $\begin{array}{r}\text { Period interval } \\
\text { (s) }\end{array}$ & $\begin{array}{c}\text { Frequency bands } \\
\text { in interval } \\
\text { (No.) }\end{array}$ \\
\hline 1 to 2 & 47 & 7.8 to 8.5 & 1 \\
2 to 3 & 15 & 8.5 to 9.3 & 1 \\
3 to 4 & 8 & 9.3 to 10.3 & 1 \\
4 to 5 & 4 & 10.3 to 11.6 & 1 \\
5 to 6 & 4 & 11.6 to 13.3 & 1 \\
6 to 6.6 & 1 & 13.3 to 15.5 & 1 \\
6.6 to 7.2 & 1 & 15.5 to 18.6 & 1 \\
7.2 to 7.8 & 1 & 18.6 to 23.3 & 1 \\
\hline
\end{tabular}

Period intervals of 1 second were used for periods shorter than 6 seconds (Table 2). Individual spectra with relatively short peak periods are generally more poorly focused in frequency than spectra with long peak periods. Thus, period intervals encompassing more than one spectral band could be used for short periods without creating much artificial broadening of the peak in the average spectrum. This treatment is further defensible on the grounds that (a) short-period waves are in relatively deeper water than long-period waves at the measurement site and hence exhibit less depth-induced modification, and (b) spectra with peak periods shorter than 6 seconds are generally not important for coastal engineering design applications at ocean sites.

After the spectra were grouped into height-period intervals, average spectra were computed. Intervals were selected for averaging to include all intervals containing a reasonable number of cases and all high wave intervals regardless of the number of cases. The minimum number of cases considered for low and moderate waves was 10 at most locations. The wave height above which all intervals were considered varies between locations. The average spectrum for a height-period interval was obtained by averaging energy values in each band. The standard deviation of spectral energy values about the mean for each band was also computed. Averages and standard deviations of spectra for the locations 1 isted in Table 1 are discussed in the next section.

It is important to note that the spectrum for any individual record never duplicates the mean spectrum. Any application which is sensitive to the precise form of the spectrum should make use of individual spectra rather than the mean spectrum. One reasonable approach might be to select a small random sample of spectra from each group, apply each spectrum to 
the problem at hand, and combine the individual results to estimate response probabilities, as suggested by Hoffman (1974, 1975).

\section{(2) Spectral Parameters.}

(a) Number of Peaks. It is relatively common in the ocean for two or more independent wave trains with different frequency and direction to occur simultaneously (e.g., Harris, 1972; McClenan and Harris, 1975; Ochi and Hubble, 1976; Thompson, 1977). The marine surface observation reporting code even includes provisions for reporting major secondary wave trains observed visually. Certainly, the concept of a simple, single-peaked spectrum is misleading in many ocean wave records. Yet, there is a lack of reliable quantitative information as to how often major secondary trains occur and how much energy they contain.

To investigate the occurrence of multiple wave trains, a computer routine was adapted for use in identifying major spectral peaks. The routine (described in App. D) smoothes over spectral peaks and valleys which differ in energy density by less than 3 percent of the total energy in the spectrum. Examples of individual spectra were shown in Figure 5. The major peaks identified in each case by the computer routine are marked with asterisks.

A fraction of the spectral energy is assigned to each major spectral peak by a simple method. The spectrum is partitioned at the lowest point between successive major peaks (Fig. 7). All spectral energy within the partition for a peak is assigned to that peak. The energy is expressed as a dimensional quantity and as a fraction of the total spectral energy.

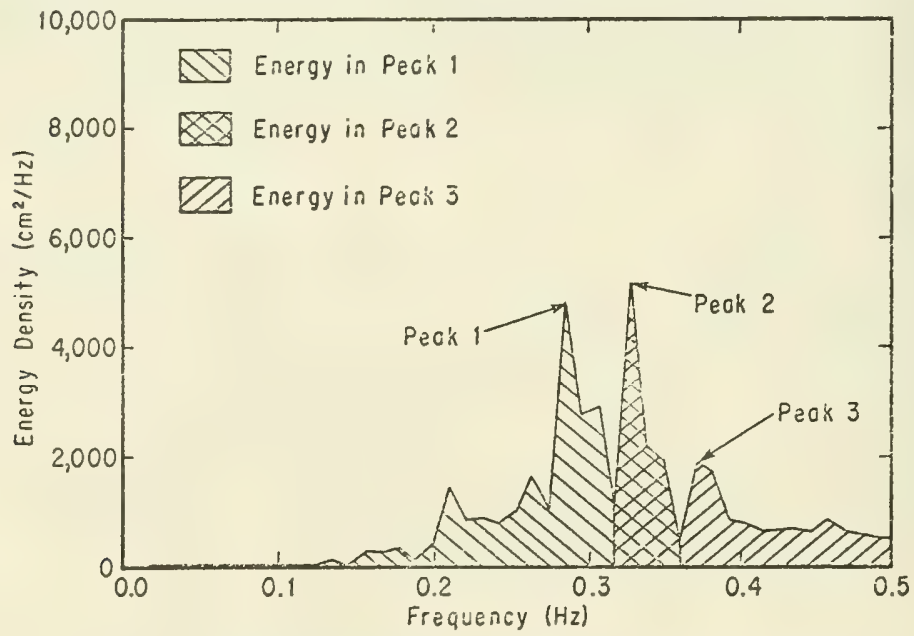

Figure 7. Technique for partitioning spectral energy and assigning the energy to major peaks. 
Statistics on the occurrence of multiple spectral peaks identified by the above techniques (presented in the next section) are based only on the part of the spectrum between 0.03 and 0.5 hertz for the staff and accelerometer-buoy gages. The high-frequency cutoff for the pressure gages was 0.33 hertz in the Great Lakes and 0.31 hertz at Pt. Mugu as discussed earlier.

(b) Spectral Peakedness. It is highly desirable to parameterize a spectrum. Various parameters have been considered in the literature, but most are derived from moments of the spectrum as defined in equation (1).

In practical application equation (1) becomes

$$
\mathrm{m}_{n}=\int_{\mathbf{f}_{L F}}^{\mathrm{f}_{H F}} \mathrm{~s}(\mathrm{f}) \mathbf{f}^{n} \mathrm{df}
$$

where $f_{L F}$ is the low-frequency spectral cutoff, and $f_{H F}$ the highfrequency spectral cutoff used for computation. When applied to field records of finite length, the integral in equation (2) becomes a summation.

Equation (2) shows that the higher the value of $\mathbf{f}_{H F}$, the greater the magnitude of $m_{n}$ provided that $S(f)$ is greater than zero at high frequencies. In practice, the choice of $f_{H F}$ has a significant influence on the values computed for $m_{n}$, especially for the higher moments. The choice of $f_{L F}$ is less ambiguous in practice because contributions to $m_{n}$ from the low-energy and low-frequency part of the spectrum are generally negligible.

The sensitivity of $\mathrm{m}_{n}$ and parameters based on $\mathrm{m}_{n}$ to the choice of $f_{H F}$ was investigated by Rye (1977). He considered two theoretical spectral shapes: a sharply peaked JONSWAP spectrum and a flat JONSWAP spectrum equivalent to a Pierson-Moskowitz spectrum. Rye recommended three spectral parameters for general use:

(a) Significant wave height, $\mathrm{H}_{S}$ where

$$
\mathrm{H}_{S}=4 \sqrt{\mathrm{m}_{0}}
$$

(b) period of the spectral peak, $T_{p}$

(c) spectra1-peakedness parameter, Qp where

$$
Q_{p}=\frac{2}{m_{0}^{2}} \int_{0}^{\infty} f[S(f)]^{2} d f
$$

The spectral-peakedness parameter was originally proposed and shown to be directly related to the average number of high waves occurring in 
succession in simulated wave records by Goda (1970). However, Goda (1976) could not find a clear relationship between $Q_{p}$ and the extent of grouping of high waves in field records.

The value of $Q_{Q}$ as a spectral parameter is shown in Figure 8 . The two spectra shown have nearly the same significant height and peak period. The spectra also have comparable values of the frequently used spectralwidth parameter, $\varepsilon$, defined as

$$
\varepsilon^{2}=1-\frac{m_{0}^{2}}{m_{0} m_{4}}
$$

However, $Q_{p}$ for one spectrum is 66 percent greater than for the other, indicating substantial differences in spectral shape.

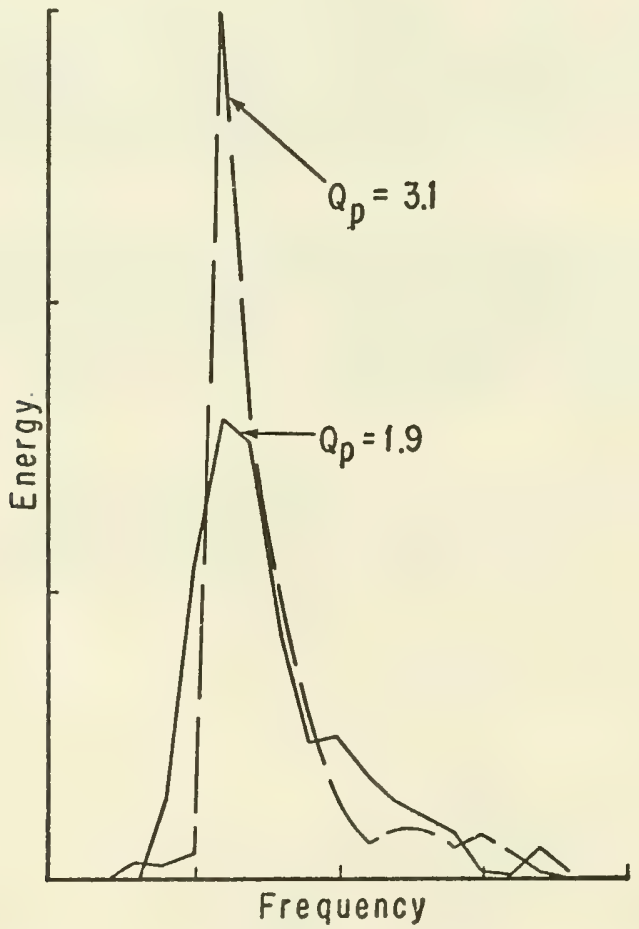

Figure 8. Comparison of two measured spectra from the North Atlantic Ocean with $\mathrm{H}_{S}=3.3$ meters, $\mathrm{T}_{p}=10.5$ seconds, and $\varepsilon=0.61$ (after Hoffman, 1974). 
Both $Q_{p}$ and $\varepsilon$ are designed to fit the concept of a single-peaked spectrum, but multipeaked ocean wave spectra are commonly observed. The suitability of spectral parameters for representing multipeaked field wave spectra has received little attention in the literature, although Ochi and Hubble (1976) have developed a computationally complicated technique for parameterizing field spectra with two major peaks.

Since $Q_{Q}$ seems to be a potentially important and useful parameter, it was computed for each of the spectra considered in this report. $\mathrm{Q}_{p}$ was based on the part of the spectrum between 0.03 and 0.2 hertz for staff and accelerometer-buoy gages, between 0.03 and 0.33 hert $z$ for the Great Lakes pressure gages, and between 0.03 and 0.31 hertz for the Pt. Mugu pressure gage.

c. Parameters of Distribution Function of Sea-Surface Elevation. The distribution function for instantaneous sea-surface elevations provides useful insight on shallow-water spectra and spectral parameters. It also provides probabilities associated with instantaneous surface elevations above the mean.

The distribution function of sea-surface elevations can conveniently be parameterized by its moments defined as:

$$
q_{n}=\sum_{i=1}^{N} n_{i}^{n} p\left(n_{i}\right)
$$

where

$\mathrm{q}_{n}=\begin{aligned} & \text { nth moment of the distribution function of sea-surface } \\ & \text { elevations }\end{aligned}$

$N=$ number of intervals in the distribution function

$n_{i}=$ sea-surface elevation associated with the $i$ th interval in the distribution function

$p\left(n_{i}\right)=$ probability associated with $n_{i}$

The zeroth and first moments, $q_{0}$ and $q_{1}$, are equivalent to the mean and variance of the distribution function. $q_{3}$ and $q_{4}$ are often referred to as the skewness and kurtosis of the distribution function.

The distribution function of sea-surface elevations is often assumed to be Gaussian. When normalized, the Gaussian distribution function has a mean of zero, a variance of one, a skewness of zero, and a kurtosis of three.

Steep waves in shallow water assume a decidedly nonsinusoidal profile with broad, flat troughs and narrow, high crests. The distribution of sea-surface elevations measured at a point is obviously non-Gaussian. 
The skewness and perhaps the kurtosis of surface elevations in very shallow water can be expected to differ from the values for a normalized Gaussian distribution. For the cnoidal wave profile in Figure 9 , the skewness and kurtosis are equal to 2.0 and 5.8 , respectively. The figure also shows the distribution function, skewness, and kurtosis for several idealized wave profiles.

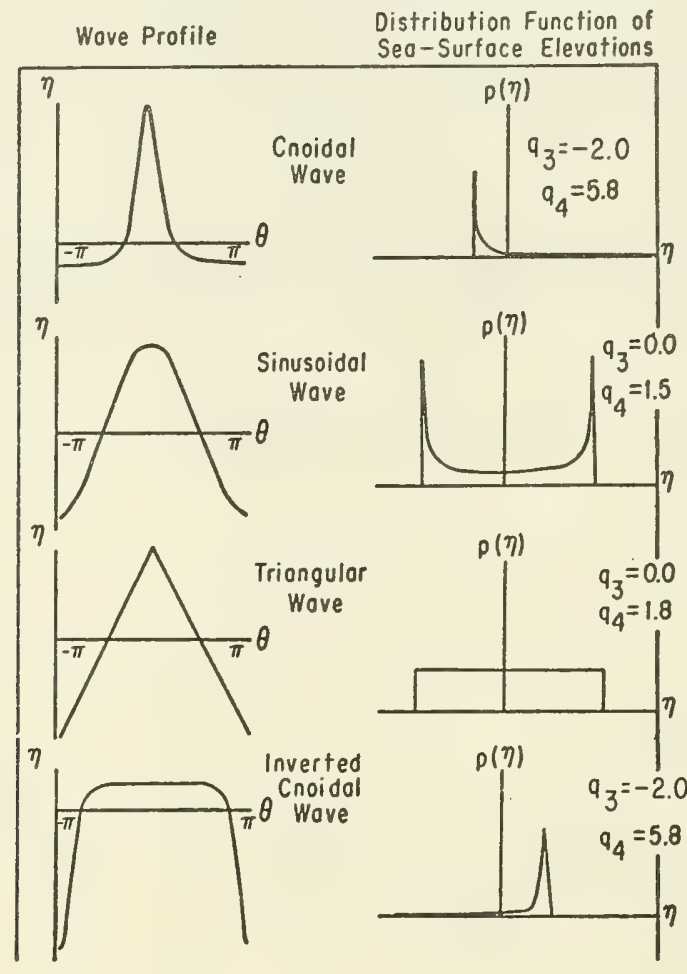

Figure 9. Distribution function of seasurface elevations for several idealized wave profiles.

Both skewness and kurtosis for the normalized distribution function of sea-surface elevations were computed for each record and are summarized in the following section. For the accelerometer-buoy data, the distribution functions represent doubly integrated vertical-surface accelerations rather than directly measured sea-surface elevations. For the pressure-gage data, the distribution functions represent subsurface pressure fluctuations. 


\section{SPECTRA, SPECTRAL SUMMARIES, AND SEA-SURFACE}

ELEVATION DISTRIBUTION FUNCTION PARAMETERS

1. High-Energy Wave Spectra.

Since high-energy spectra are of greatest concem in most engineering applications, plots of individual spectra containing the most energy for each station are provided in Appendix A. Spectra are grouped by gage location in the order listed in Table 1 . The appendix includes 24 spectra for each location, arranged and numbered in descending order of significant height.

Each plot in Appendix A shows the significant wave height, period corresponding to the highest spectral peak, spectral-peakedness parameter $\left(Q_{p}\right)$, and number of major spectral peaks identified by the computer routine SMOOTH (App. D). Spectral plots for days associated with tropical storms and hurricanes are labeled accordingly. The energy density scale can vary between plots.

Pressure-gage spectra in Appendix A are cut off at high frequencies above 0.33 hertz for the Great Lakes gages and 0.31 hertz for the Pt. Mugu gage. Several of the Pt. Mugu high-energy spectra were obviously overcompensated for attenuation of pressure with depth so that the highfrequency energy was much greater than the low-frequency energy. These spectra were omitted from Appendix A. This problem can arise because the high-frequency cutoff is constant while the compensation increases as the depth of water over the gage increases with the tide. Thus, the high-frequency end of the spectrum is sometimes overcompensated when water levels are high. This problem did not arise with pressure-gage spectra in the Great Lakes (where there is no tide).

Energy computed for wave periods longer than 30 seconds (frequencies less than 0.043 hertz) does not directly represent wind-generated waves. In some cases it is questionable whether such very long-period energy has any physical meaning. Therefore, it was omitted from spectral plots for the Great Lakes and Pacific coast locations and should be ignored in plots for the Atlantic and gulf coast locations.

Spectral plots for each location in Appendix A are followed by a table which contains auxiliary data for each plot, including sequential number, date, time, significant wave height, peak wave period, water depth, relative water depth (where $I_{p}$ is the shallow-water wavelength for a wave with frequency equal to the frequency of maximum spectral energy density), ratio of significant wave height to water depth, wave steepness, ratio of depth to $\mathrm{gT}_{p}^{2}$ (which is related to wavelength), spectral-peakedness parameter, and skewness and kurtosis of the distribution function of seasurface elevations. Wavelength used in the tables was computed in each case from period corresponding to the highest spectral peak and the equations of linear wave theory. The largest ratio of significant wave height to depth is 0.54 . None of the significant height-to-depth ratios approach the commonly used limit of 0.78 . 
Multiple major spectral peaks are evident in many of the spectra in Appendix A. However, some of the multipeaked spectra and many of the single-peaked spectra appear to approximate the form of the JONSWAP spectrum for waves undergoing active generation (Hasselmann, et al., 1973). Only seven of the spectra selected for inclusion in Appendix A were collected during hurricanes. This small sample does not illustrate any clear differences between spectra generated by hurricanes and spectra generated by extratropical storms.

\section{Mean Spectra.}

a. Grouped by Height and Period. Spectra from each gage site were grouped into sets by significant height and peak spectral period. Intervals of 30.5 centimeters were used for significant height; intervals of about 1 second were used for peak period (Table 2).

Mean spectra were plotted for all height-period intervals containing more than one case with heights greater than a cutoff height, which varied with location. In addition, mean spectral plots were generated for height-period intervals with heights below the cutoff if there were a reasonably large number of cases in the interval. This approach provided mean spectral plots for the most statistically meaningful low wave cases and for all high wave cases. Energy computed for periods longer than 30 seconds was omitted from plots for Great Lakes and Pacific coast locations as discussed earlier.

The mean spectral plots grouped by location are given in Appendix B. The approximate relative water depth and ratio of significant wave height to water depth for each location are listed in Table B-1; the dates covered are in Table 1.

The range of significant wave height and peak spectral period represented and the number of cases are listed on each plot. Each plot representing more than one case contains several dashlines in addition to the solid line showing the mean spectrum. The dashline nearest the mean and above it represents the mean plus one standard deviation. Similarly, the dashline nearest the mean and below it represents the mean minus one standard deviation. When the mean minus one standard deviation is negative, it is plotted as zero. For plots representing more than two cases, another dashline above the mean shows the highest single-energy density value occurring in each band. This line forms an envelope inside which all of the individual spectra would fall. The dashlines should not be treated as a spectrum, and are included on $1 y$ as indicators of the observed variability of energy density in each spectral band. Some of the plots show a relatively large concentration of energy at the lowest frequency $(0.005$ hertz). This concentration is at a frequency which is irrelevant to wind-generated gravity waves and should be ignored.

The mean spectral plots for each 1ocation in Appendix B are arranged in order of increasing significant height and peak period in most cases; i.e., all mean spectra in a colum represent the same peak-period interval 
and all mean spectra in a row represent the same significant height interval. Thus, the effect of increasing height on spectra with similar peak periods and the effect of increasing peak period on spectra with similar heights can be easily followed. A small number of plotted mean spectra are not included in Appendix B because the spectra (a) usually represented low or moderate wave heights with relatively few cases or high wave heights with only one case for which the spectrum is shown in Appendix A, or (b) were high-energy cases for Pt. Mugu which had obviously been overcompensated for attenuation of pressure with depth.

Mean spectra for low wave heights and peak periods less than 5 seconds along the Atlantic coast show evidence of secondary peaks at low frequency in many cases. The low-frequency peaks are broad and flat, are generally located near 0.1 hertz, and are likely to represent low-energy swell in the Atlantic Ocean. Corresponding broad, low-frequency secondary peaks are also evident in mean spectra for Pt. Mugu on the Pacific coast. These peaks are not evident in mean spectra for the gulf and Great Lakes gages, although the Presque Isle pressure-gage spectra show a sharp secondary peak which is consistently centered on 0.038 hertz. This 10 -frequency peak at Presque Isle may not be physically meaningful. For all locations, the differences between mean spectra are smaller than the differences between the individual spectra used to compute the means.

Mean spectra from the ocean gages for peak periods longer than about 10 seconds show evidence of secondary peaks at high frequency, especially for high wave heights. For example, several selected mean spectra for high wave, long-period groups are plotted in Figure 10 in dimensionless form. Energy density was made dimensionless for each mean spectrum by dividing by the total energy in the spectrum and converting to percent; frequency was made dimensionless by dividing by the peak frequency.

The figure clearly shows that the main secondary peak in each mean spectrum is at twice the peak frequency. The spectrum for one cnoidal wave (see Fig. 2) is also shown to clearly resemble the field spectra. A section of the Lake Worth pen-and-ink strip-chart record taken at nearly the same time as the Lake Worth spectrum in Figure 10 is shown in Figure 11. The profiles of the larger waves closely resemble the cnoidal wave profile. Many of the high-frequency secondary peaks in mean spectra for high, long-period waves are probably indicative of cnoidal-type wave profiles. Spectra for high, long-period waves in which secondary peaks at about two or three times the peak frequency represent independent wave trains are expected to be rare.

The plots in Appendix B also show interesting variations with wave height in mean spectra with short peak periods. In some cases, the mean spectra for high waves exhibit secondary peaks at low frequency. The emergence of the low-frequency secondary peaks for Nags Head is shown by dimensionless spectra plotted in Figure 12 . The figure also indicates that the largest secondary peak is at one-half the frequency of the dominant frequency. A section of pen-and-ink strip-chart record corresponding to two high wave, short-period cases is shown in Figure 13. 


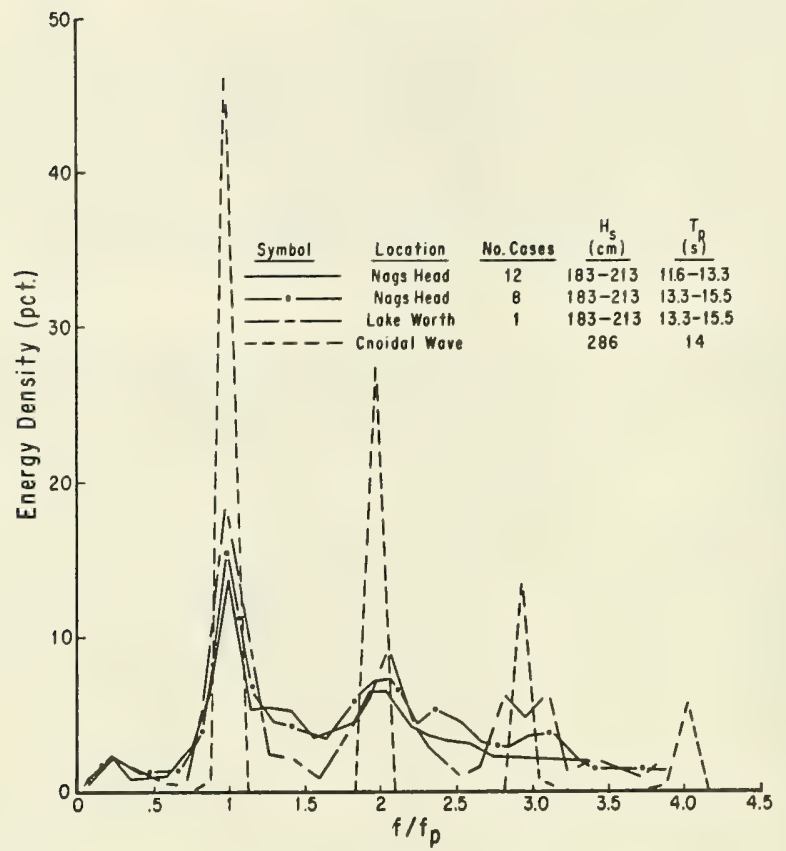

Figure 10. Di pensionless mean spectra for several high wave, long-period groups and for the cnodial wave shown in Figure 2 , case 3 .
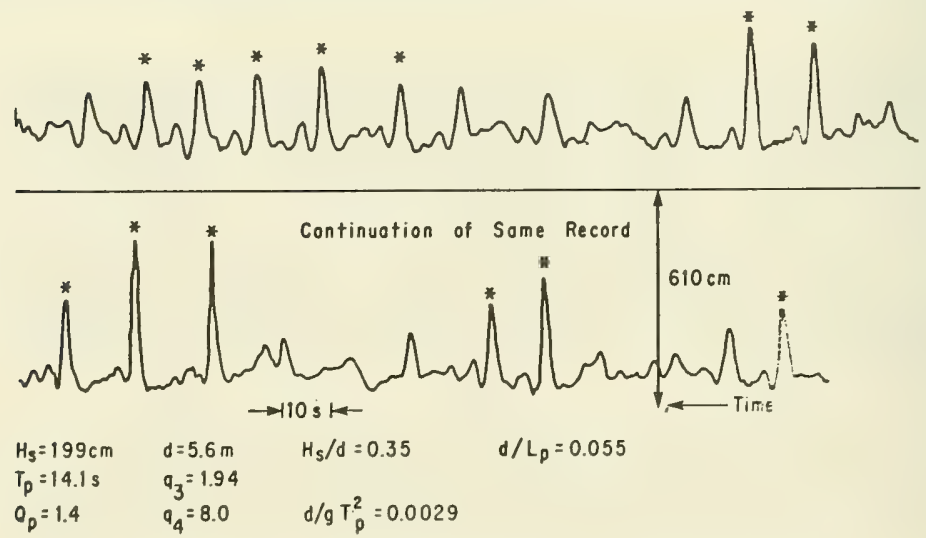

Figure 11. Section of pen-and-ink strip-chart record from iake fiorth, Florida, beginning at 0810 e.s.t., 20 Fcoruary 1969.

parameters are derived from analysis of a digital record beginning at 6723 , e.s.t., 20 February 1969. Individual waves with height greater thar $\mathrm{H}_{S}$ are marked by asterisks. 


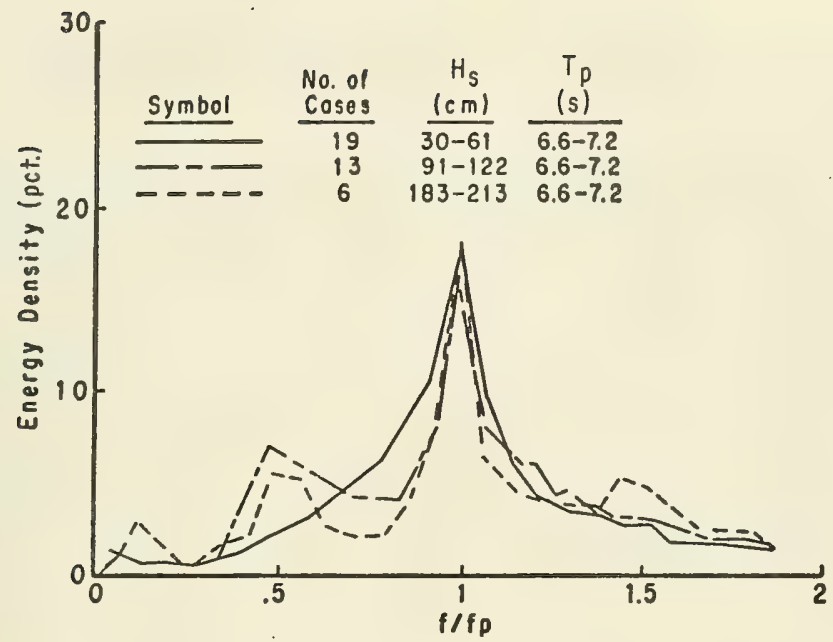

Figure 12. Dimensionless mean spectra for several high wave, short-period groups at Nags Head, North Carolina.

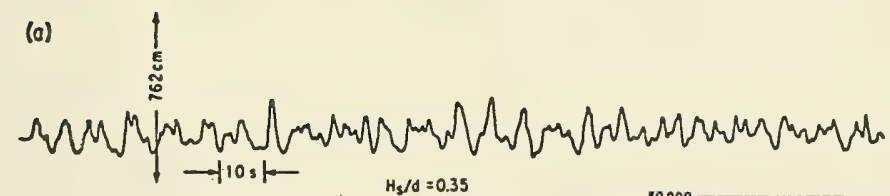

$$
\begin{array}{llll}
N_{s}=190 \mathrm{~cm} & O_{p}=2.1 & Q_{3}=0.78 & d / g T_{D}^{2}=0.012 \\
T_{D}=6.8 \mathrm{~s} & d=5.4 \mathrm{~m} & Q_{4}=3.8 & d / L_{D}=0.119
\end{array}
$$
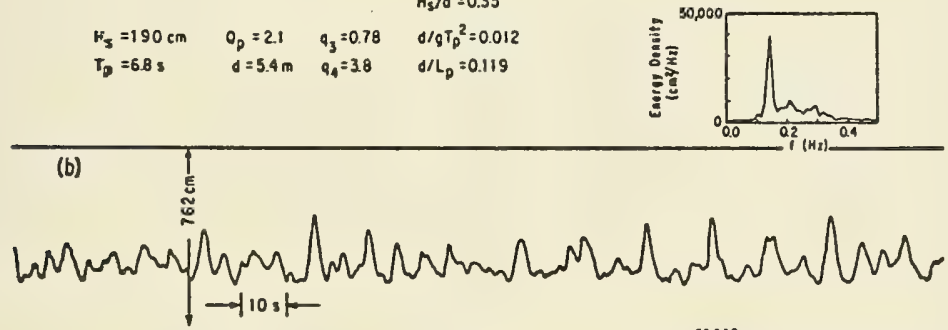

$$
\begin{array}{llll}
H_{s}=205 \mathrm{cn} & Q_{D}=1.5 & Q_{3}=1.03 & d / g T_{D}^{2}=0.013 \\
T_{D}=6.88 & d=5.7 \mathrm{~m} & Q_{4}=4.7 & d / L_{D}=0.122
\end{array}
$$

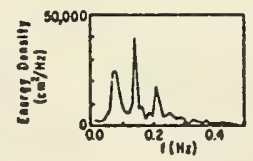

Figure 13. Two pen-and-ink strip-chart records and corresponding spectra from Nags liead, North Carolina. (a) Record at 0800 e.s.t., 20 April 1969; analysis at 0642 e.s.t., 20 April 1969; (b) record at 2000 e.s.t., 1 March 1969; analysis at 2040 e.s.t., 1 March 1969.. - 
In one case the spectrum has a single dominant peak; in the other case the spectrum has a large peak at one-half the dominant frequency and another major peak at about 1.5 times the dominant frequency.

A laboratory parallel of this behavior has been observed by Sawaragi and Iwata (1976). A single-peaked spectrum was generated in shallow water of uniform depth. As the waves propagated and broke, an increasing fraction of the energy shifted to frequencies which are multiples of the dominant frequency, $f_{p}$. Eventually, the spectral peak at $2 f_{p}$ was higher than the peak at $f_{p}$.

The individual spectral points used in computing mean spectra are plotted for Lake Worth in Appendix B. The distribution of the spectral points about the mean for each band is decidedly unsymmetric in most cases. The distribution usually has a high positive skewness indicating some relatively high values above the mean in the distribution which are not offset by correspondingly low values below the mean. However, the distribution of spectral points about the mean for the band of maximum energy density tends to be more symmetric and more nearly Gaussian.

Third and fourth moments of the normalized distribution of spectral points in selected bands were computed for all locations considered in this report. The moments are defined analogous to the moments of the distribution function of sea-surface elevations (eq. 6). For all locations, both the third and fourth moments are generally lowest in the vicinity of the spectral peak indicating a relatively symmetric and broad distribution about the mean.

Typical variations of the third and fourth moments of the normalized distribution of spectral points as a function of frequency are shown in Figures 14 and 15 for mean spectra with peak periods between 7.2 and 7.8 seconds at Nags Head. The third and fourth moments in the band of peak energy density actually fall below the values for a normalized Gaussian distribution. Deviations from the normalized Gaussian distribution over all frequency bands are generally less for high-energy spectra than lowenergy spectra. It may be concluded that the normalized Gaussian distribution gives a reasonable representation of the scatter of individual spectral energy densities about the peak of each mean spectrum in Appen$\operatorname{dix} B$, but it is not reliable for representing scatter about lower energy bands away from the peak.

Seasonal variations in the mean spectrum for each height-period interval were studied for Nags Head. Four 3-month seasons were selected using the seasonal summaries in Thompson (1977) as a guide. Mean spectra were computed for winter (December, January, and February) and for summer (June, July, and August). Seasonal differences in the mean spectra did not appear to be significant. The number of cases per height-period interval was considerably reduced when the spectra were grouped by season. Hence, extensive seasonal summarization was not considered in this study. 

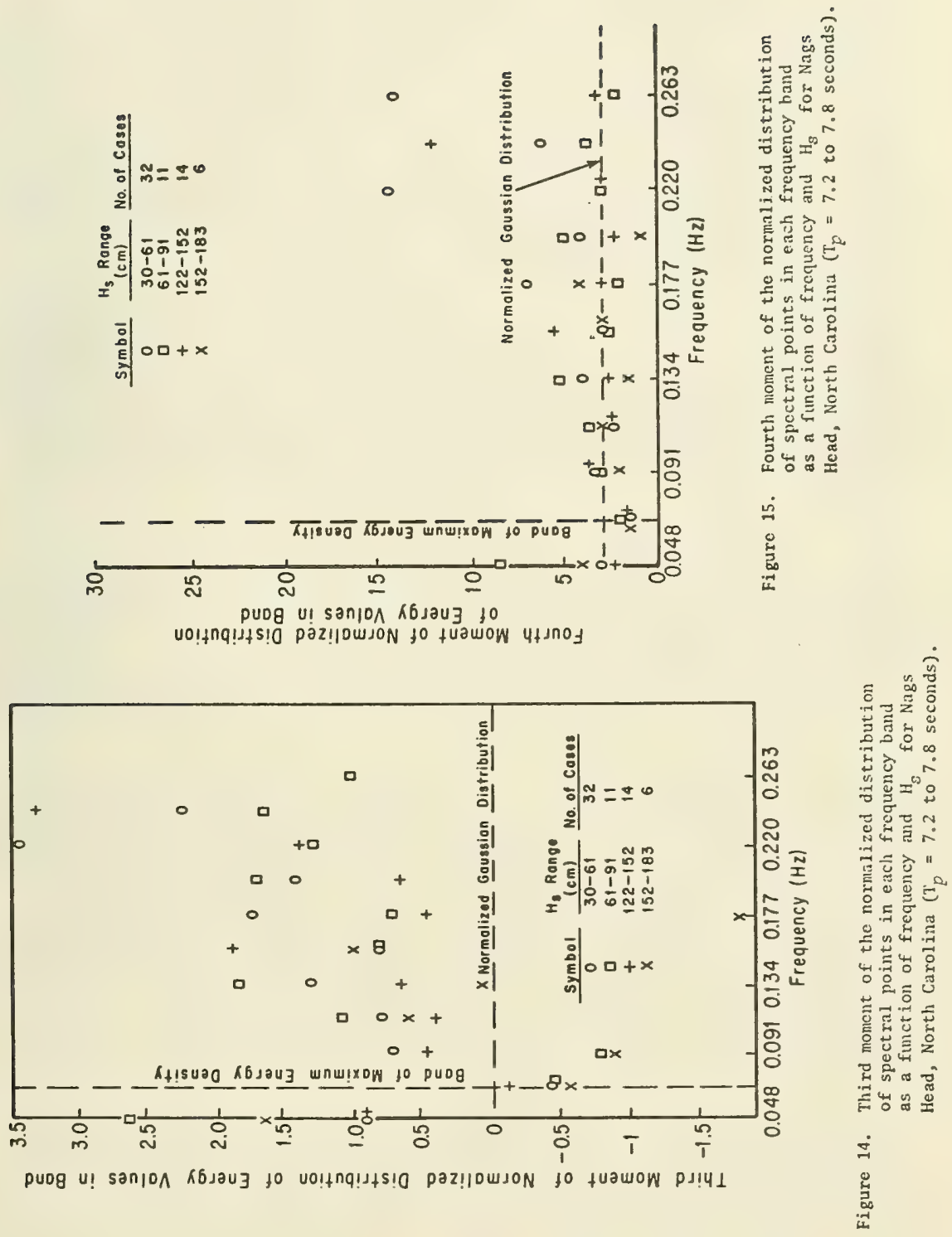
Comparison of mean spectra in Appendix B for the same height-period intervals at different locations provides additional perspective. Mean spectra for the Atlantic coast locations are generally quite similar to each other (Fig. 16, a and b). Mean spectra for the gulf coast location differ from the Atlantic coast spectra in that spectral energy at frequencies lower than 0.1 hertz is absent in virtually al1 cases. Mean spectra for the Great Lakes locations show an even more pronounced absence of low-frequency energy, especially for low wave conditions. This effect is illustrated in Figure 16a. The absence of low-frequency energy gives the gulf and Great Lakes mean spectra a tendency to have higher peaks than the mean spectra for corresponding height-period groups at Atlantic coast locations.

Mean spectra for the Pacific coast locations show that peak periods longer than 10 seconds are more common than for Atlantic coast locations. Reduced amounts of energy are also shown at frequencies higher than about 0.15 hertz in comparison to Atlantic coast spectra with long peak periods (Fig. 16b). Hence, the Pacific coast long-period mean spectra generally have higher peaks than their counterparts for the Atlantic coast. The few Pacific coast mean spectra shown with peak periods shorter than 9 seconds also show a distinct swell energy concentration at frequencies less than 0.1 hertz.

b. Grouped by Height, Period, and Water Leve1. Numerous field studies have indicated that shallow-water spectral shape is dependent on local water depth (e.g., Barnett 1969; Hasselmann, et al., 1973; Wang and Yang, 1976). Therefore, many of the results in this report are expected to be strongly influenced by the water depth at the gage site. The higher wave conditions at many of the sites can represent situations where waves occasionally break seaward of the gage, or, in the extreme, cases where the gage is actually in the surf zone as discussed in Section II.

To give more perspective on the systematic influence of water depth on spectral shape, the spectra within each significant height-peak period interval for the gage at Nags Head were further grouped according to mean water level in the record. Three water level groups were arbitrarily defined. Plots of average spectra by water level for height-period intervals in which there were a reasonably large number of cases are shown in Appendix C. Each plot is labeled with the height and period intervals represented and with a mean water level designator. A mean equal to 1 indicates the mean water level was relatively low; a mean of 2 indicates midtide water levels and 3 high water levels. Water level 2 encompassed a range of 49 centimeters. The differences between mean spectra as a function of mean water level are small.

\section{Spectral and Sea-Surface Elevation Distribution Function Parameters.}

a. Secondary Spectral Peaks. The computerized procedure described in Section III and Appendix D was used to identify major peaks in all spectra considered for this report. For five of the six ocean locations only about one-third of the shallow-water spectra are single peaked (Fig. 17). 

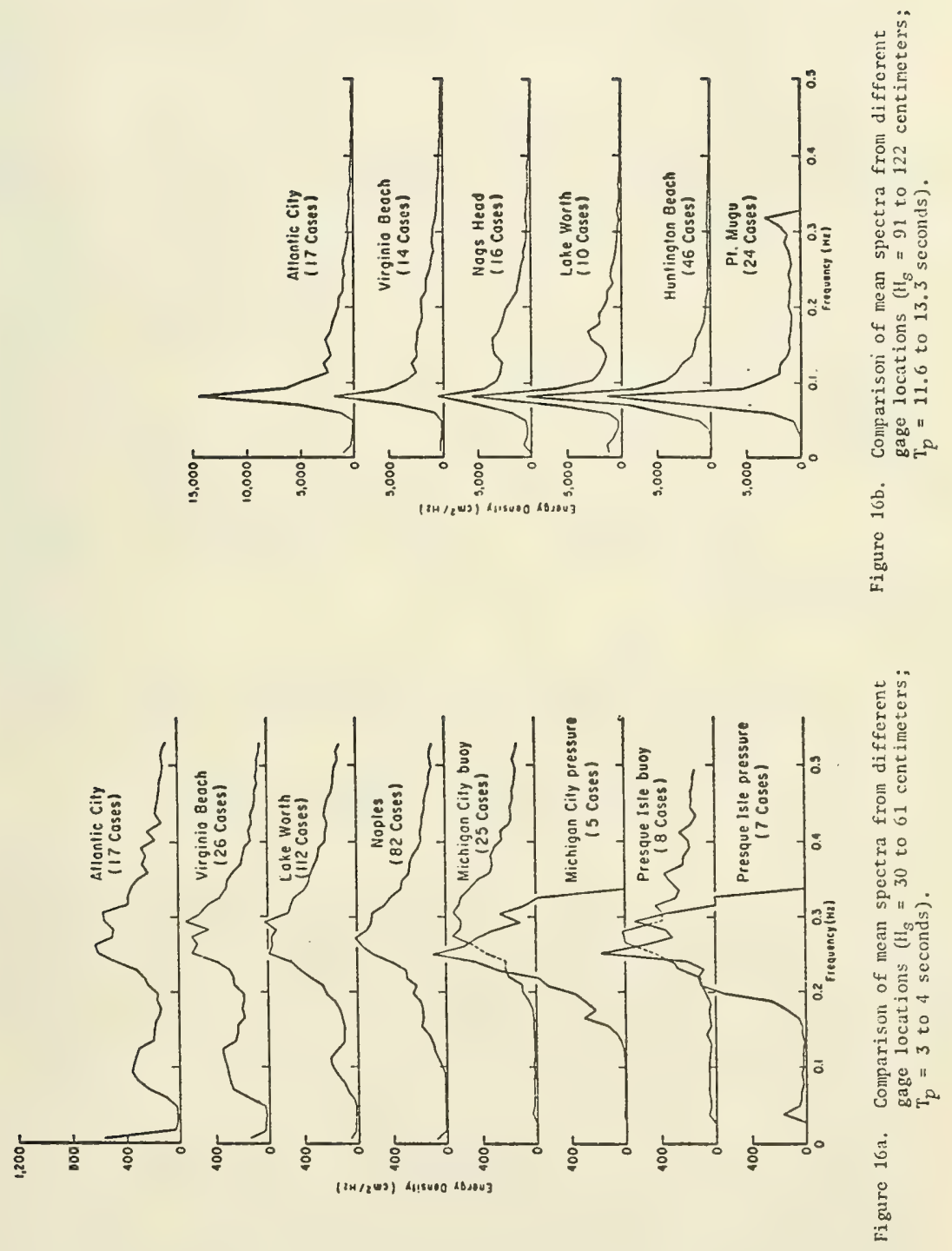


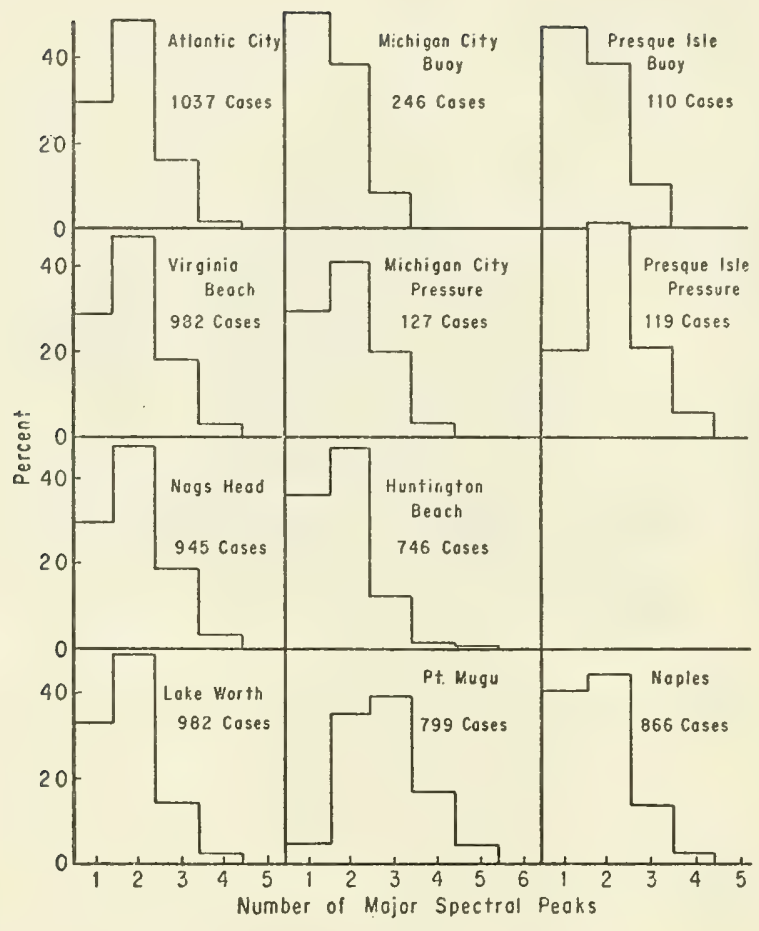

Figure 17. Percentage of spectra versus number of major spectral peaks.

At the remaining ocean location (Pt. Mugu) only 5 percent of the spectra were single peaked. The infrequency of single-peaked spectra at Pt. Mugu may be attributed both to common simultaneous occurrence of sea and swell waves and to pressure-compensation effects on the spectrum which often make the high-frequency end of the spectrum look like a meaningful peak. At all ocean locations, about one-half the spectra are double peaked with the rest containing three, four, and in a few cases, five major peaks. Several spectra with five major peaks and corresponding pen-and-ink traces are shown in Figure 18.

Single-peaked spectra are more common for the gulf and Great Lakes sites than for the ocean sites (see Fig. 17). About 40 percent of the Naples spectra and about one-half of the Great Lakes spectra from accelerometer buoys 6 kilometers offshore were single peaked. Spectra from the Great Lakes nearshore pressure gages show that only 20 to 30 percent of the cases are single peaked. However, these percentages are considered low because the pressure-compensation procedure often creates a 
(o)

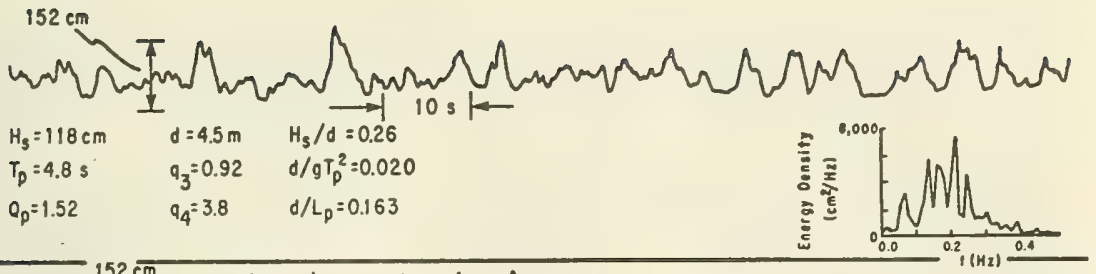

(b)

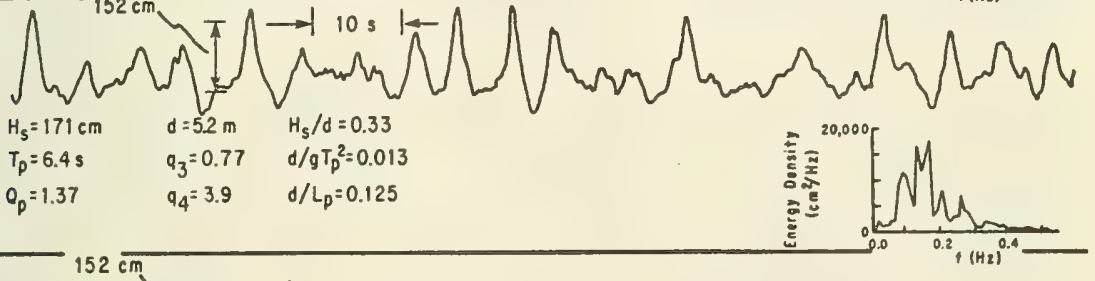

$(c)$

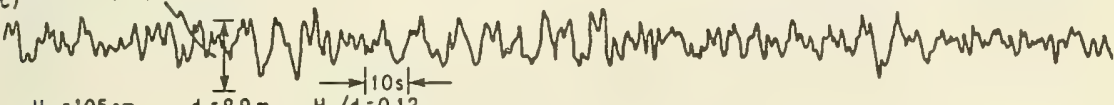

$H_{s}=105 \mathrm{~cm} \quad d=8.9 \mathrm{~m} \quad \mathrm{H}_{\mathrm{s}} / \mathrm{d}=0.12$

$T_{p}=8.83 \quad a_{3}=0.31 \quad d / 9 T_{p}^{2}=0.011$

$Q_{p}=1.40 \quad Q_{4}=3.2 \quad d / L_{p}=0.117$

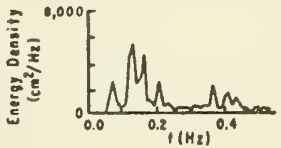

Figure 18. Pen-and-ink strip-chart records and corresponding spectra for some cases with five major spectral peaks: (a) Nags Head record at 0400 e.s.t., 25 December 1968; analysis at 0643 e.s.t., 25 December 1968; (b) Nags Head record at 0800 e.s.t., 24 February 1969; analysis at 0642 e.s.t., 24 February 1969; (c) Huntington Beach record at 1900 e.s.t., 9 May 1972; analysis at 1840 e.s.t., 9 May 1972.

small peak at high frequency. Small peaks at frequencies less than 0.05 hertz appeared in some of the Great Lakes spectra, especially spectra from the Presque Isle pressure gages (App. B). These peaks were considered spurious and are not counted as major spectral peaks. Double-peaked spectra are shown to be common at both the gulf and Great Lakes locations.

It was noted that secondary spectral peaks do not always represent independent wave trains. When waves are nonlinear, i.e., when $\mathrm{H}_{s} / \mathrm{d}$ or $\mathrm{H}_{\mathcal{S}} / \mathrm{L}_{p}$ are large, the wave profile will be nonsinusoidal. For such cases, a secondary spectral peak at twice the dominant frequency is expected even though a photo would show a single train of waves. The effect is most evident for high, long waves at low tide; i.e., cases with high values of $\mathrm{H}_{S} / \mathrm{d}$ and low values of $\mathrm{d} / \mathrm{L}_{p}$. Appendixes $\mathrm{A}$ and $\mathrm{B}$ clearly show that secondary peaks tend to occur systematically for high, long shallow-water waves. However, the joint distribution table of number of major spectral peaks versus significant height at each location shows 
no clear evidence of a relationship (see Table 3). The correlation between number of peaks and $\mathrm{H}_{S}$ is less than 0.3 at all locations (Table 4). The joint distribution table of number of major spectral peaks versus period corresponding to the highest spectral peak at each location also shows little evidence of a relationship (Table 5). The correlation between number of peaks and $\mathrm{T}_{p}$ is also very low (Table 4). For most wave conditions the occurrence of secondary spectral peaks does not appear to be systematically related to $\mathrm{H}_{S}$ and $\mathrm{T}_{p}$. The overall statistics on multiple peaks as indicators of multiple wave trains should be reasonably correct.

Several other attempts have been made to quantify the likelihood of having multiple wave trains. Shepard and Inman (1951) report visual wave observations to identify secondary and dominant wave trains from the Scripps pier in southern California during a 10-month period. They report secondary wave trains in 56 percent of 302 observations. This figure may be an underestimate because of the difficulty of visually identifying secondary trains, but is reasonably consistent with the Huntington Beach gage data.

Table 3: Percentage of cases in each significant height group corresponding to number of major spectral peaks.

\begin{tabular}{|c|c|c|c|c|c|c|c|}
\hline \multicolumn{2}{|c|}{$\mathrm{II}_{\mathrm{g}}(\mathrm{cm})$} & \multicolumn{5}{|c|}{ Major spoctrul pouks } & \multirow[t]{2}{*}{ Cases } \\
\hline & & 1 & 2 & 3 & 4 & 5 & \\
\hline \multicolumn{8}{|c|}{ Nags Head, N.C. } \\
\hline & to 30 & 29 & 39 & 29 & 3 & -1 & 38 \\
\hline 30 & to 61 & 40 & 45 & 14 & 2 & - & 301 \\
\hline $61 t$ & to 91 & 36 & 42 & 19 & 2 & - & 208 \\
\hline $91 t$ & to 122 & 20 & 58 & 21 & 1 & 1 & 158 \\
\hline 122 & to 152 & 22 & 59 & 17 & 2 & - & 95 \\
\hline 152 & to 183 & 25 & 44 & 22 & 7 & 2 & 59 \\
\hline 183 & to 213 & 13 & 50 & 31 & 6 & - & 52 \\
\hline 213 & to 244 & 21 & 50 & 25 & 4 & - & 28 \\
\hline 244 & to 274 & $\ldots 1$ & 60 & 40 & -1 & - & 5 \\
\hline 274 & to 305 & 100 & $\ldots 1$ & --1 & -- & - & 1 \\
\hline \multicolumn{8}{|c|}{ Naples, Fla. } \\
\hline 0 & to 30 & 45 & 45 & 9 & 1 & - & 482 \\
\hline 30 & to 61 & 36 & 42 & 19 & 2 & - & 288 \\
\hline $61 t$ & to 91 & 34 & 45 & 16 & 1 & 3 & 73 \\
\hline 91 & to 122 & 15 & 55 & 30 & -- & - & 20 \\
\hline 122 & to 152 & 33 & 67 & -- & -- & - & 3 \\
\hline \multicolumn{8}{|c|}{ Michigan City, Ind. (pressure gage) } \\
\hline $0 \mathrm{t}$ & to 30 & 17 & 50 & 29 & 4 & - & 24 \\
\hline $30 t$ & to 61 & 18 & 64 & 18 & -- & - & 11 \\
\hline 61 & to 91 & 22 & 37 & 26 & 15 & - & 27 \\
\hline 91 & to 122 & 30 & 50 & 20 & -- & - & 20 \\
\hline 122 & to 152 & 33 & 33 & 33 & -- & - & 12 \\
\hline 152 & to 183 & 64 & 18 & 9 & 9 & - & 11 \\
\hline 183 & to 213 & 55 & 36 & 9 & -- & - & 11 \\
\hline $213 t$ & to 244 & 25 & 63 & 13 & -- & - & 8 \\
\hline $244 t$ & to 274 & 50 & 50 & -- & -- & - & 2 \\
\hline $274 t$ & to 305 & 100 & --- & -- & -- & - & 1 \\
\hline \multicolumn{8}{|c|}{ Huntington Beach, Calif. } \\
\hline 0 & to 30 & & & & & & \\
\hline $30+$ & to 61 & 32 & 45 & 23 & 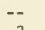 & - & 31 \\
\hline 61 & to 91 & 37 & 50 & 11 & 2 & - & 311 \\
\hline 91 & to 122 & 36 & 49 & 13 & 2 & - & 264 \\
\hline 122 & to 152 & 36 & 46 & 16 & 3 & - & 90 \\
\hline 152 & to 183 & 44 & 41 & 12 & 3 & - & 34 \\
\hline 183 & to 213 & 36 & 45 & 18 & -. & - & 11 \\
\hline 213 & to 244 & 67 & 33 & -- & -- & - & 3 \\
\hline 244 & to 274 & -. & 100 & -- & -- & - & 1 \\
\hline 274 & to 305 & $\ldots$ & 100 & -- & -- & - & 1 \\
\hline
\end{tabular}


Table 4. Linear correlation betwecn number of major spectral peaks, significant height and period corresponding to the highest peak.

\begin{tabular}{|l|c|c|r|}
\hline \multicolumn{2}{|c|}{ Location } & \multicolumn{2}{|c|}{ Correlation } \\
\cline { 2 - 4 } & $\begin{array}{c}\mathrm{H}_{8} \text { vs. } \\
\text { No. of peaks }\end{array}$ & $\begin{array}{c}\mathrm{T}_{p} \text { vs. } \\
\text { No. of peaks }\end{array}$ & Cases \\
\hline Atlantic City, N.J. & 0.12 & 0.07 & 1,037 \\
Virginia Beach, Va. & 0.10 & 0.10 & 982 \\
Nags Head, N.C. & 0.16 & 0.06 & 945 \\
Lake Worth, Fla. & 0.02 & 0.05 & 982 \\
Naples, Fla. & 0.17 & 0.05 & 866 \\
Michigan City, Ind. (buoy) & 0.24 & 0.17 & 246 \\
Michigan City, Ind. (pressure) & 0.26 & 0.24 & 127 \\
Presque Isle, Pa. (buoy) & 0.09 & 0.18 & 110 \\
Presque Isle, Pa. (pressure) & 0.19 & 0.32 & 119 \\
Huntington Beach, Calif. & 0.01 & 0.17 & 746 \\
Pt. Mugu, Calif. & 0.02 & 0.16 & 799 \\
\hline
\end{tabular}

Table 5. Percentage of cases in each peak period group corresponding to number of major spectral peaks.

\begin{tabular}{|c|c|c|c|c|c|c|c|}
\hline \multirow{2}{*}{\multicolumn{2}{|c|}{$\mathrm{T}_{p}(\mathrm{~s})$}} & \multicolumn{5}{|c|}{ Major spectral peaks } & \multirow[t]{2}{*}{ Cases } \\
\hline & & 1 & 2 & 3 & 4 & 5 & \\
\hline \multicolumn{8}{|c|}{ Nags Head, N.C. } \\
\hline & to 1 & --1 & --1 & --1 & --1 & -1 & \\
\hline & to 2 & -- & --- & -- & -- & - & \\
\hline 2 & to 3 & -- & 100 & -- & -- & - & 3 \\
\hline 3 & to 4 & -- & 67 & 17 & 17 & - & 6 \\
\hline 4 & to 5 & 21 & 50 & 21 & 4 & 4 & 28 \\
\hline 5 & to 6 & 20 & 54 & 22 & 4 & - & 54 \\
\hline 6 & to 7 & 30 & 45 & 20 & 5 & 1 & 132 \\
\hline 7 & to 8 & 36 & 49 & 12 & 3 & - & 73 \\
\hline 8 & to 9 & 43 & 40 & 15 & 2 & - & 258 \\
\hline 9 & to 10 & 34 & 46 & 20 & 1 & - & 142 \\
\hline 10 & to 11.6 & 29 & 53 & 15 & 3 & - & 87 \\
\hline 11.6 & to 13.3 & 11 & 58 & 28 & 3 & - & 105 \\
\hline 13.3 & to 15.5 & 16 & 59 & 22 & 4 & - & 51 \\
\hline 15.5 & to 13.6 & -- & 33 & 67 & -- & - & 6 \\
\hline \multicolumn{8}{|c|}{ liuritington Beach, Calif. } \\
\hline & to 1 & -- & -- & - & $-\infty$ & - & \\
\hline & to 2 & -- & --- & -- & -- & - & \\
\hline & to 3 & -- & -- & -- & -- & - & \\
\hline 3 & to 4 & 20 & 60 & 20 & -- & - & 5 \\
\hline 4 & to 5 & -- & 50 & 25 & 25 & - & 4 \\
\hline 5 & to 6 & -- & 57 & 43 & -- & - & 7 \\
\hline 6 & to 7 & 8 & 46 & 33 & 8 & 4 & 24 \\
\hline 7 & to 8 & 27 & 40 & 20 & 13 & - & 15 \\
\hline 8 & to 9 & 18 & 61 & 9 & 9 & 2 & 44 \\
\hline 9 & to 10 & 35 & 45 & 20 & -- & - & 20 \\
\hline 10 & to 11.6 & 40 & 53 & 7 & -- & - & 43 \\
\hline 11.6 & to 13.3 & 45 & 45 & 10 & 1 & - & 173 \\
\hline 13.3 & to 15.5 & 39 & 47 & 13 & -- & - & 250 \\
\hline 15.5 & to 18.6 & 37 & 51 & 10 & 1 & - & 147 \\
\hline 18.6 & to 23.3 & 29 & 50 & 21 & -- & - & 14 \\
\hline
\end{tabular}

${ }^{1}$ No observed cases. 
Hoffman (1978) reports on the occurrence of multipeaked spectra from hindcasts generated for a grid point in the North Atlantic Ocean by the Spectral Ocean Wave Model of the U.S. Navy Fleet Numerical Weather Central, Monterey, California. The criterion for accepting a secondary peak was that its peak energy be at least 30 percent of the energy in the highest peak and that it be reasonably separate in frequency from the main peak. About 25 percent of 572 cases considered were multipeaked. There was a tendency for multipeaked spectra to be more common during low wave conditions than during high wave conditions.

It is of some engineering interest to know whether a spectrum with a certain $\mathrm{T}_{p}$ value is more likely to contain major secondary peaks than a spectrum with a different $T_{p}$ value. Evidence at many locations shows that spectra associated with certain ranges of $T_{p}$ do indeed exhibit a preference for multiple peaks. At Atlantic City, Virginia Beach, and Nags Head on the Atlantic coast and at Huntington Beach on the Pacific coast, multipeaked spectra are more common for long and short $\mathrm{T}_{p}$ cases than for intermediate $T_{p}$ cases (shown in Fig. 19). Multipeaked spectra are least common for $T_{p}$ values between about 8 and 10 seconds at the three Atlantic coast locations. At Huntington Beach multipeaked spectra are least common for $\mathrm{T}_{p}$ values of 12 to 13 seconds. At Lake Worth and Naples, there is no clear evidence of a relationship between $\mathrm{T}_{p}$ and the occurrence of secondary spectral peaks. Data on secondary peaks from Pt. Mugu and the Great Lakes locations were not considered because of difficulties with the compensated pressure spectrum and because of the sma11 number of Great Lakes cases.

Additional insight on the occurrence of secondary spectral peaks can be obtained from a detailed look at their characteristics for a representative Atlantic coast location and the single Pacific coast location. For example, Figure 19 shows that 70 percent of the Nags Head spectra with $\mathrm{T}_{p}$ between 6 and 7 seconds have major secondary peaks; Figure 20 (a) shows in a histogram that the periods of those secondary peaks range from 2 to 17 seconds. The figure also shows that secondary peak periods are fairly evenly distributed over the range of 3 to 17 seconds. The relatively low percentage of secondary peaks at 7 to 8 seconds shown in Figure 20 (a) is artificially low because the CERC analysis procedure gives a nonuniform resolution in wave period which tends to decrease the number of cases in the 7- to 8-second intervals and increase the number of cases in the 6- to 7- and 8- to 9-second intervals. The procedure also precludes any cases with intervals of 11 to 12,13 to 14,15 to 16 , and 17 to 20 seconds.

Although the histograms in Figures 20 and 21 show how often secondary peaks occur, no indication is given of how much energy is contained in the secondary peaks. Therefore, another curve was added to the figures to show the average energy for secondary spectral peaks in each period interval. The energy associated with each peak was estimated by the procedures discussed in Section III and shown in Figure 7. Relatively highenergy secondary peaks tend to occur in Figure 20 (a) at periods. slightly less than $T_{p}$ and at periods of 12 to 14 seconds. The long-period secondary peaks generally represent swel1 waves. 

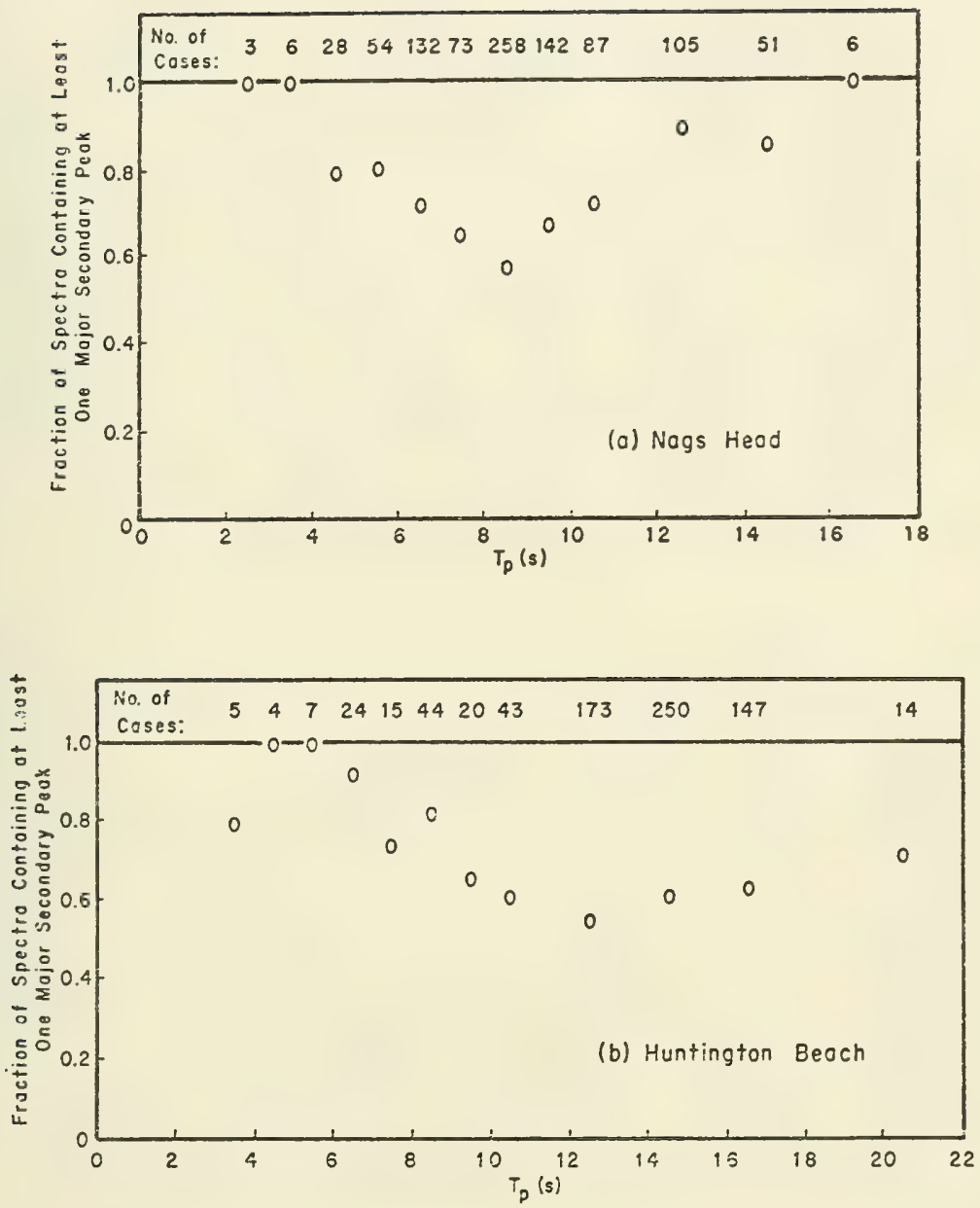

Figure 19. Fraction of spectra with at least one major secondary peak versus $\mathrm{T}_{p}$. 

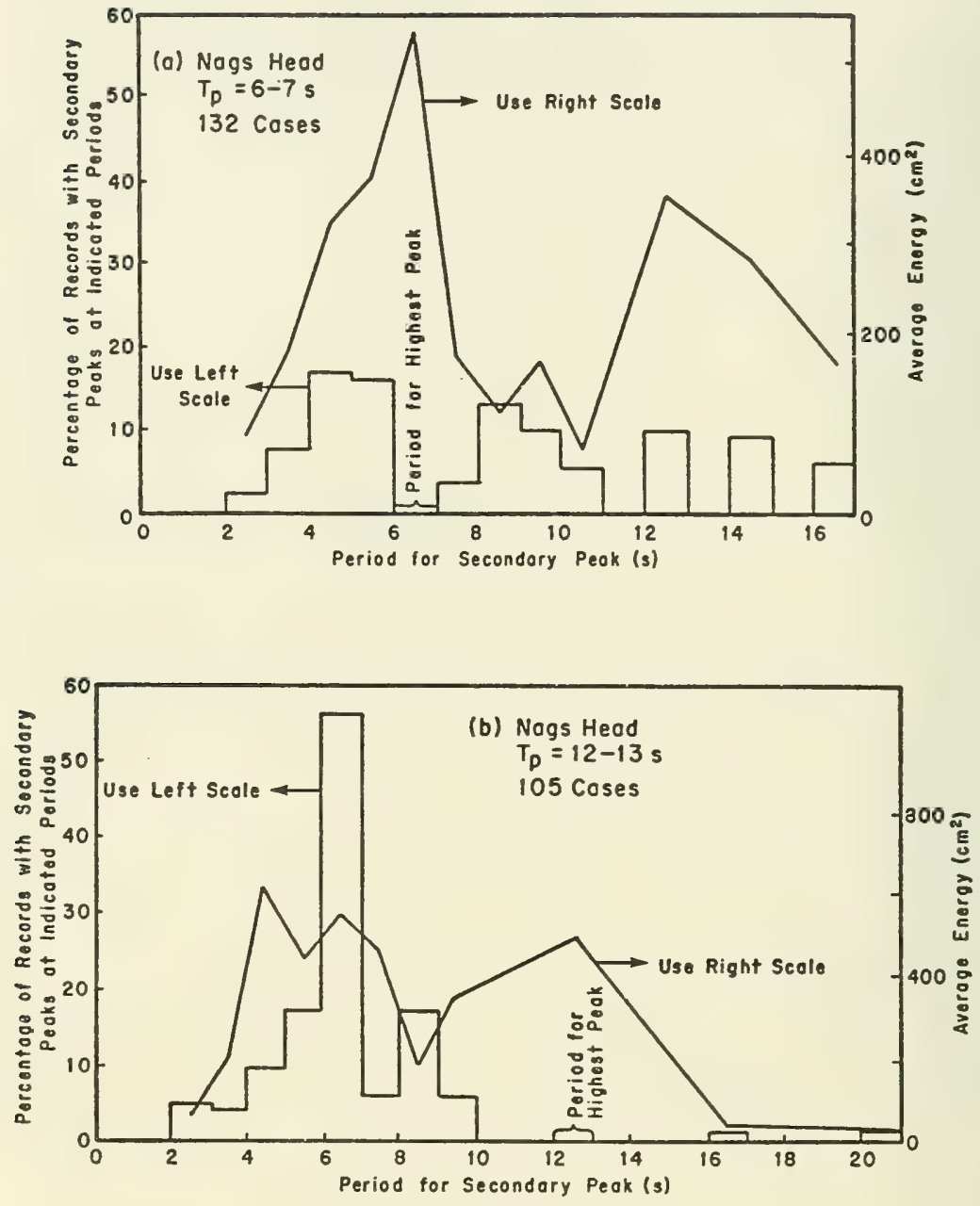

Figure 20. Frequency of occurrence and average energy for secondary peaks as a function of secondary peak period at Nags Head, North Carolina. 

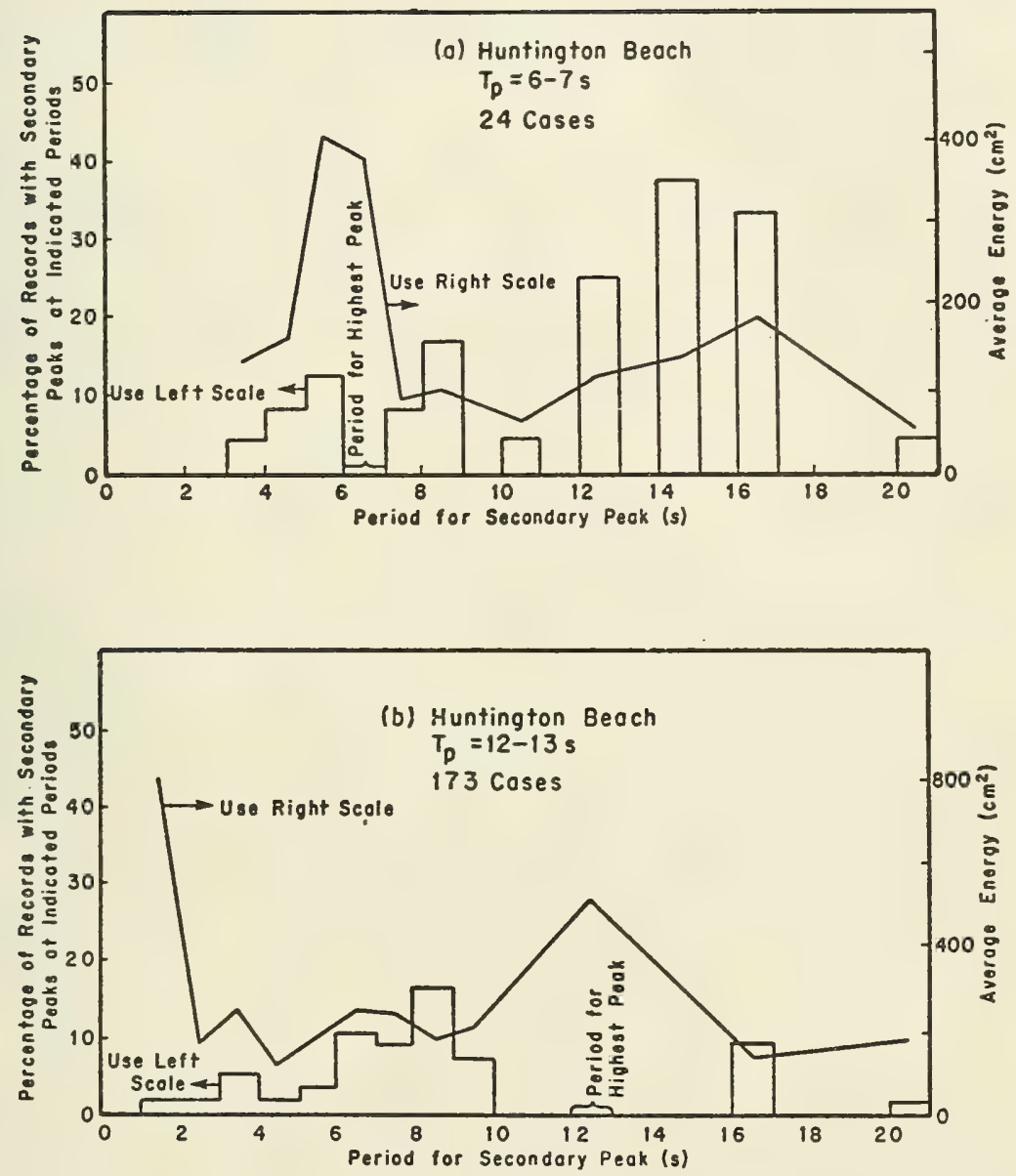

Figure 21. Frequency of occurrence and average energy for secondary peaks as a function of secondary peak period at Huntington Beach, California. 
Figure 20(b) shows characteristics of secondary spectral peaks at Nags Head when period of the dominant peak is 12 to 13 seconds. Secondary peak periods of 4 to 9 seconds are common. In most cases these secondary peaks represent 1 ocally generated wave energy or swell waves generated near the Nags Head coast. The average energy associated with these peaks is relatively high. Secondary peaks at periods longer than 10 seconds are almost totally absent.

At Huntington Beach, spectra with relatively short $T_{p}$ have a very strong tendency for a secondary peak at long period (see Fig. 21,a). Locally generated waves at Huntington Beach are usually superimposed on long-period swel1 waves. Huntington Beach spectra with long Tp have a small tendency for secondary peaks with short periods (see Fig. 21,b). They also have a small tendency for secondary peaks at long period, which presumably correspond to secondary swe11 waves superimposed on the dominant swe11. However, most Huntington Beach spectra with long $T_{p}$ appear to be dominated by the main spectral peak.

b. Spectral Peakedness. The spectral-peakedness parameter, $Q_{p}$, defined by equation (4) was computed for each spectrum. The spectralpeakedness parameter is shown on each plot in Appendix A.

Cumulative distribution functions of $Q_{p}$ are shown in Figure 22 for the selected locations. The $Q_{p}$ values cover a wide range at most locations-from less than one to greater than five. $Q_{p}$ values tend to be smallest for the Atlantic coast sites. The highest Qp values tend to occur for the Great Lakes gages, with the pressure gages having higher Qp values than the buoy gages. Qp values for the gulf and Pacific coast gages tend to be intermediate to values for the Great Lakes and Atlantic coast gages except for the highest 5 percent of the Pt. Mugu $Q_{p}$ values. The cumulative distribution function for Pt. Mugu shows a rapid increase in $Q_{p}$ values associated with probabilities of less than 5 percent. This feature is a result of occasional large overcompensation of the pressure spectrum which creates a high spectral peak at high frequency. Several cases in which $Q_{p}$ was greater than nine are omitted from Figure 22. These cases all correspond to very low wave conditions except for several overcompensated Pt. Mugu cases.

Goda (1976) indicated that high values of $Q_{p}$ are associated with strong grouping of high waves. Pen-and-ink record traces for several cases with reasonably high waves and high $Q_{p}$ values are shown in Figure 23. Some grouping of the high waves is evident in the records. Records with low $Q_{p}$ values in Figures 13 and 18 show little evidence of wave grouping; yet the record in Figure 11 for high, 1ong waves shows evidence of high waves occurring together, but the $Q_{p}$ value is only 1.35 .

The spectral-peakedness parameter might be expected to weakly correlate with the number of major spectral peaks so that single-peaked spectra tend to have high peakedness. The data indicate a low correlation at some locations, but not at others (Table 6). Q $Q_{p}$ also appears to be 


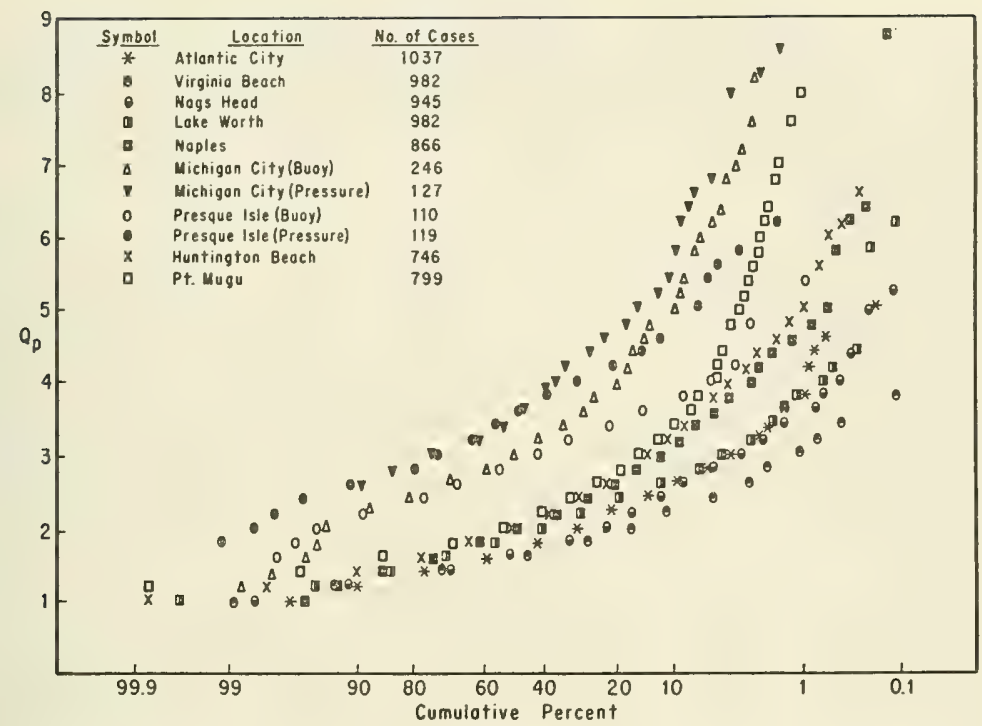

Figure 22. Cumulative probability distribution functions for spectral peakedness.

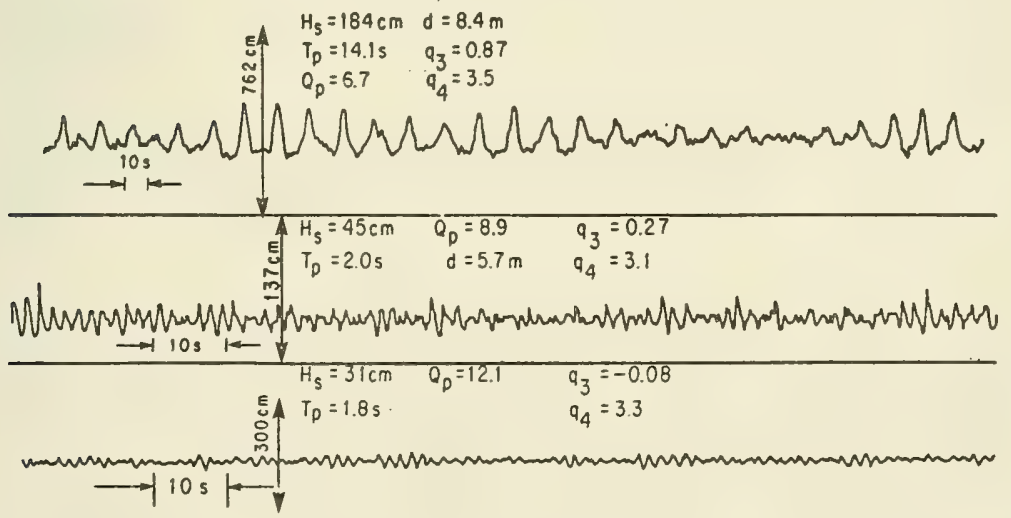

Figure 23. Pen-and-ink strip-chart records for selected cases with high $\mathrm{Q}_{p}$ values: (a) Huntington Beach record at 0100 e.s.t., 3 September 1972; analysis at 0040 e.s.t., 3 September 1972; (b) Naples record at 1220 e.s.t., 9 June 1969; analysis at 1340 e.s.t., 9 June 1969; (c) Michigan City (buoy) record at 2025 e.s.t., 14 September 1975; analysis at 2220 e.s.t., 14 September 1975. 
Table 6. Correlation between spectral-peakedness parameter and other wave parameters.

\begin{tabular}{|c|c|c|c|c|c|}
\hline \multirow[t]{3}{*}{ Location } & \multirow[t]{3}{*}{ Cases } & \multicolumn{2}{|c|}{ Correlations } & \multirow[t]{2}{*}{ Cases } & \multirow{2}{*}{$\begin{array}{c}\text { Correlations } \\
T_{p} \text { vs. } Q_{p}\end{array}$} \\
\hline & & \multirow{2}{*}{$\begin{array}{l}\text { Q vs. } \\
\text { No. of peaks }\end{array}$} & \multirow{2}{*}{$H_{3}$ vs. QD } & & \\
\hline & & & & (single & -peaked cases) \\
\hline Atlantic City, N.J. & 1,037 & 0.22 & 0.08 & 322 & 0.27 \\
\hline Virginia Beach, Va. & 982 & 0.13 & 0.02 & 292 & 0.20 \\
\hline Nags Head, N.C. & 945 & 0.31 & 0.20 & 286 & 0.20 \\
\hline Lake worth, Fla. & 982 & 0.05 & 0.08 & 332 & 0.29 \\
\hline Naples, Fla. & 866 & 0.06 & 0.16 & 351 & 0.31 \\
\hline Michigan City, Ind. (buoy) & 246 & 0.09 & 0.27 & 128 & 0.34 \\
\hline Michigan City, Ind. (pressure) & 127 & 0.06 & 0.61 & 39 & 0.80 \\
\hline Presque Isle, $\mathrm{Pa}$. (buoy) & 110 & 0.10 & 0.14 & 54 & 0.25 \\
\hline Presque Isle, $\mathrm{Pa}$. (pressure) & 119 & 0.06 & 0.36 & 25 & 0.43 \\
\hline Hunt ington Beach, Calif. & 746 & 0.34 & 0.24 & 274 & 0.05 \\
\hline Pt. Mugu, Calif. & 799 & 0.22 & 0.25 & 34 & 0.73 \\
\hline
\end{tabular}

weakly correlated with relative water depth as evidenced by a small correlation between peak period and $Q_{p}$ for single-peaked spectra (Table 6). This may also be a result of the definition of Qp. A low correlation between significant height and $Q_{p}$ is also shown in the table.

The spectral-peakedness parameter appears to be related to significant wave height and peak spectral period in a complicated way (see Table 7 for Nags Head and Huntington Beach). High mean values of $Q_{p}$ occur for significant wave heights and peak periods near the annual mean for most locations (Table 7). Mean $Q_{p}$ values decrease fairly systematically for $T_{p}$ increasingly higher than the annual mean $T_{p}$ in most cases (Table 7). Qp values have a tendency to increase with $\mathrm{H}_{S}$ for $\mathrm{T}_{p}$ shorter than the mean and decrease with $\mathrm{H}_{S}$ for $\mathrm{H}_{S}$ and $\mathrm{T}_{p}$ greater than the annual means. High values of $\mathrm{H}_{S}$ are often associated with relatively high mean $Q_{p}$ for short $T_{p}$, but low mean $Q_{p}$ for long $\mathrm{T}_{p}$. The latter is mostly a result of the nonsinusoidal profile for long waves in shallow water.

On the basis of evidence in this report and Goda (1976), it seems reasonable to hypothesize that high peakedness parameters are indicative of strong wave grouping, but low peakedness parameters in shallow water are not necessarily indicative of weak grouping, especially when the relative water depth is small.

c. Skewness and Kurtosis of Sea-Surface Elevation Distribution Function. The distribution function for sea-surface elevation also provides useful insight on shallow-water spectral statistics. Mean values of skewness and kurtosis (defined in eq. 6) for the selected locations are given in Table 8. It is evident that, except at the Great Lakes sites, the shallow-water distribution functions tend to have more high than low extremes (high skewness) and that they tend to be more sharply focused than the normalized Gaussian distribution (high kurtosis). These findings are consistent with cnoidal wave profiles shown in Figure 2.

Cumulative distribution curves for skewness and kurtosis are shown in Figures 24, 25, and 26. The Atlantic coast locations have a tendency for higher skewness and kurtosis values than the gulf and Pacific coast 
Table 7, Mean $Q_{p}$ values for each $\mathrm{H}_{s}-\mathrm{T}_{p}$ group. ${ }^{1}$

\begin{tabular}{|c|c|c|c|c|c|c|c|c|c|}
\hline \multirow{2}{*}{\multicolumn{3}{|c|}{$\mathrm{T}_{p}(\mathrm{~s})$}} & \multicolumn{7}{|c|}{$\mathrm{H}_{s}(\mathrm{~cm})$} \\
\hline & & & 0 to 30 & 30 to 61 & 61 to 91 & 91 to 122 & 122 to 152 & 152 to 183 & 183 to 213 \\
\hline \multicolumn{10}{|c|}{ Nags Head, N.C. } \\
\hline & to 1 & & $\ldots--^{2}$ & $\cdots$ & --- & ---- & $-\ldots$ & --- & $-\ldots$ \\
\hline & to 2 & & --- & --- & $\cdots$ & $\therefore-$ & $-\ldots$. & $-\cdots-$ & -...... \\
\hline & to 3 & & $\cdots$ & --- & $\cdots$ & $\cdots$ & - - & -...... & -...- \\
\hline & to 4 & & $-\cdots$ & --- & --- & --- & $-\cdots-$ & $-\cdots-$ & $\cdots-$ \\
\hline & to 5 & & $-\cdots$ & $\cdots$ & --- & --- & $(2.21)^{3}$ & $(1.65)$ & -...- \\
\hline & to 6 & & $-\cdots$ & 1.62 & 1.73 & 1.86 & 1.99 & $(1.70)$ & $-\cdots$ \\
\hline 6 & to 6 & 6.6 & $-\cdots$ & 1.66 & 1.55 & 1.59 & $(1.90)$ & $(1.86)$ & -..... \\
\hline 6.6 & to 7 & 7.2 & --- & 1.93 & 1.85 & 1.61 & $(1.72)$ & $(2.01)$ & $-\cdots$ \\
\hline 7.2 & to 7 & 7.8 & --- & 2.13 & 2.26 & --- & 1.83 & $(2.02)$ & -...-. \\
\hline 7.8 & to 8 & 8.5 & $\cdots$ & 2.25 & 1.92 & 1.76 & $(1.56)$ & $(1.61)$ & $-\cdots$ \\
\hline 8.5 & to 9 & 9.3 & 1.55 & 1.95 & 1.98 & --- & (1.64) & $(1.88)$ & ------ \\
\hline 9.3 & to 1 & 10.3 & $\cdots$ & 1.96 & 1.91 & 1.65 & 1.65 & (1.51) & -mo- \\
\hline 10.3 & to 1 & 11.6 & --- & 1.71 & 1.63 & 1.69 & (1.43) & $(1.28)$ & -...- \\
\hline 11.6 & to 1 & 13.3 & $\cdots$ & 1.51 & 1.57 & 1.31 & 1.47 & $1.49^{\circ}$ & $\cdots$ \\
\hline 13.3 & to 1 & 15.5 & --- & 1.50 & -..- & ---- & $(1.34)$ & $(1.25)$ & ----.- \\
\hline 15.5 & to 1 & 18.6 & $\ldots$ & --- & $\cdots$ & --- & (1.16) & $(1.08)$ & \\
\hline \multicolumn{10}{|c|}{ Hurtington Beach, Calif. } \\
\hline 0 & to 1 & & $\cdots$ & -- & --- & $-\cdots$ & ----- & $-\cdots--$ & ----- \\
\hline & to 2 & & $--\cdot$ & --- & $-\cdots$ & $\cdots$ & - - & $\cdots-$ & - - \\
\hline & to 3 & & $-\cdots$ & ---- & $-\cdots$ & --- & $-\cdots$ & ---- & ----- \\
\hline & to 4 & & $\cdots$ & --- & --- & $-\cdots$ & -..... & ---- & $-\cdots$ \\
\hline 4 & to 5 & & $+\cdots$ & ---- & $-\cdots$ & -- & --n- & $-2--2$ & $\cdots-$ \\
\hline $\begin{array}{l}5 \\
6\end{array}$ & to 6 & 6 & --- & $-\cdots$ & --- & --- & -..... & $(1.50)$ & - n \\
\hline $\begin{array}{r}6 \\
6.6\end{array}$ & $\begin{array}{l}\text { to } 6 \\
\text { to } 7\end{array}$ & $\begin{array}{l}6.6 \\
7.2\end{array}$ & --- & $-\cdots$ & - & $-\ldots$ & $\cdots$ & - n & $(1.70)$ \\
\hline 7.2 & to 7 & 7.8 & $-\cdots$ & ---- & $\cdots$ & $-\cdots$ & ----- & $(2.18)$ & ...... \\
\hline 7.8 & to 8 & 8.5 & $\cdots$ & ---- & $-\cdots$ & $-\cdots$ & 1.82 & $(2.21)$ & $(1.84)$ \\
\hline 8.5 & to 9 & 9.3 & --- & $-\cdots$ & $-\cdots$ & $-\cdots$ & -n.- & $(2.23)$ & $(1.64)$ \\
\hline 9.3 & to 1 & 10.3 & $\cdots$ & $-\cdots$ & $\cdots$ & $-\cdots$ & $\cdots$ & $(2.75)$ & $-\cdots$ \\
\hline 10.3 & to 1 & 11.6 & $\cdots$ & $-\cdots$ & 2.25 & 2.33 & ------ & $(2.26)$ & $(4.05)$ \\
\hline 11.6 & to 1 & 13.3 & $\cdots$ & 1.98 & 2.01 & 2.31 & 2.65 & $(2.81)$ & $(1.67)$ \\
\hline 13.3 & to 1 & 15.5 & $\cdots$ & 1.80 & 2.16 & 2.22 & 2.34 & (3.11) & $(3.59)$ \\
\hline 15.5 & to 1 & 18.6 & $\cdots$ & --- & 2.00 & 2.46 & 2.38 & $(1.79)$ & $(2.04)$ \\
\hline
\end{tabular}

${ }^{1}$ Annual means: $H_{s}=94$ centimeters and $\mathrm{T}_{p}=8.9$ seconds for Nags Head;

$H_{s}=87$ centimeters and $T_{p}=13.2$ seconds for Huntington Beach.

${ }^{2}$ No cases in the $H_{s}-T_{p}$ groups.

3parentheses indicate value is based on less than 10 cases.

Table 8. Statistics on skewress and kurtosis of distribution of sea-surface elevations.

\begin{tabular}{|l|c|c|c|c|c|}
\hline \multicolumn{1}{|c|}{ Location } & Cases & \multirow{2}{*}{$\begin{array}{c}\text { Mean } \\
\text { skewness }\end{array}$} & $\begin{array}{c}\text { Mean } \\
\text { kurtosis }\end{array}$ & \multicolumn{2}{|c|}{ Correlations } \\
\cline { 5 - 6 } & & & & $\begin{array}{c}\text { Skewness vs. } \\
\text { kurtosis }\end{array}$ & $\begin{array}{c}H_{\text {S }} \text { vs. } \\
\text { skekness }\end{array}$ \\
\hline Atlantic City, N.J. & 1,037 & 0.36 & 3.36 & 0.84 & 0.82 \\
Virginia Beach, Va. & 982 & 0.27 & 3.26 & 0.58 & 0.51 \\
Nags Heac, N.C. & 945 & 0.41 & 3.38 & 0.56 & 0.64 \\
Lake Worth, Fla. & 982 & 0.37 & 3.43 & 0.84 & 0.56 \\
Naples, Fla. & 866 & 0.16 & 3.17 & 0.23 & 0.53 \\
Michigan City, Ind. (buoy) & 246 & -0.03 & 4.30 & 0.49 & 0.09 \\
Michigan City, Ind. (pressure) & 127 & -0.17 & 4.76 & 0.15 & 0.17 \\
Presque Isle, Pa. (buoy) & 110 & -0.20 & 3.86 & 0.96 & 0.04 \\
Presque Isle, Pa. (pressure) & 119 & -0.02 & 2.45 & 0.75 & 0.15 \\
Huntington Beach, Calif. & 746 & 0.24 & 3.13 & 0.58 & 0.51 \\
Pt. Mugu, Calif. & 799 & 0.06 & 3.00 & 0.25 & 0.23 \\
\hline
\end{tabular}




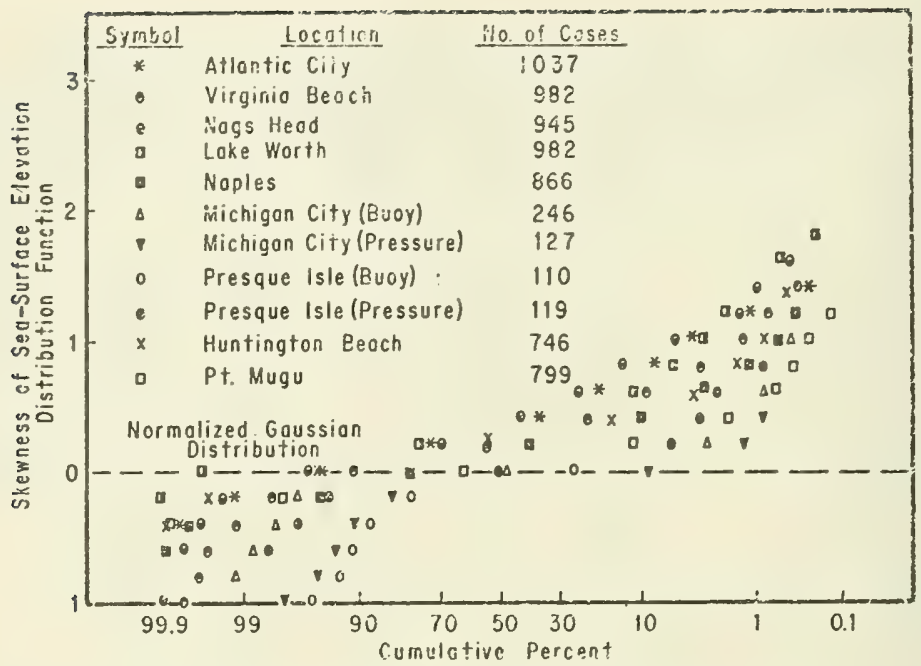

Figure 24. Cumulative probability distribution functions for skewness of sea-surface elevation distribution function.

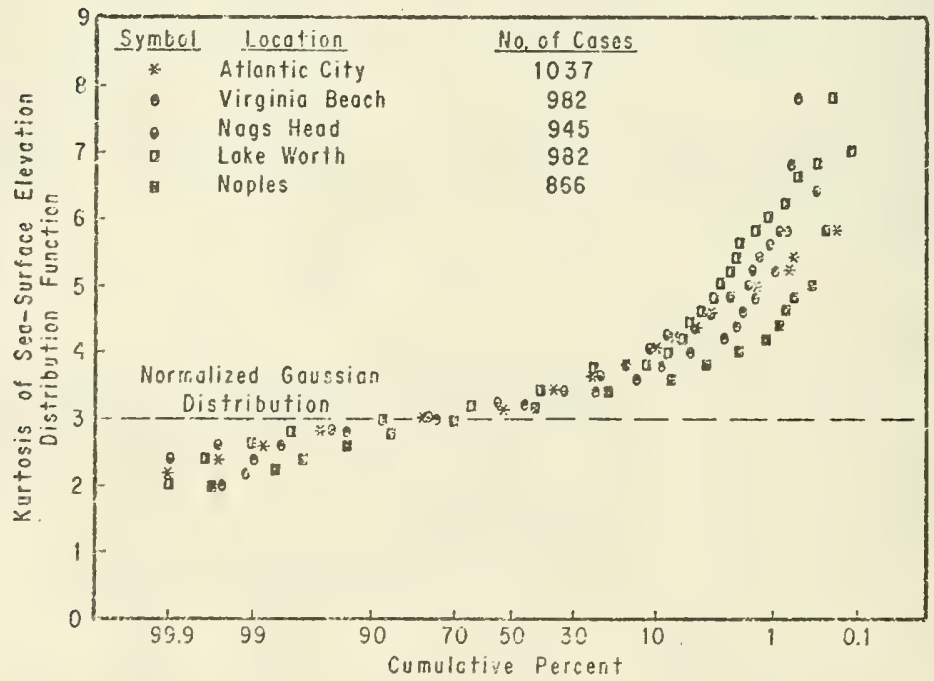

Figure 25. Cumulative probability distribution functions for kurtosis of sea-surface elevation distribution function at Atlantic and gulf coast locations. 


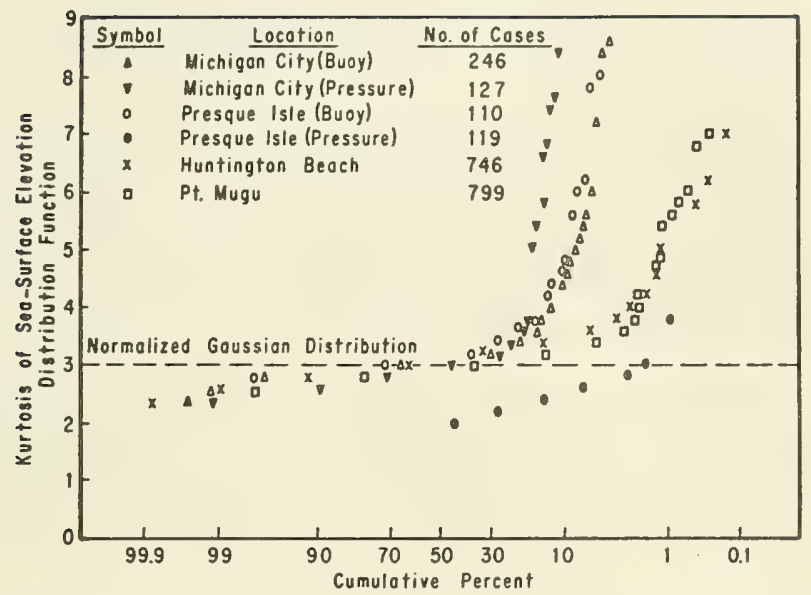

Figure 26. Cumulative probability distribution functions for kurtosis of sea-surface elevation distribution function at Great Lakes and Pacific coast locations.

locations. The Great Lakes locations and Pt. Mugu tend to have the lowest skewness values. The Michigan City locations and the Presque Isle buoy gage show a tendency for occasional very high kurtosis values which are associated with very low significant wave heights. Although several kurtosis values greater than nine occurred for the Michigan City locations and Pt. Mugu, the values are omitted from Figures 25 and 26. The Presque Isle pressure gage shows a tendency for exceptionally low kurtosis values. A section of pen-and-ink record for a case with high kurtosis (equal to 8.0) was shown in Figure 11.

Some of the kurtosis values in Figures 25 and 26 are questionably high. Since kurtosis is based on the fourth power of the deviation of sea-surface elevations from the mean (i.e., $n=4$ in eq. 6), it is more affected by a few elevations far from the mean than any other parameters considered in this report. Noise or momentary signal losses in a record which are comparable to the size of the largest waves will pass uncorrected through the editing process described earlier. These bad data points usually have little effect on the spectrum but they can have a significant effect on the kurtosis of the distribution of sea-surface elevations.

Another factor which leads to questionably high values of kurtosis is the occasional tendency of the step-resistance gage to become electrically shorted at a particular elevation, often by marine growth, and to produce wave records in which the troughs are unrealistically flat. Because kurtosis is especially sensitive to these problems (known to have occurred intermittently in the data considered in this report), 
the percentages associated with kurtosis values in Figures 25 and 26 higher than about 4 should be considered somewhat inflated.

The correlation between skewness and peak spectral period is less than 0.25 at all locations; for single-peaked cases it is similarly low. However, the correlation between skewness and significant height is moderatly high for the ocean and gulf coast locations (Table 8). There is a clear tendency for skewness to increase with significant height for the ocean and gulf coast locations as evidenced in a plot of mean skewness versus significant height (Fig. 27). This tendency is not evident for the Great Lakes locations (Fig. 28).

It is apparent that cnoidal wave profiles (see Fig. 2) with very high skewness and kurtosis values are rarely observed at the selected gage locations. However, some of the records contain wave profiles which are more nearly cnoidal than sinusoidal. Figures 24, 25, and 26 indicate that cnoidal profiles appear in about 10 percent of the records or 1ess.

\section{CONCLUSIONS}

The following conclusions are drawn from evidence and discussion presented in this report:

1. About 60 to 70 percent of the ocean and gulf coast energy spectra in shallow water have one or more major peaks in addition to the dominant peak.

2. At least 50 percent of the spectra in Lakes Michigan and Erie have one or more major secondary peaks.

3. Major secondary spectral peaks are common for both high and low energy spectra.

4. The very small sample of spectra for hurricane waves examined (seven spectra) does not reveal any special characteristics of hurricanegenerated spectra.

5. Major secondary spectral peaks are usually indicative of secondary wave trains.

6. When secondary spectral peaks occur at frequencies of two or three times the dominant frequency, they may represent a single train of steep waves rather than independent wave trains, especially if the relative water depth for the dominant wave is small.

7. When secondary spectral peaks occur at frequencies of 0.5 or 1.5 times the dominant frequency and the waves are high enough for breaking to occur, the secondary peaks may not represent independent wave trains. 


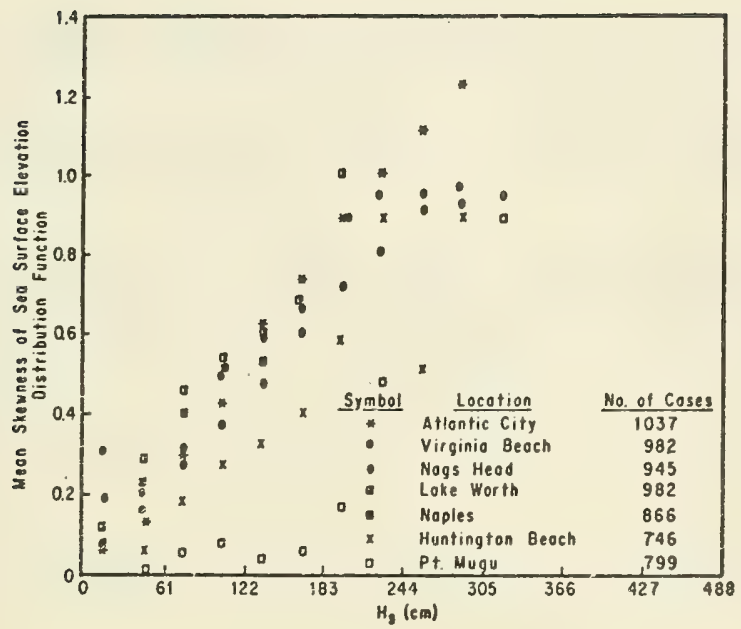

Figure 27. Mean skewness of sea-surface elevation distribution function as a function of $\mathrm{H}_{8}$ for ocean and gulf coast lucations.

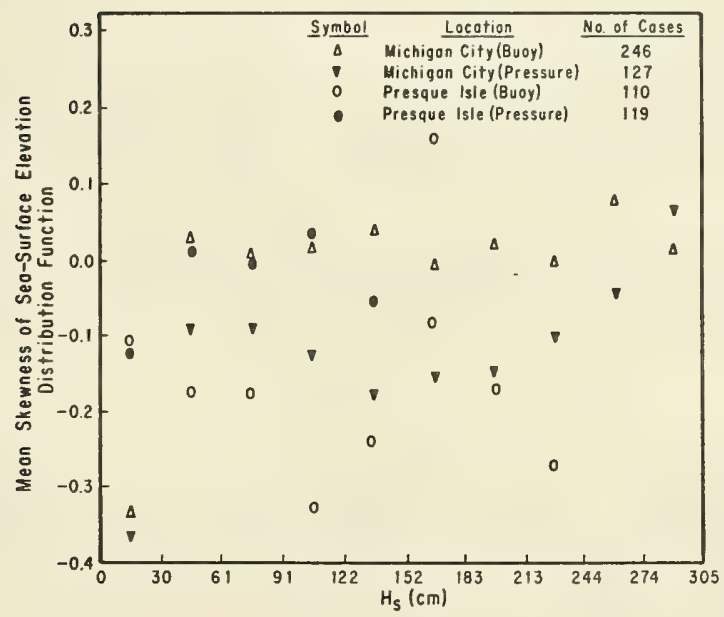

Figure 28. Mean skewness of sea-surface elevation distribution functions as a function of $\mathrm{H}_{B}$ for Great Lakes locations. 
8. There is evidence that wave breaking limits the ratio $H_{S} / d$ at the shallow-water gage locations considered to less than 0.55 rather than the commonly used limit of 0.78 .

9. Individual shallow-water ocean spectra with comparable significant heights and peak periods are highly variable in shape.

10. Mean spectra for the same significant height-peak period group show a surprising similarity between locations; however, there is a notable lack of low-frequency energy in gulf and Great Lakes spectra and a lack of high-frequency energy in most southern Pacific coast spectra.

11. The distribution of individual energy values about the mean energy for each spectral band tends to be nearly Gaussian in the vicinity of the dominant peak but non-Gaussian for low-energy bands away from the peak.

12. For most exposed ocean locations, a spectrum is more likely to contain major secondary peaks when the period of the dominant peak is long or short than when it has intermediate values.

13. High values of the spectral-peakedness parameter, $Q_{p}$, indicate that high waves may be occurring in groups; however, high $Q_{p}$ values in shallow water are usually associated with low-energy wave conditions.

14. Low values of $Q_{p}$ generally indicate that high waves are pooriy grouped. However, if the spectrum has secondary peaks which do not represent independent wave trains, $Q_{p}$ is not a direct indicator of the extent of wave grouping.

15. $Q_{p}$ values tend to be higher in the Great Lakes than along the ocean and gulf coasts.

16. The distribution function for sea-surface elevations in shallow water tends to have more high than low values far from the mean and tends to show less variability than the normalized Gaussian distribution. These features are consistent with cnoidal-type, shallow-water wave profiles.

\section{SUMMARY}

Digital wave records were obtained from 11 gages at 9 shallow-water sites along the U.S. Atlantic, Pacific, gulf, and Great Lakes coasts. The records were analyzed with a fast Fourier transform procedure to produce energy spectra. Selected spectral parameters, including the number of major spectral peaks and Goda's (1970) spectral-peakedness parameter, and parameters of the distribution function of sea-surface elevations were also computed. The physical meaning of the shallowwater spectrum and computed parameters was discussed and illustrated with three cases of cnoidal wave profiles. 
Spectra for the 24 highest energy cases from each gage were summarized individually. Many of the spectra had more than one major peak. Although many of the high-energy cases represent breaking wave conditions, the ratio of significant height to water depth was less than 0.55 in all cases. This value differs significantly from the value 0.78 which is usually used in conjunction with depth-limited wave heights.

Al1 spectra were grouped according to significant height and period corresponding to the highest spectral peak. A mean spectrum was computed for most height-period groups. The standard deviation of spectral values about the mean was also included. The mean spectra show a clear lack of low-frequency energy at the gulf and Great Lakes sites and a lack of high-frequency energy at the southern California site. They also show evidence of systematic variations in shape as a function of significant height and peak period.

Multipeaked spectra are common; 60 to 70 percent of the ocean and gulf coast spectra and at least 50 percent of the Great Lakes spectra have more than one major peak. Major spectral peaks are usually indicative of independent wave trains.

High values of the spectral-peakedness parameter appear to be related to the occurrence of high waves in groups. However, low values of the spectral-peakedness parameter are not necessarily indicative of a lack of grouping of high waves in shallow water. The distribution function of sea-surface elevations in shallow water tends to deviate from a normalized Gaussian distribution in a way which is consistent with cnoidal-type wave profiles.

In the course of this investigation, a computer program was developed to identify major peaks and valleys in an irregular signal. The program has many potential applications, including identification of major peaks in a spectrum and identification of meaningful crests and troughs in a time series of sea-surface elevation. 


\section{LITERATURE CITED}

BARNETT, T.P., "Wind Waves in Shallow Water," Final Report, Westinghouse Ocean Research Laboratory, San Diego, Calif., June 1969.

EDMISTEN, J.R., "Toward Fulfillment of An Urgent Need, Coastal Wave Data Acquisition and Analyses," Shore and Beach, Vo1. 46, No. 3, July 1978, pp. 3-14.

ESTEVA, D.C., "Evaluation of the Computation of Wave Direction With Three-Gage Arrays," TP 77-7, U.S. Army, Corps of Engineers, Coastal Engineering Research Center, Fort Belvoir, Va., July 1977.

ESTEVA, D.C., and HARRIS, D.L., "Comparison of Pressure and Staff Wave Gage Records," Ch. 7, Proceedings of the 12th Coastal Engineer Conference, American Society of Civil Engineers, 1970, pp. 101-115 (also Reprint 2-71, U.S. Army, Corps of Engineers, Coastal Engineering Research Center, Washington, D.C., NTIS 732 637.).

GODA, Y., "Numerical Experiments on Wave Statistics with Spectral Simulation," Report of the Port and Harbour Research Institute, Japan, Vol. 9, No. 3, Sept. 1970, pp. 3-57.

GODA, Y., "Estimation of Wave Statistics From Spectral Information," Proceedings of the Intemational Symposium on Ocean Wave Measurement and. Analysis (WAVES '74), American Society of Civil Engineers, Vo1. 1, 1974, pp. $320-337$.

GODA, Y., "Irregular Wave Deformation in the Surf Zone," CoastaZ Engineering in Jopan, Tokyo, Japan, Vol. 18, Dec. 1975, pp. 13-26.

GODA, Y., "On Wave Groups," Ch. 6, Proceedings of the First Conference on Behaviour of Offshore Structures (BOSS 176), Norwegian Institute of Technology, 1976, pp. 28-41.

GOSPODNETIC, D., and MILES, M.D., "Some Aspects of the Average Shape of Wave Spectra at Station 'India' $\left(50^{\circ}\right.$ N., $19^{\circ}$ W. $)$," Proceedings of the Intemational Symposium on the Dynamies of Marine Vehicles and Stmuctures in Waves (IMECHE '74), Institution of Mechanical Engineers, 1974, pp. 19-32.

HARRIS, D.L., "Wave Estimates for CoastaI Regions," Ch. 5, Shelf Sediment Transport, Process and Patterm, D.J.P. Swift, D.B. Duane, and O.H. Pilkey, eds., Dowden, Hutchinson \& Ross, Inc., Stroudsburg, Pa., 1972, pp. $99-125$.

HASSELMANN, K., et al., "Measurement of Wind-Wave Growth and Swe11 Decay During the Joint North Sea Wave Project (JONSWAP)," Deutsches Hydrographisches Institut, Hamburg, Germany, 1973.

HERTERICH, K., and HASSELMANN, K., "A Similarity Relation for the NonLinear Energy Transfer in A Finite-depth Gravity--Wave Spectrum," Joumal of Fluid Mechanies (in preparation, 1980). 
HOFFMAN, D., "Analysis of Measured and Calculated Spectra," Proceedings of the Intermational Symposizm on the Dynamics of Marine Vehicles and Structures in Waves (IMECHE 174), 1974, pp. 8-18.

HOFFMAN, D., "Wave Data Application for Ship Response Predictions," Final Report, David Taylor Naval Ship Research and Development Center, Bethesda, Md., Oct. 1975.

HOFFMAN, D., and CHEN, H.H., "The Use of Directional Hindcast Spectra Design Wave Data," Proceedings of the 10th Annual Offshore Technology Conference 3279, Vo1. 4, 1978, pp. 1989-1996.

IRIE, I., "Examination of Wave Deformation with Fie1d Observation Data," Coastal Engineering in Jopan, Tokyo, Japan, Vo1. 18, Dec. 1975, pp. 27-35.

KENYON, K.E., "Wave Refraction in Ocean Currents," Deep-Sea Research, Vo1. 18, No. 10, Oct. 1971, pp. 1023-1034.

McCLENAN, C.M., and HARRIS, D.L., "The Use of Aerial Photography in the Study of Wave Characteristics in the Coasta1 Zone," TM-48, U.S. Army, Corps of Engineers, Coastal Engineering Research Center, Fort Belvoir, Va., Jan. 1975.

OChil, M.K., and HUBBLE, E.N., "Six-Parameter Wave Spectra," Ch. 18., Proceedings of the Coastal Engineering Conference, American Society of Civil Engineers, Vo1. 1, 1976, pp. 301-328.

PITT, E.G., DRIVER, J.S., and EWING, J.A., "Some Inter-Comparisons Between Wave Recorders," Report No. 43, Institute of Oceanographic Sciences, Taunton, Somerset, United Kingdom, unpublished, 1978.

RYE, H., "The Stability of Some Currently Used Wave Parameters," Coastal Engineering, Elsevier Publishing Co., Amsterdam, Netherlands, Vo1. 1, Mar. 1977, pp. 17-30.

SAWARAGI, T., and IWATA, K., "Wave Spectrum of Breaking Wave," Ch. 33, Proceedings of the Coastal Engineering Conference, American Society of Civil Engineers, Vol. 1, 1976, pp. 580-594.

SEELIG, W.N., and AHRENS, J.P., "Estimating Nearshore Conditions For Irregular Waves," U.S. Army, Corps of Engineers, Coastal Engineering Research Center, Fort Belvoir, Va. (in preparation, 1980).

SHEPARD, F.P., and INMAN, D.L., "Sand Movement on the Shallow InterCanyon Shelf at La Jolla, California," TM-26, U.S. Army, Corps of Engineers, Beach Erosion Board, Washington, D.C., Nov. 1951. 
THOMPSON, E.F., "Results from the CERC Wave Measurement Program," Proceedings of the International Symposizm on Ocean Wave Measurement and Analysis, American Society of Civil Engineers, Vol. 1, 1974 (also Reprint 7-74, U.S. Army, Corps of Engineers, Coastal Engineering Research Center, Fort Belvoir, Va., NTIS 002 114).

THOMPSON, E.F., "Wave Climate at Selected Locations Along U.S. Coasts:" TR 77-1, U.S. Army, Corps of Engineers, Coasta1 Engineering Research Center, Jan. 1977.

THOMPSON, E.F., "An Evaluation of Two Great Lakes Wave Models," TR 78-1, U.S. Army, Corps of Engineers, Coastal Engineering Research Center, Fort Belvoir, Va., Oct. 1978.

U.S. ARMY, CORPS OF ENGINEERS, COASTAL ENGINEERING RESEARCH CENTER, Shore Protection Manual, 3d ed., Vols. I, II, and III, Stock No. 008-022-00113-1, U.S. Government Printing Office, Washington, D.C., $1977,1,262 \mathrm{pp}$.

VINCENT, C.L., and RESIO, D.T., "An Eigenfunction Parameterization of A Time Sequence of Wave Spectra," Coastal Engineering, Elsevier Scientific Publishing Co., Amsterdam, Netherlands, Vo1. 1, No. 1, 1977, pp. 185-205.

WANG, H. , and YANG, W-C., "Measurements and Computation of Wave Spectral Transformation at Island of Sylt, North Sea," Technical Report No. 3, Office of Naval Research, Washington, D.C., Nov. 1976. 
APPENDIX A

INDIVIDUAL HIGH-ENERGY WAVE SPECTRAL PLOTS 

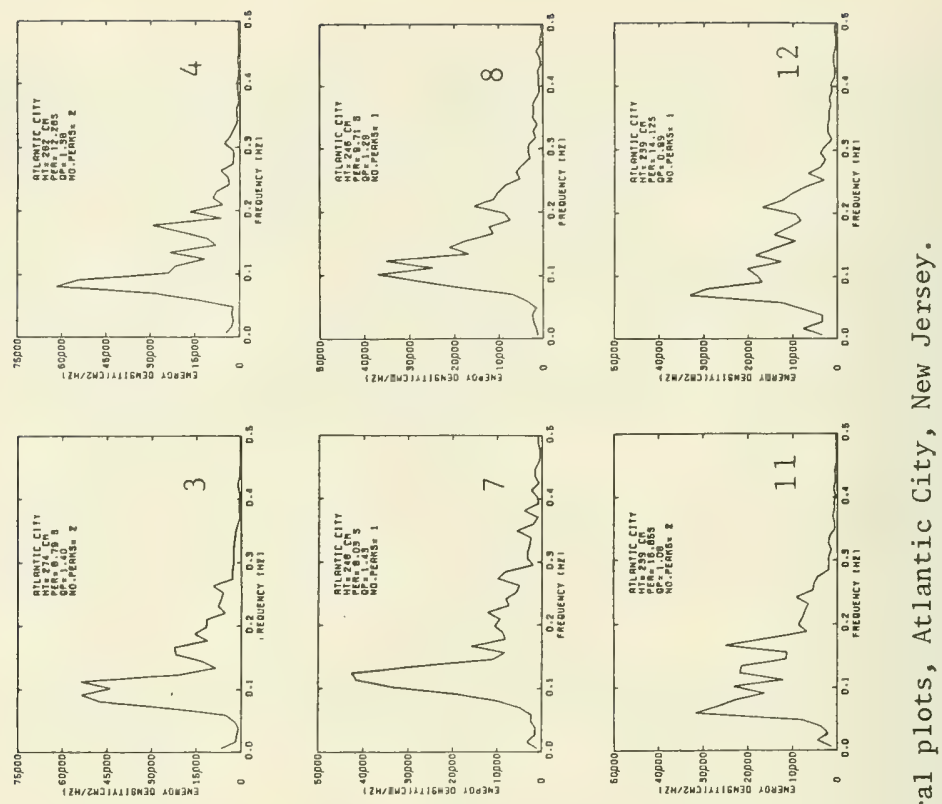

तु
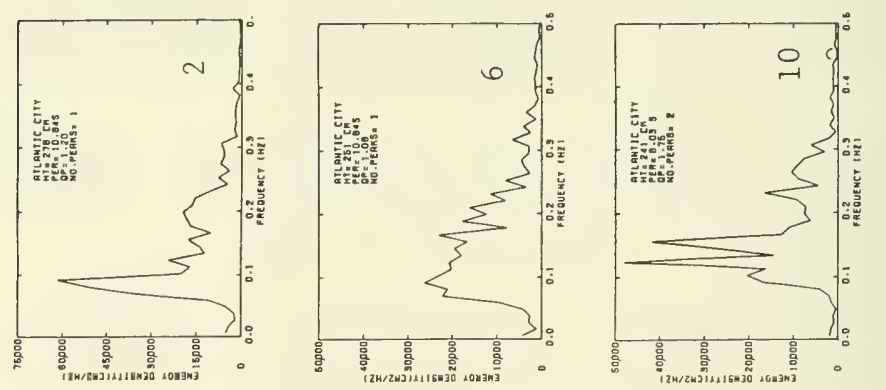

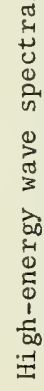
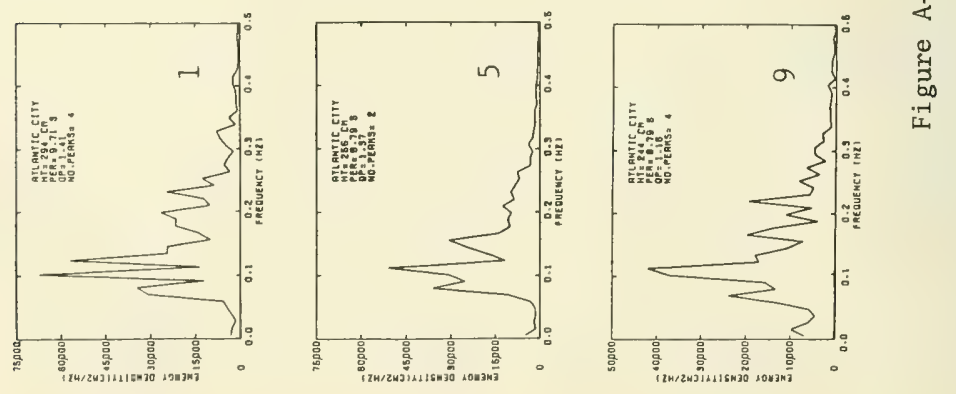

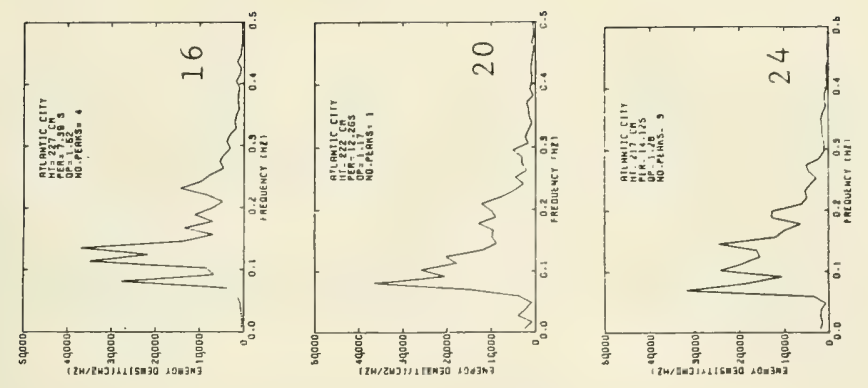

ت
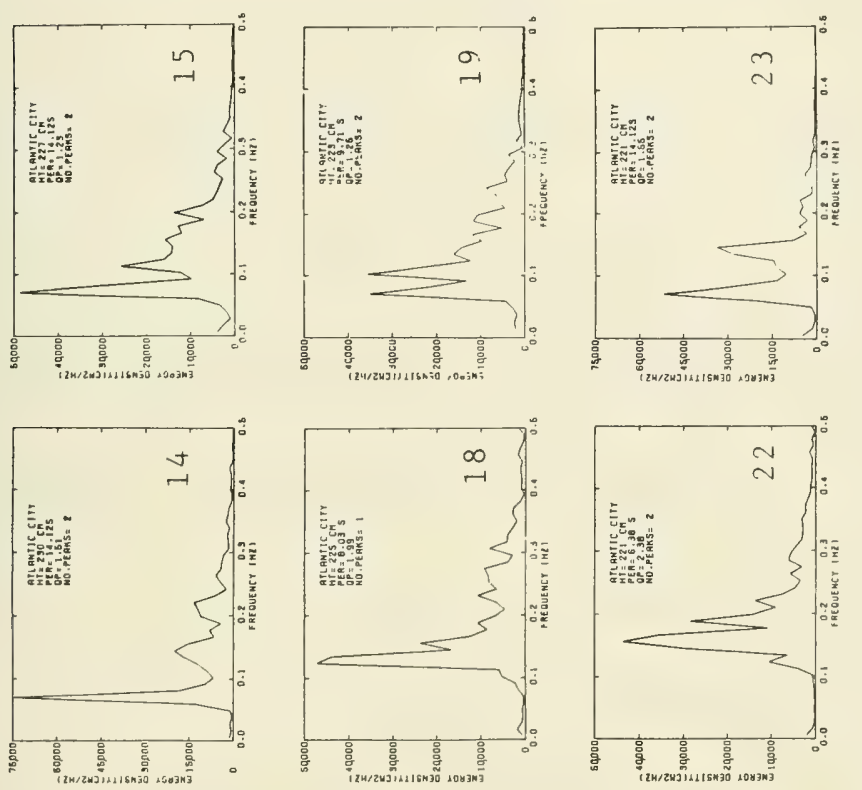

苟

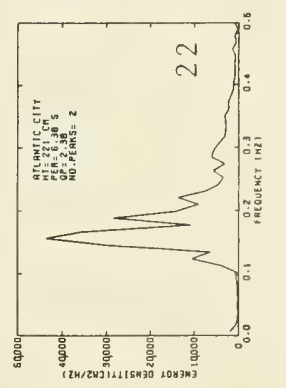

0
7
0
0
0
0
0
in
0
3
3
3
00
0
0
0
1
$\frac{1}{00}$
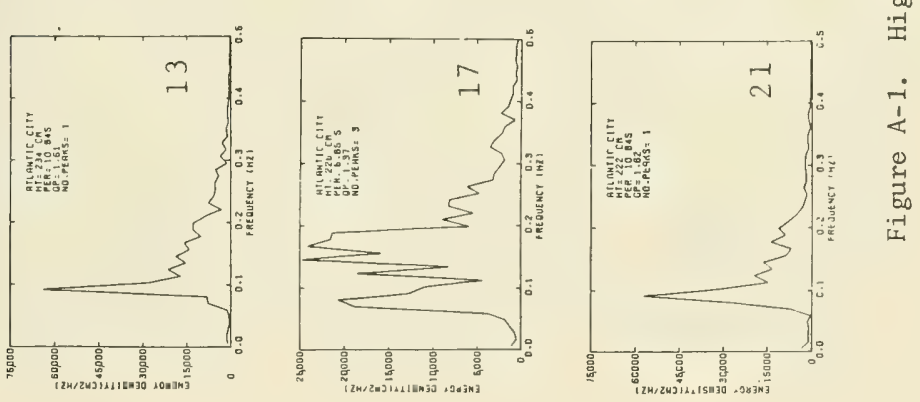


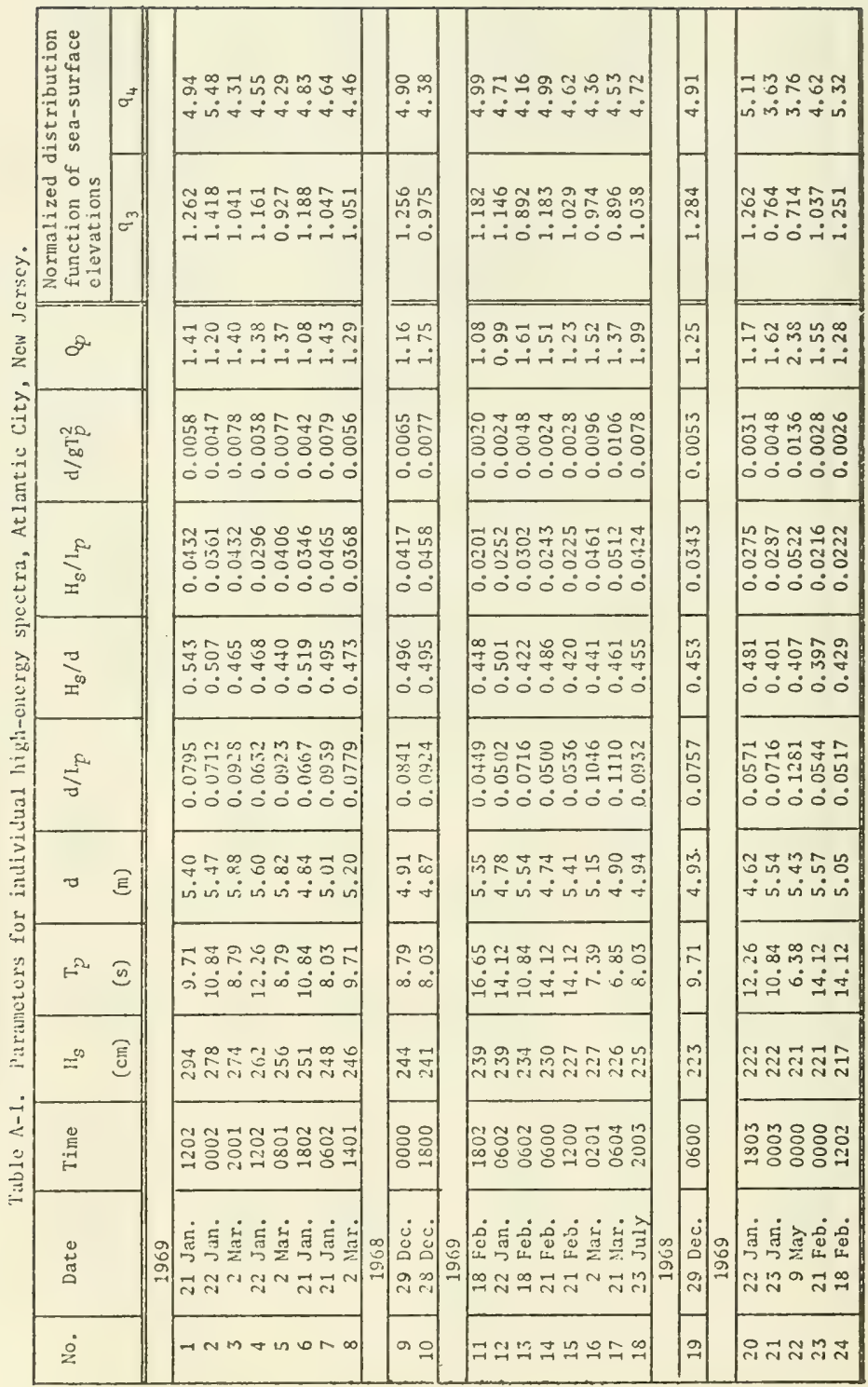



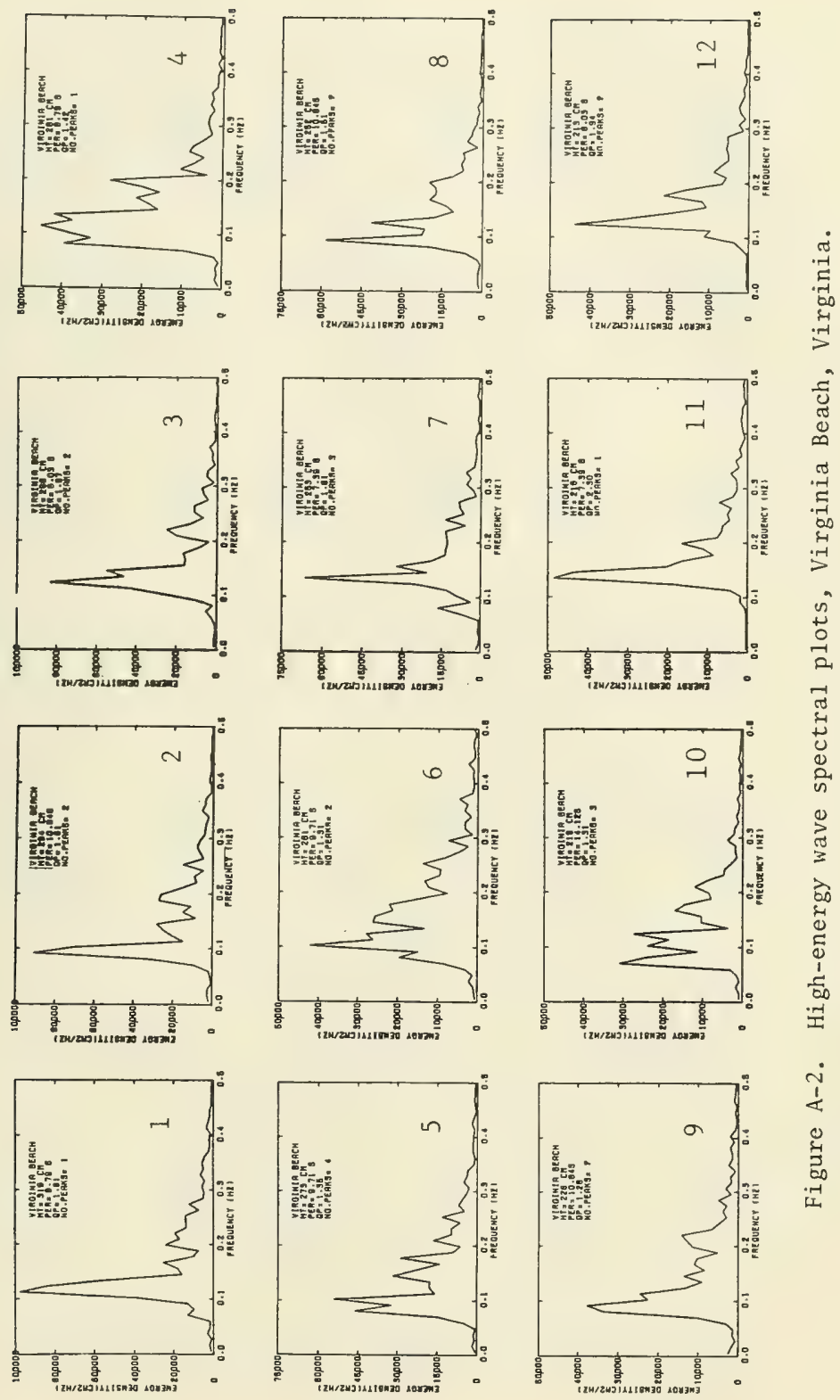

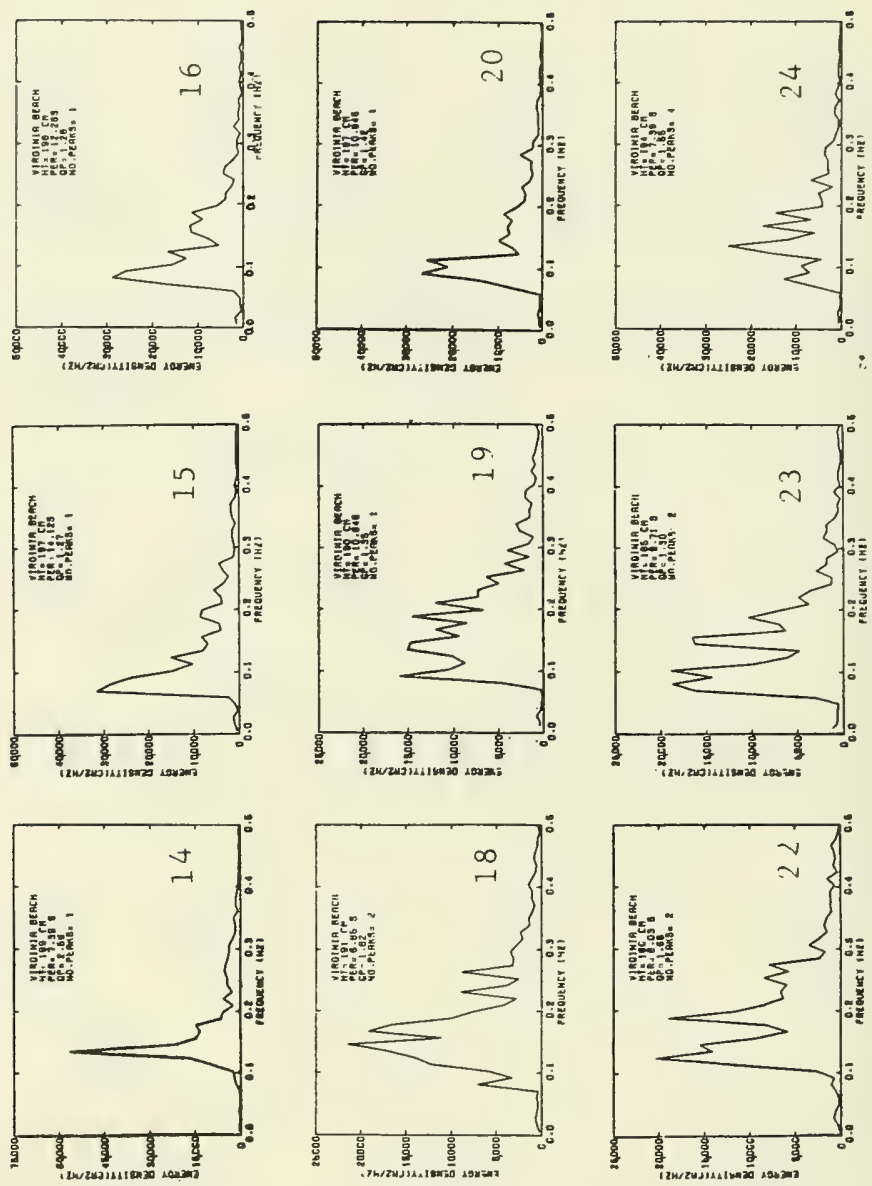


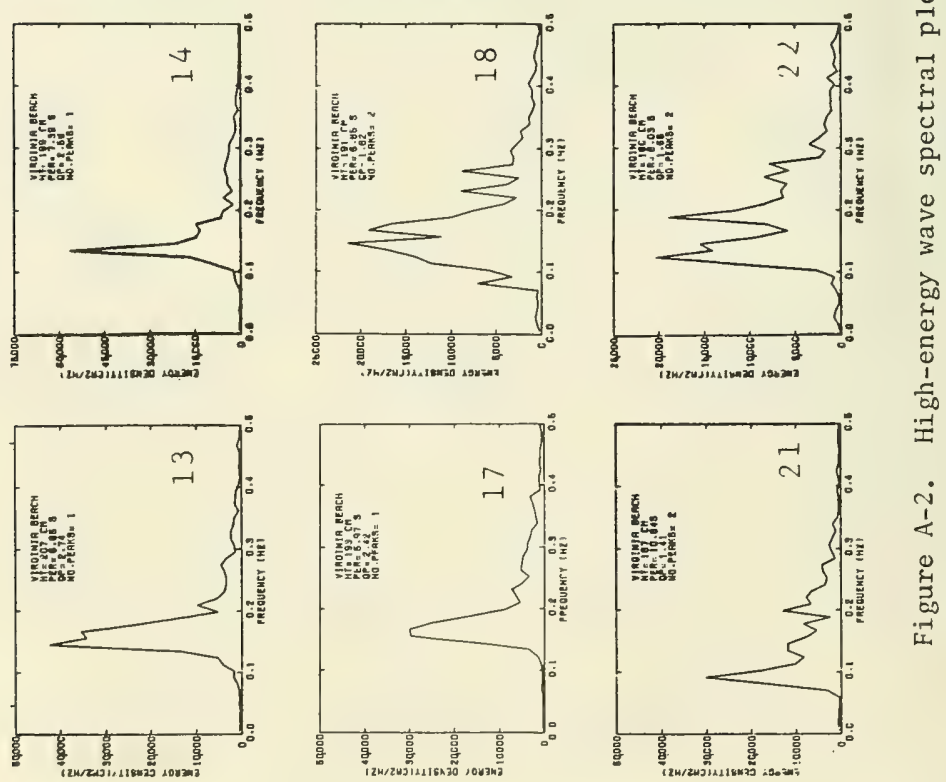


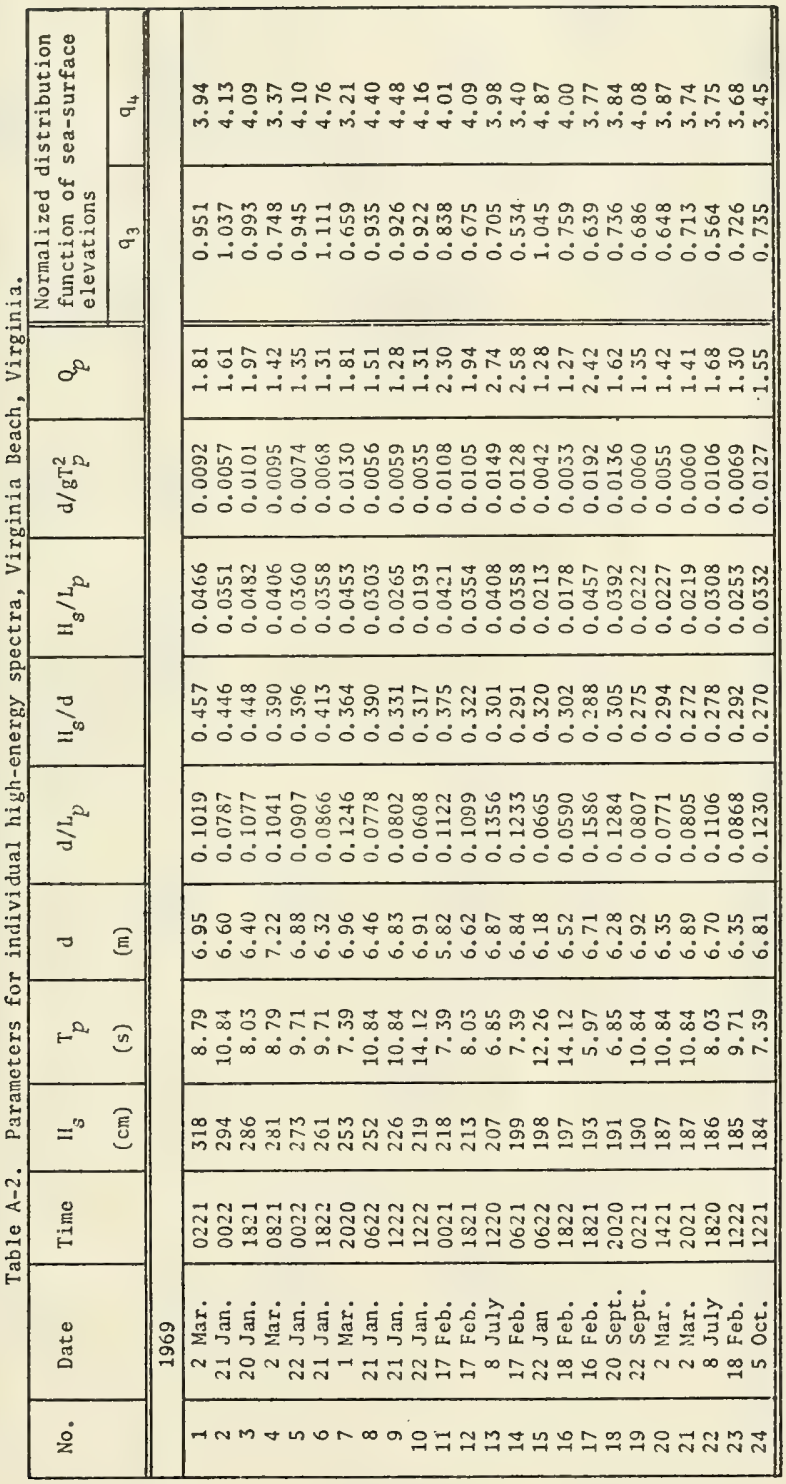



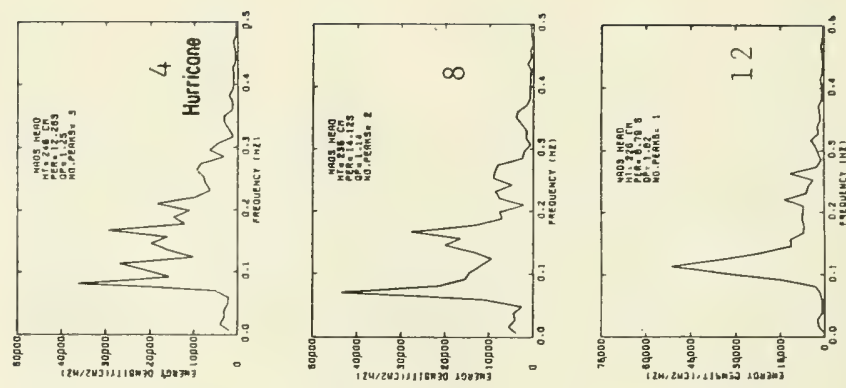

ت્.
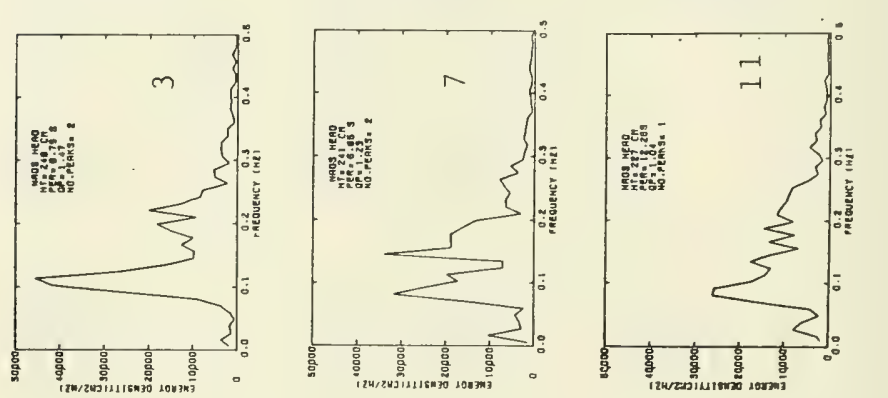

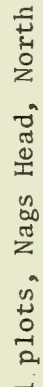
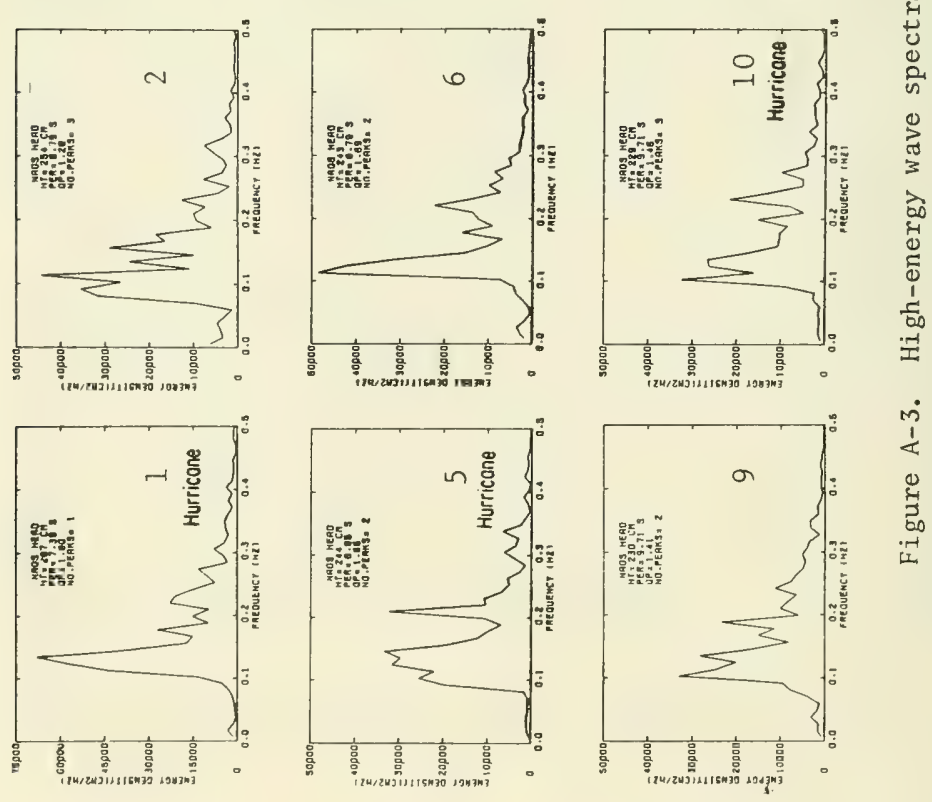

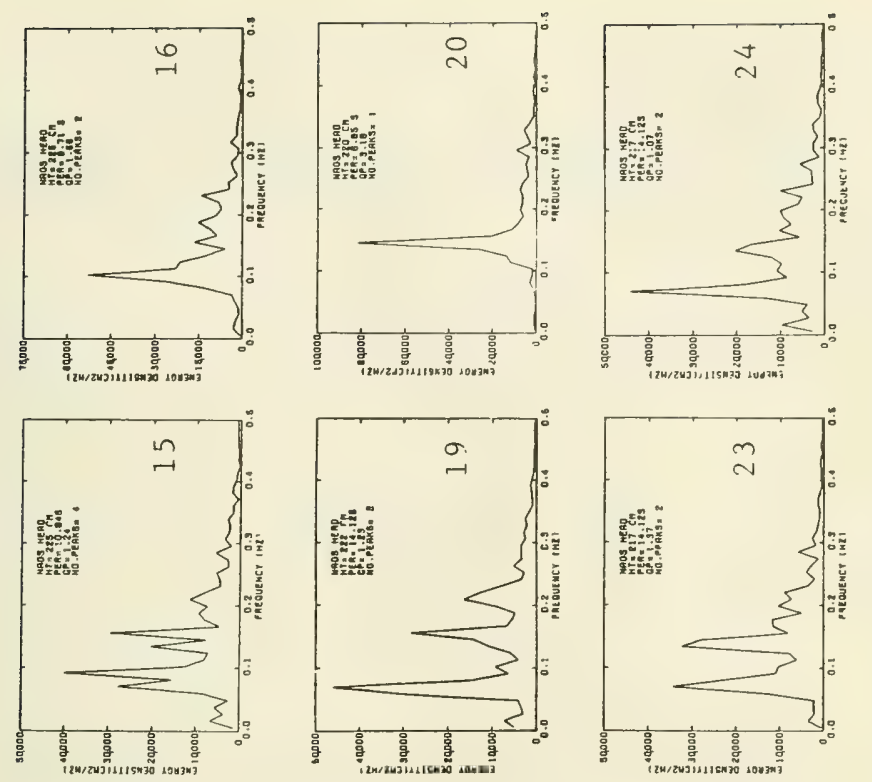

ב્ּ
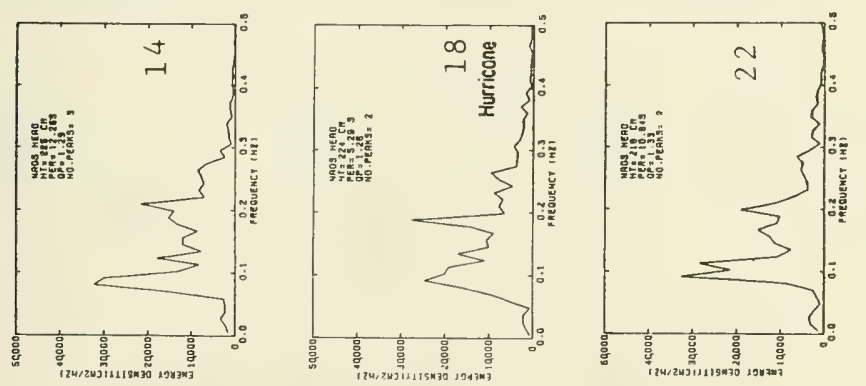

훌

롬
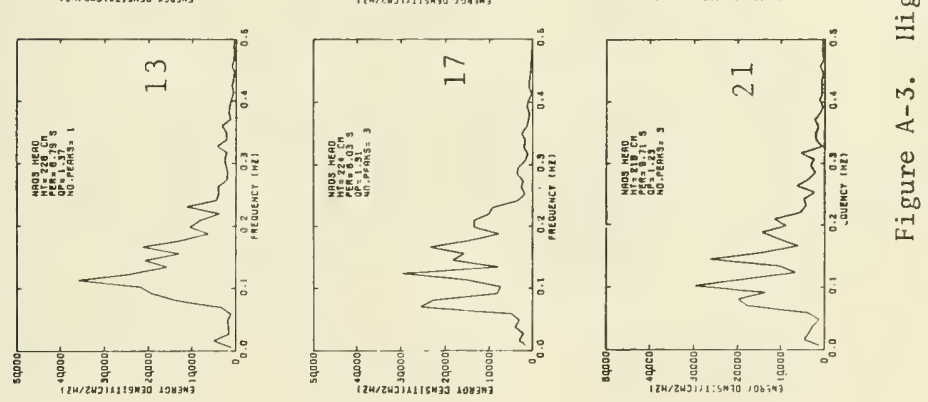


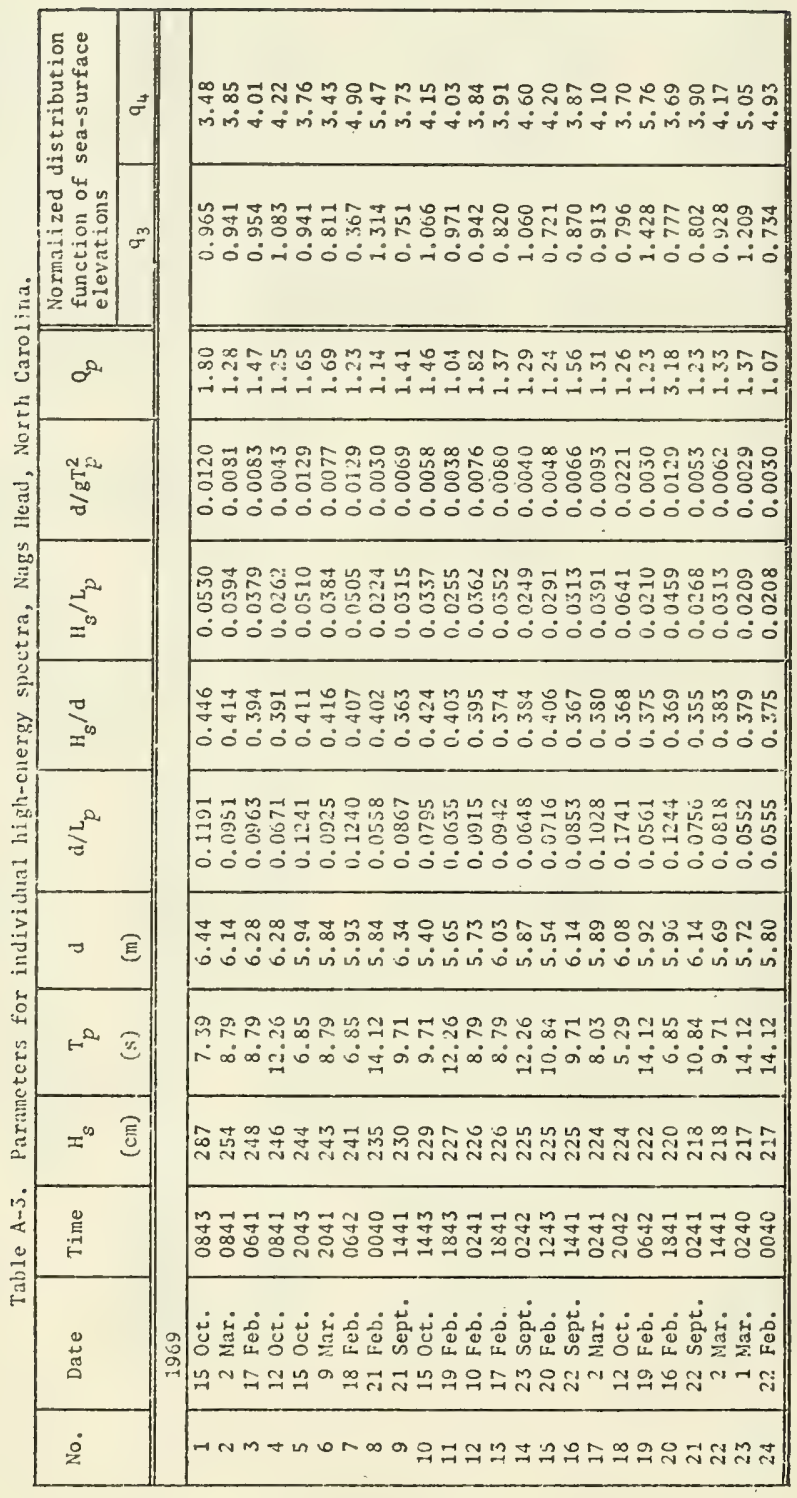



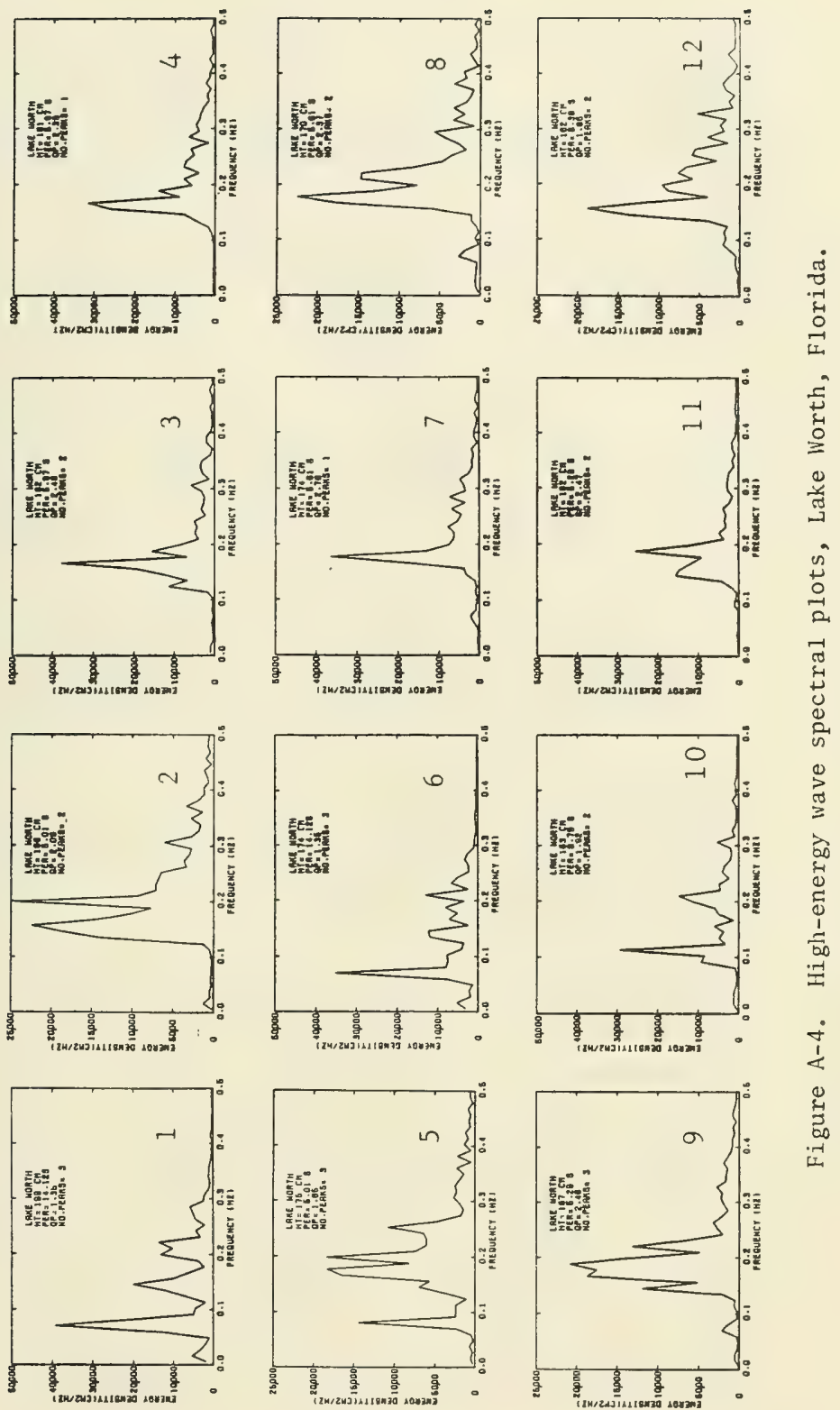

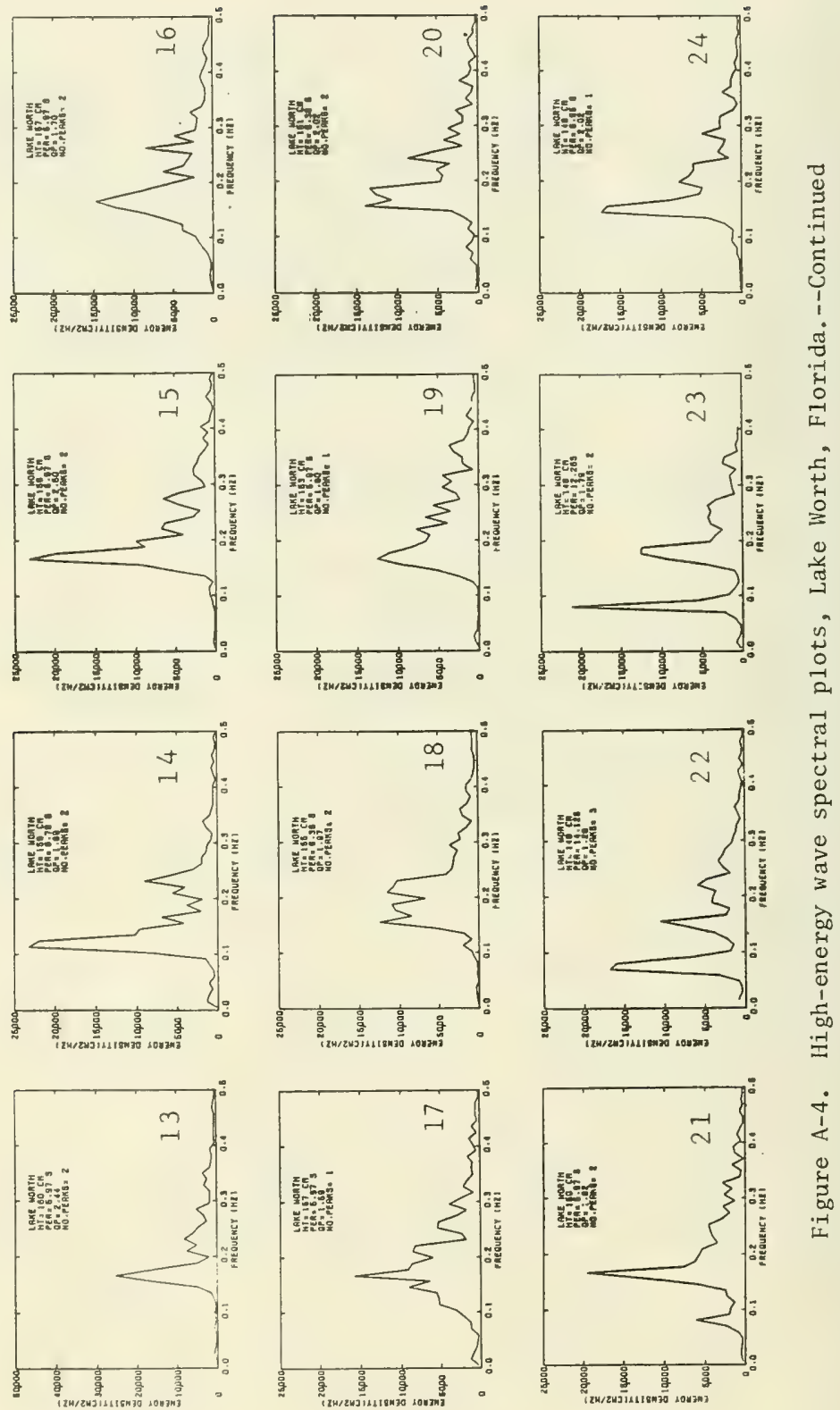


\begin{tabular}{|c|c|}
\hline 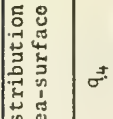 & 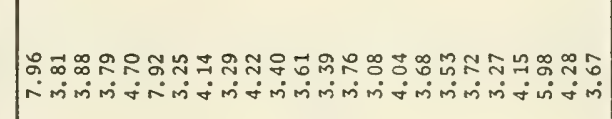 \\
\hline 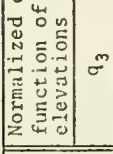 & 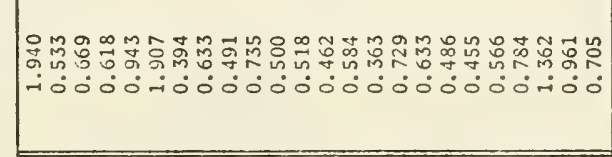 \\
\hline on & 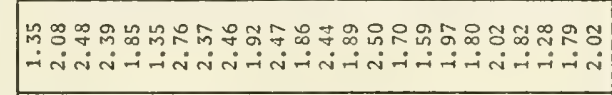 \\
\hline$\frac{3}{3}$ & 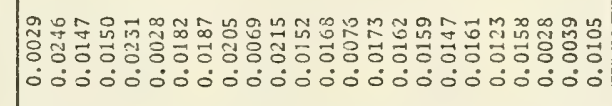 \\
\hline$=$ & 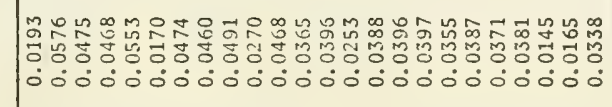 \\
\hline$=$ & 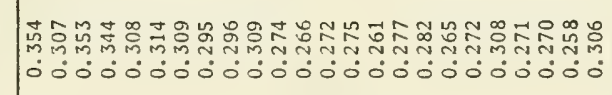 \\
\hline$\sum^{2}$ & 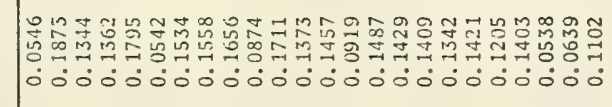 \\
\hline$-\quad \Xi$ & 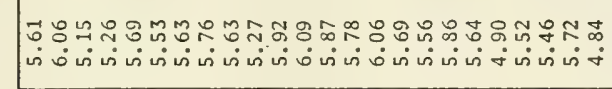 \\
\hline$=0$ & 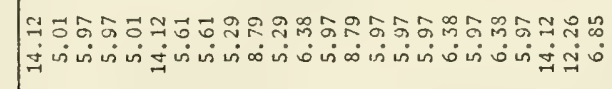 \\
\hline$=$ ह ह & 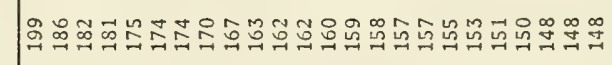 \\
\hline$\stackrel{\varrho}{\stackrel{E}{E}}$ & 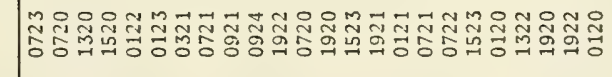 \\
\hline 菎 & 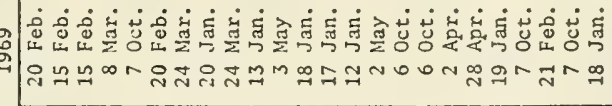 \\
\hline$\dot{z}$ & $\because r$ \\
\hline
\end{tabular}



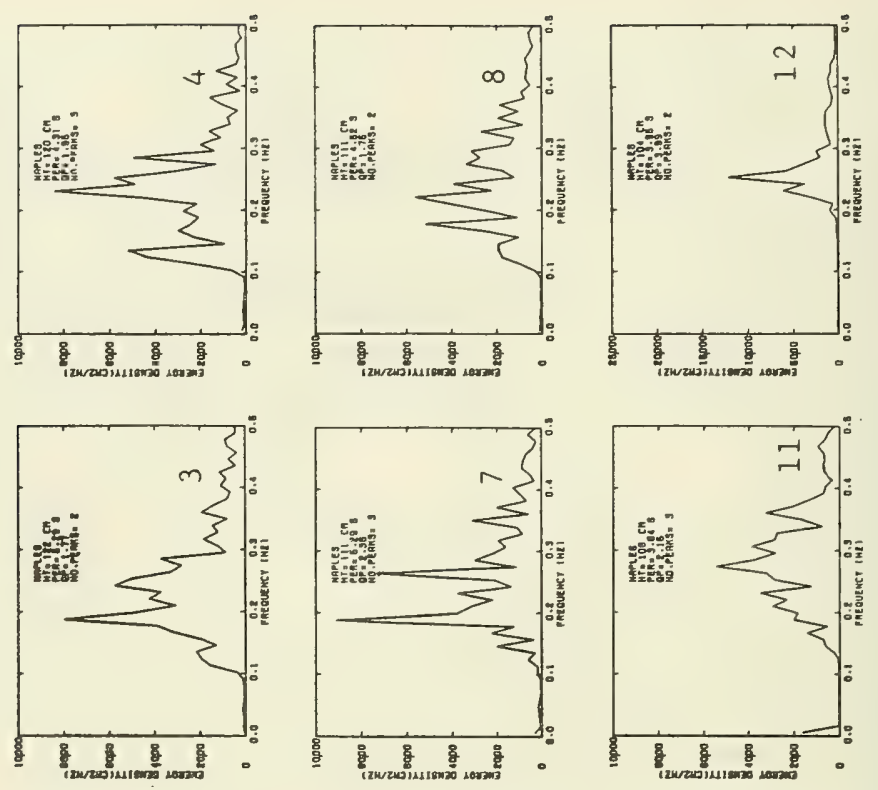

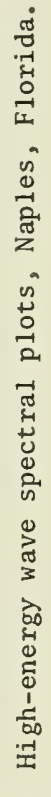
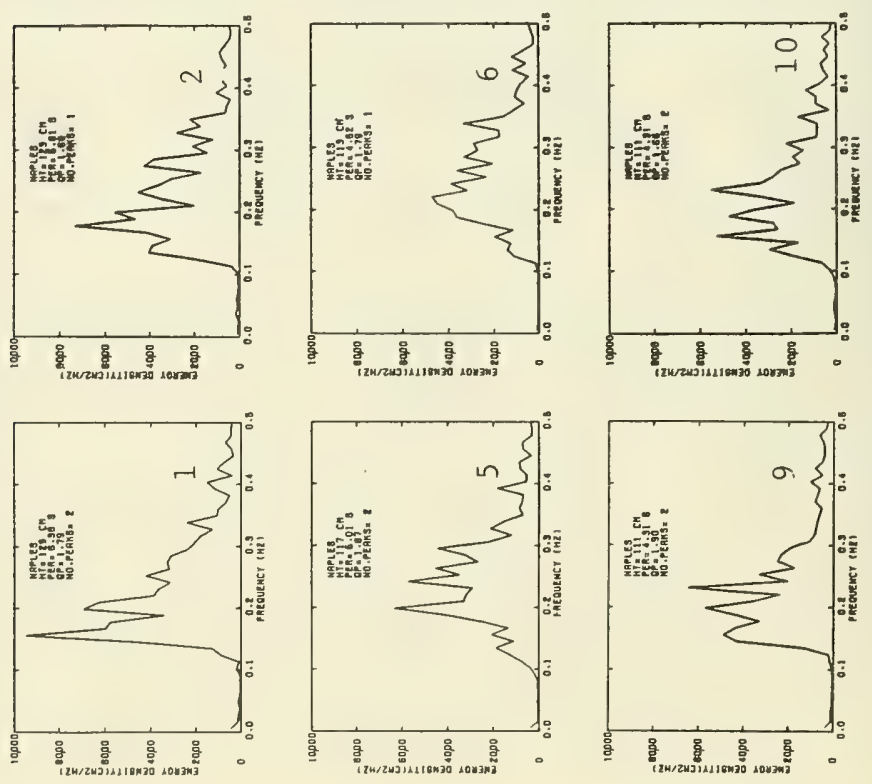

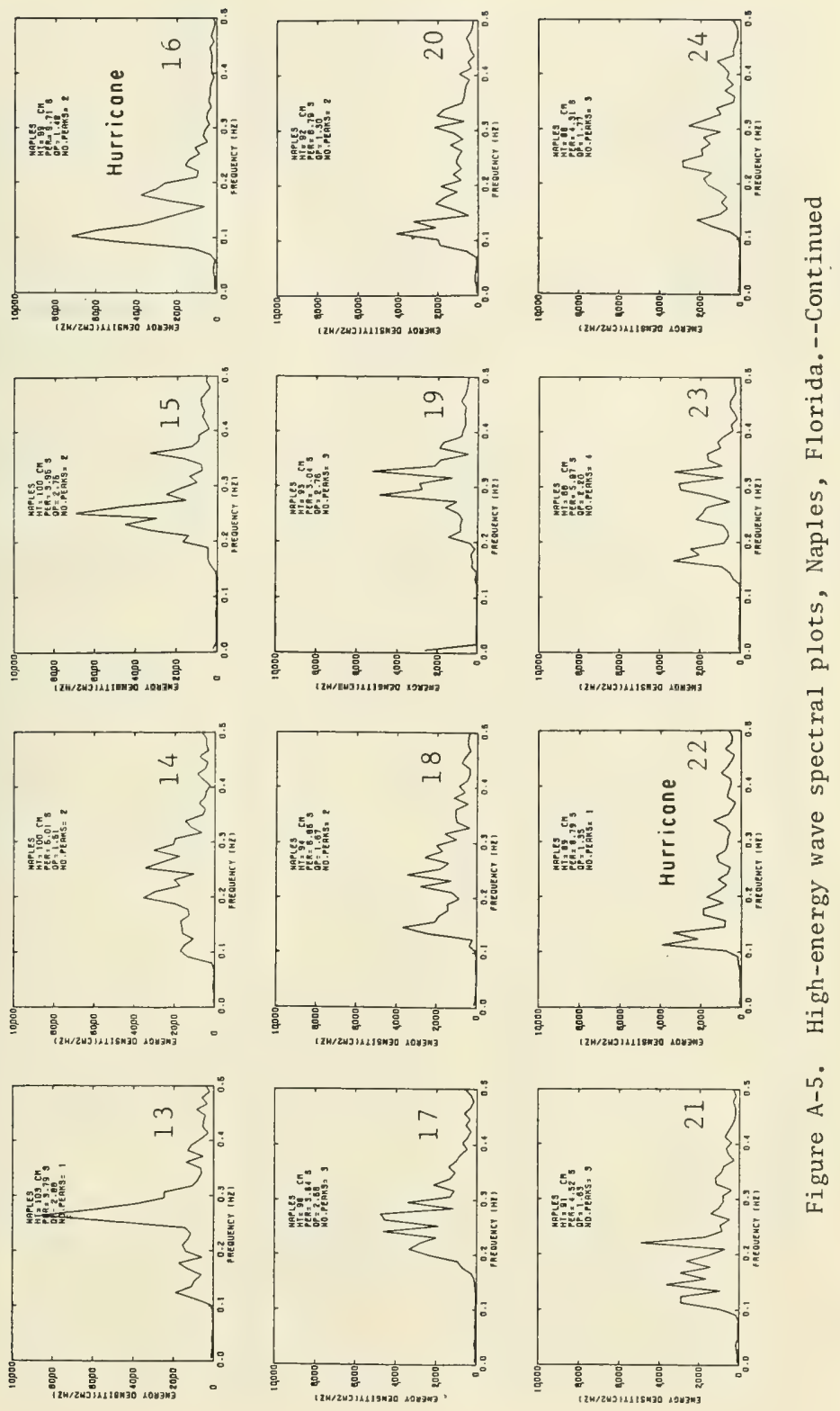


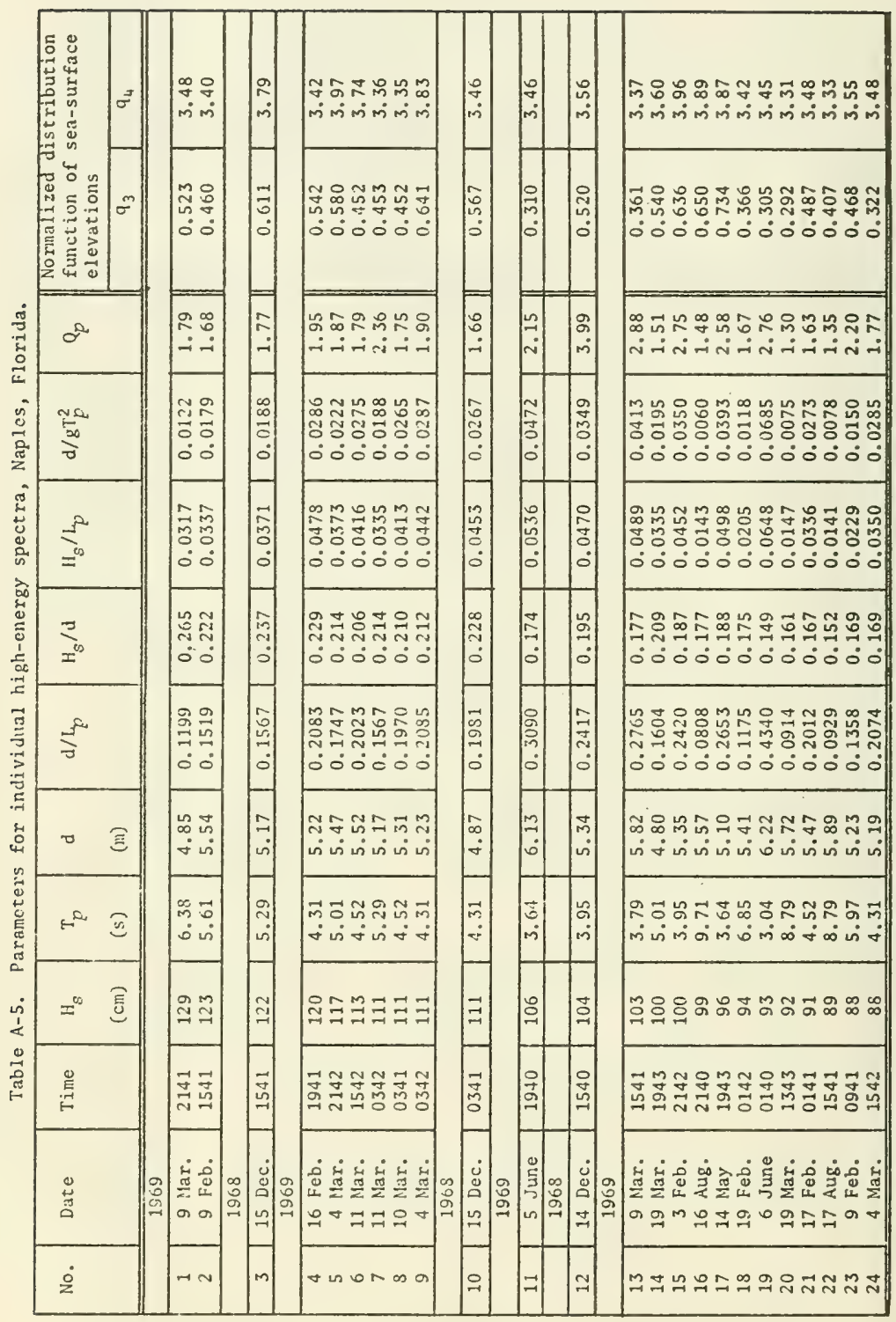



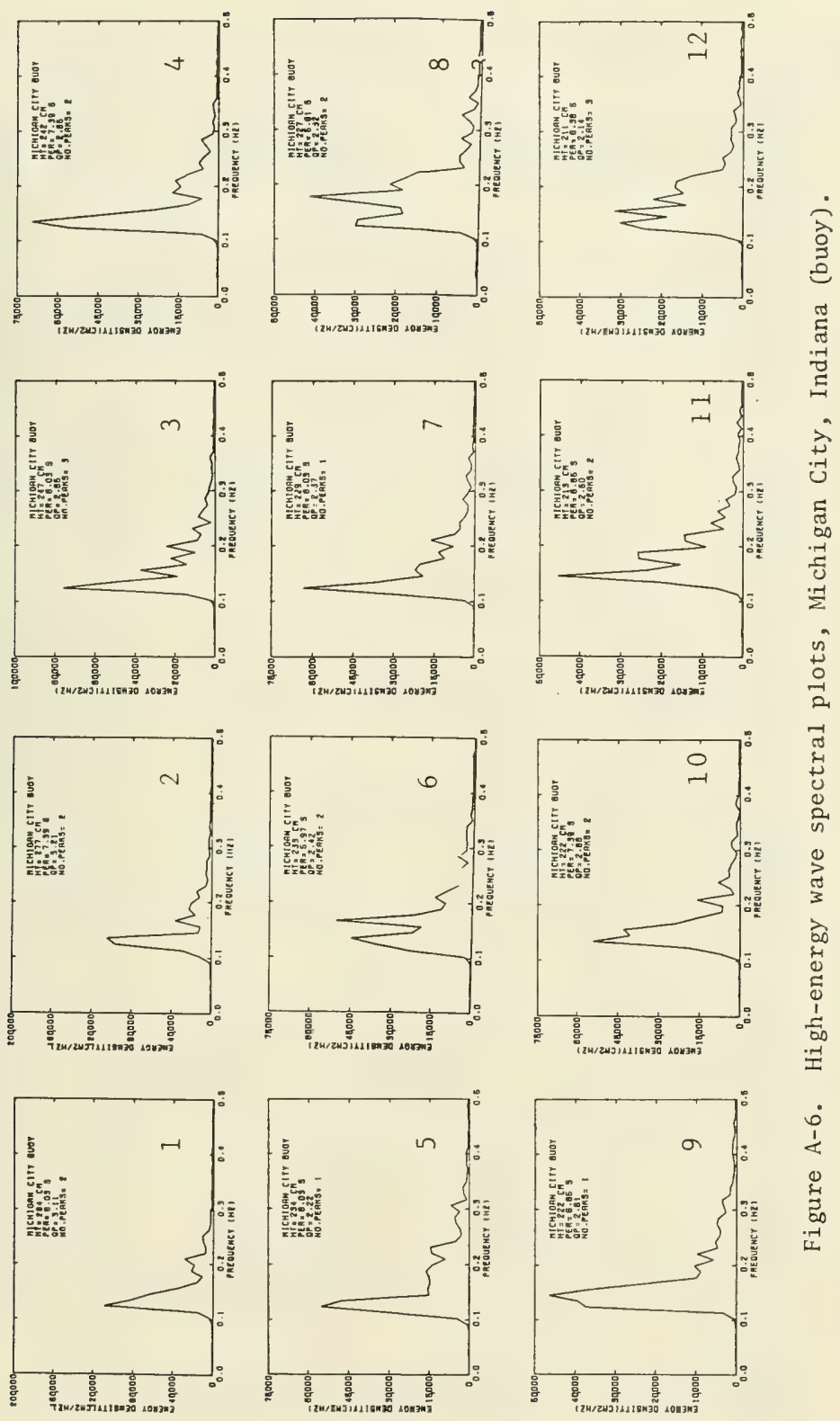

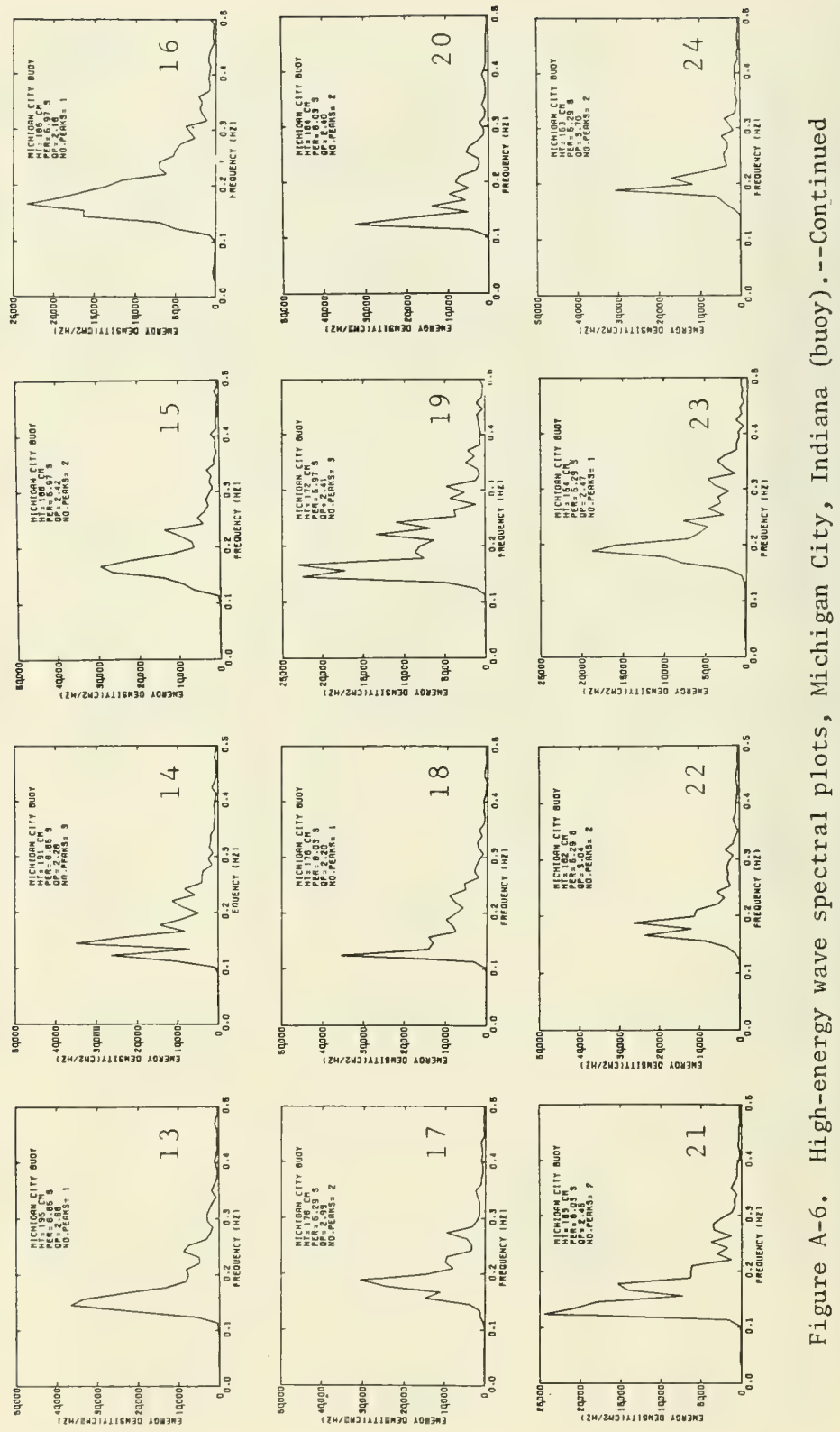


\begin{tabular}{|c|c|}
\hline \multirow{2}{*}{ 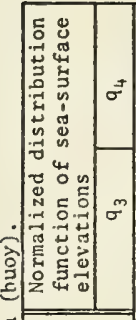 } & 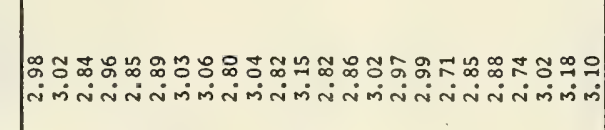 \\
\hline & 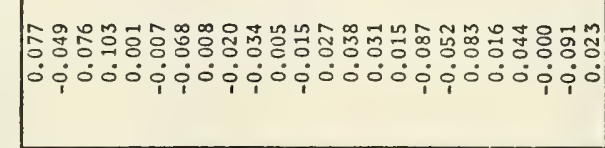 \\
\hline$\infty^{\circ}$ & 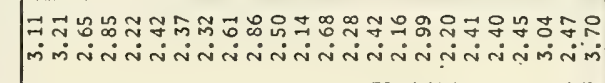 \\
\hline 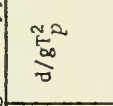 & 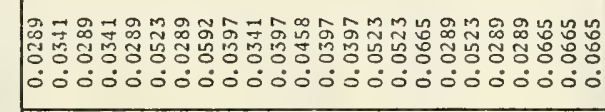 \\
\hline$\sum_{=\infty}^{\infty}$ & 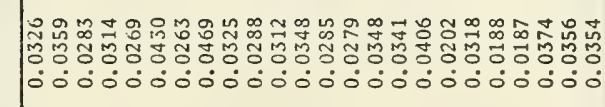 \\
\hline$=$ & 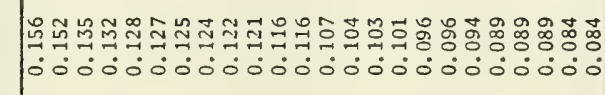 \\
\hline$\frac{9}{4}$ & 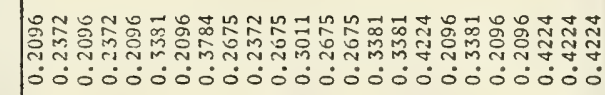 \\
\hline$\therefore$ ह & 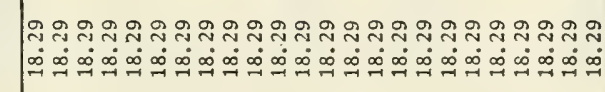 \\
\hline$N^{\alpha} \widehat{\sigma}$ & 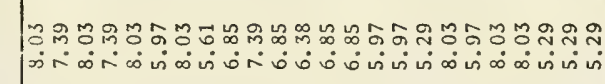 \\
\hline$\Rightarrow$ 焉 & 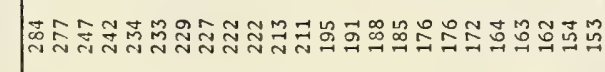 \\
\hline 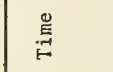 & 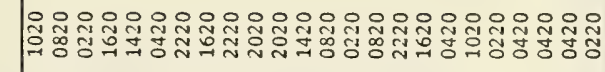 \\
\hline 苋 & 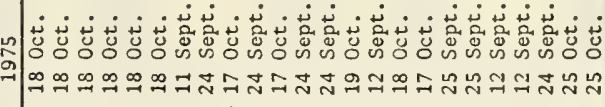 \\
\hline$\dot{z}$ & - \\
\hline
\end{tabular}



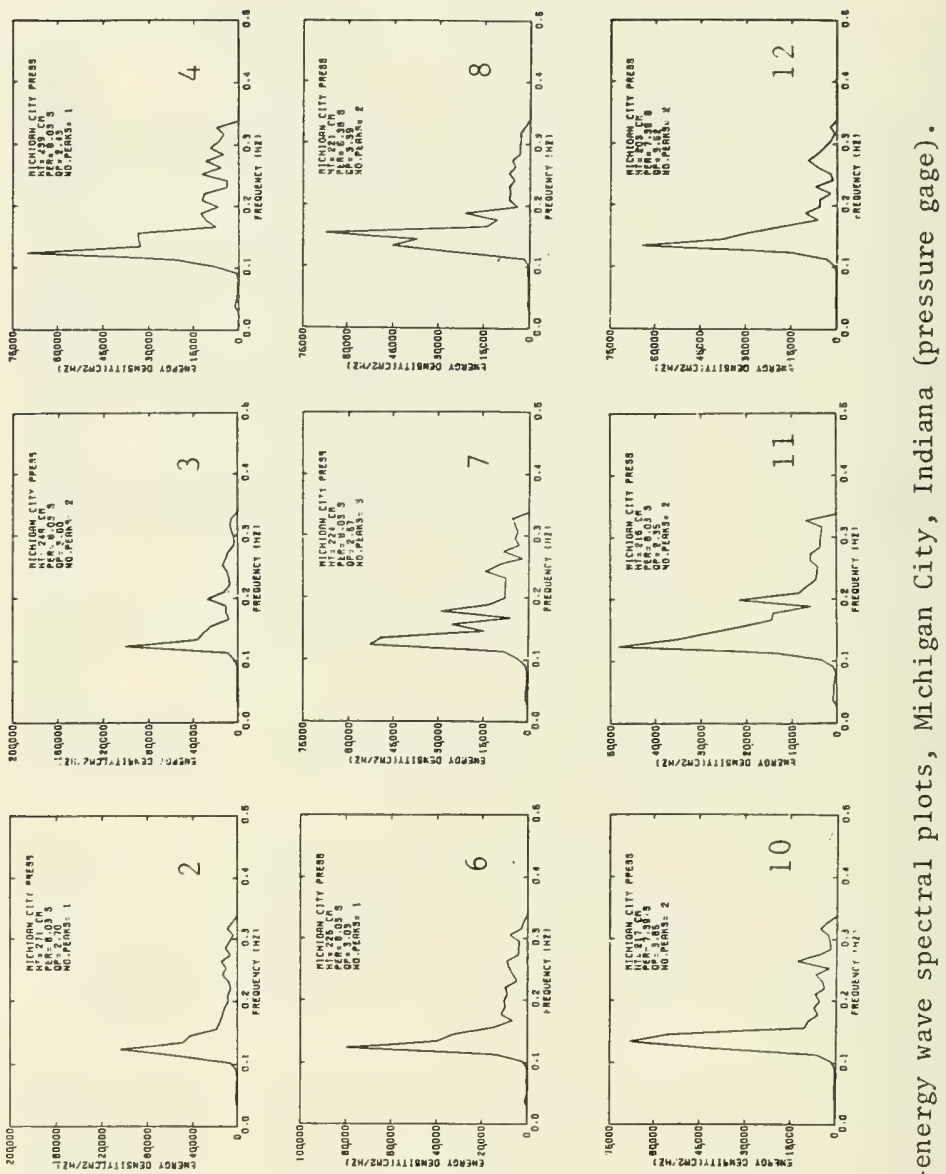

告
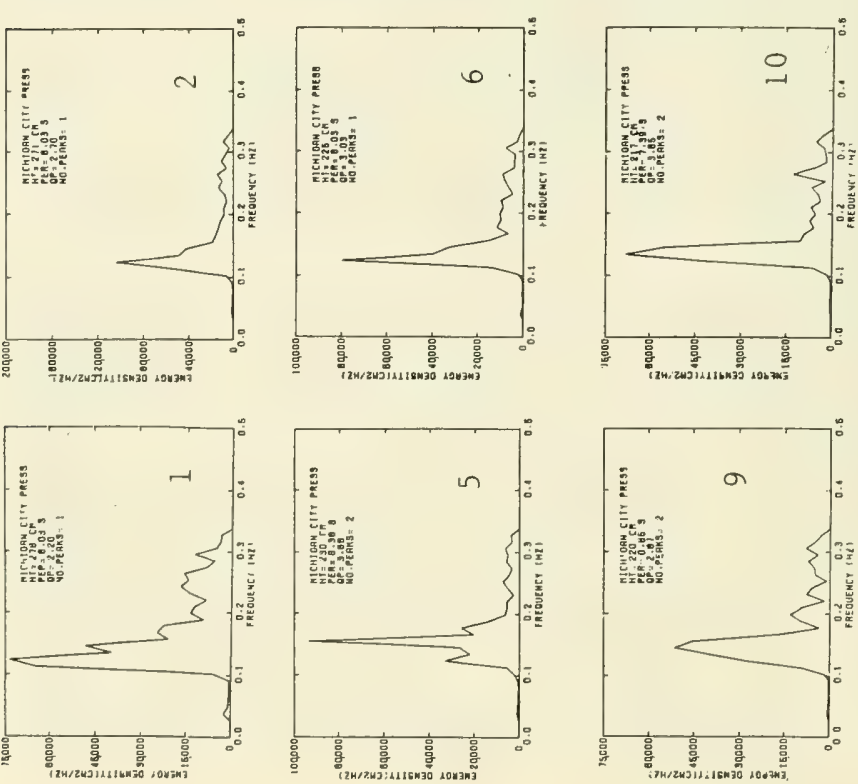

告

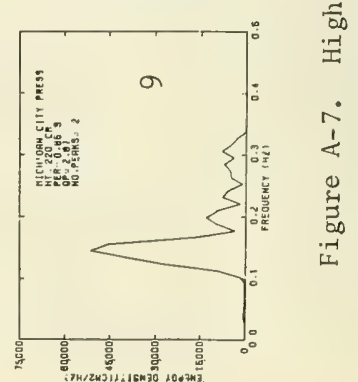



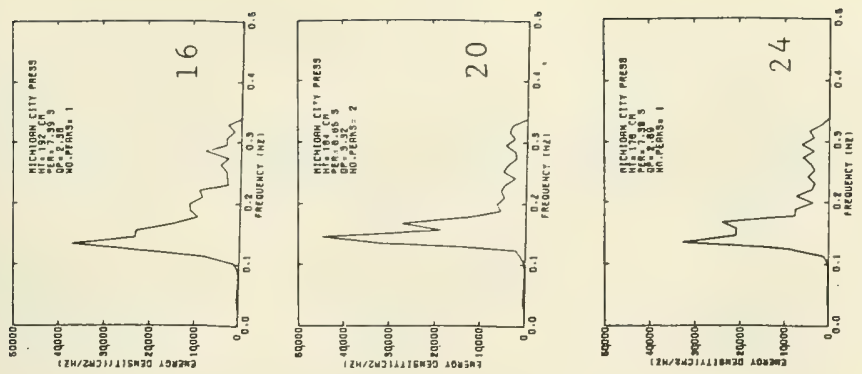


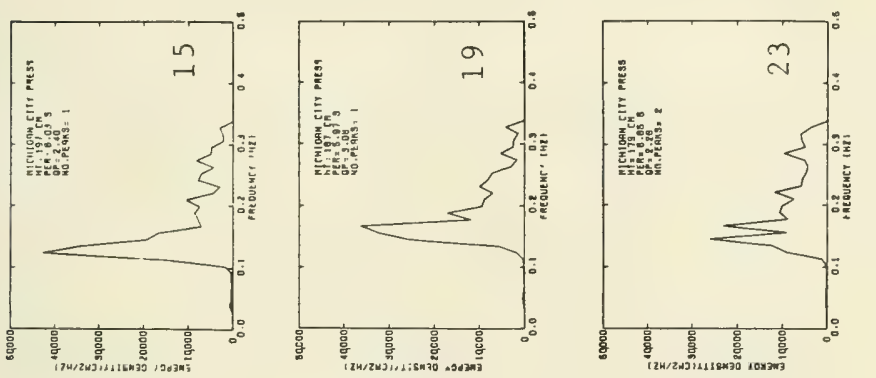

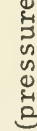
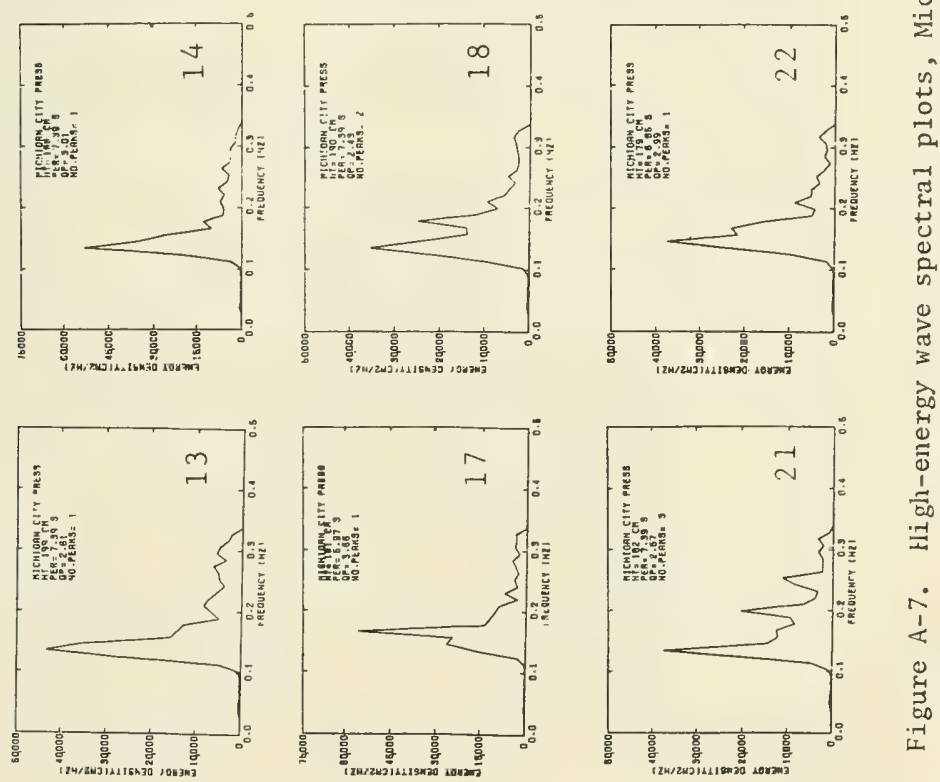


\begin{tabular}{|c|c|c|c|c|}
\hline & 范 & $\sigma^{*}$ & & 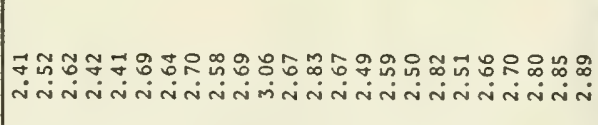 \\
\hline & 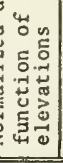 & $\sigma^{m}$ & & 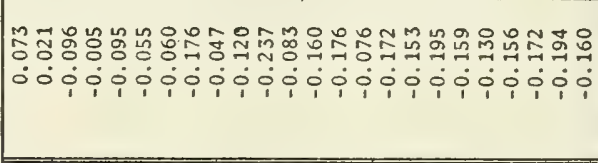 \\
\hline & 2 & & & 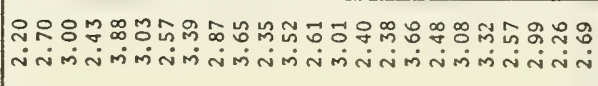 \\
\hline & $\frac{\overbrace{0}^{\infty}}{\partial}$ & & & 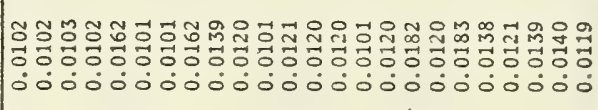 \\
\hline & $\underbrace{2}_{x^{2}}$ & & & 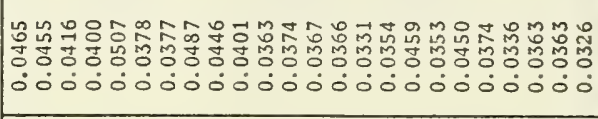 \\
\hline & $\sum_{\infty}^{0}$ & & & 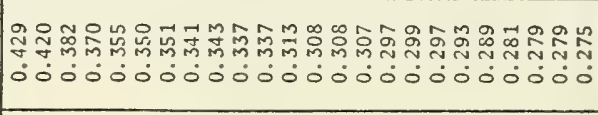 \\
\hline & $\stackrel{3}{\partial}$ & & & 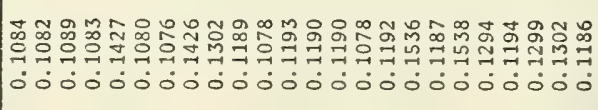 \\
\hline & & $\Xi$ & & 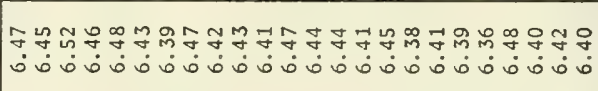 \\
\hline & 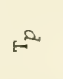 & $\sqrt[n]{2}$ & & 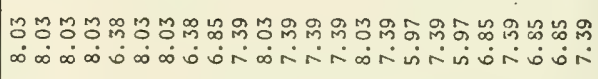 \\
\hline & & త్ర & & 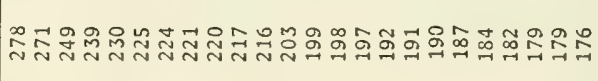 \\
\hline & 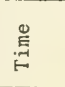 & & & 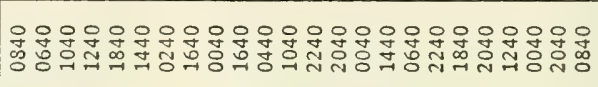 \\
\hline & 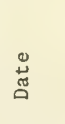 & & م్ & 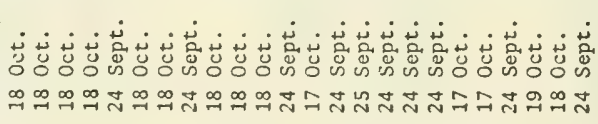 \\
\hline & $\dot{z}$ & & & 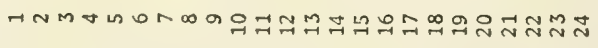 \\
\hline
\end{tabular}



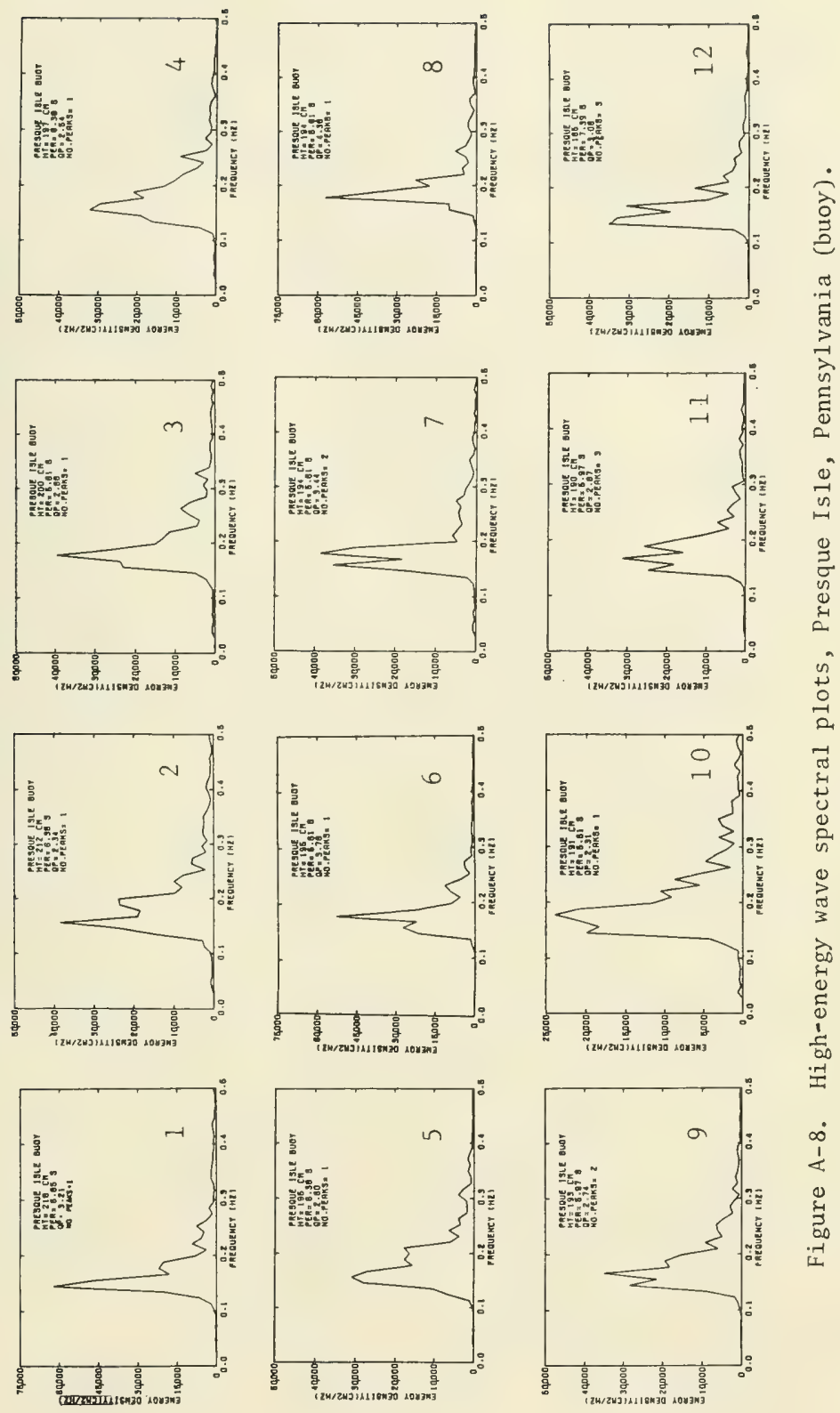

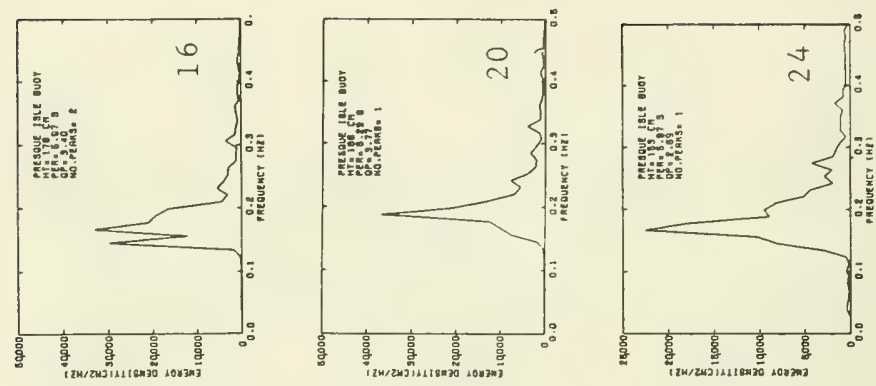

2.
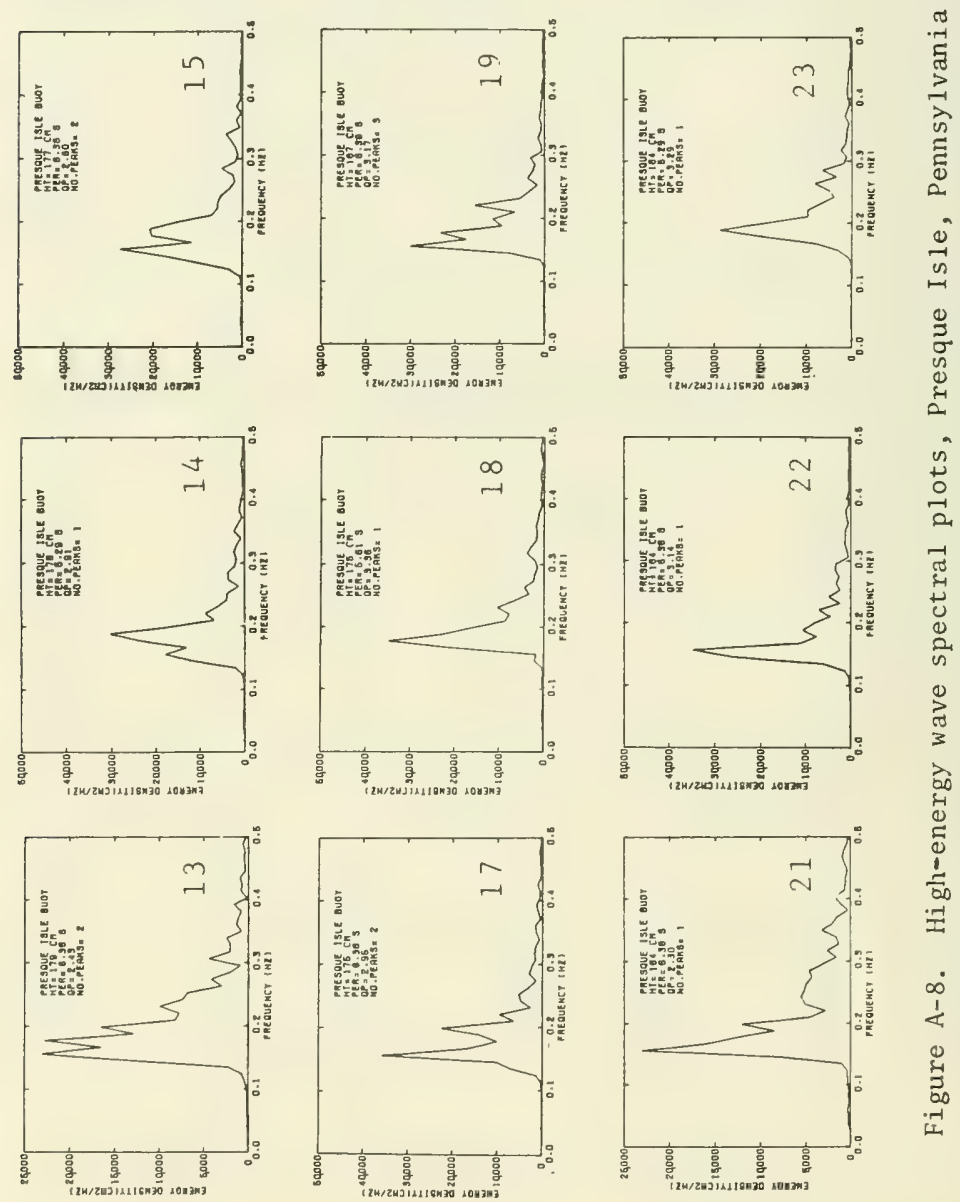


\begin{tabular}{|c|c|}
\hline 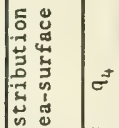 & 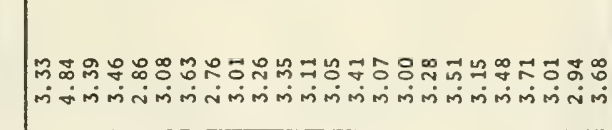 \\
\hline 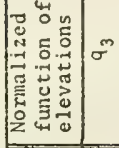 & 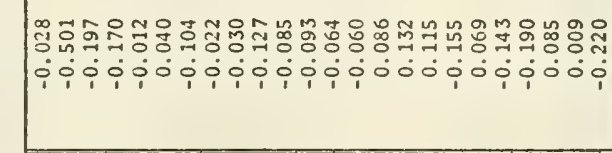 \\
\hline$a^{2}$ & 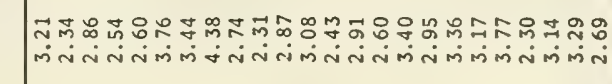 \\
\hline 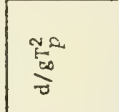 & 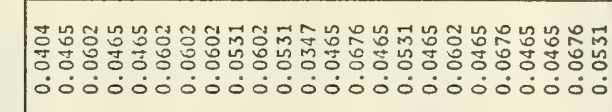 \\
\hline$x^{\infty}$ & 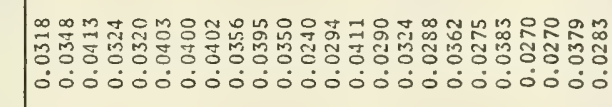 \\
\hline$x^{2}$ & 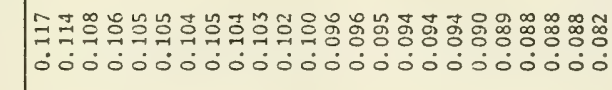 \\
\hline $5^{3}$ & 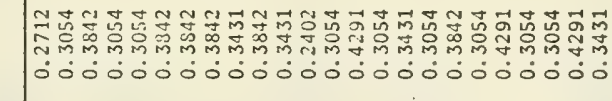 \\
\hline$\sqsupset$ E & 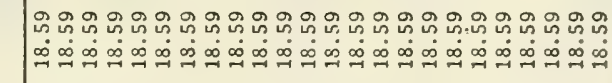 \\
\hline$F^{2} \sigma$ & 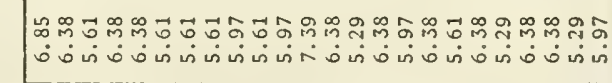 \\
\hline 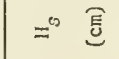 & 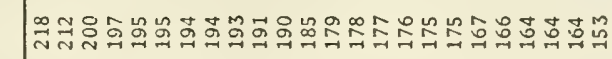 \\
\hline$\stackrel{0}{\stackrel{0}{E}}$ & 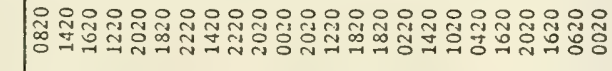 \\
\hline 苋 & 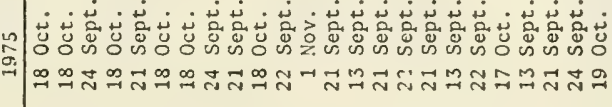 \\
\hline$\dot{z}$ & 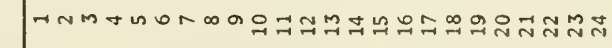 \\
\hline
\end{tabular}



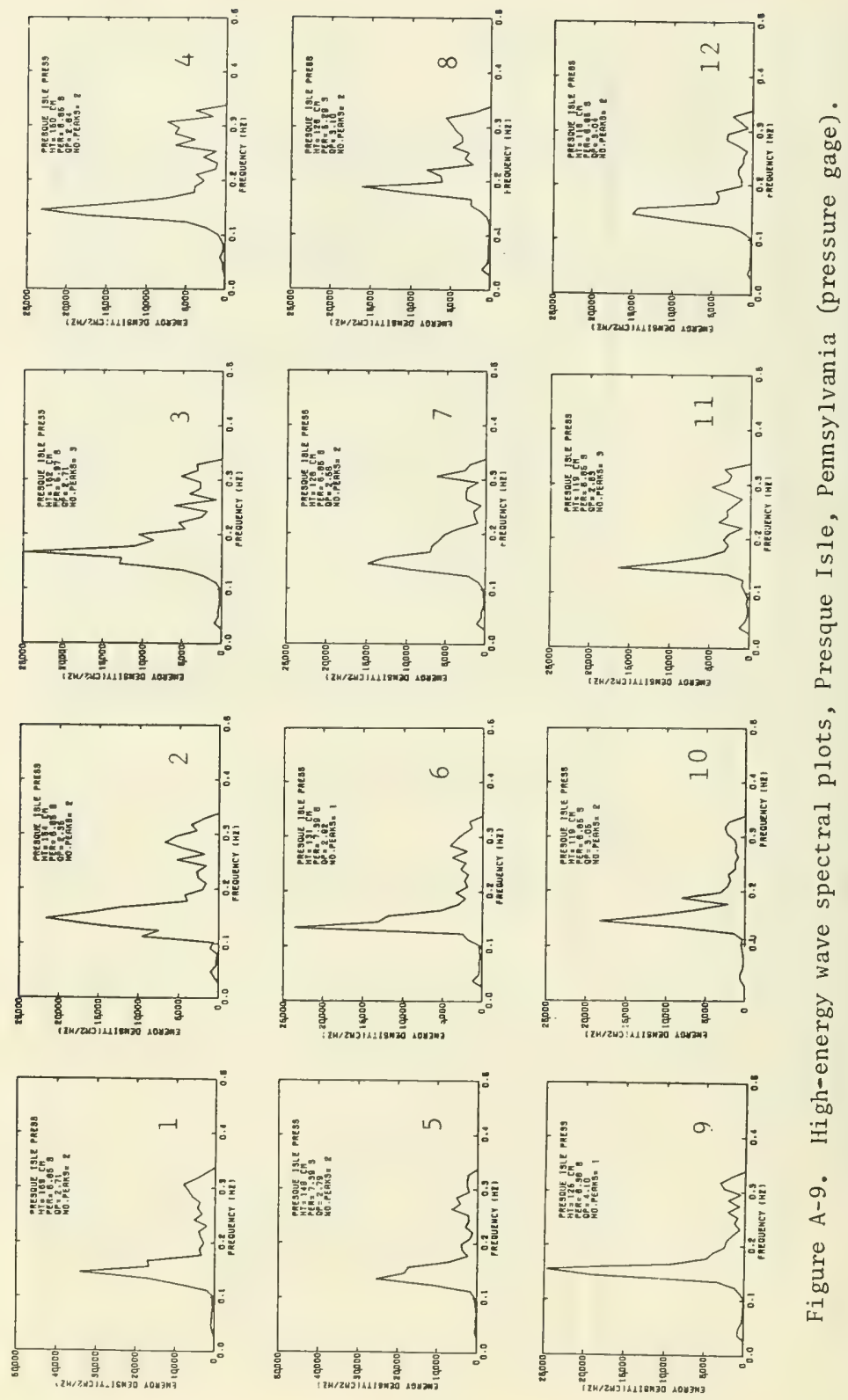

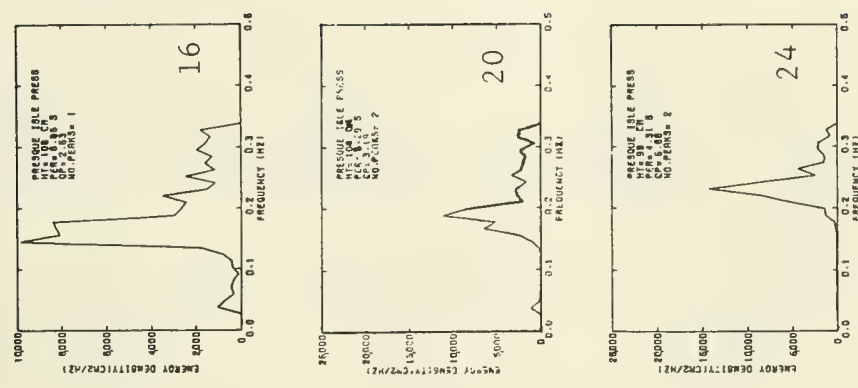

0
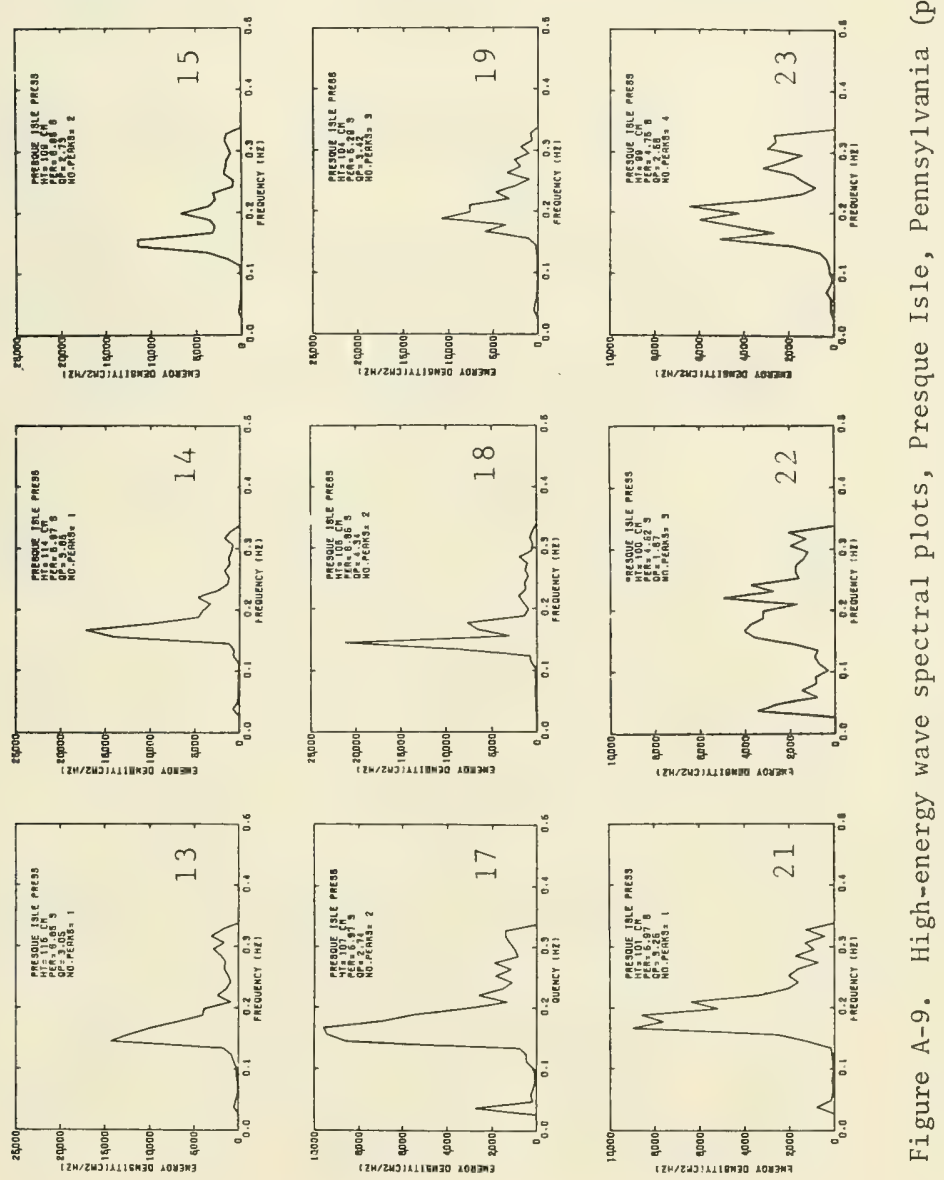


\begin{tabular}{|c|c|c|}
\hline 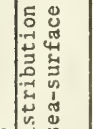 & $\vec{\sigma}$ & 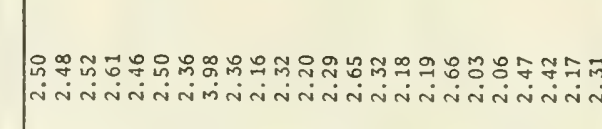 \\
\hline 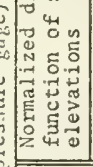 & $\stackrel{m}{-}$ & 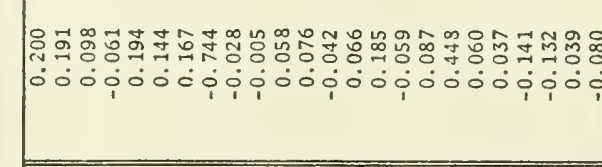 \\
\hline 8 & & 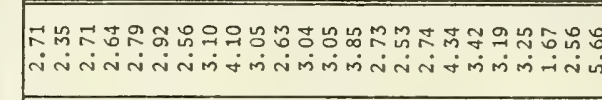 \\
\hline$\frac{T^{\infty}}{N_{\infty}^{\infty}}$ & & 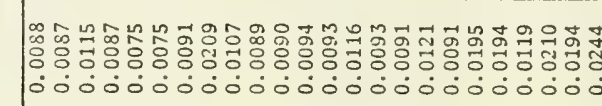 \\
\hline$\sum_{=0}^{2}$ & & 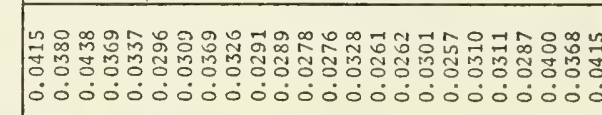 \\
\hline$\sum_{x}^{0}$ & & 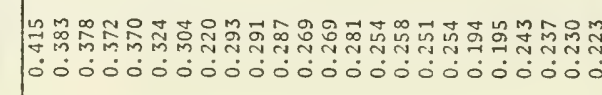 \\
\hline$\stackrel{0}{3}$ & & 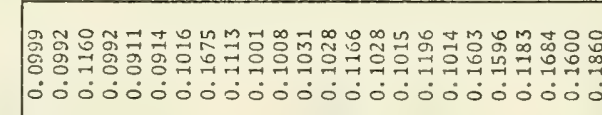 \\
\hline$\exists$ & 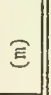 & 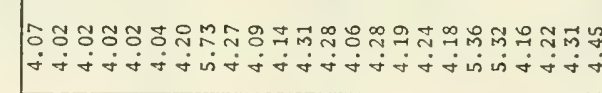 \\
\hline & $\sqrt[n]{ }$ & 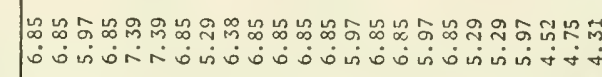 \\
\hline 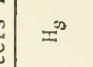 & Е & 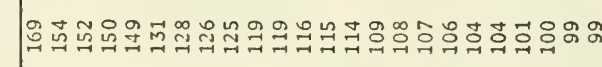 \\
\hline$\underset{:}{\stackrel{E}{E}}$ & & 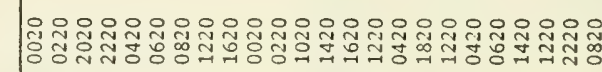 \\
\hline$\stackrel{0}{\stackrel{0}{0}}$ & & 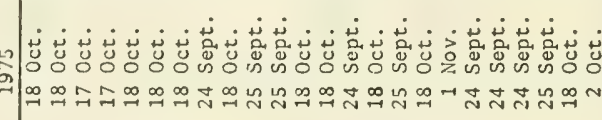 \\
\hline$\dot{0}$ & & 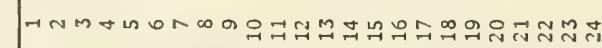 \\
\hline
\end{tabular}



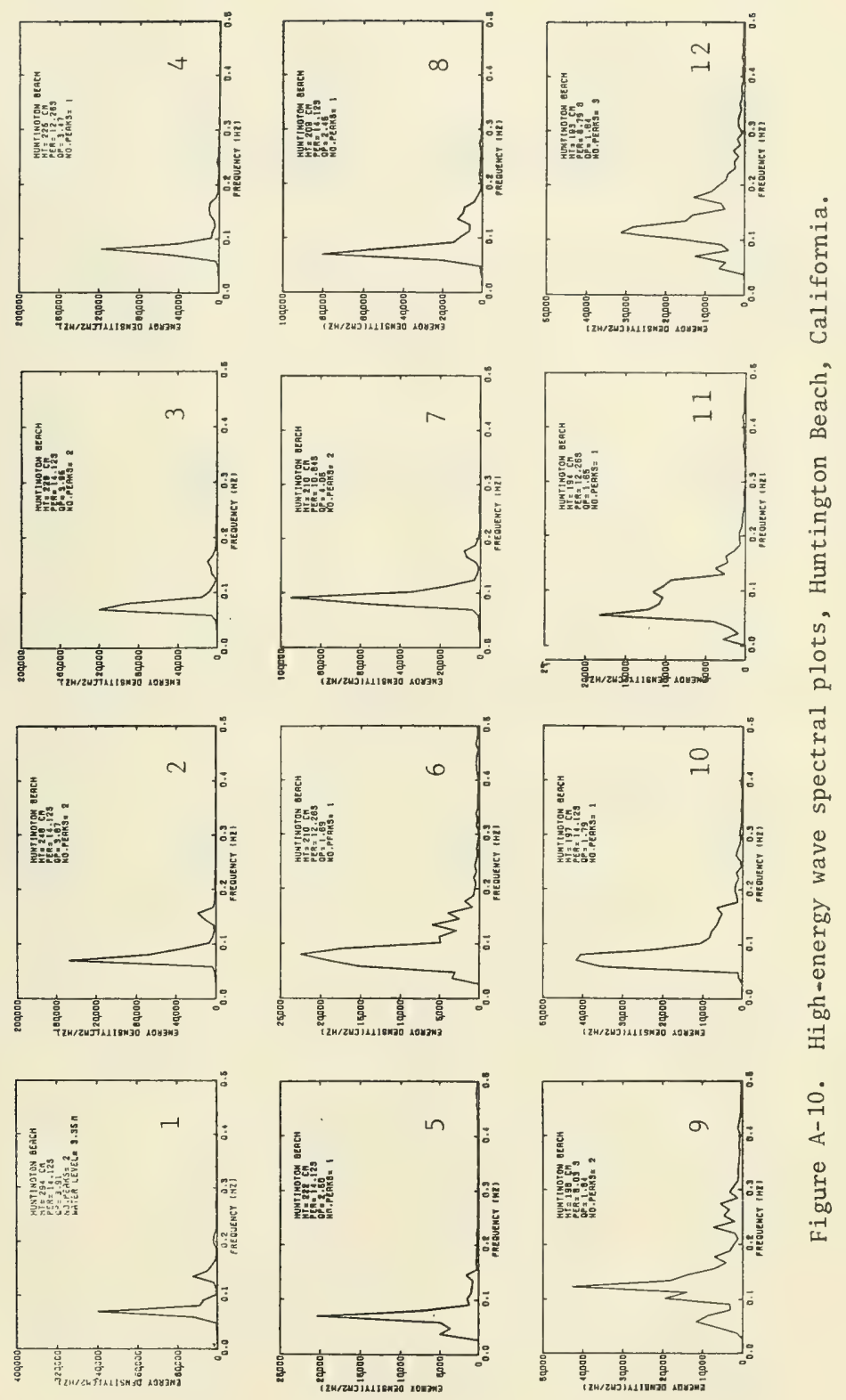

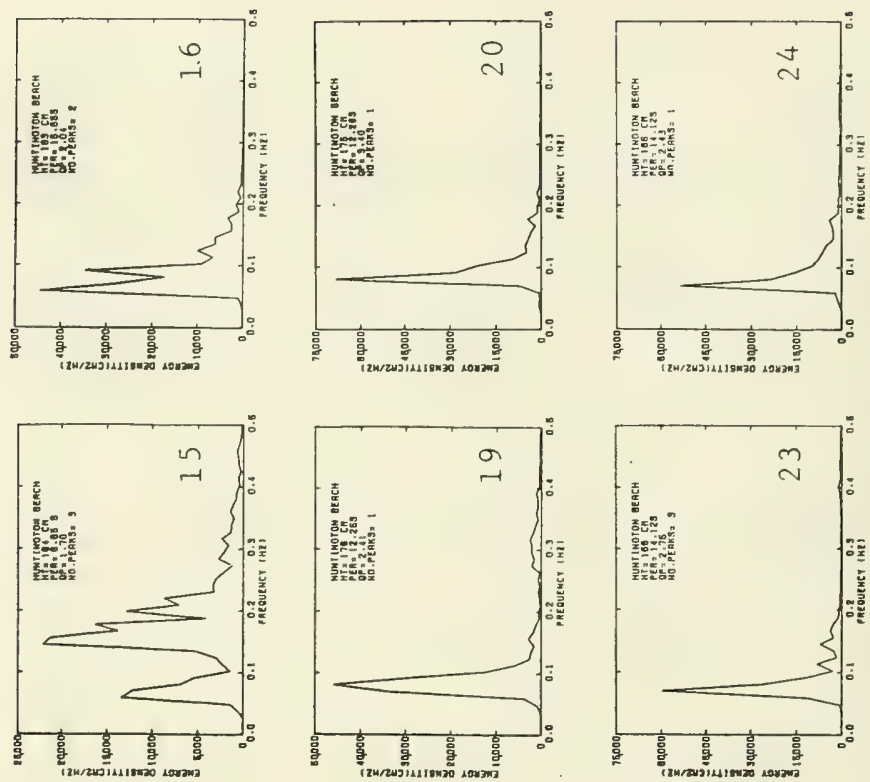

ป
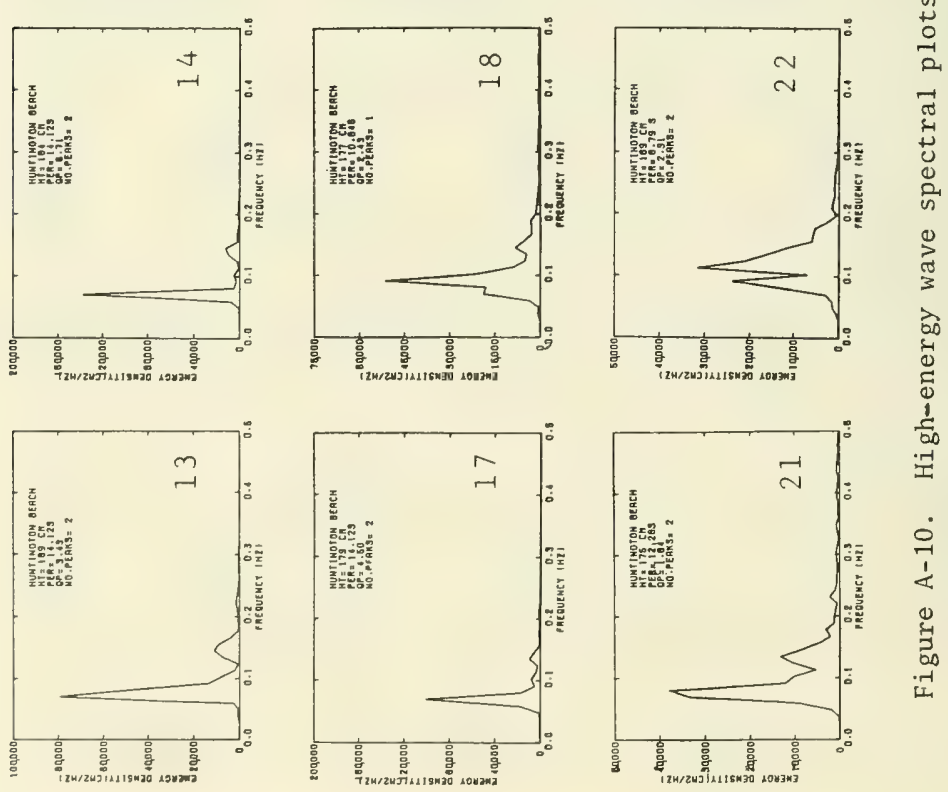


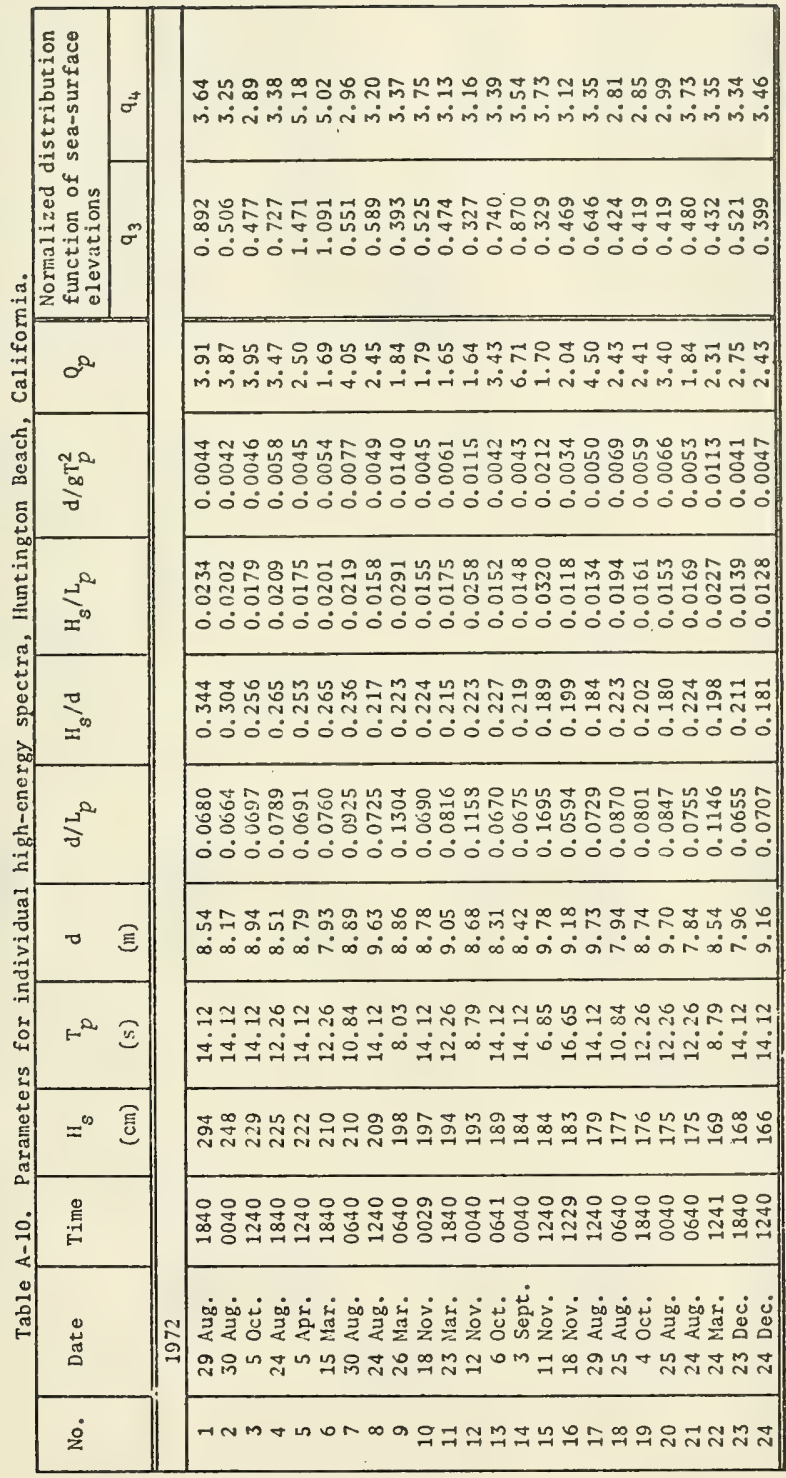



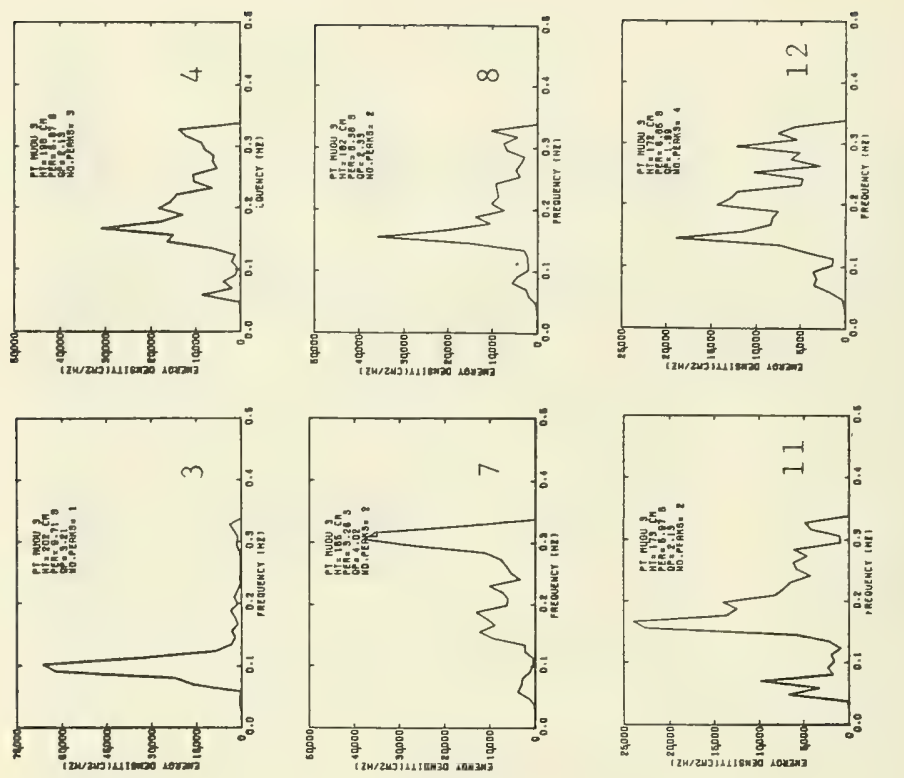


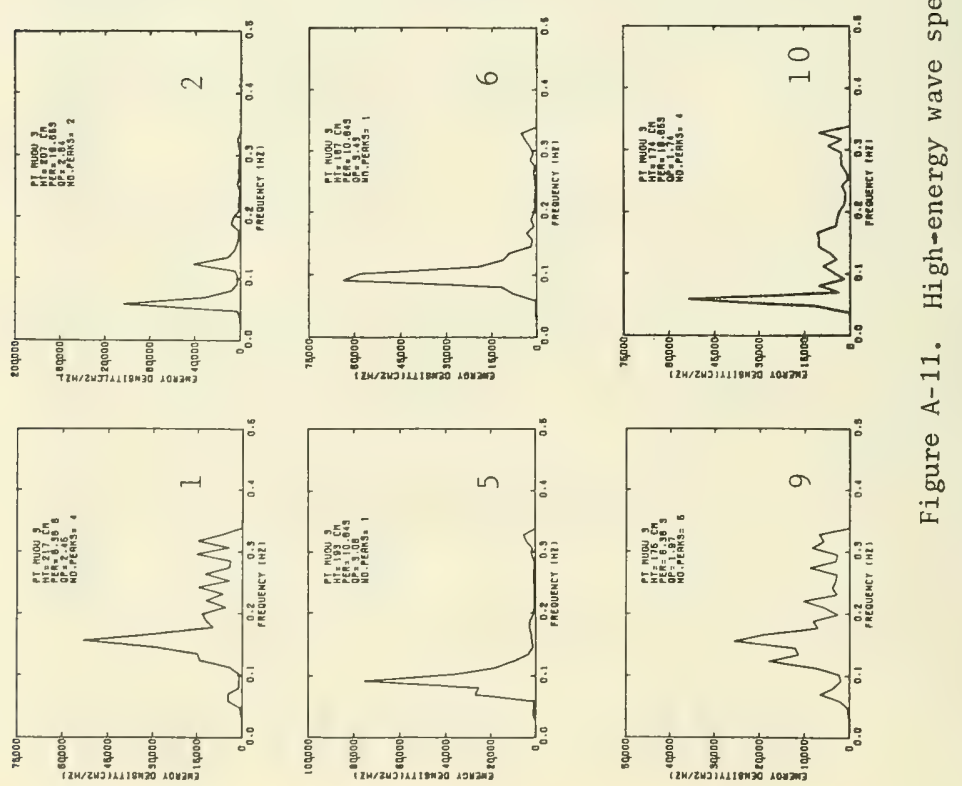

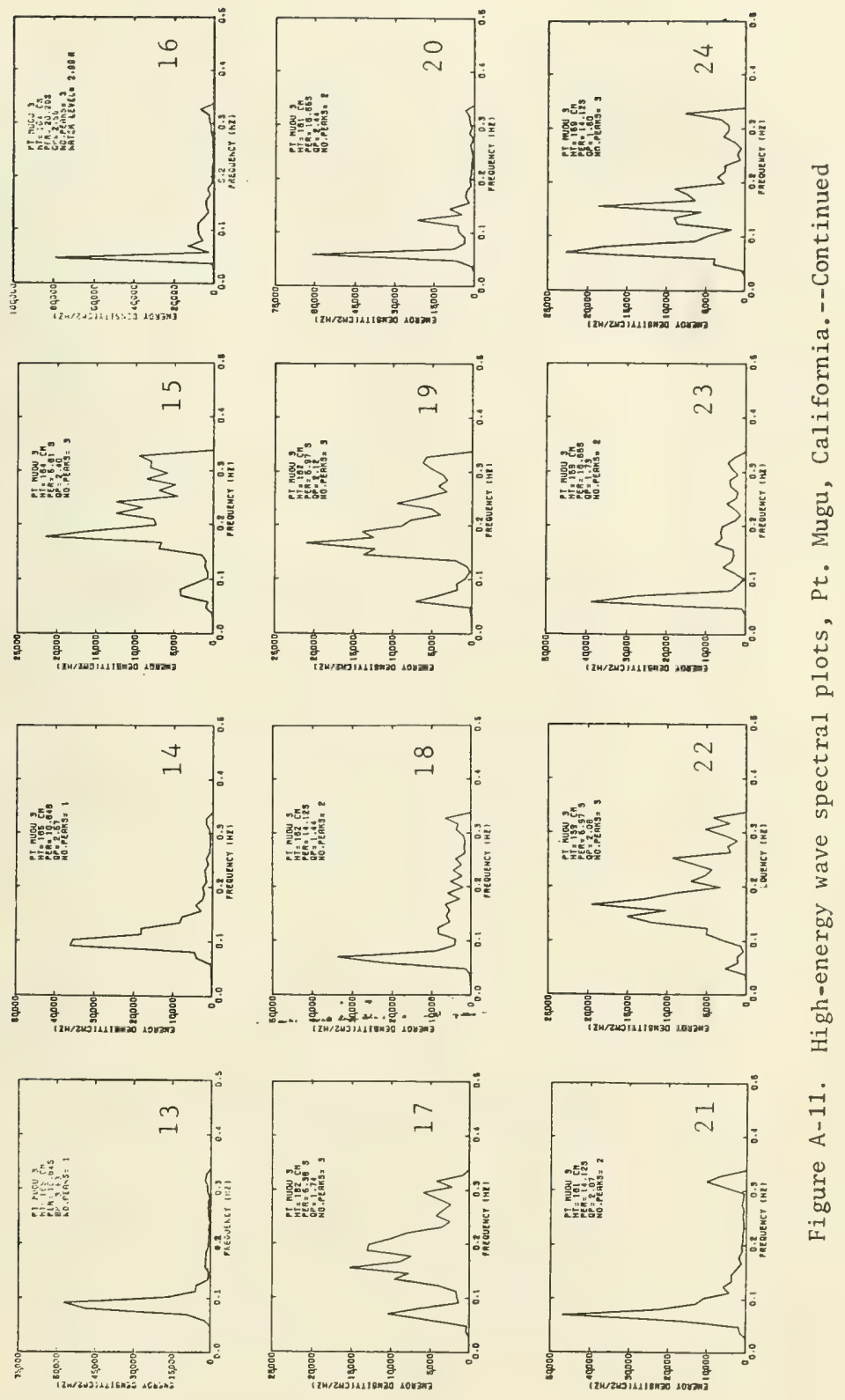


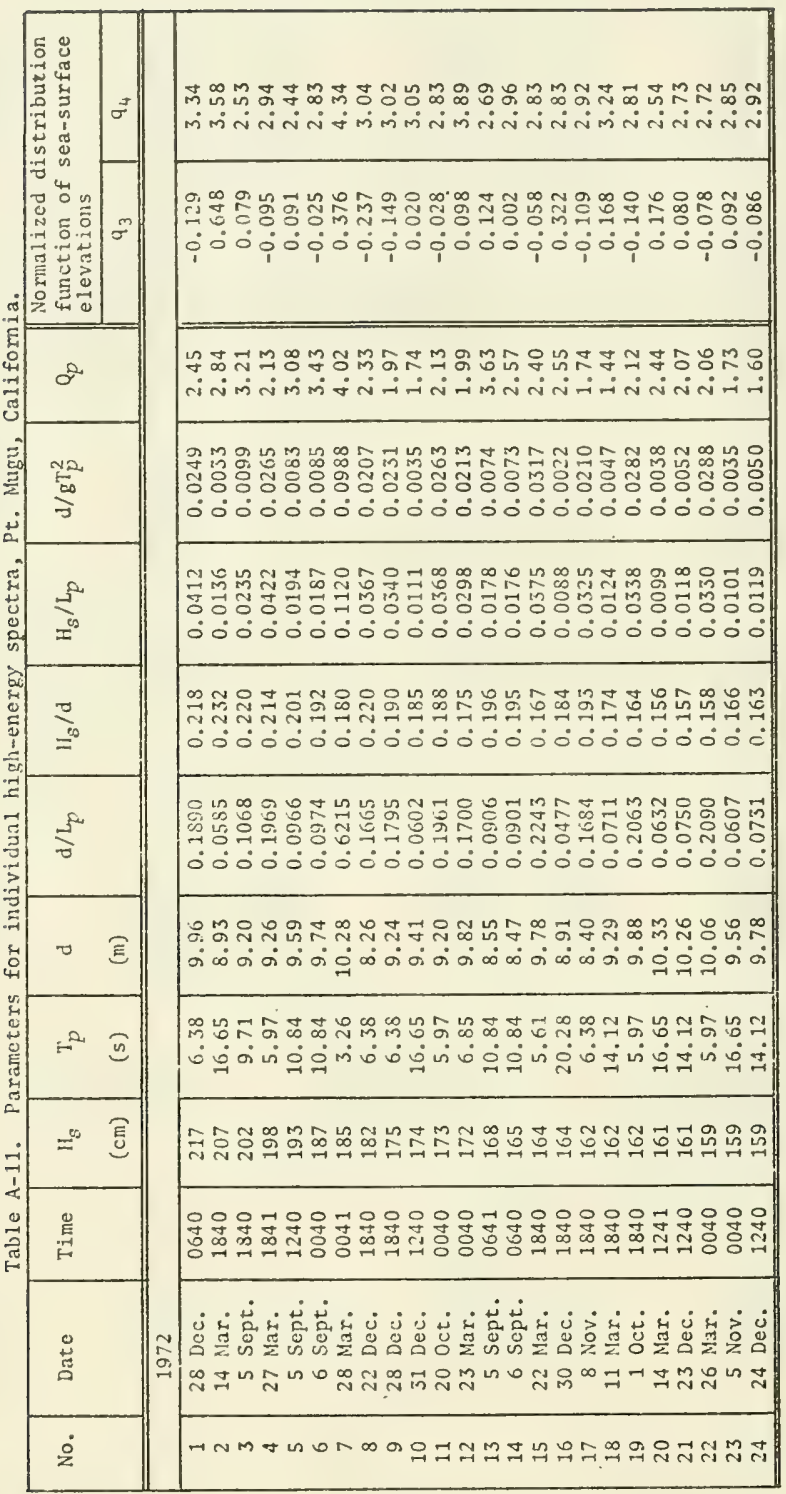




\section{APPENDIX B}

MEAN SPECTRA GROUPED BY HEIGHT AND PERIOD 
Table B-1. Approximate relative depth and ratio of significant height to depth for mean spectra grouped by height and period.

\begin{tabular}{|c|c|c|c|c|}
\hline \multicolumn{3}{|c|}{ Parameters based on period } & \multicolumn{2}{|c|}{ Parameters based on height } \\
\hline $\begin{array}{r}\mathrm{T}_{p} \\
(\mathrm{~s})\end{array}$ & $\mathrm{d} / \mathrm{L}_{p}$ & $\mathrm{~d} / \varepsilon^{\mathrm{T}} \mathrm{T}_{p}^{2}$ & $\begin{array}{c}\mathrm{H}_{\mathrm{g}} \\
(\mathrm{cm})\end{array}$ & $\mathrm{H}_{\mathrm{g}} / \mathrm{d}$ \\
\hline \multicolumn{5}{|c|}{ Atlantic City } \\
\hline 3.5 & 0.286 & 0.043 & 46 & 0.088 \\
\hline 4.5 & 0.195 & 0.026 & 76 & 0.147 \\
\hline 5.5 & 0.149 & 0.017 & 107 & 0.206 \\
\hline 6.4 & 0.124 & 0.013 & 137 & 0.265 \\
\hline 6.8 & 0.115 & 0.011 & 168 & 0.324 \\
\hline 7.4 & 0.105 & 0.010 & 198 & 0.382 \\
\hline 8.0 & 0.096 & 0.008 & 229 & 0.441 \\
\hline 8.8 & 0.086 & 0.007 & 259 & 0.500 \\
\hline 9.7 & 0.078 & 0.006 & & \\
\hline 10.5 & 0.069 & 0.005 & & \\
\hline 12.3 & 0.060 & 0.003 & & \\
\hline 14.1 & 0.052 & 0.003 & & \\
\hline 16.7 & 0.044 & 0.002 & & \\
\hline \multicolumn{5}{|c|}{ Virginia Bcach } \\
\hline 3.5 & 0.327 & 0.051 & 46 & 0.075 \\
\hline 4.5 & 0.218 & 0.031 & 76 & 0.125 \\
\hline 5.5 & 0.165 & 0.021 & 107 & 0.175 \\
\hline 6.4 & 0.136 & 0.015 & 168 & 0.275 \\
\hline 6.8 & 0.127 & 0.013 & 198 & 0.325 \\
\hline 7.4 & 0.115 & 0.011 & 229 & 0.375 \\
\hline 8.0 & 0.105 & 0.010 & 259 & 0.425 \\
\hline 8.8 & 0.094 & 0.008 & 290 & 0.475 \\
\hline 9.7 & 0.085 & 0.007 & & \\
\hline 10.8 & 0.075 & 0.005 & & \\
\hline 12.3 & 0.066 & 0.004 & & \\
\hline 14.1 & 0.057 & 0.003 & & \\
\hline \multicolumn{5}{|c|}{ Nags Head } \\
\hline 5.5 & 0.149 & 0.017 & 46 & 0.088 \\
\hline 6.4 & 0.124 & 0.013 & 76 & 0.147 \\
\hline 6.8 & 0.115 & 0.011 & 107 & 0.206 \\
\hline 7.4 & 0.105 & 0.010 & 137 & 0.265 \\
\hline 8.0 & 0.096 & 0.008 & 168 & 0.324 \\
\hline 8.8 & 0.086 & 0.007 & 198 & 0.382 \\
\hline 9.7 & 0.078 & 0.006 & 229 & 0.441 \\
\hline 10.8 & 0.069 & 0.005 & 259 & 0.500 \\
\hline 12.3 & 0.060 & 0.003 & & \\
\hline 14.1 & 0.052 & 0.003 & & \\
\hline 16.7 & 0.044 & 0.002 & & \\
\hline
\end{tabular}


Table B-1. Approximate relative depth and ratio of significant height to depth for mean spectra grouped by height and period.--Continued

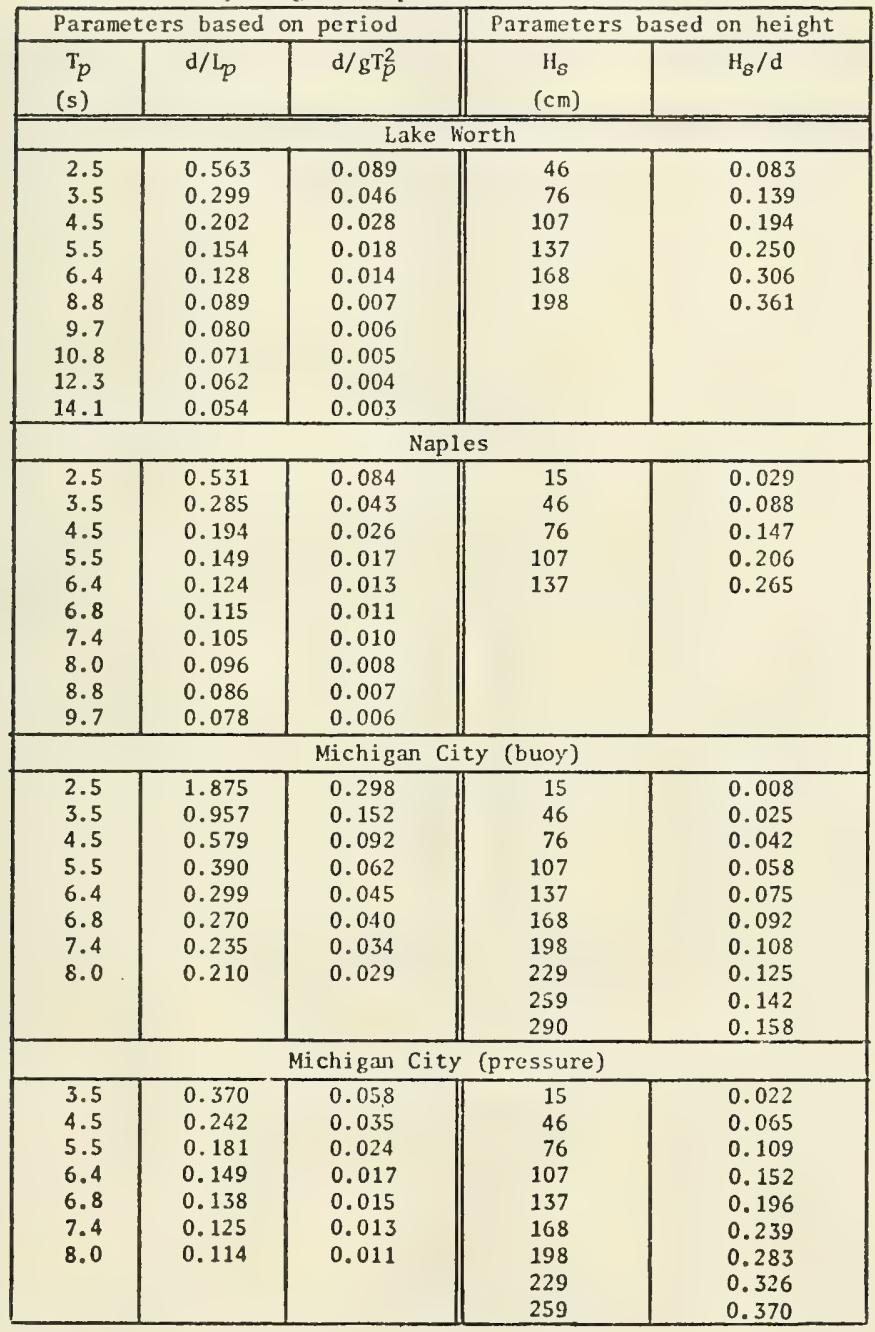


Table B-1. Approximate relative depth and ratio of significant height to depth for mean spectra grouped by height and period.--Continued

\begin{tabular}{|c|c|c|c|c|}
\hline \multicolumn{3}{|c|}{ Parameters based on period } & \multicolumn{2}{|c|}{ Parameters based on height } \\
\hline $\begin{array}{r}\mathrm{T}_{p} \\
\text { (s) }\end{array}$ & $\mathrm{d} / \mathrm{L}_{p}$ & $\mathrm{~d} / \mathrm{gT}_{p}^{2}$ & $\begin{array}{c}\mathrm{H}_{8} \\
(\mathrm{~cm})\end{array}$ & $\mathrm{H}_{\mathcal{B}} / \mathrm{d}$ \\
\hline \multicolumn{5}{|c|}{ Presque Isle (buoy) } \\
\hline $\begin{array}{l}3.5 \\
4.5 \\
5.5 \\
6.4 \\
6.8 \\
7.4\end{array}$ & $\begin{array}{l}0.973 \\
0.588 \\
0.397 \\
0.301 \\
0.272 \\
0.238\end{array}$ & $\begin{array}{l}0.155 \\
0.094 \\
0.063 \\
0.046 \\
0.041 \\
0.035\end{array}$ & $\begin{array}{r}46 \\
76 \\
107 \\
137 \\
168 \\
198 \\
229 \\
\end{array}$ & $\begin{array}{l}0.025 \\
0.041 \\
0.057 \\
0.074 \\
0.090 \\
0.107 \\
0.124\end{array}$ \\
\hline \multicolumn{5}{|c|}{ Presque Isle (pressure) } \\
\hline $\begin{array}{l}3.5 \\
4.5 \\
5.5 \\
6.4 \\
6.8 \\
7.4\end{array}$ & $\begin{array}{l}0.257 \\
0.178 \\
0.138 \\
0.115 \\
0.107 \\
0.097\end{array}$ & $\begin{array}{l}0.038 \\
0.023 \\
0.015 \\
0.011 \\
0.010 \\
0.009\end{array}$ & $\begin{array}{r}15 \\
46 \\
76 \\
107 \\
137 \\
168\end{array}$ & $\begin{array}{l}0.033 \\
0.100 \\
0.167 \\
0.233 \\
0.300 \\
0.367\end{array}$ \\
\hline \multicolumn{5}{|c|}{ liuntington Beach } \\
\hline $\begin{array}{r}5.5 \\
6.4 \\
6.8 \\
7.4 \\
8.0 \\
8.8 \\
9.7 \\
10.8 \\
12.3 \\
14.1 \\
16.7 \\
20.3 \\
\end{array}$ & $\begin{array}{l}0.219 \\
0.177 \\
0.163 \\
0.146 \\
0.133 \\
0.119 \\
0.106 \\
0.094 \\
0.081 \\
0.070 \\
0.059 \\
0.048 \\
\end{array}$ & $\begin{array}{l}0.031 \\
0.023 \\
0.020 \\
0.017 \\
0.015 \\
0.012 \\
0.010 \\
0.008 \\
0.006 \\
0.005 \\
0.003 \\
0.002 \\
\end{array}$ & $\begin{array}{r}46 \\
76 \\
107 \\
138 \\
168 \\
198 \\
229 \\
259 \\
290\end{array}$ & $\begin{array}{l}0.050 \\
0.083 \\
0.117 \\
0.150 \\
0.183 \\
0.217 \\
0.250 \\
0.283 \\
0.317\end{array}$ \\
\hline \multicolumn{5}{|c|}{ Pt. Mugu } \\
\hline $\begin{array}{r}3.5 \\
4.5 \\
5.5 \\
6.4 \\
6.8 \\
7.4 \\
8.0 \\
8.8 \\
9.7 \\
10.8 \\
12.3 \\
14.1 \\
16.7 \\
20.3\end{array}$ & $\begin{array}{l}0.494 \\
0.309 \\
0.224 \\
0.181 \\
0.166 \\
0.150 \\
0.136 \\
0.121 \\
0.108 \\
0.096 \\
0.083 \\
0.072 \\
0.060 \\
0.049\end{array}$ & $\begin{array}{l}0.079 \\
0.048 \\
0.032 \\
0.024 \\
0.021 \\
0.018 \\
0.015 \\
0.012 \\
0.010 \\
0.008 \\
0.006 \\
0.005 \\
0.003 \\
0.002\end{array}$ & $\begin{array}{r}46 \\
76 \\
107 \\
137 \\
168 \\
198 \\
229\end{array}$ & $\begin{array}{l}0.048 \\
0.081 \\
0.113 \\
0.145 \\
0.177 \\
0.210 \\
0.242\end{array}$ \\
\hline
\end{tabular}



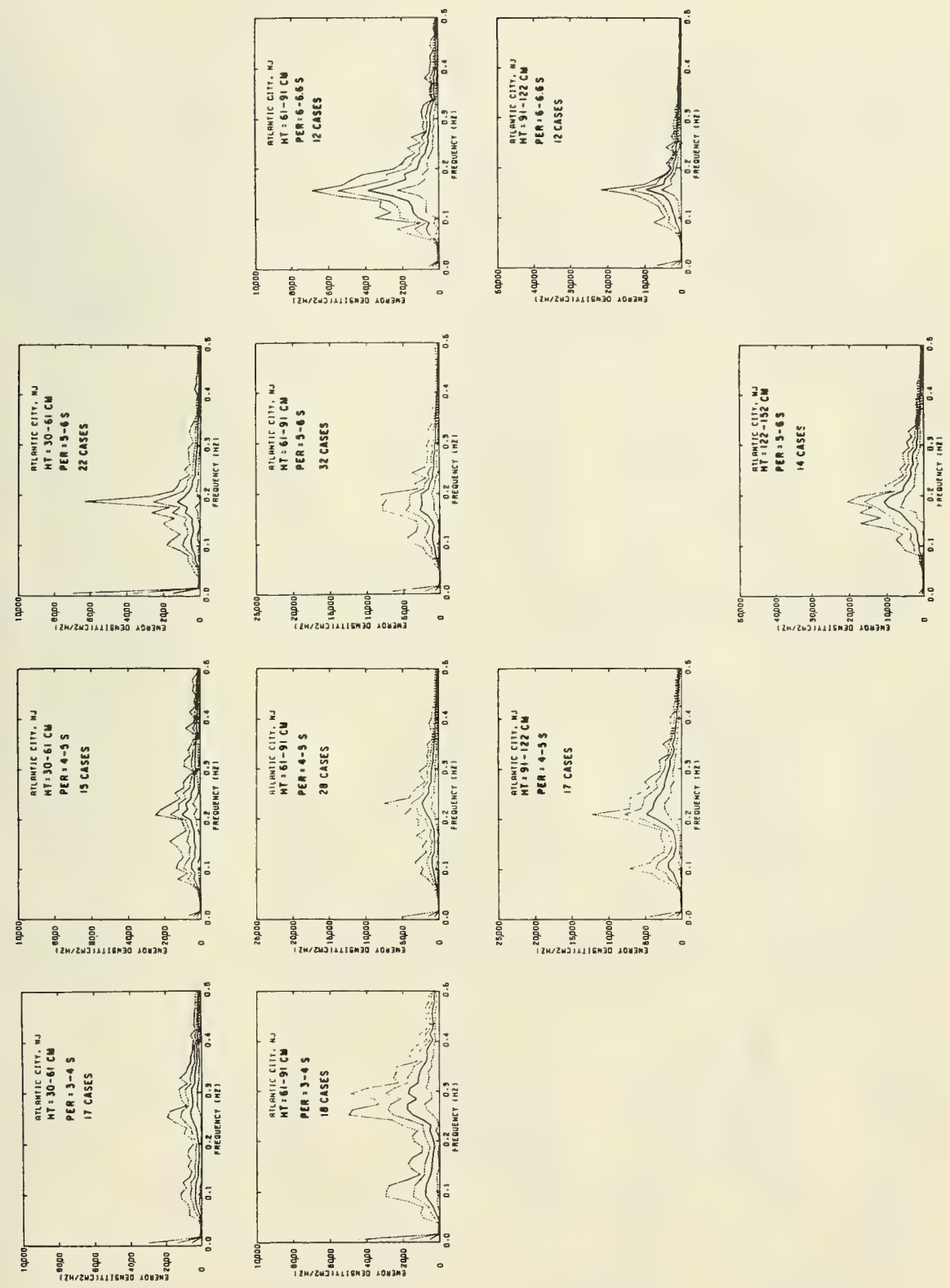

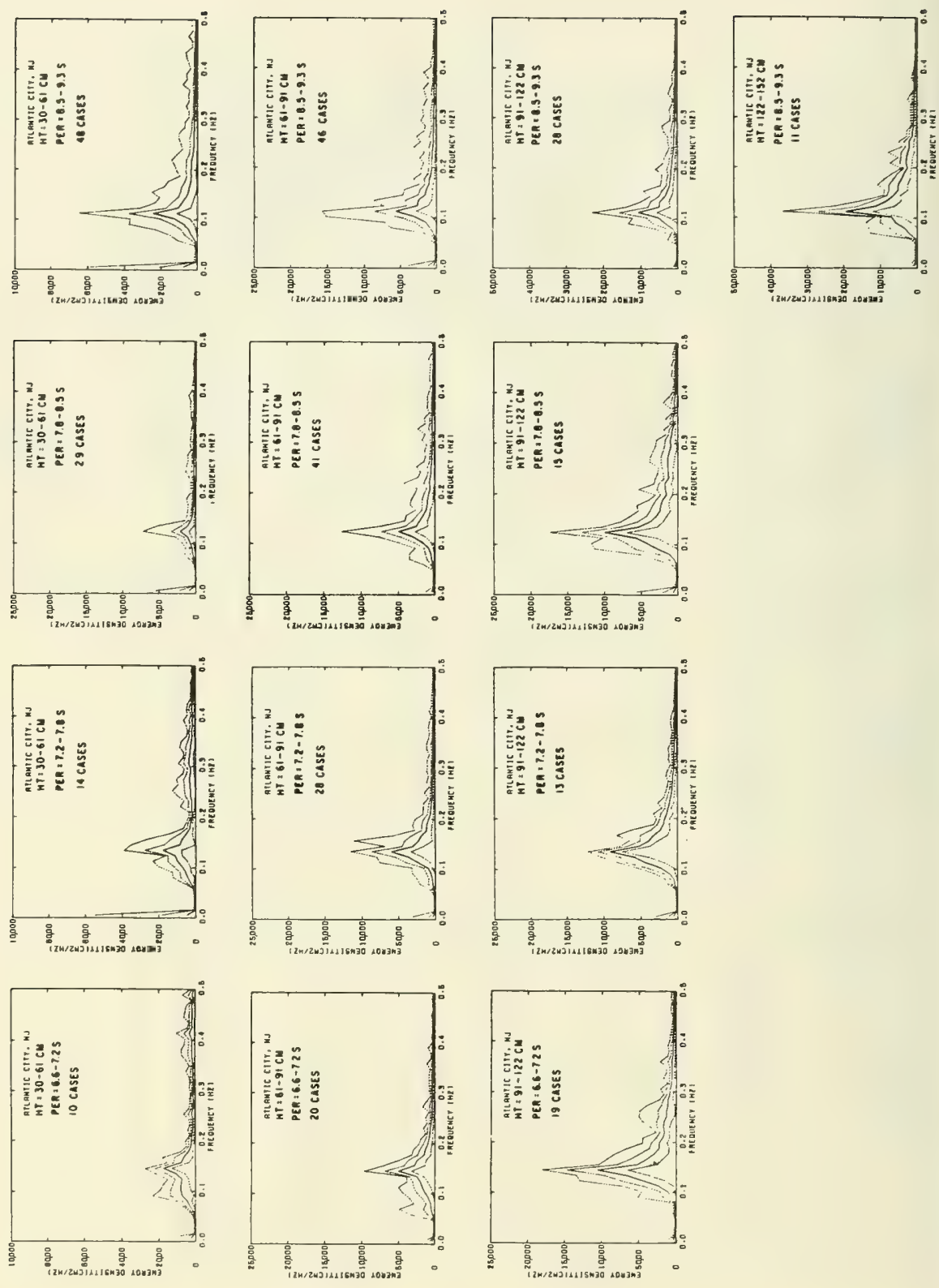

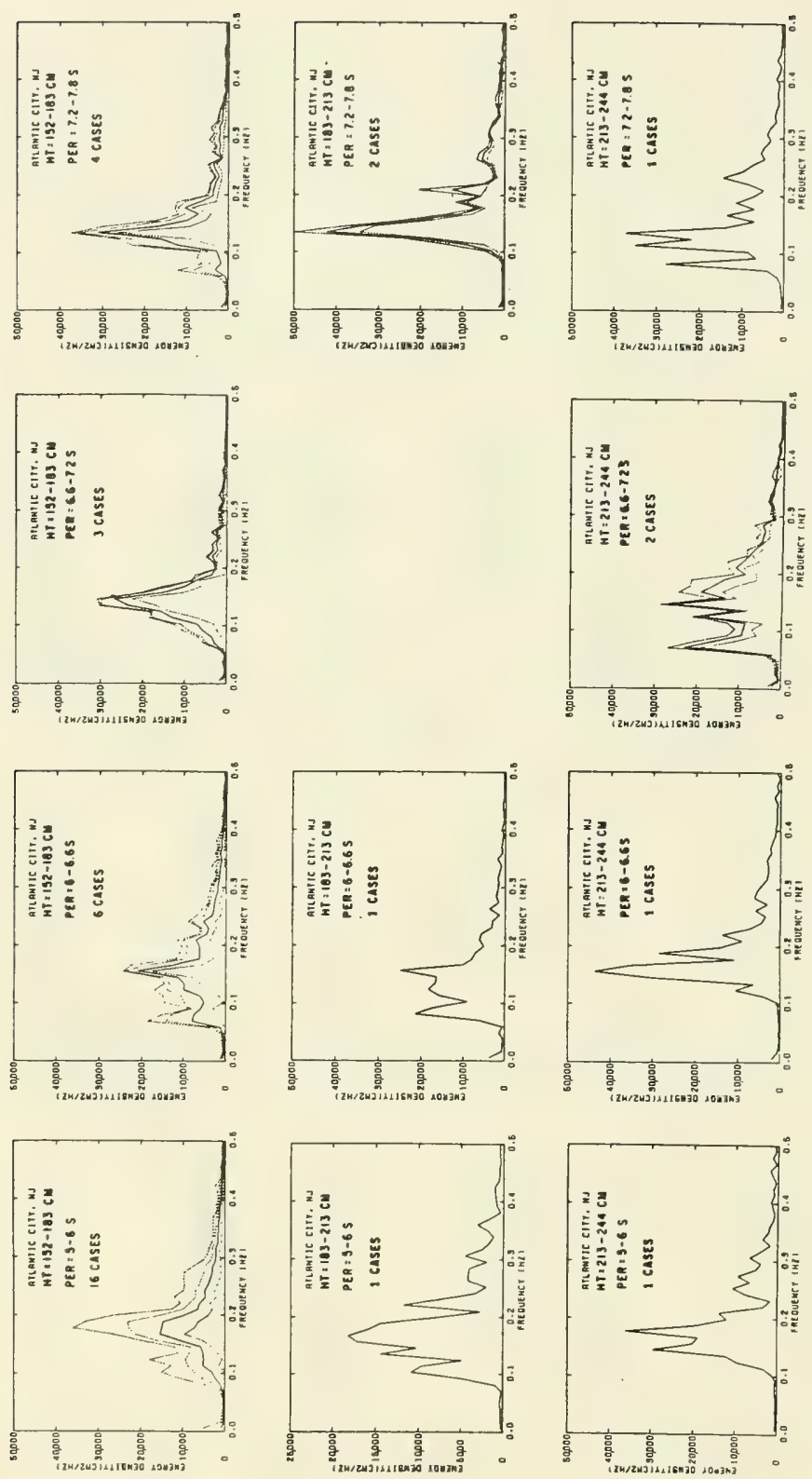

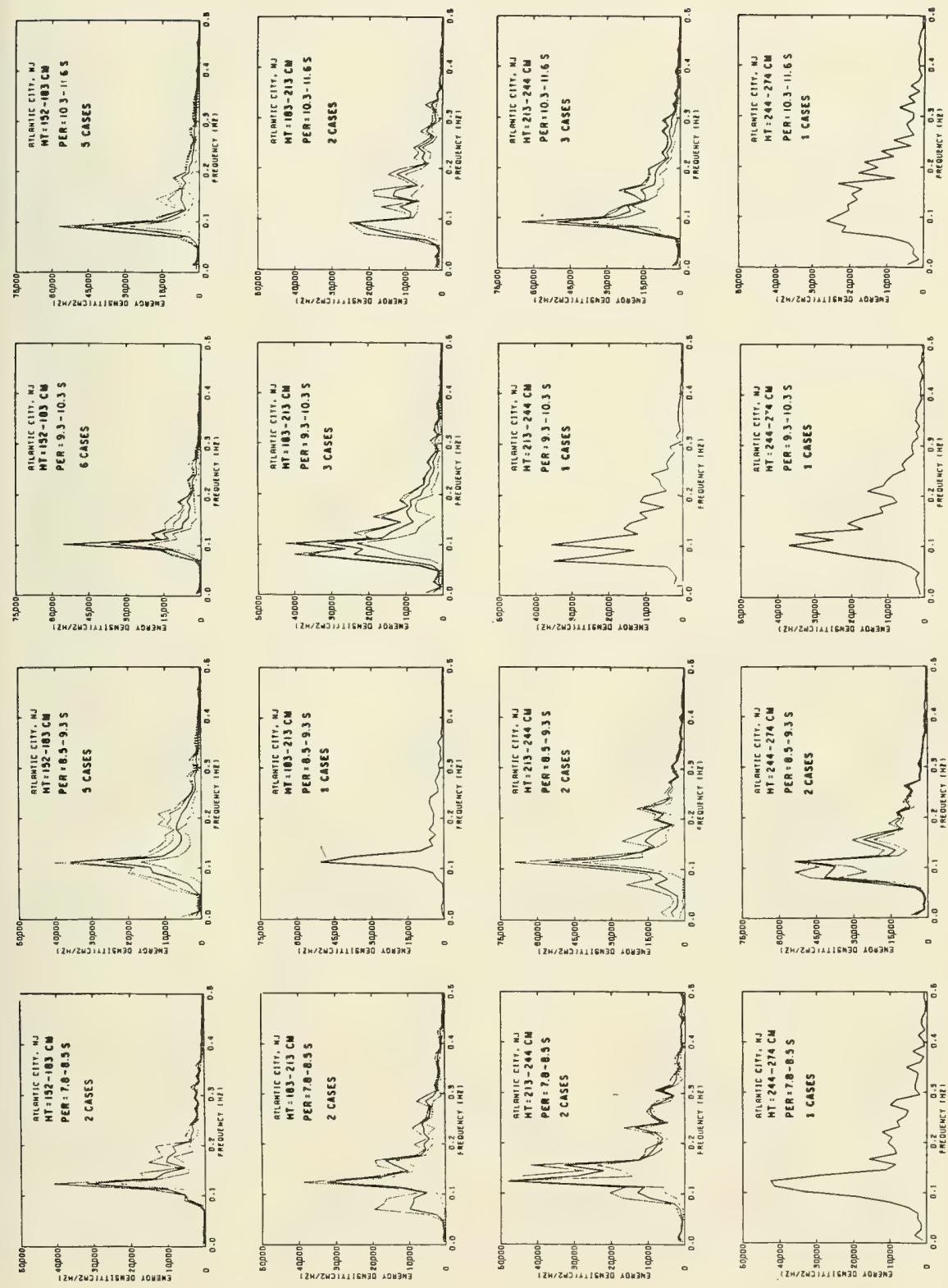

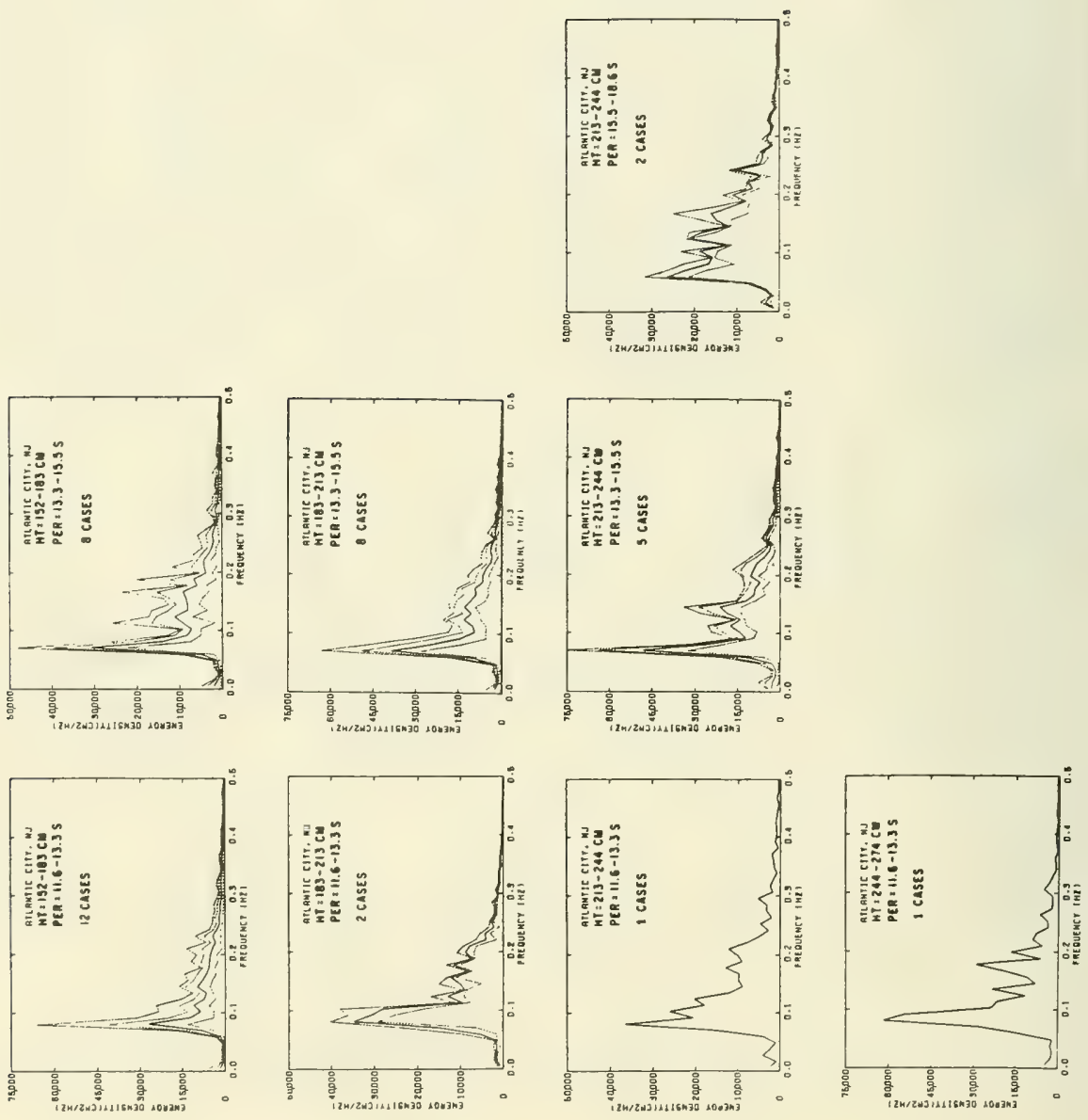

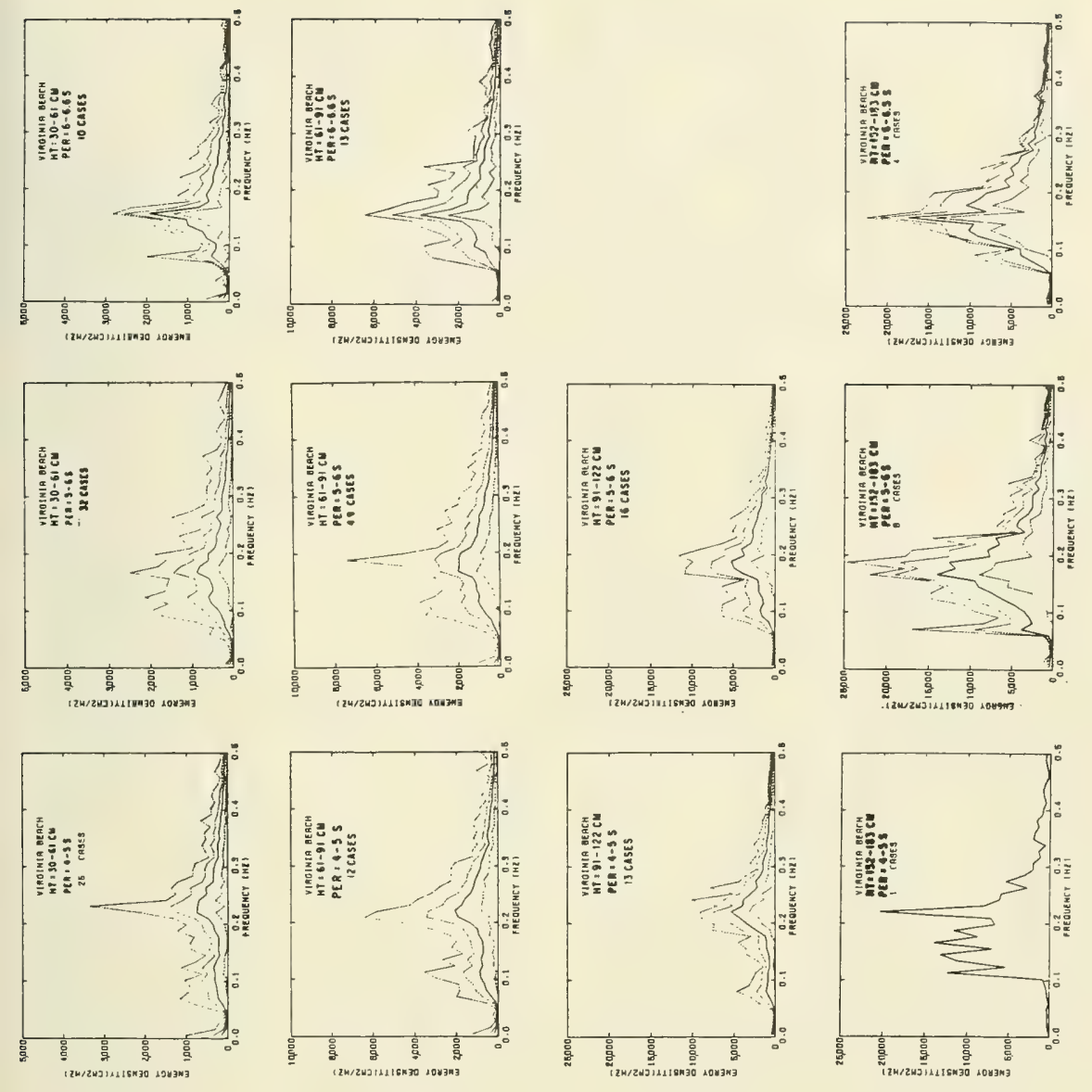

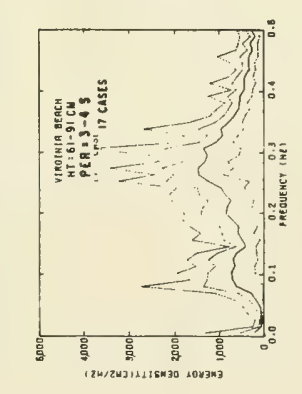

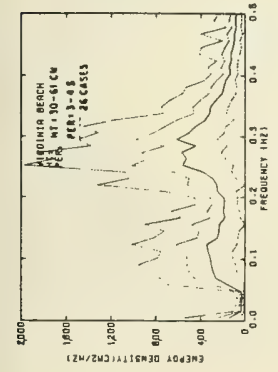



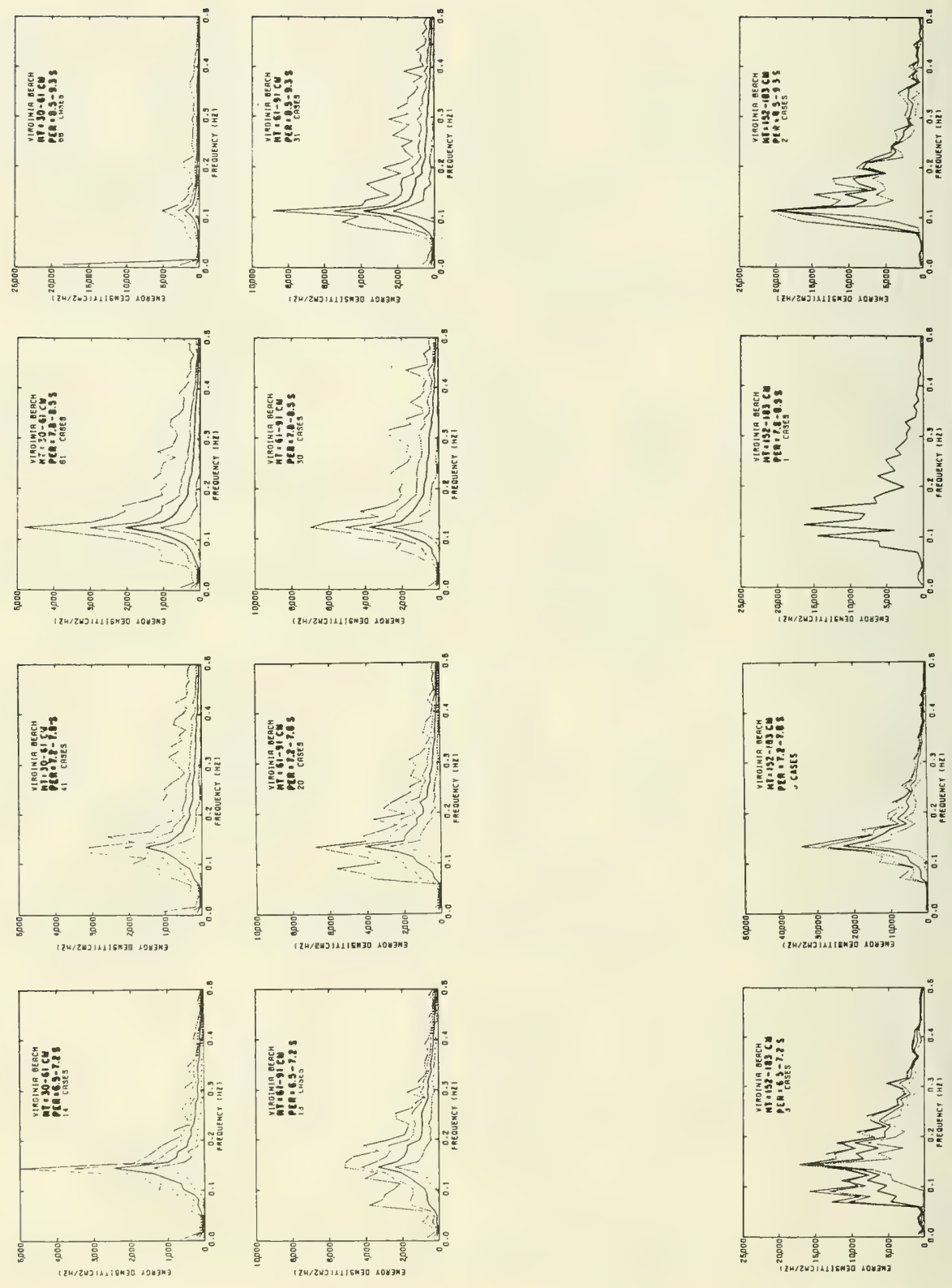

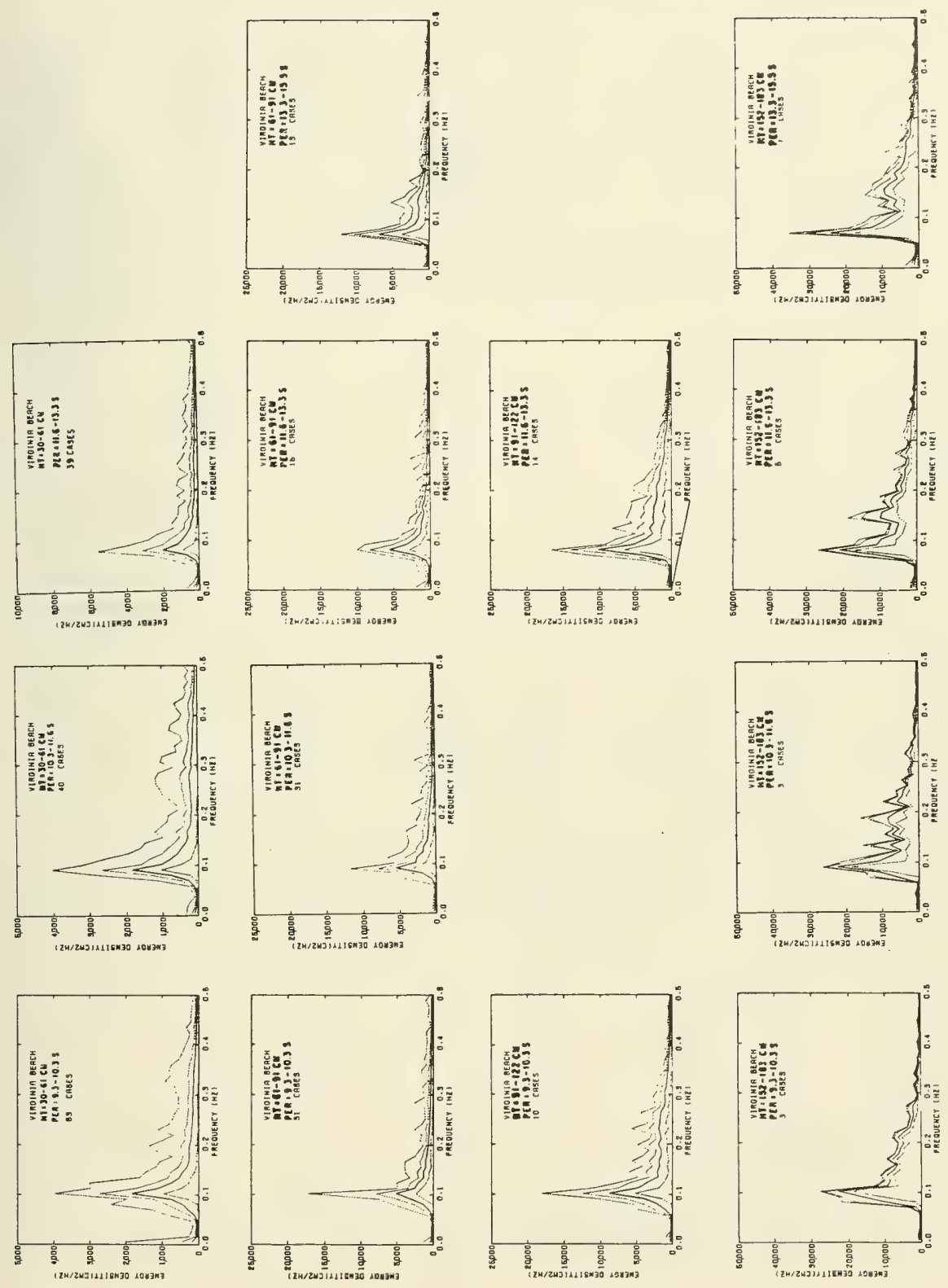

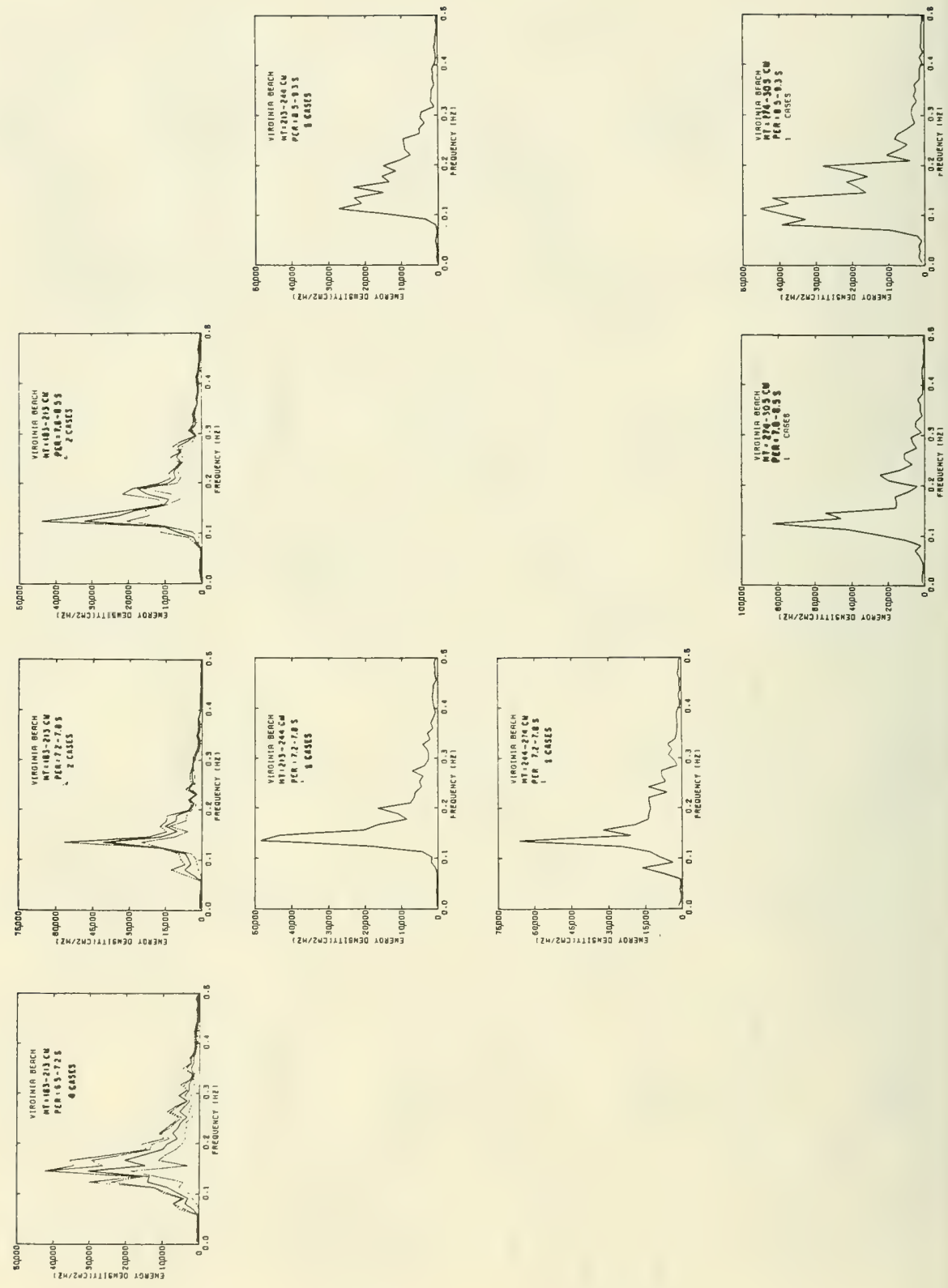

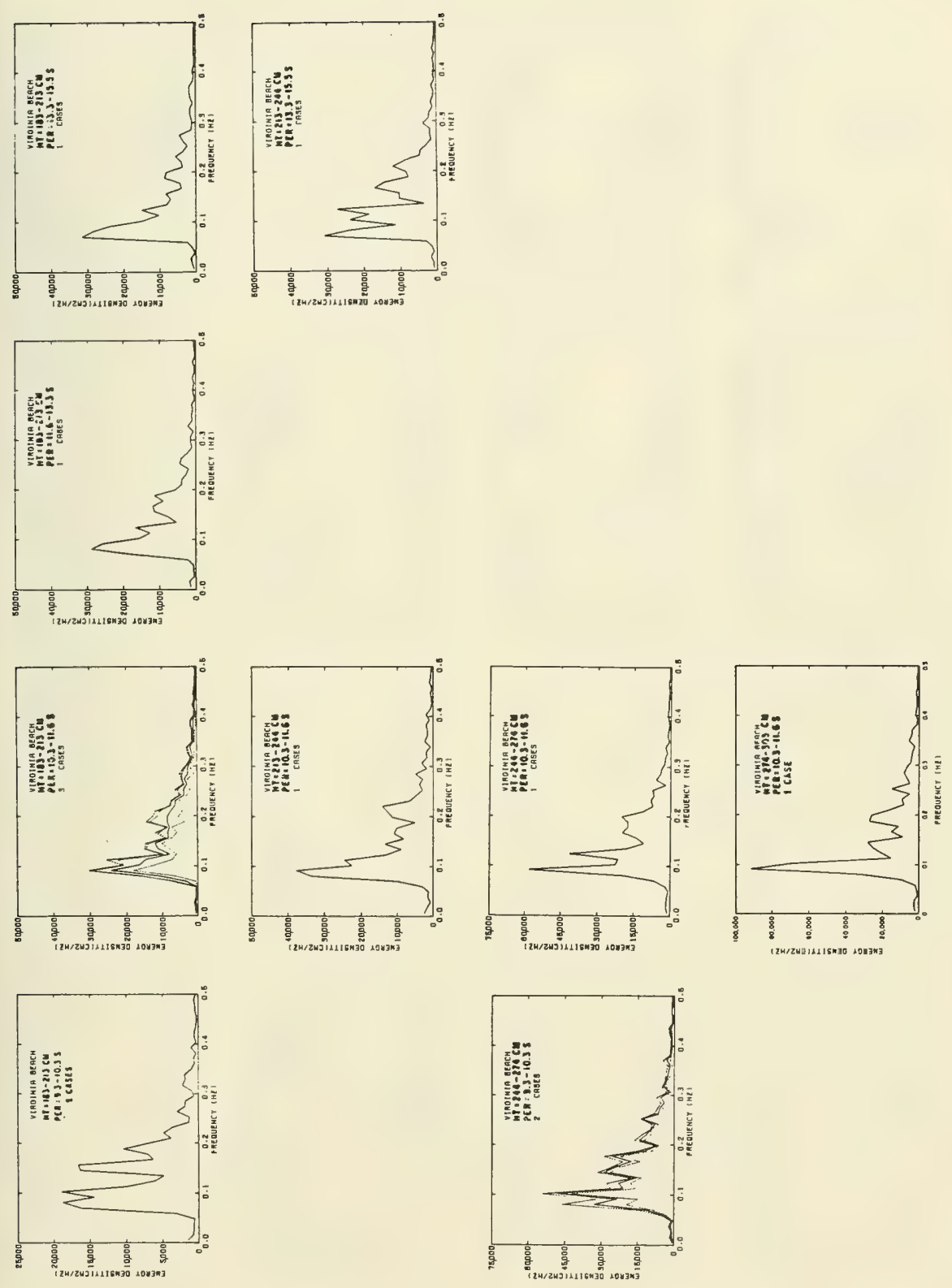

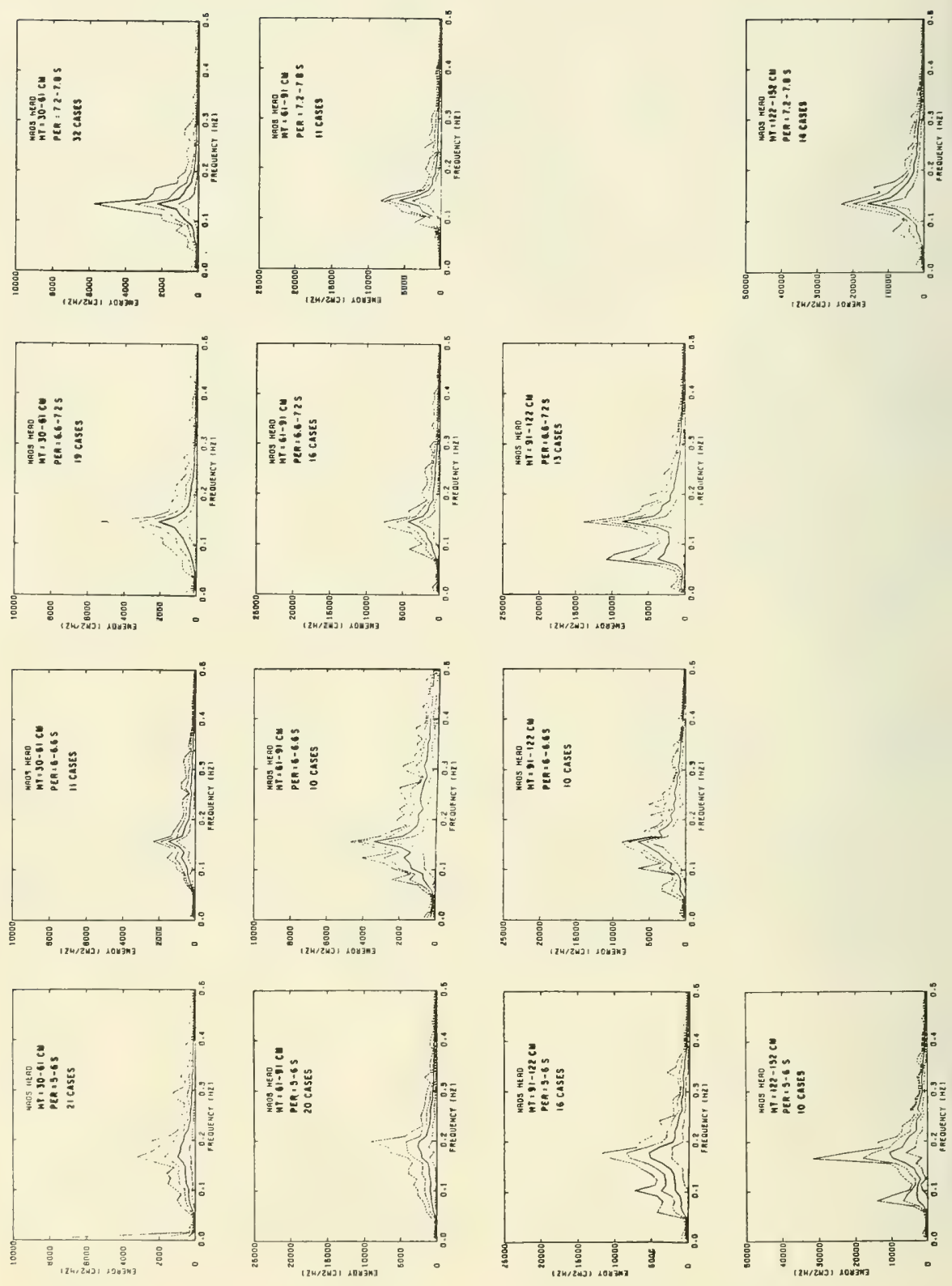

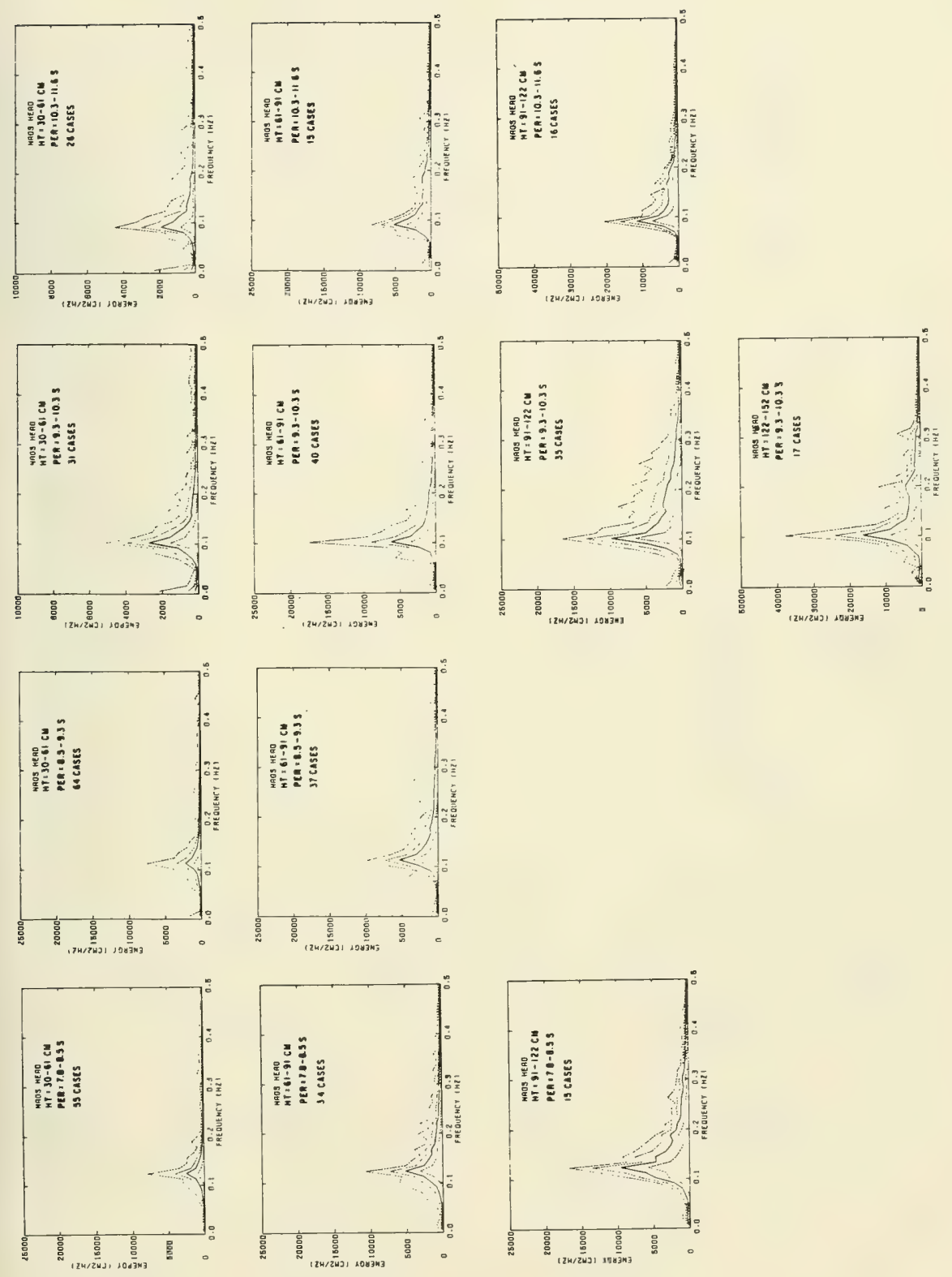

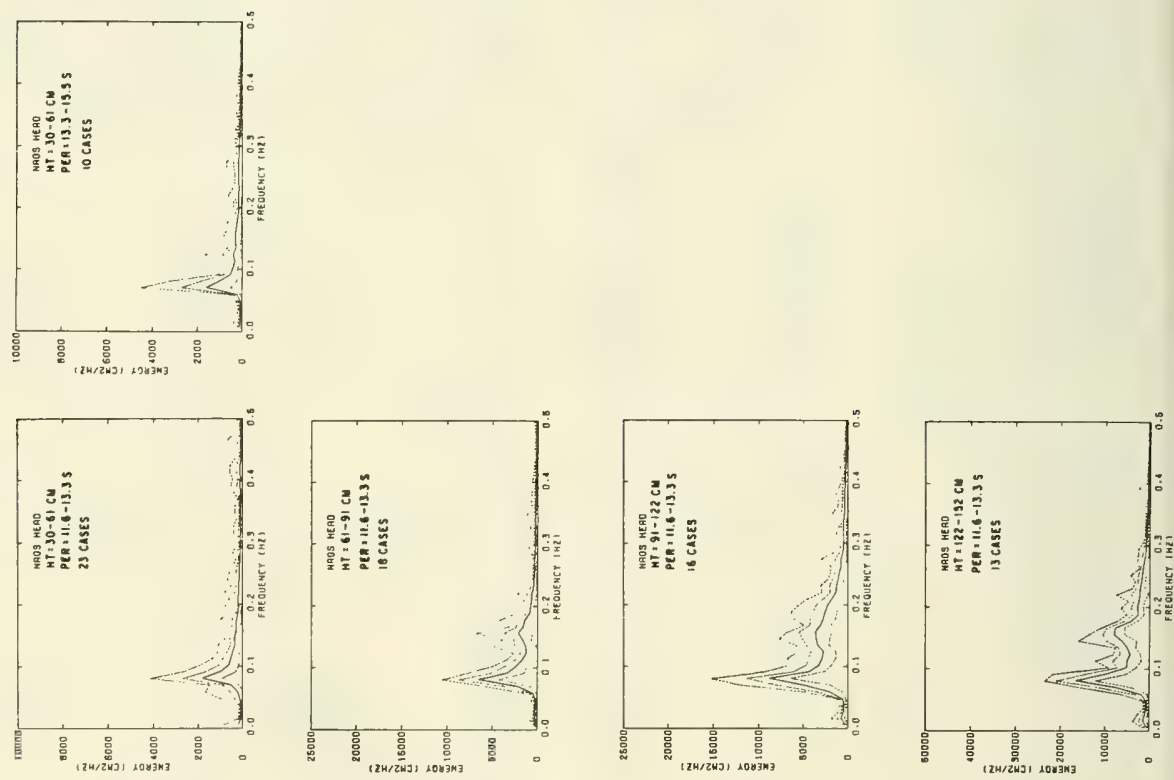

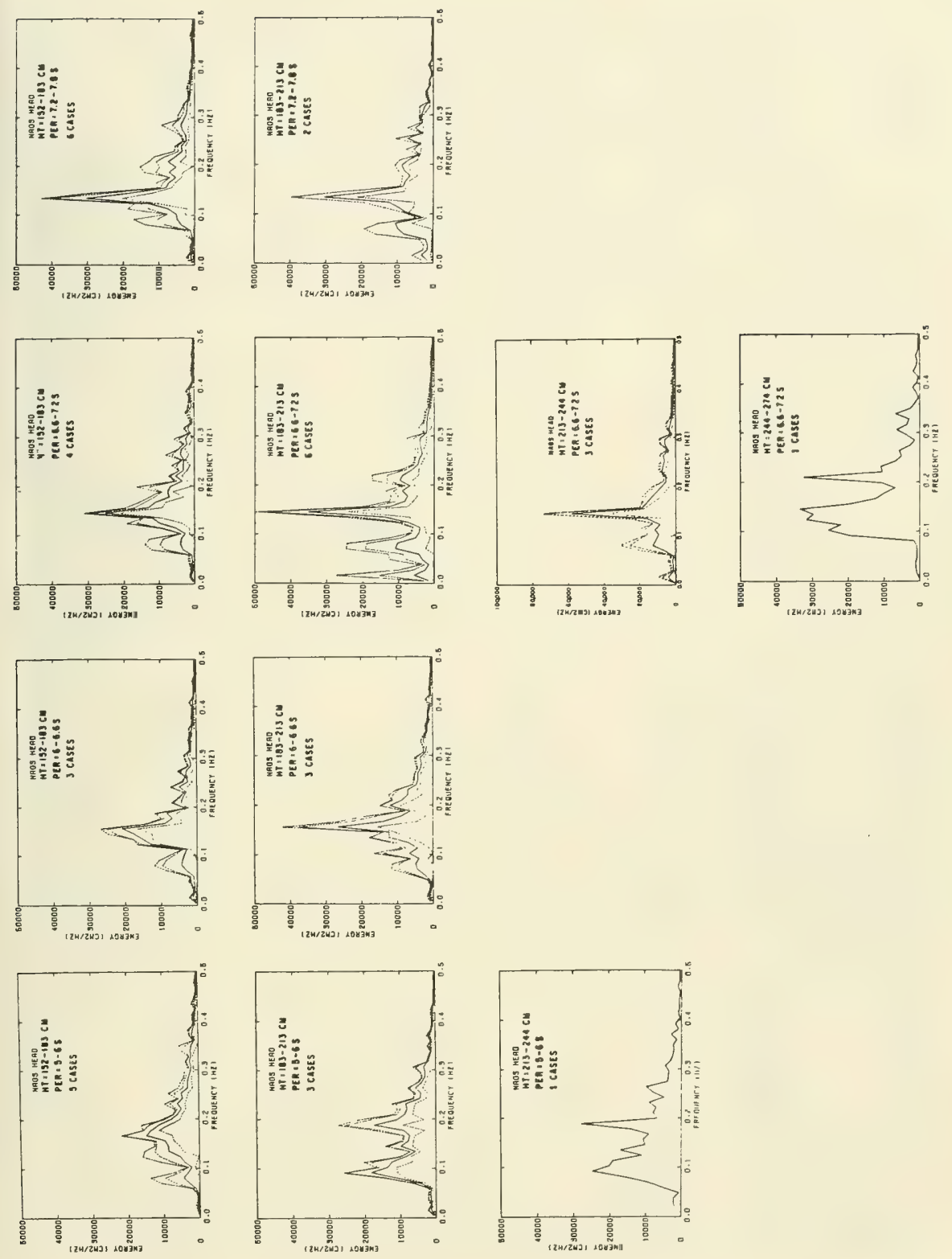

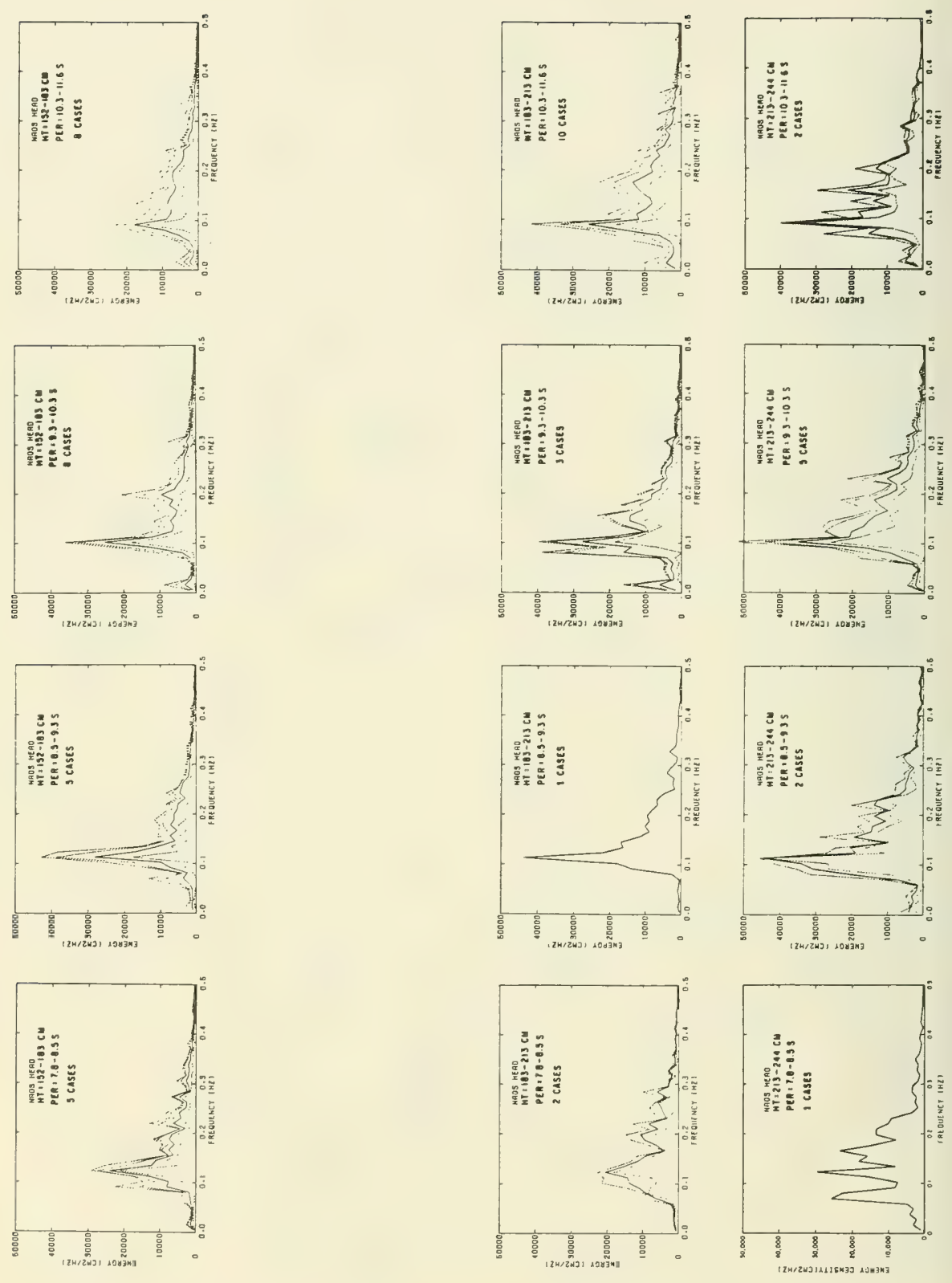

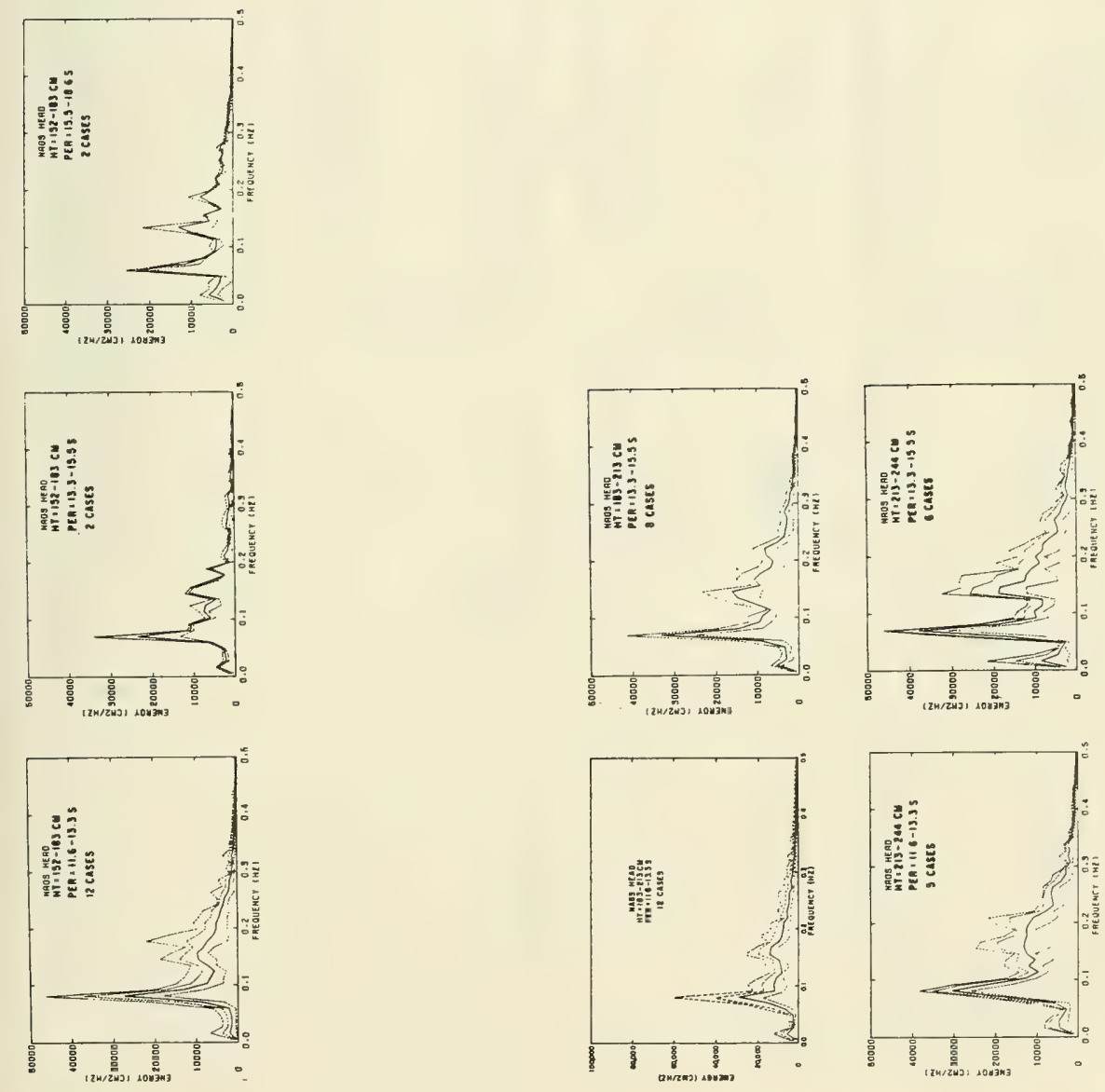

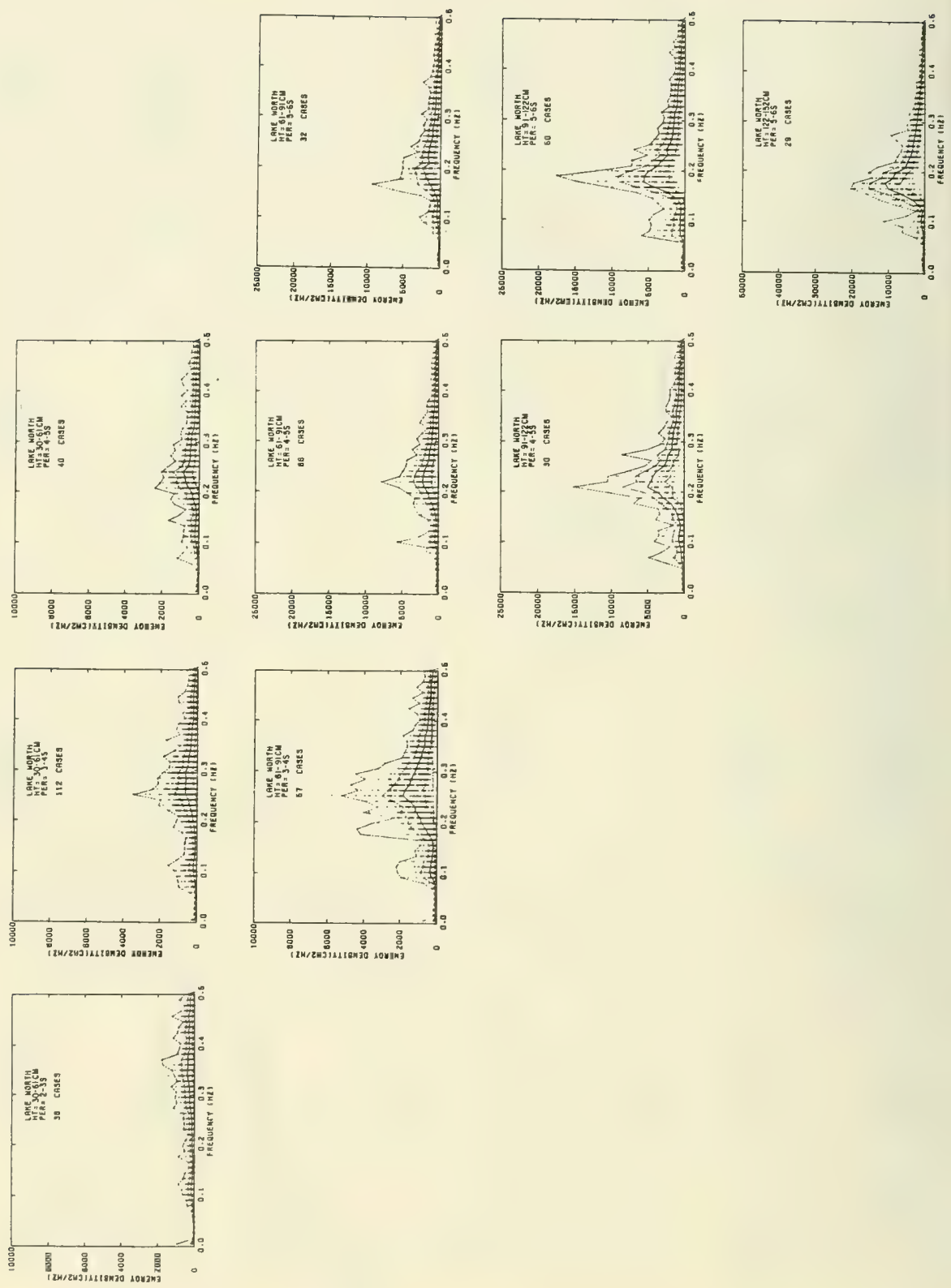

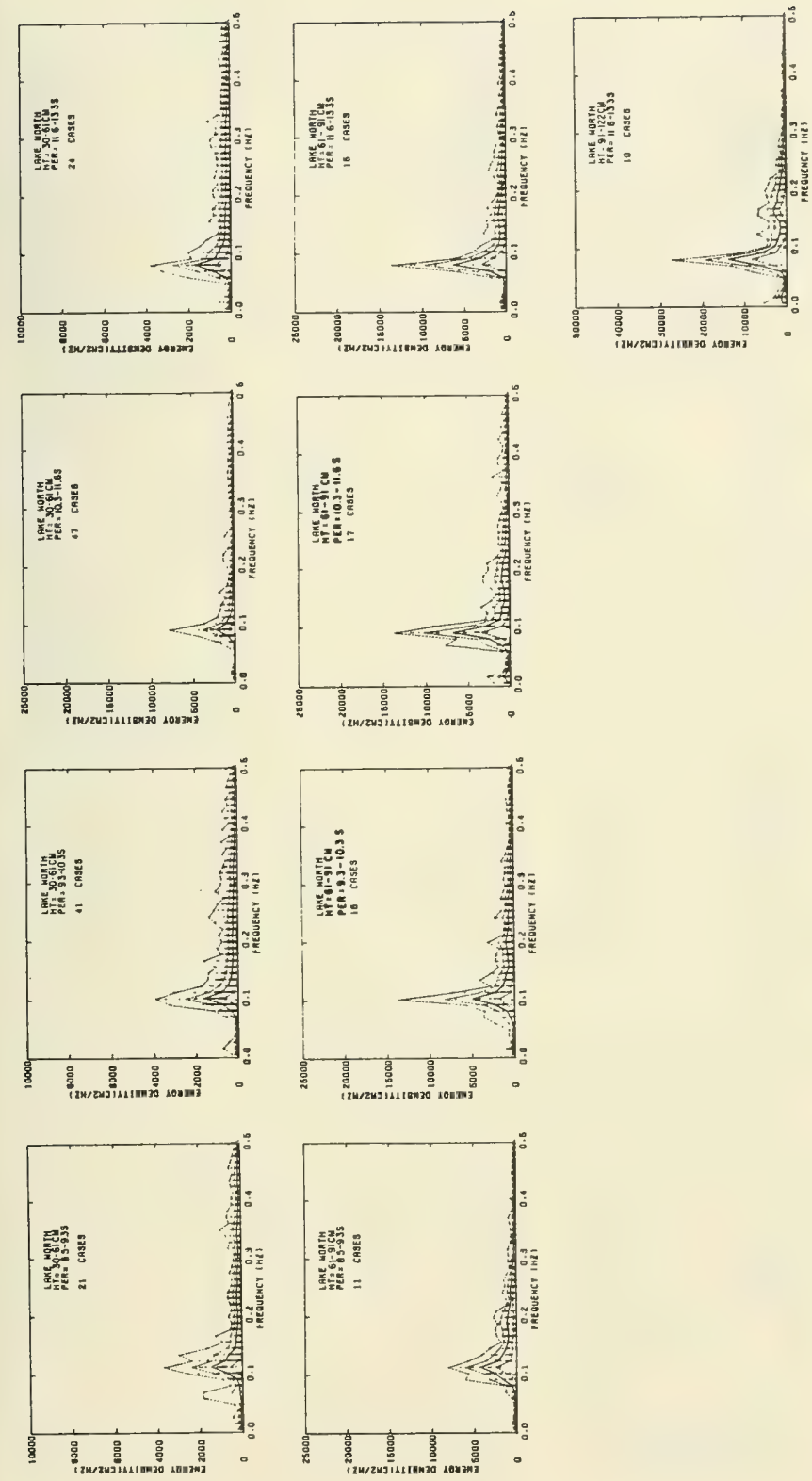

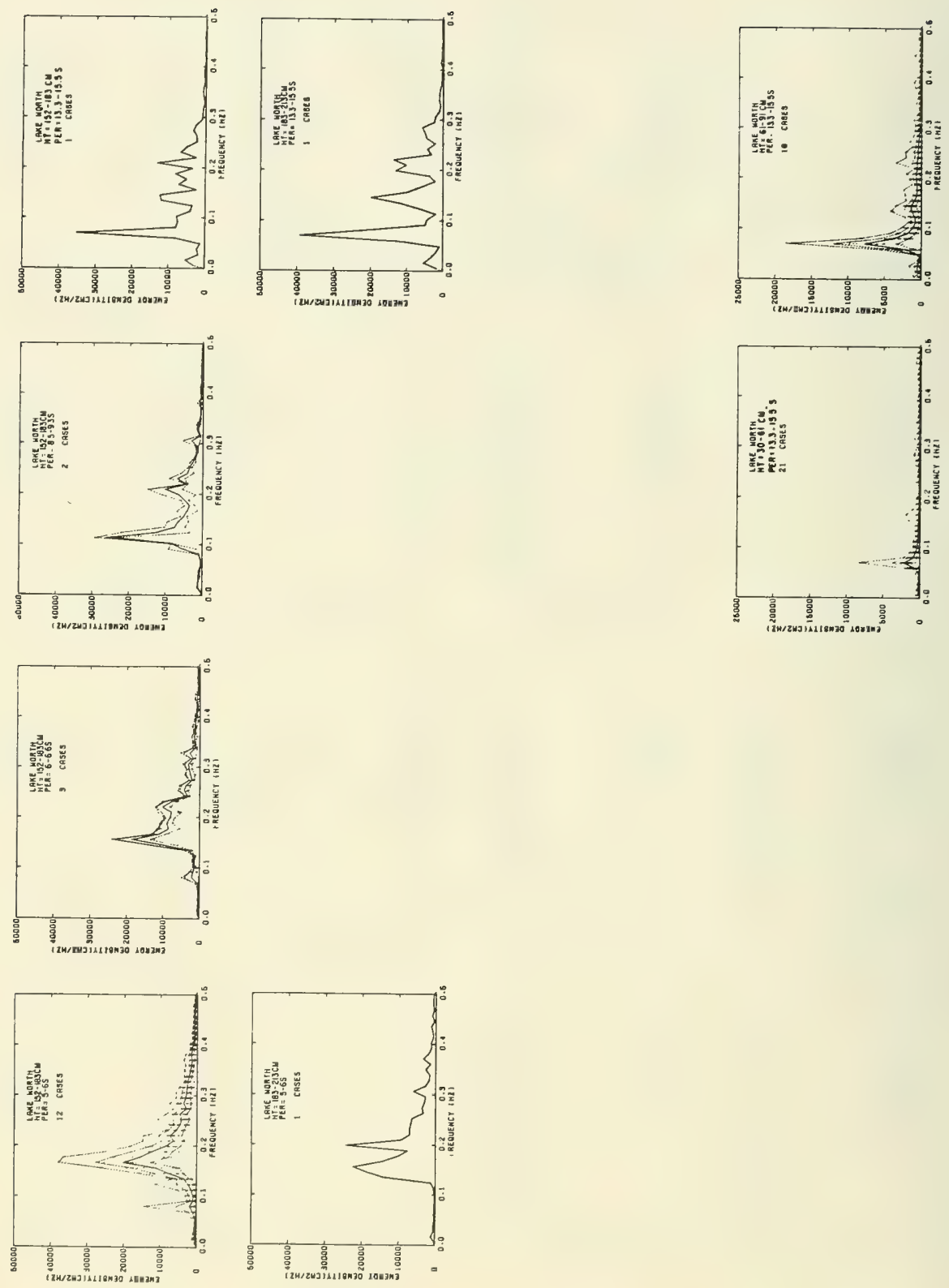

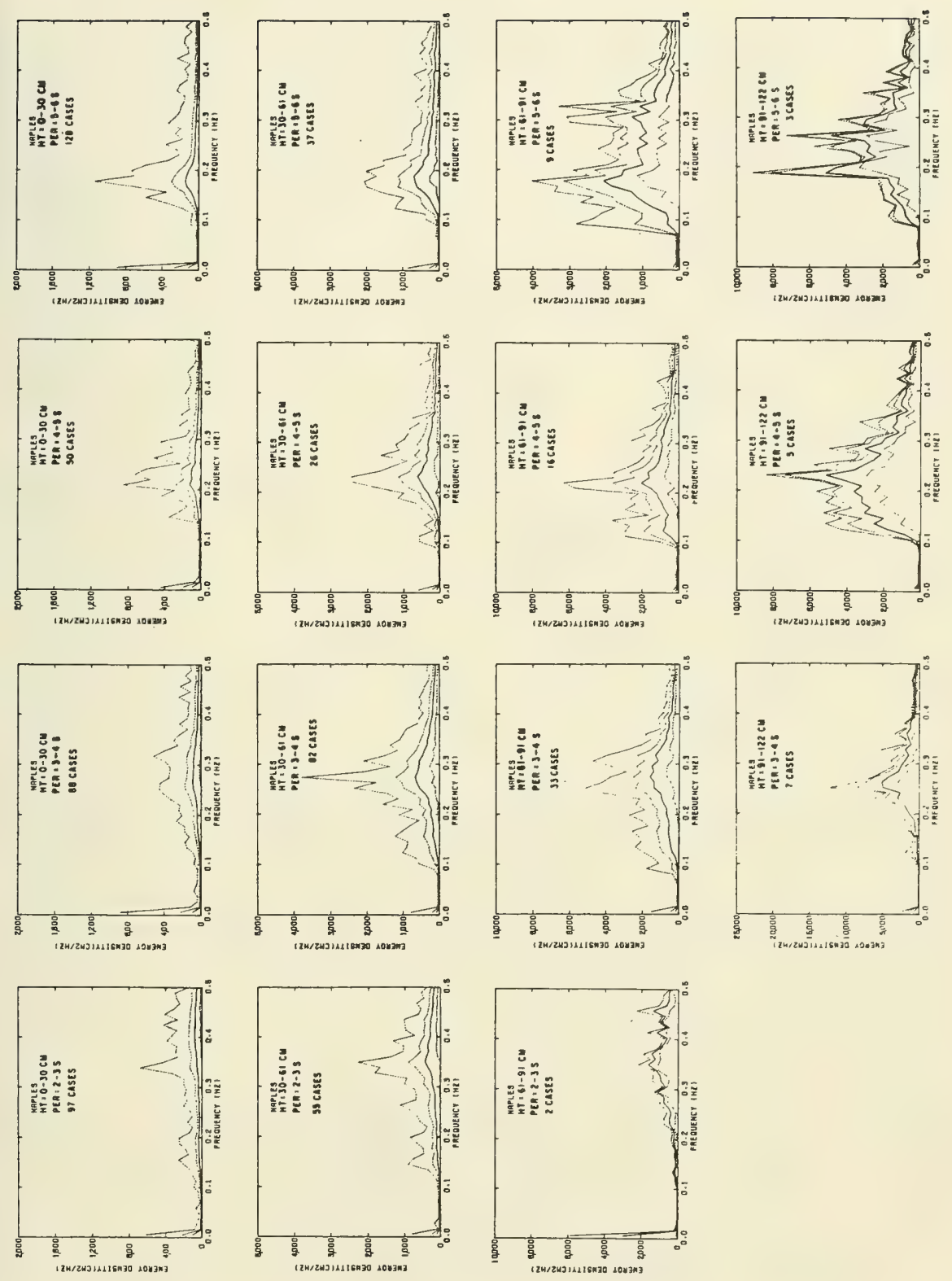

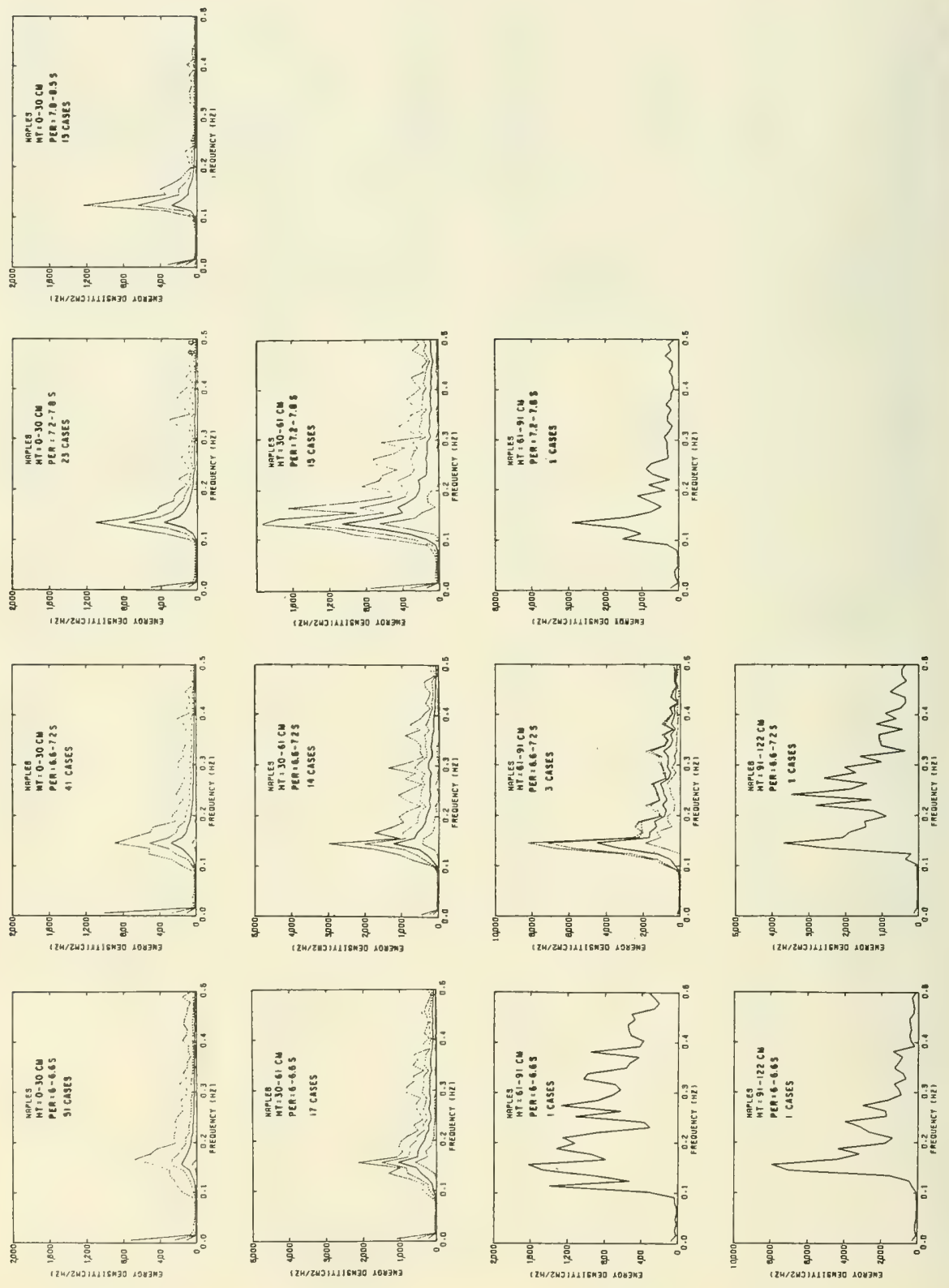

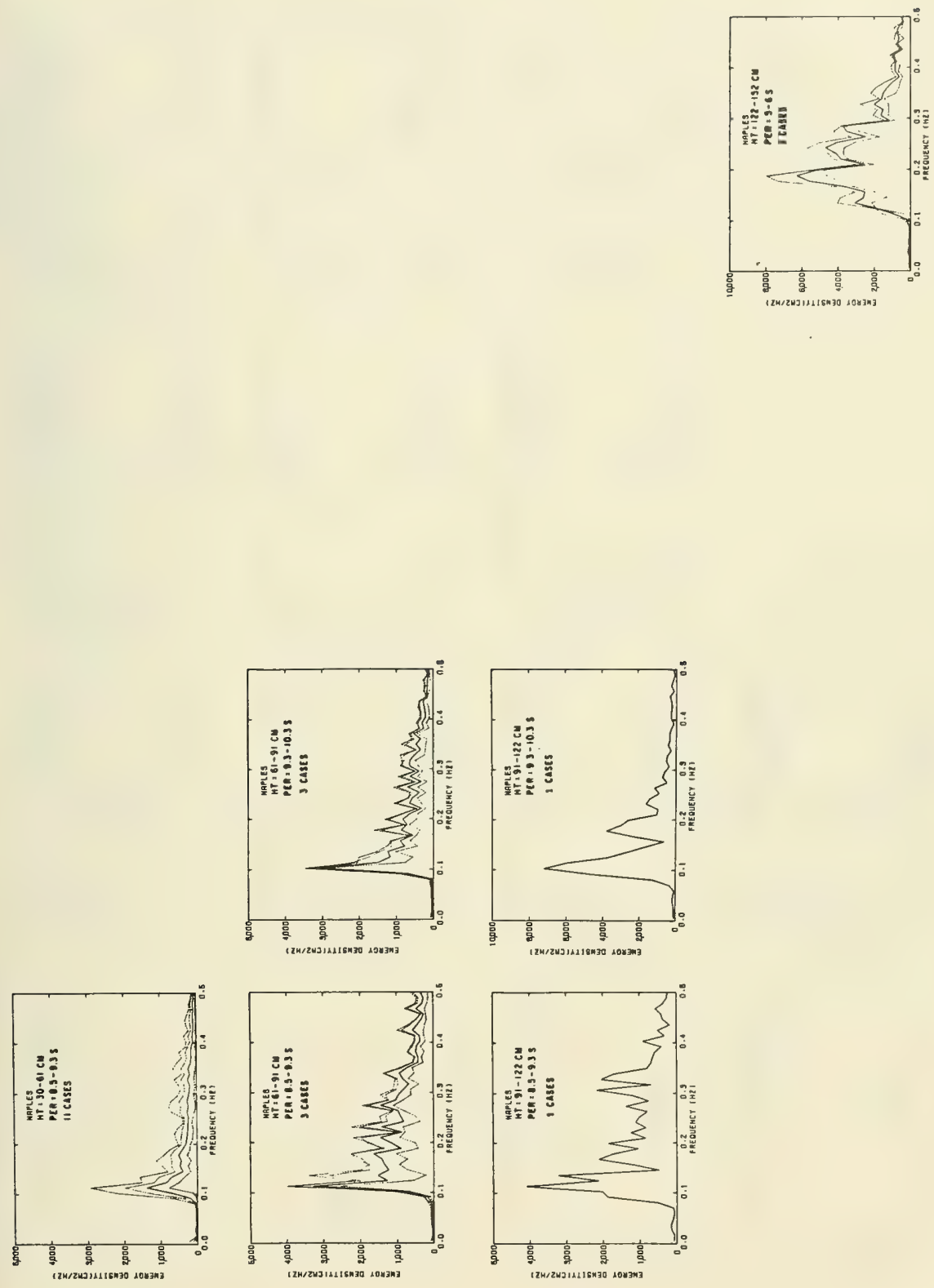

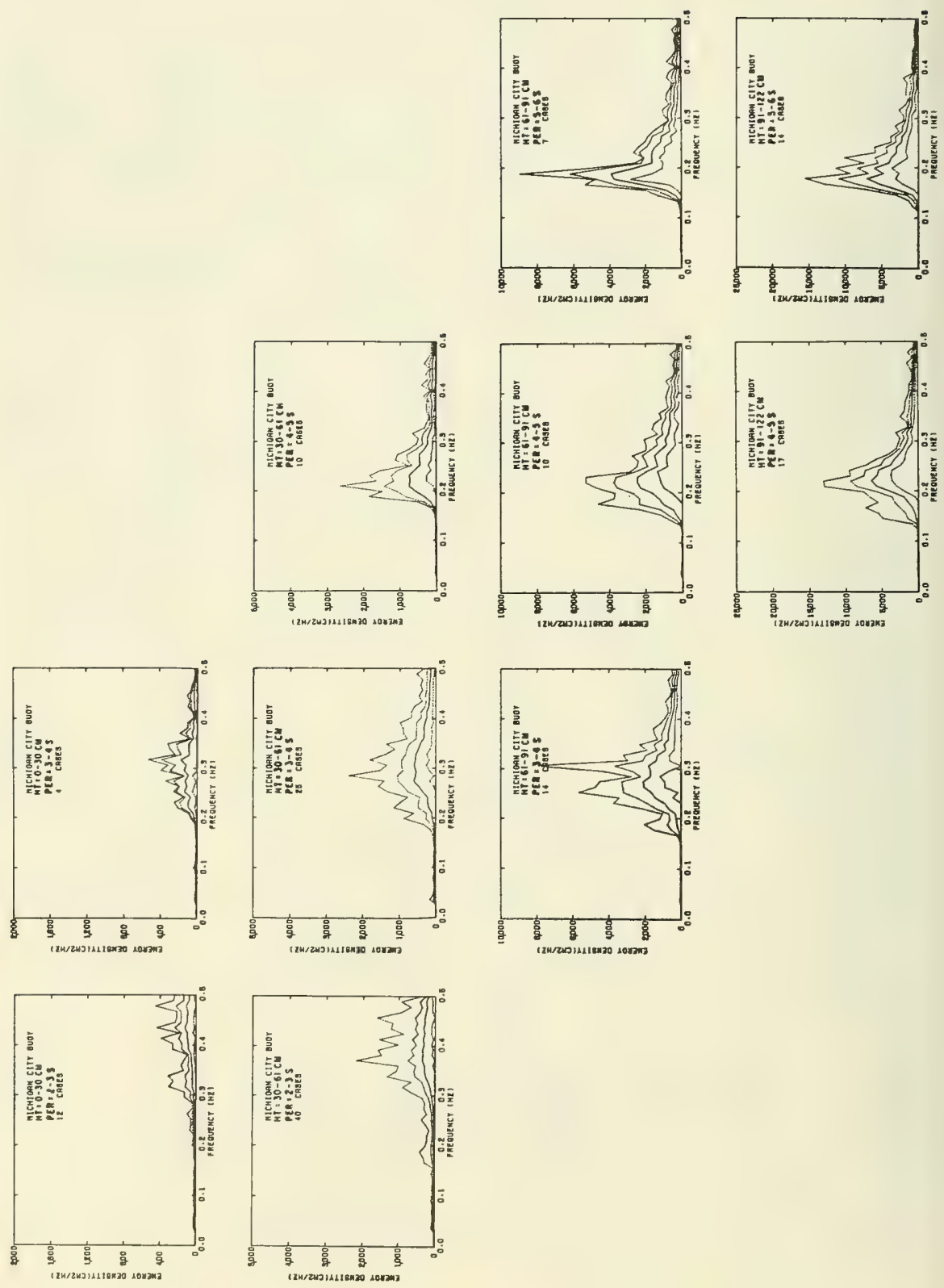

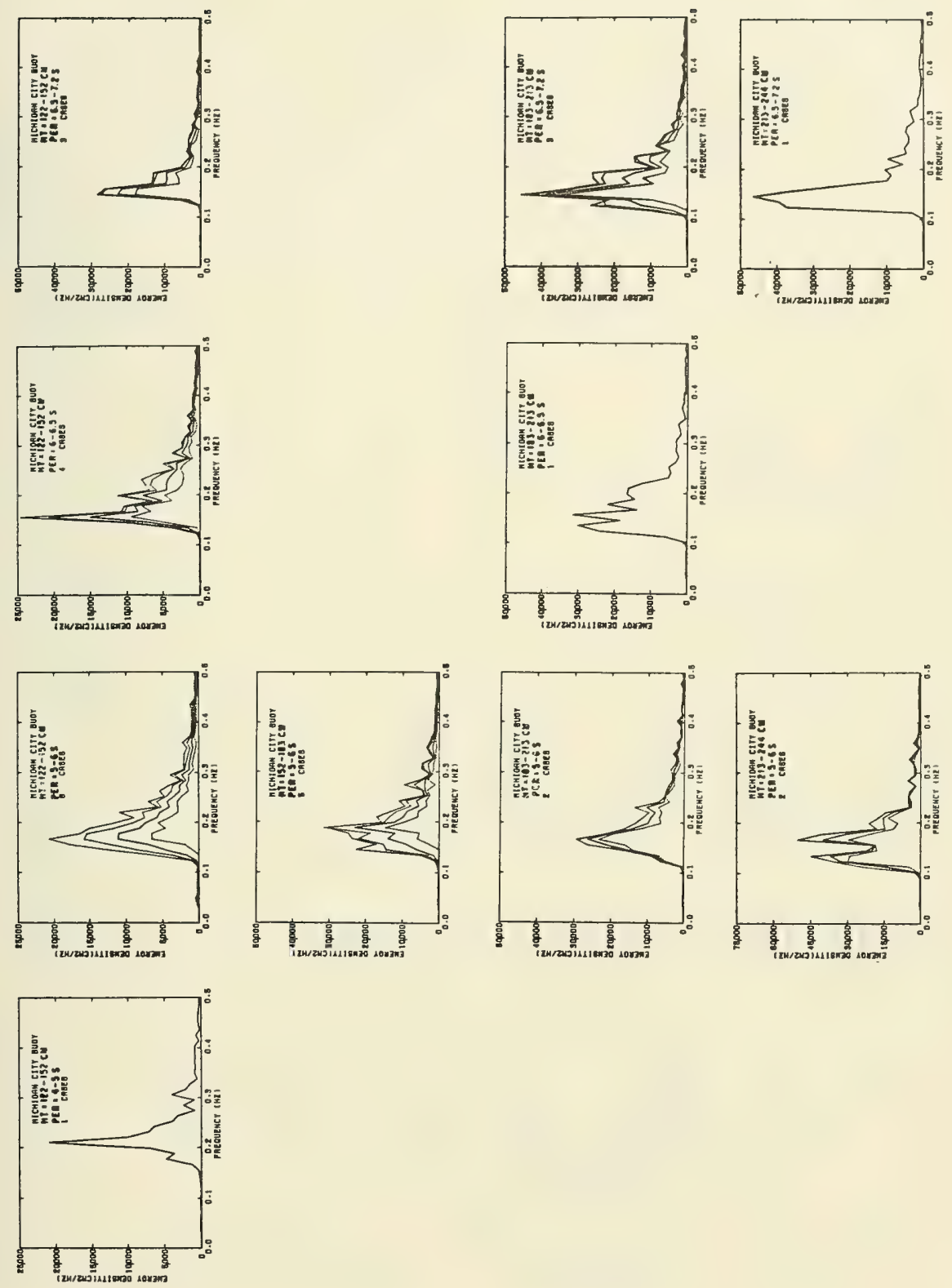

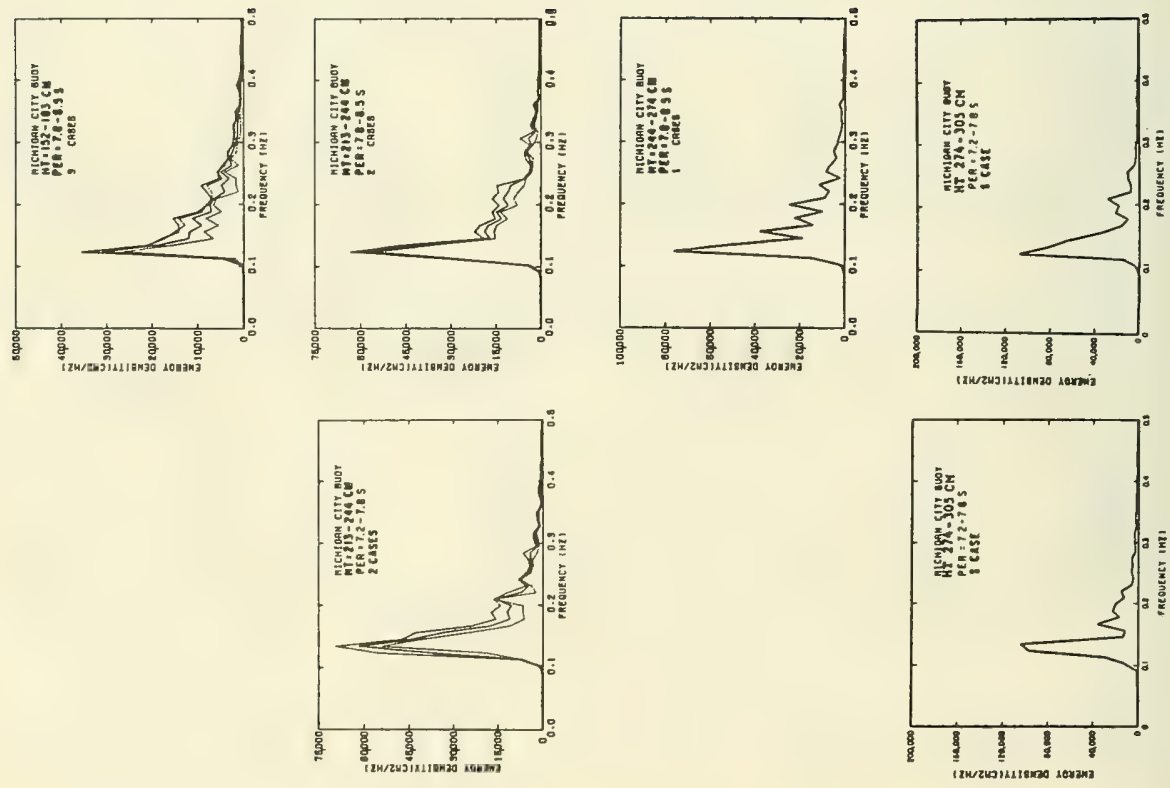

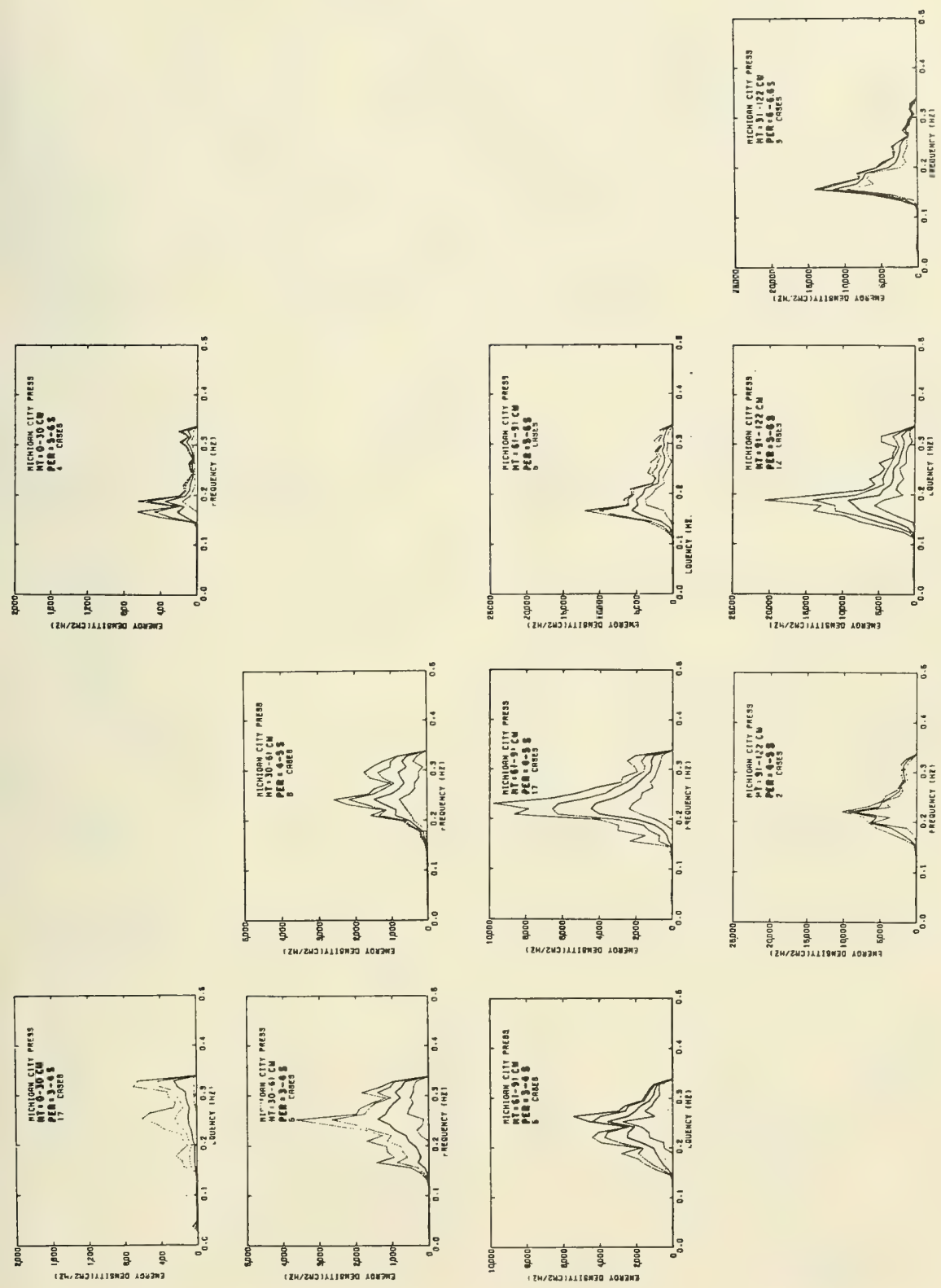

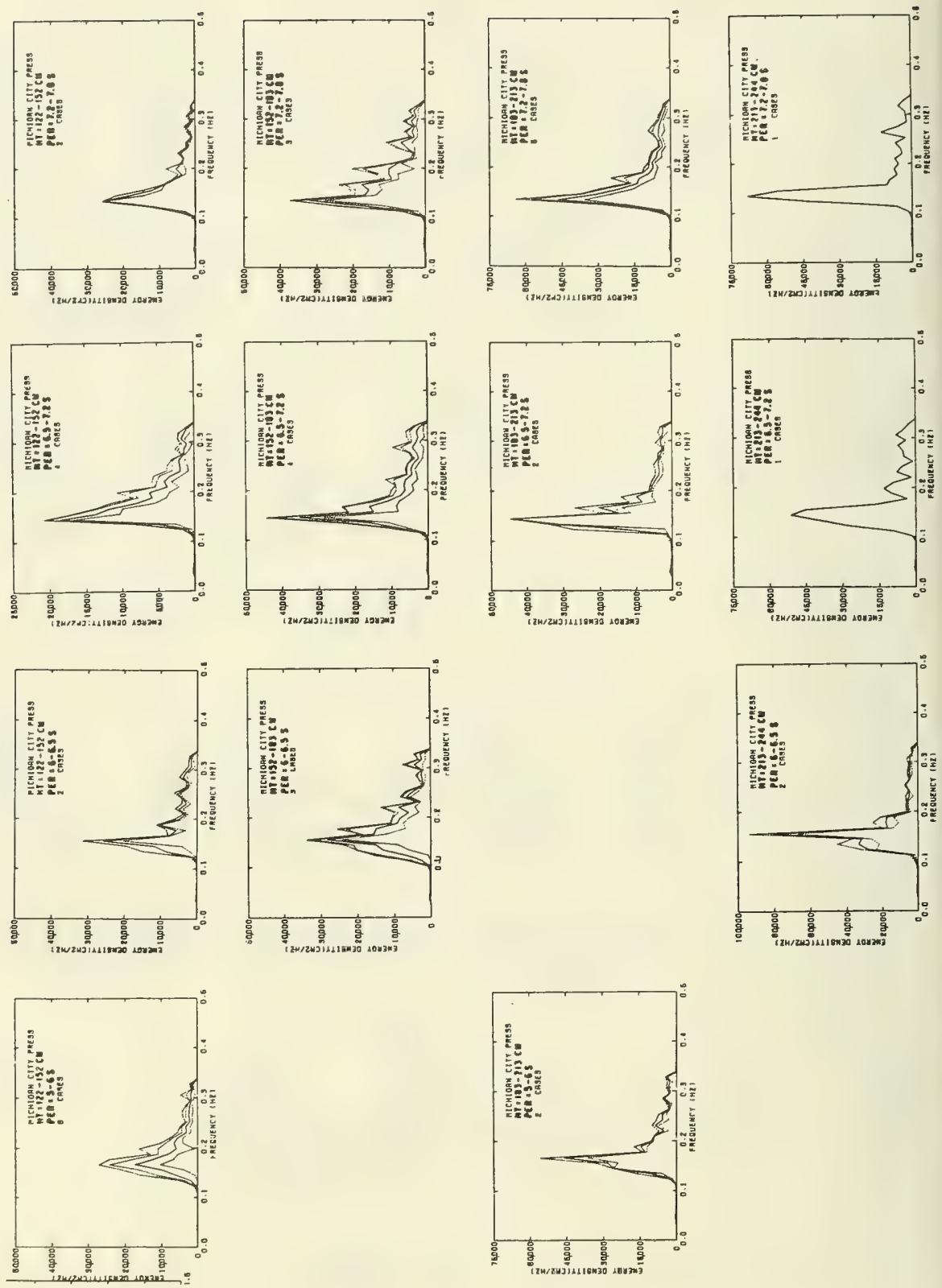

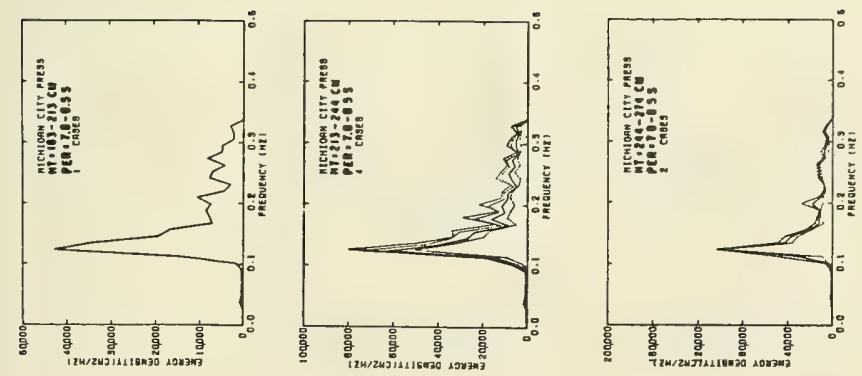

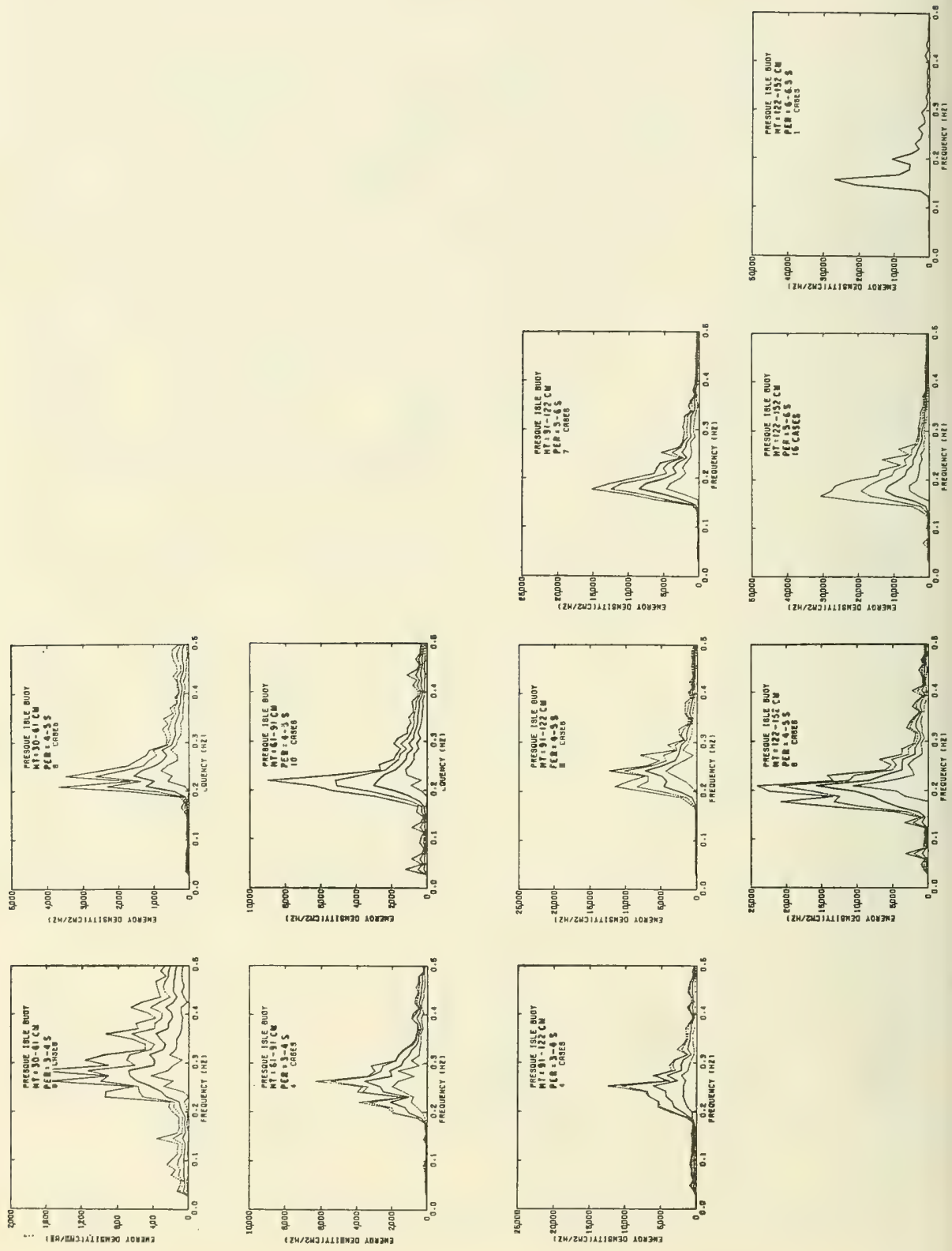

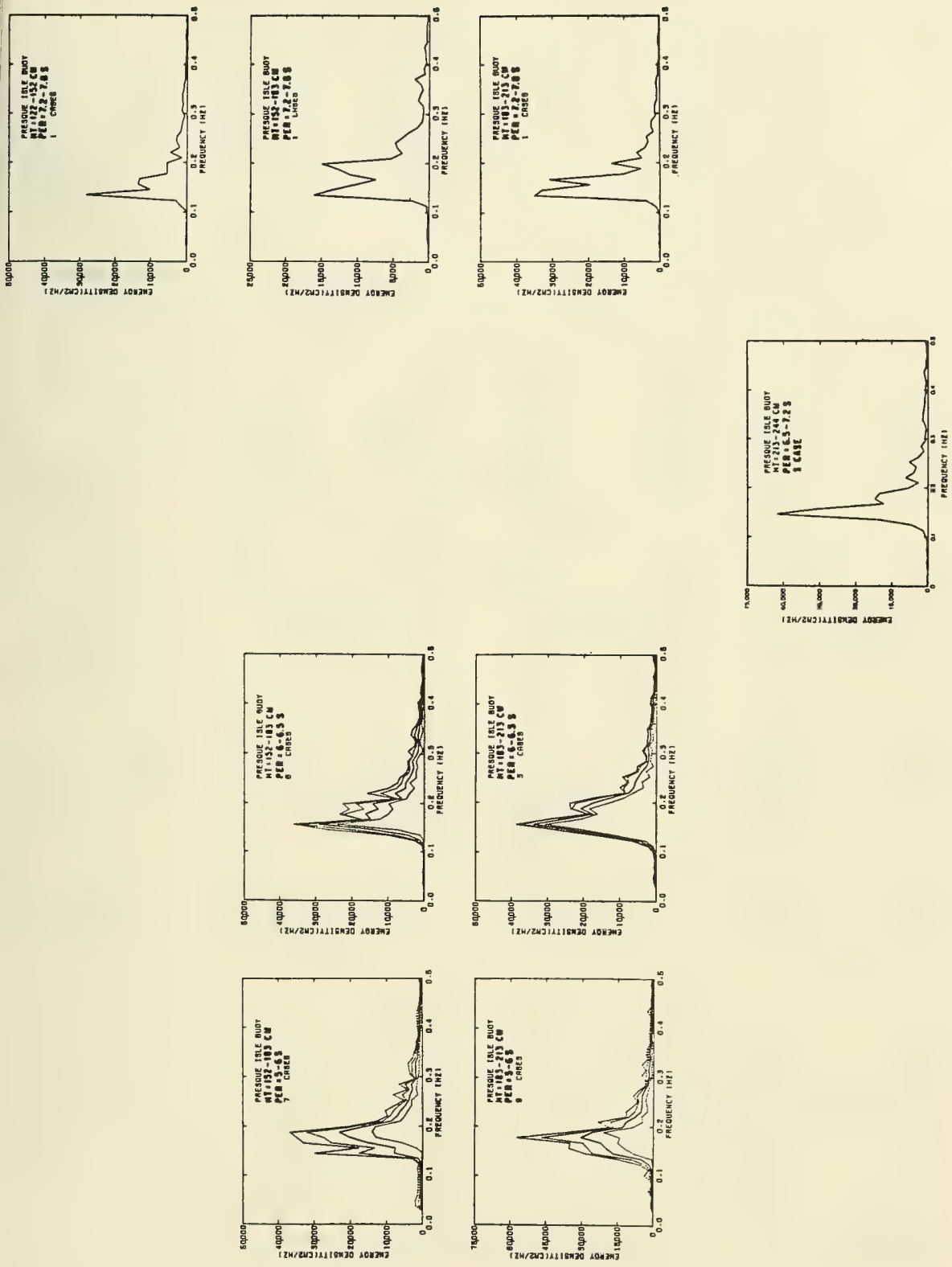

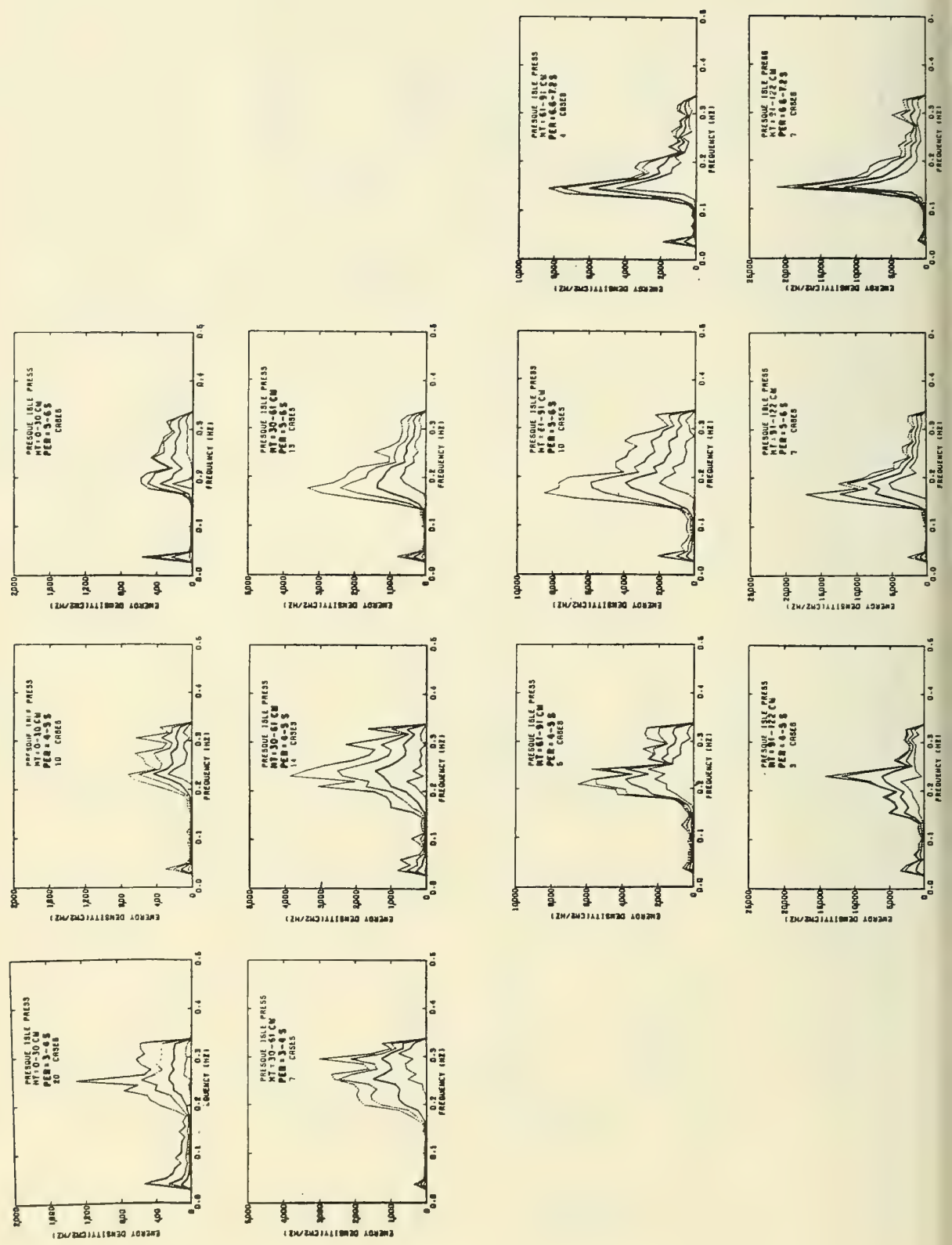

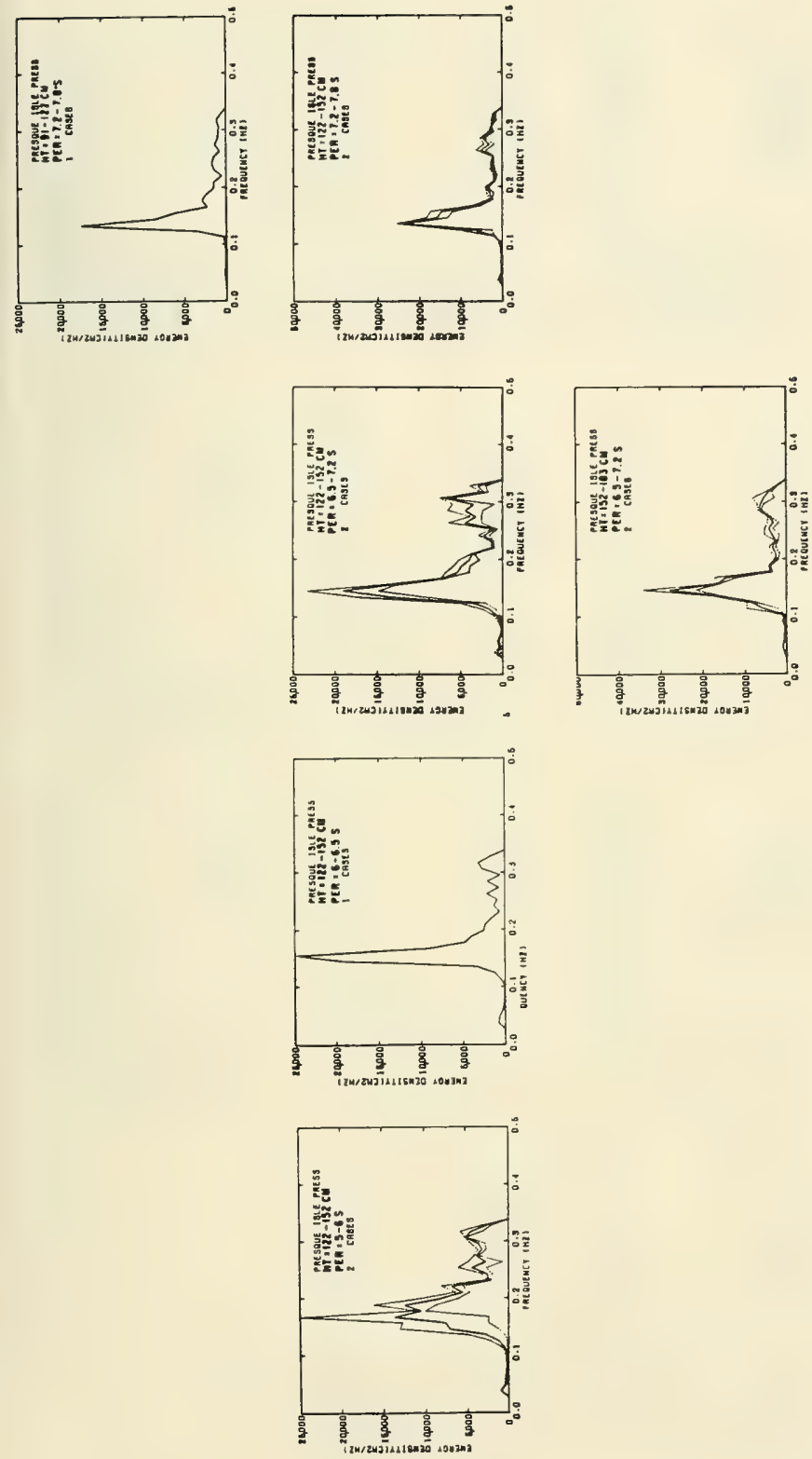

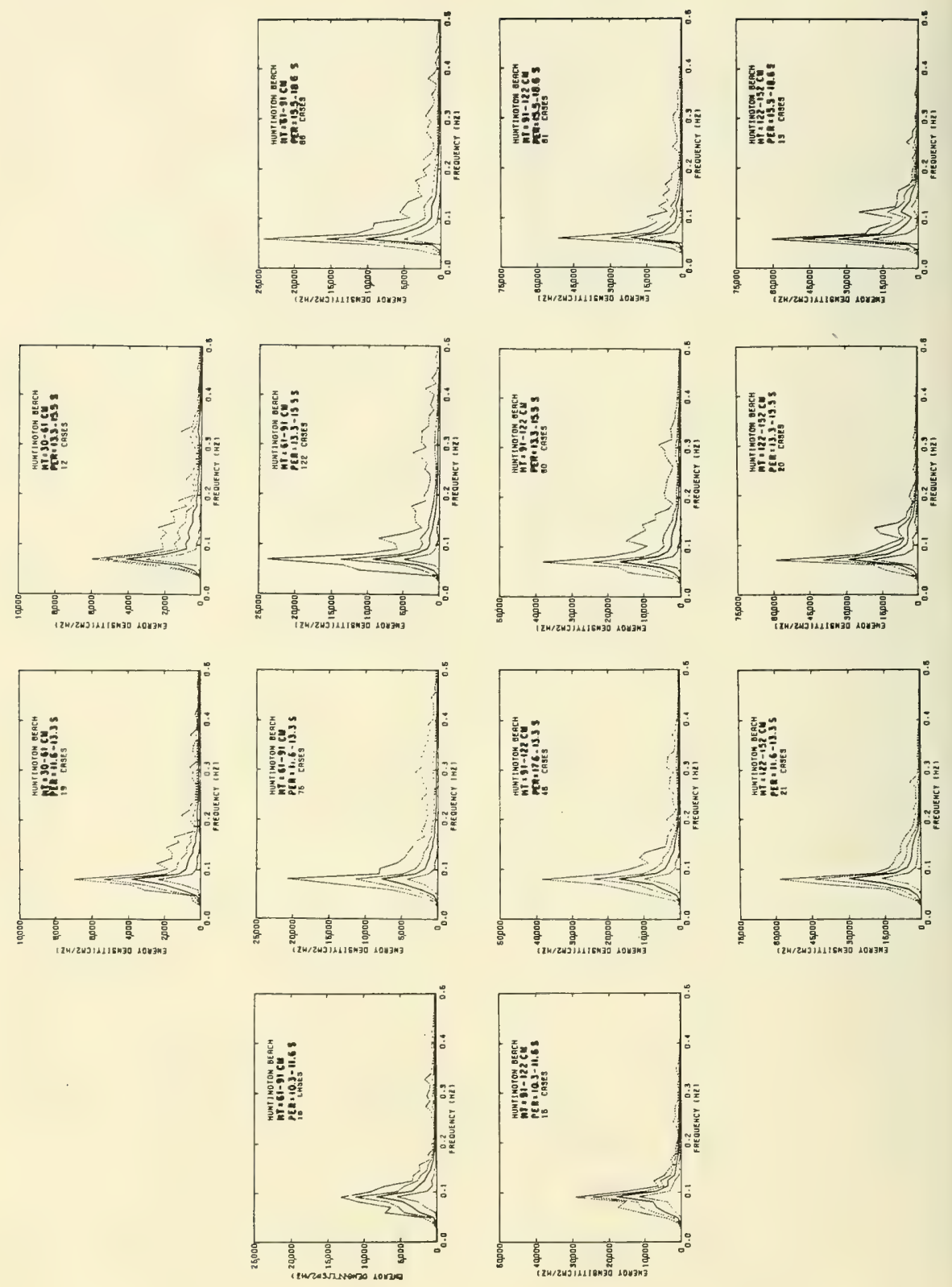

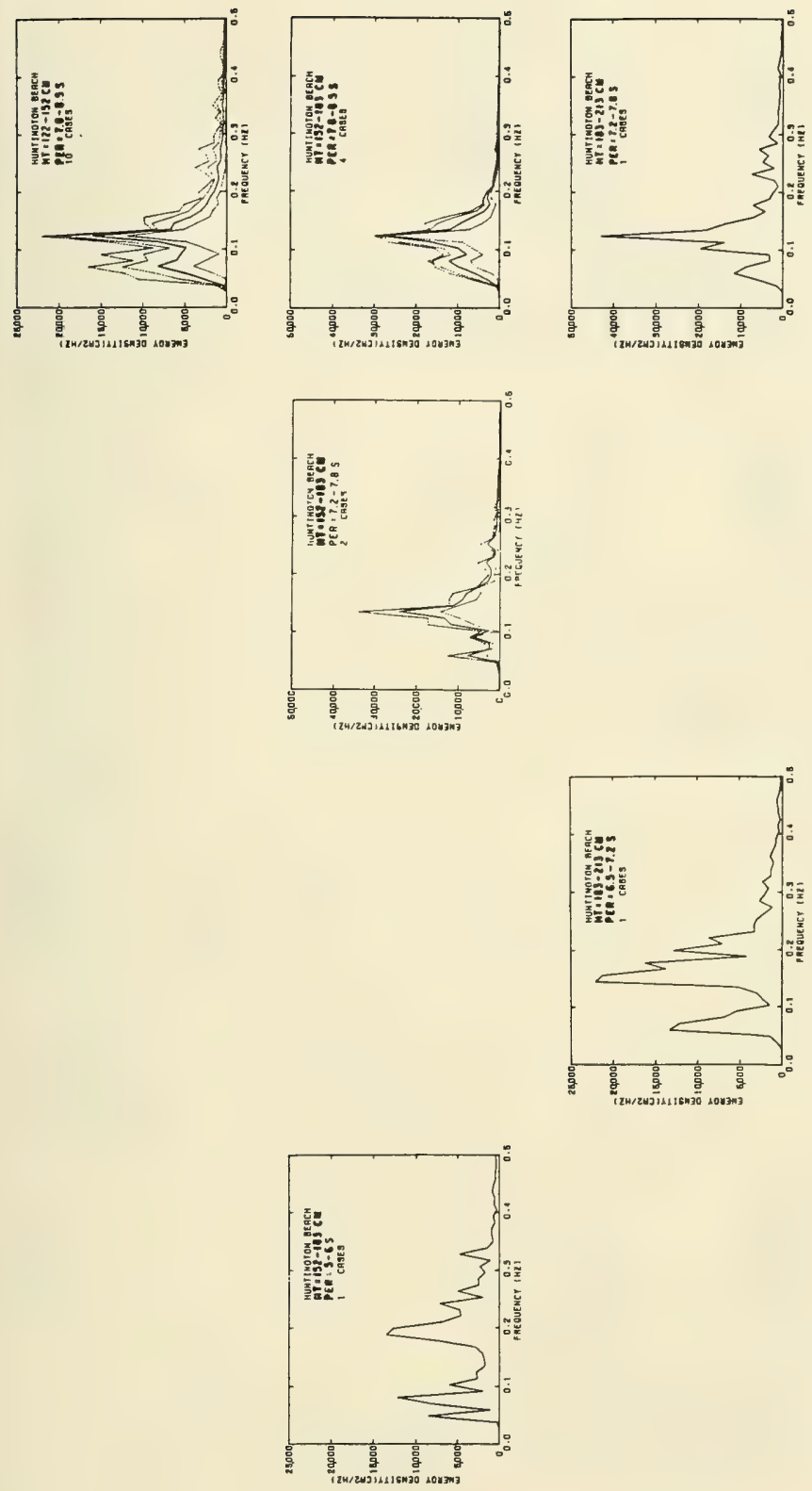

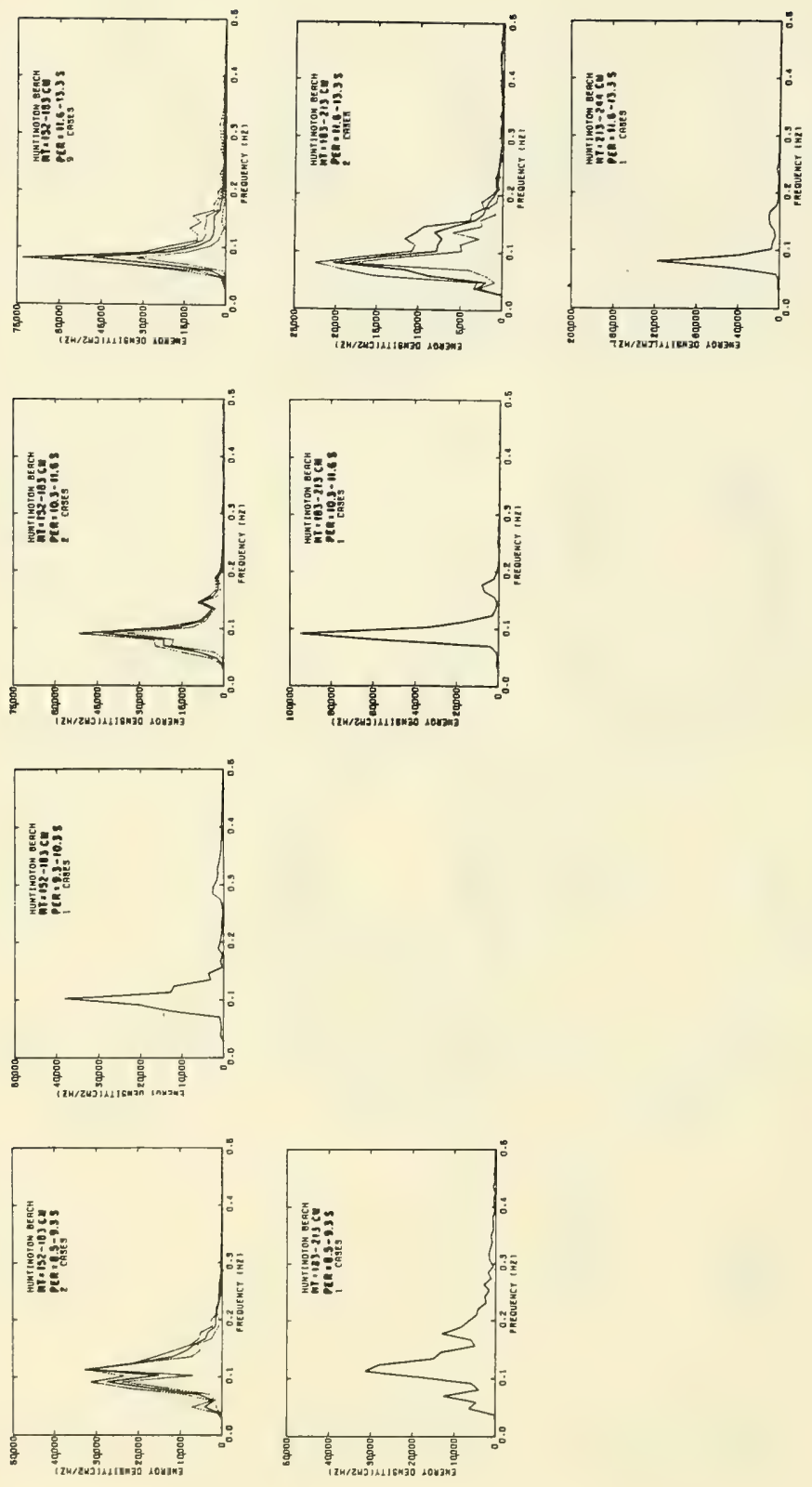

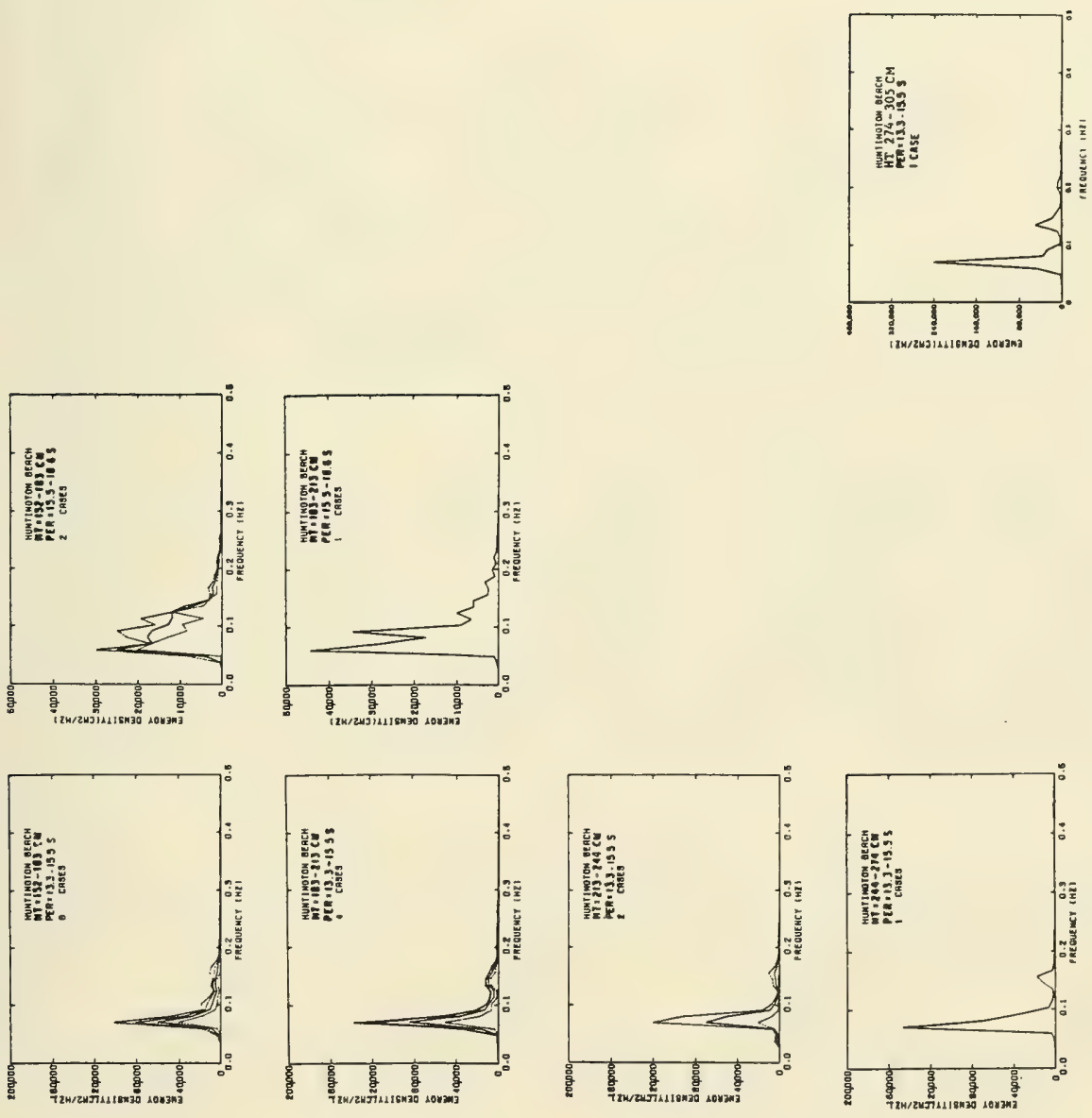

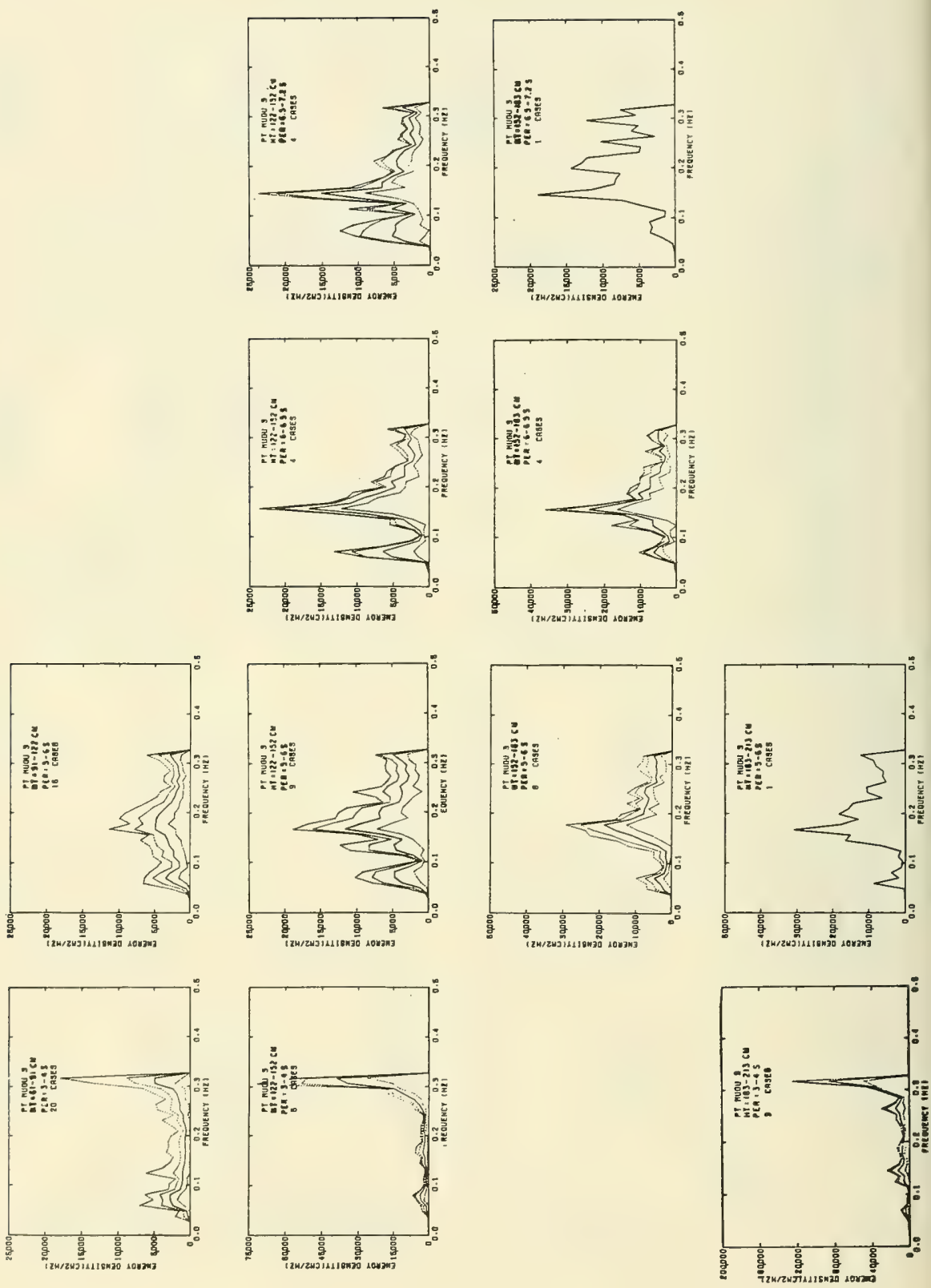

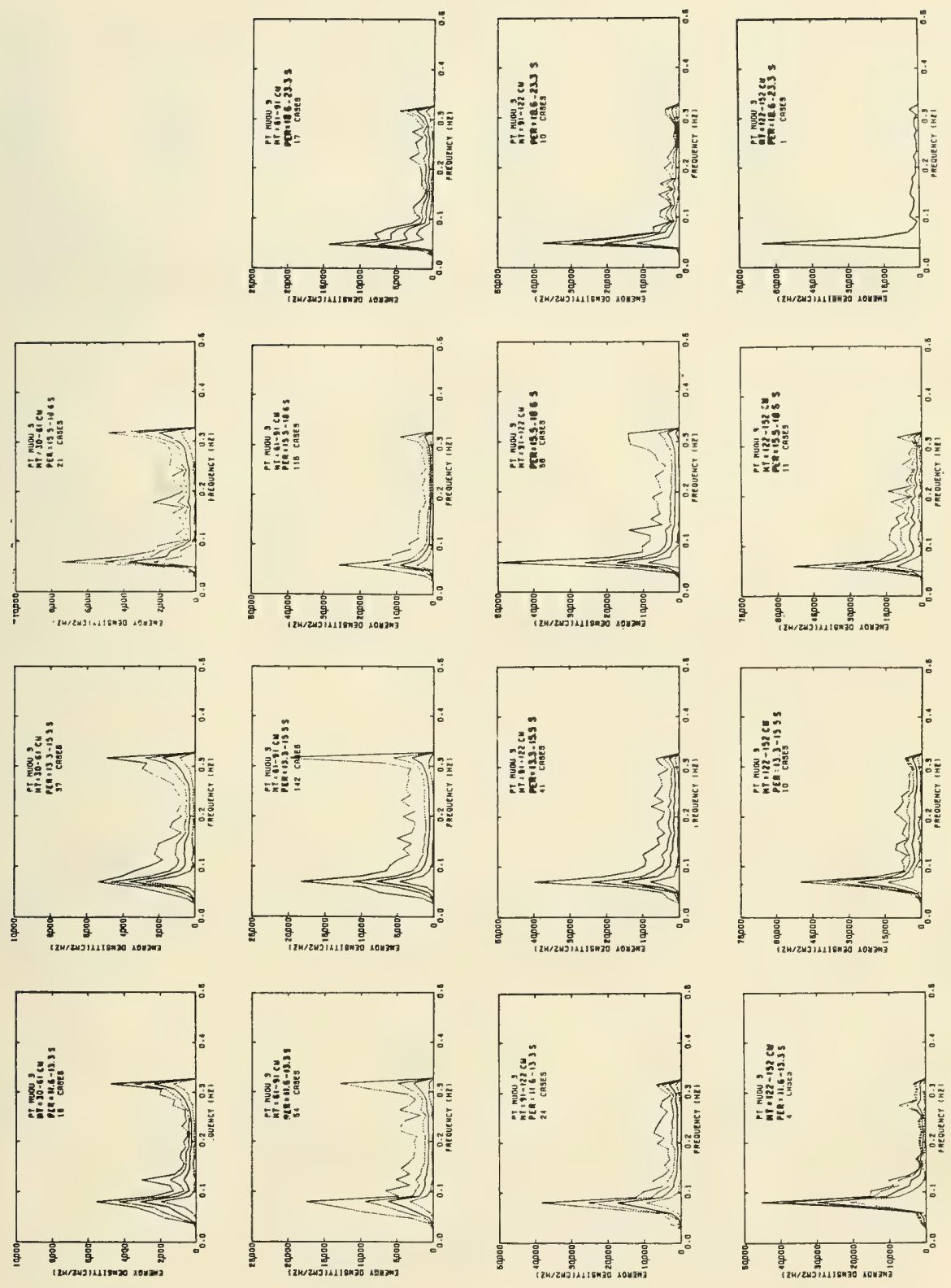

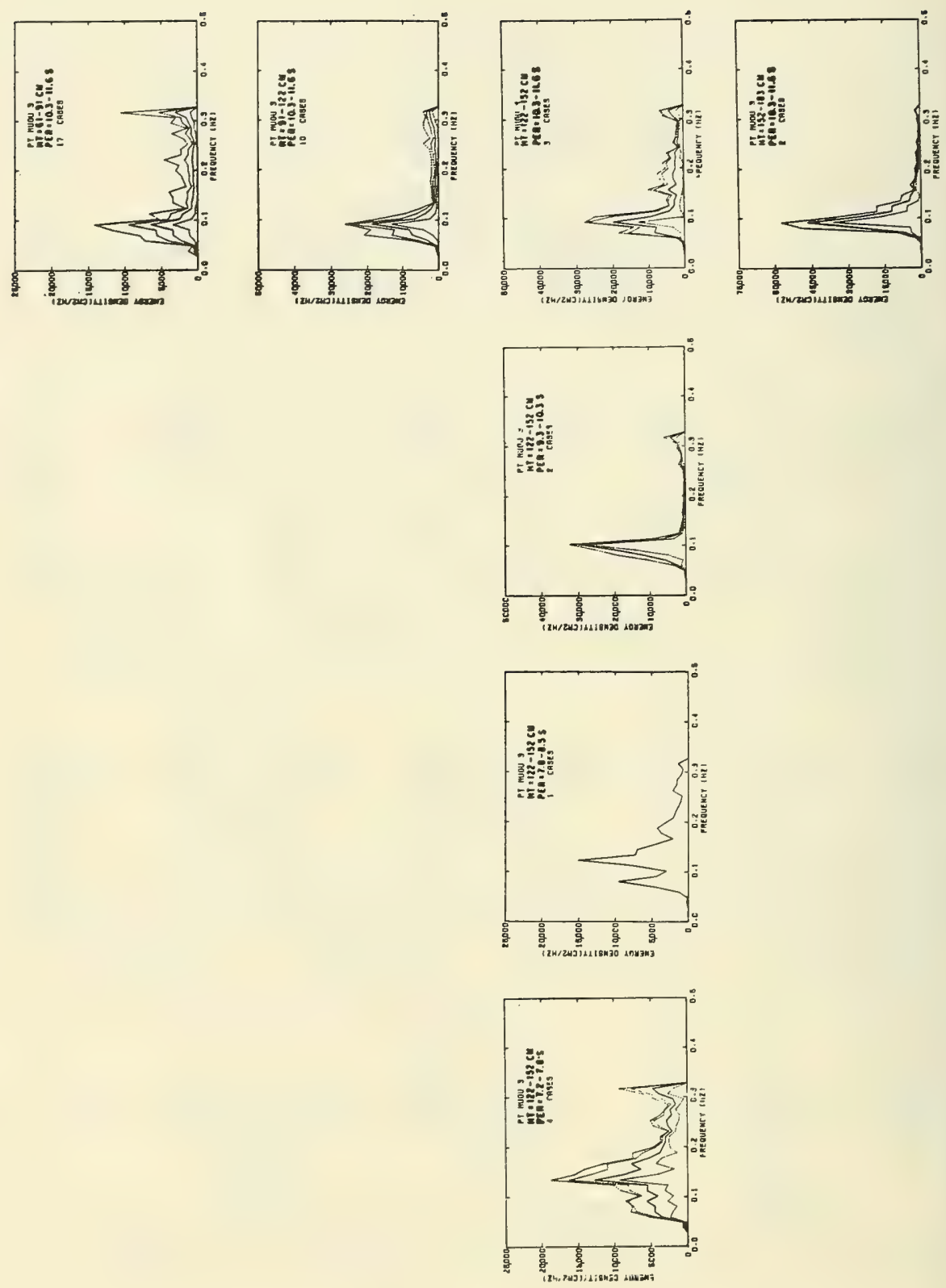
APPENDIX C

MEAN SPECTRA GROUPED BY HEIGHT, PERIOD, AND WATER LEVEL

\begin{tabular}{ll}
\multicolumn{2}{c}{ Interpretation key } \\
\hline Mean & Water leve 1 \\
\hline 1 & low \\
2 & mid \\
3 & high \\
\hline
\end{tabular}



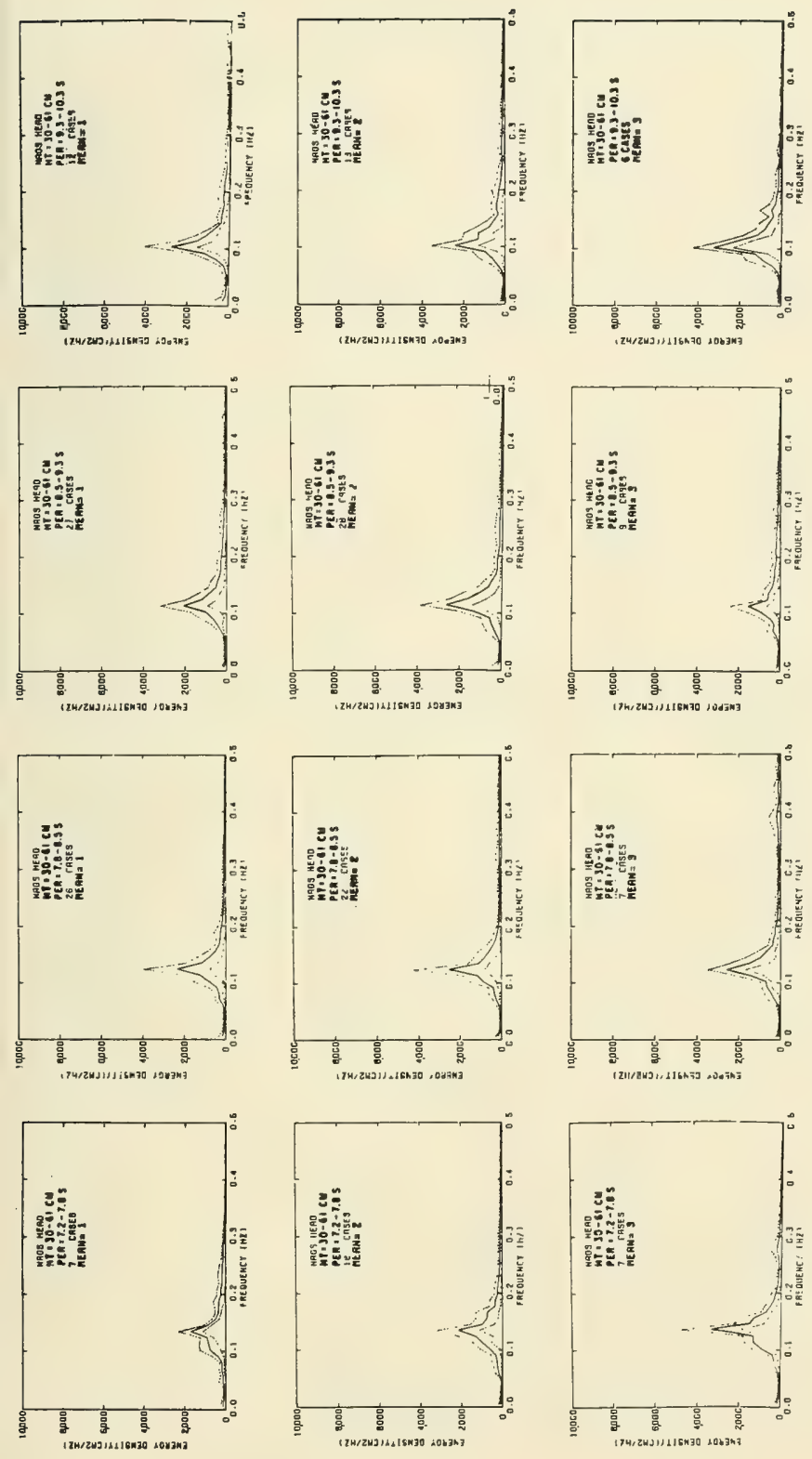

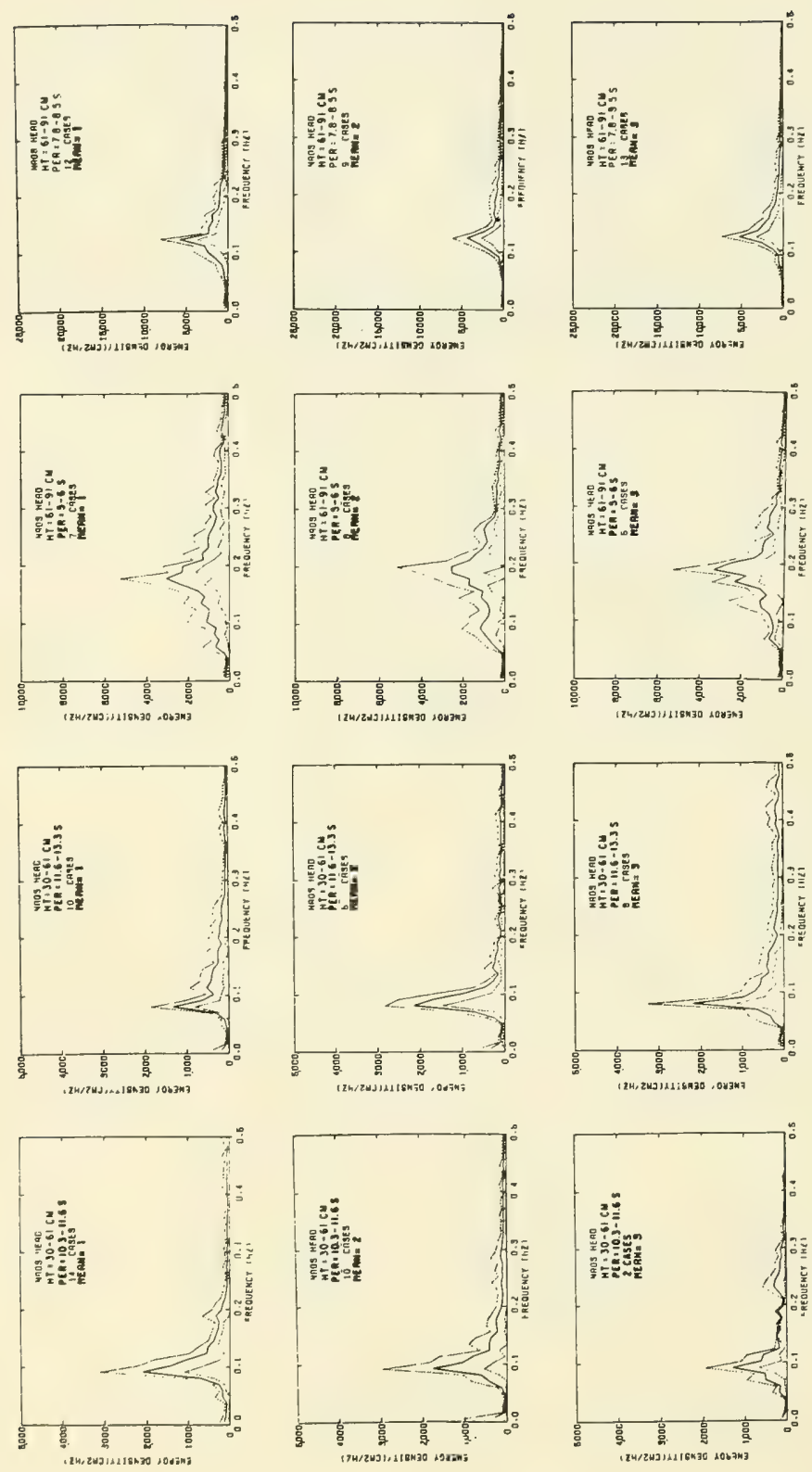

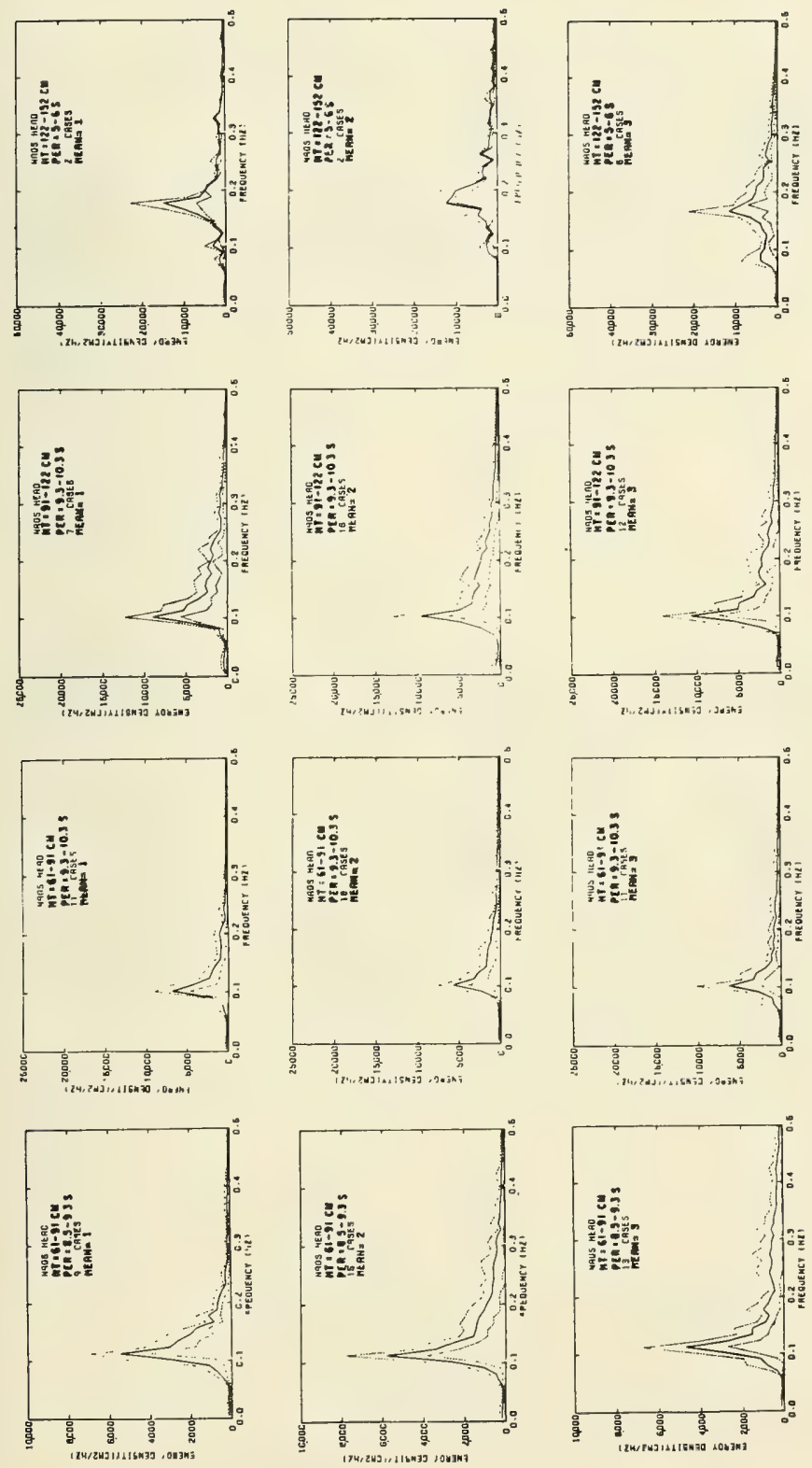

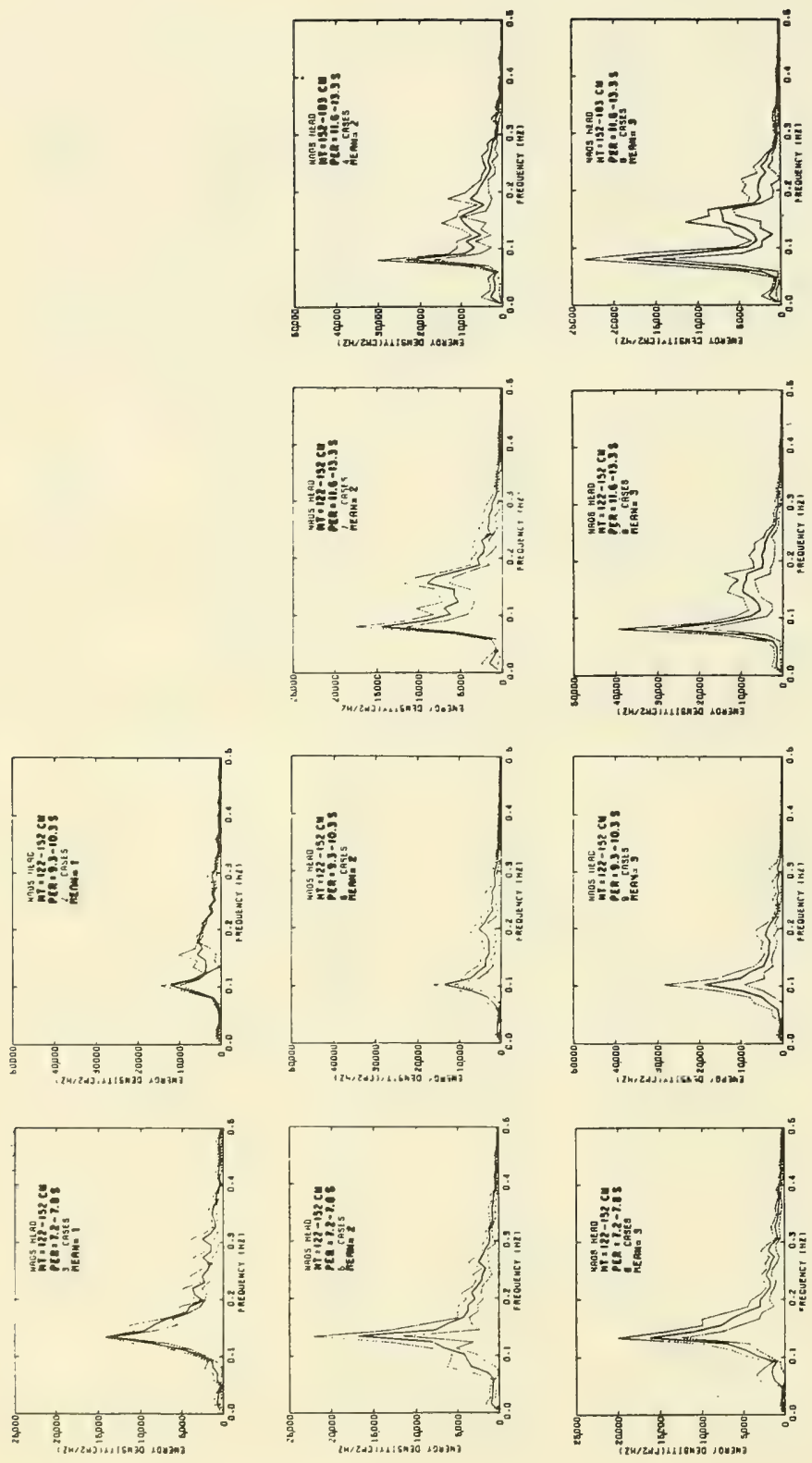


\section{APPENDIX D \\ DESCRIPTION OF COMPUTER ROUTINE SMOOTH FOR IDENTIFYING MAJOR PEAKS AND VALLEYS IN AN IRREGULAR SIGNAL}

The computer routine SMOOTH is useful for deleting small, inconsequential peaks and valleys from an irregular digital signal. Peaks and valleys that remain after application of SMOOTH represent major extrema which in many cases are more meaningful than small wiggles in the signal.

SMOOTH is a very general routine which can be applied to many different situations. It has been applied at CERC to the following three situations:

(a) Computation of statistics on individual waves. SMOOTH was applied to a time series of sea-surface elevations:

(b) Computation of statistics on tidal highs and lows. SMOOTH was applied to a time series of tidal elevations.

(c) Identification of major spectral peaks. SMOOTH was applied to a wave energy spectrum.

The operation of SMOOTH is most conveniently described in terms of its application to a time series of sea-surface elevations, although its other applications are analogous. The general scheme of operation consists of a check on the time difference and elevation difference between successive extrema. If either is less than the specified acceptable minimum then one peak and one valley are deleted from the time series.

The input to SMOOTH consists of several control parameters and an array (EXTIM) containing time and elevation for each extremum in the time series. Figure D-1 shows five extrema in a hypothetical time series. If the point labeled " 1 " were the first point in the time series, then the first 10 values in the EXTIM array would be

$$
t_{-1}, n_{-1}, t_{0}, n_{0}, t_{1}, n_{1}, t_{2}, n_{2}, t_{3} \text {, and } n_{3} \text {, }
$$

where $t_{i}$ and $\eta_{i}$ are defined as the time and elevation associated with the ith point. The control parameters which must be specified are:

$$
\begin{aligned}
& \text { FURST }= \text { time associated with the first point desired in the } \\
& \text { time series. }
\end{aligned}
$$

ITEMS $=$ total number of values in EXTIM array ( $=$ twice the number of extrema).

CHP = minimum acceptable time difference between successive points (critical half period).

HMIN = minimum acceptable elevation difference between successive points. 


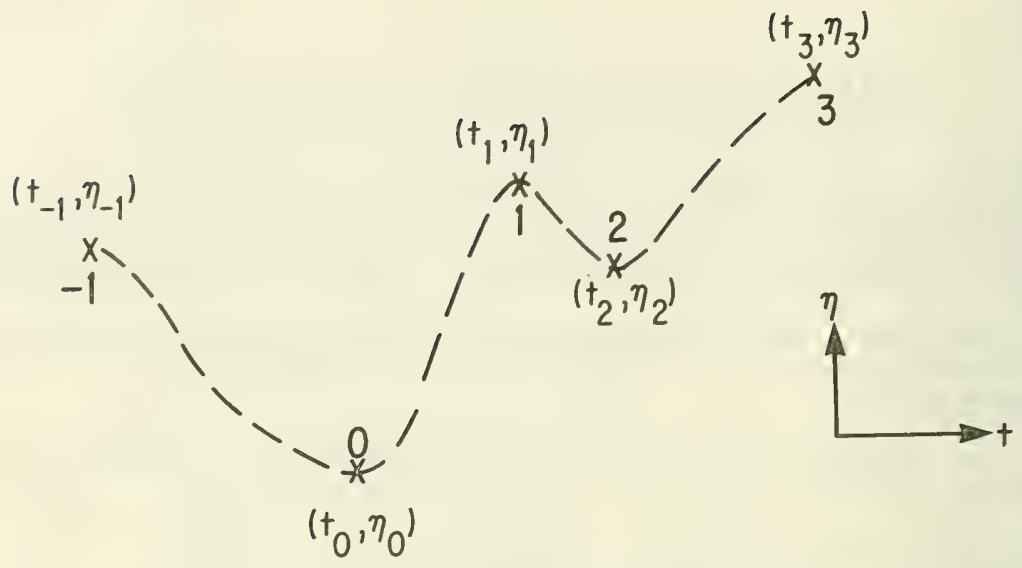

Figure D-1. Hypothetical time series.

After completion of SHOOTH, the times and elevations of major peaks and valleys are stored in the first ITEMS elements of EXTIM. The value of ITEMS has been reduced in accordance with the number of small peaks and valleys eliminated. Since the smoothing algorithm cannot work properly at the end of a record, the last few points are usually accepted regardless of whether or not they satisfy the acceptance criteria. Thus, the last six elements in EXTIM may not represent major peaks or valleys and should either be checked or categorically eliminated.

A complete list of subroutine SMOOTH with comments is provided in Figure D-2. A flow chart for the main processing loop (identified as loop 1520 in the listing) is provided in Figure D-3. The symbols $n_{i}$ and $t_{i}$ and the point numbers referred to in the flow chart are consistent with definitions in Figure D-1. $\mathrm{T}_{C H P}$ and $\mathrm{H}_{M I N}$ in the flow chart are equivalent to CHP and HMIN in the listing. 


\section{SURROUTINE SMOOTH (FURST, ITEMS)}

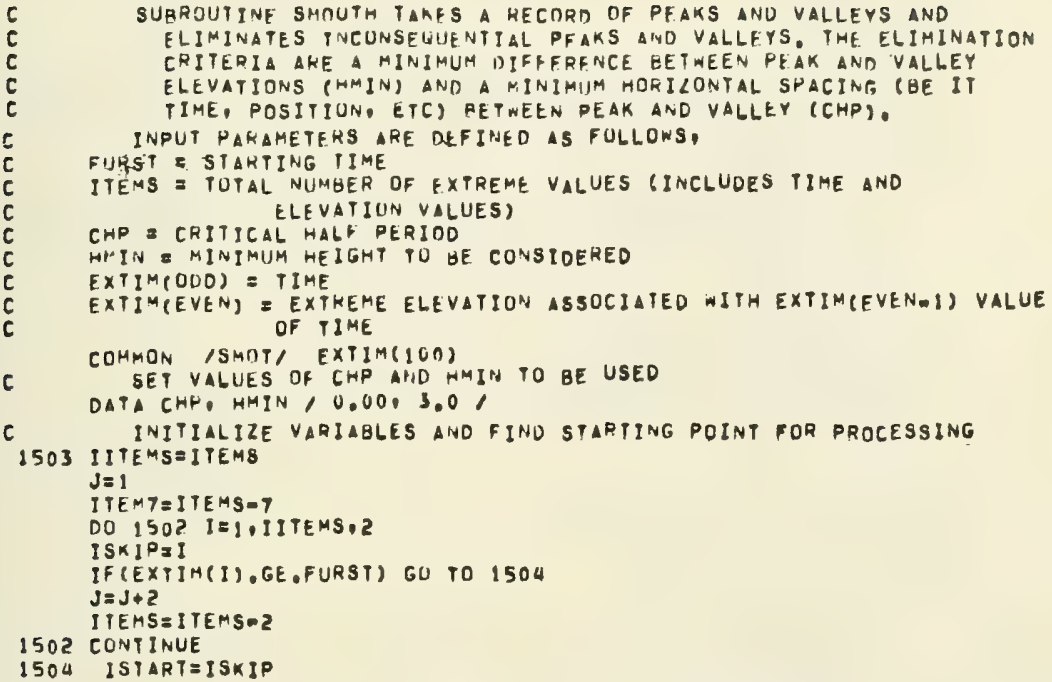

C

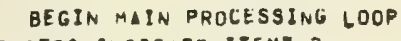

DO 1520 I ISIART,ITEMT,

$L=I$

IF (ISTAKT.GT.ITEMT)GO TO 1520

IF (EKTIMII)+CHP.GT.EXTIM(I+?)) GO TO 1511

IF (ALSCEXTIM I+I) EEXTIM(I+3)),LT.MMIN)GO TO 1511

C IF NO TRANSFER, THIS EXTREME ACCEPTEO

EXTI*(J) $=E X T I M(I)$

EXTIM $(J+1)=E X T I M(I+1)$

$j=j+5$

GO PO 1520

C WHEN THE NEXT INSTRUCTION IS REACHED, ONE HIGH AND ONE LOW WILL C BE DELETED

1511 IF (EXTIM(I+1),GT.EXIIM(I+3)) GO TO 1510

C IF NEXI INSTRUCTION IS IISED. THIS IS A LOW

IF $\left(E X I I M(I+3), G T . E X T I^{M}(1+1)\right) G 0$ TO 1512

IF (EXTIM(I+3),GT.EXTIHI $(I-1)) G 0$ TO I5Is GO TO 1517

1512 If (EXIIM I+3). GT.EXIIM $(1+7)) G 0$ TO 1519 GO TO 1516

C WHEN NEXT IASTRUCTION IS USED. THIS IS HIGH

1514 IF $\left(E X T I^{M}(1+5), G T . E X I I^{H}(1+1)\right) G 0$ TO 1515

IF $(E X T I M(1+7), G T, E X T I M(1+3)) G 0$ TO $15 t 9$

GO TO 1510

1515. IF (EXTIM(I+3).GT.EXTIM(I-1))GO TO 1519

GO TO 1518

C SET THE VALUE of ICASE

1516 ICASE $=$ I

GO $10 \quad 1521$

1517 ICASE $=2$

60 TO 1521

Figure D-2. List of subroutine SMOOTH. 


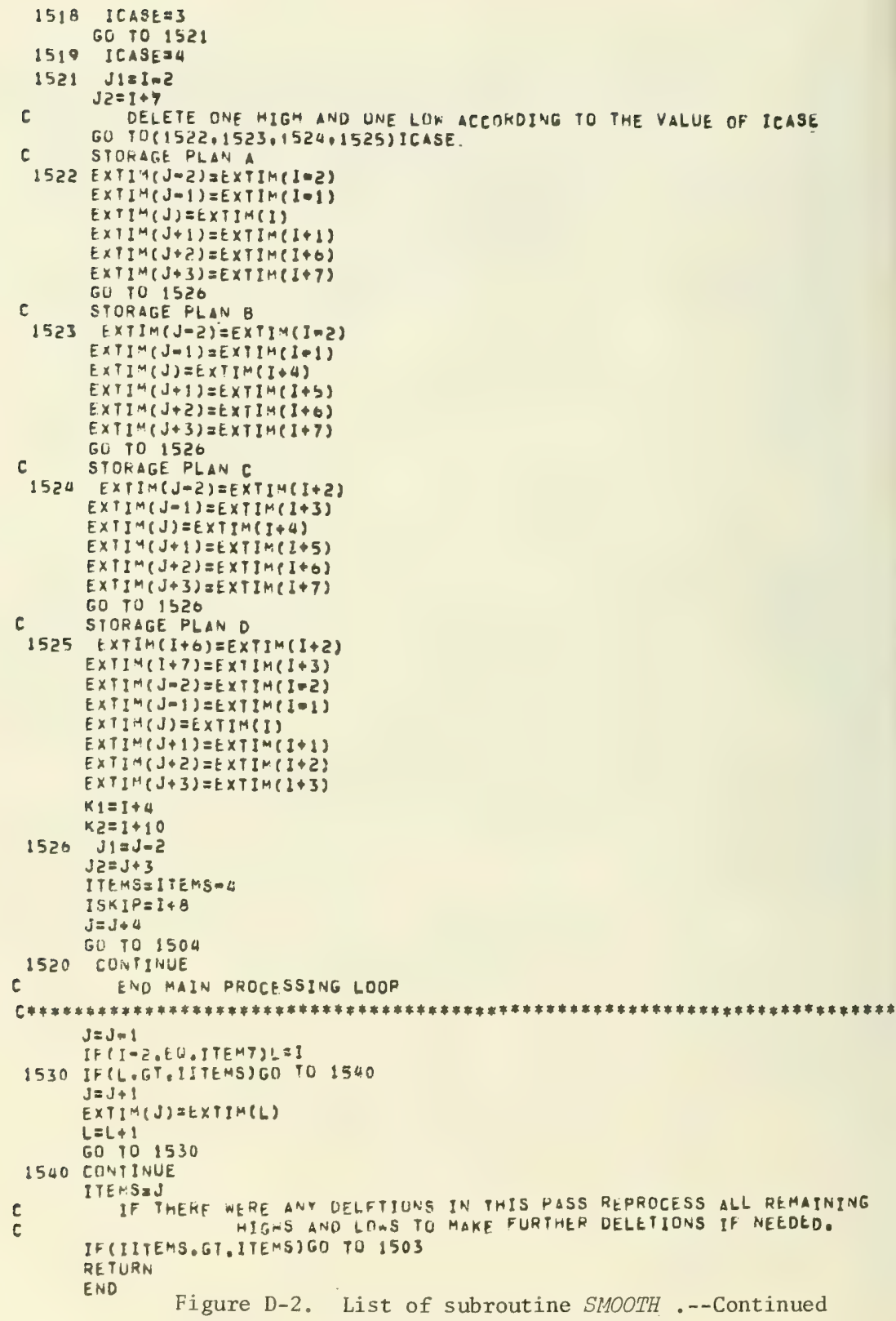

Figure D-2. List of subroutine SMOOTH .--Continued 


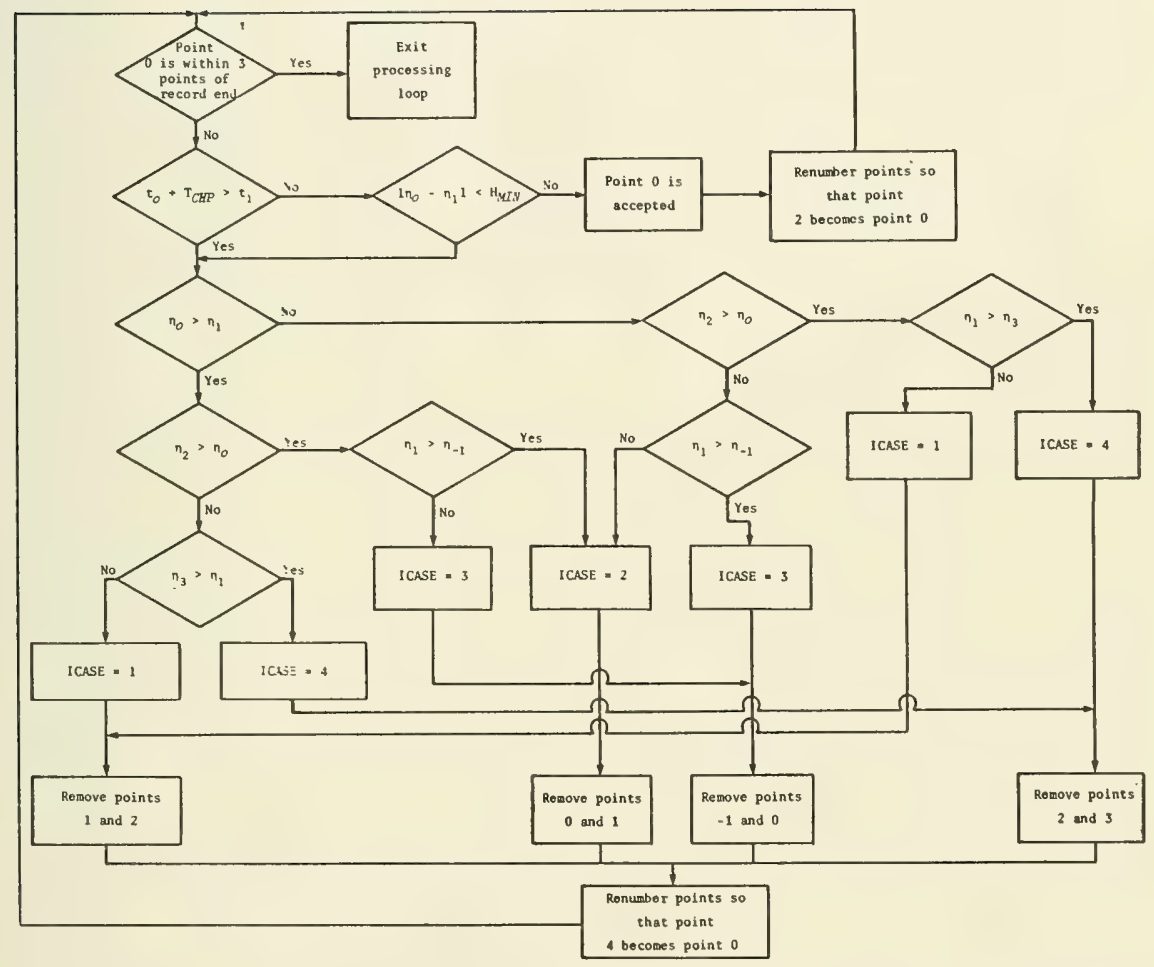

Figure D-3. Flow chart for main processing loop in SMOOTH (1oop 1520). 





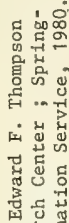

造 粗

हो

-

品 此

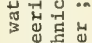

तु

in

造 नु

न न

ज.

的

预

घं

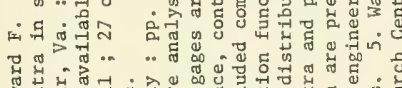

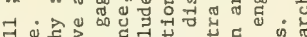
प्व

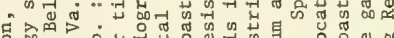

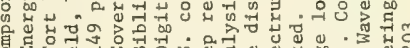

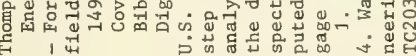

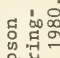

家总

in....

1. 出

गु

密苍苝

ลิ

- 茫.

出

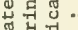

उ

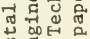

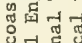

8 그

is

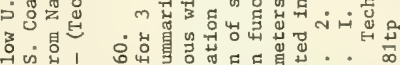

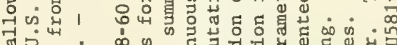

䠉...

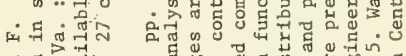

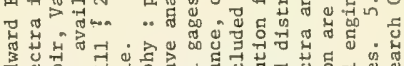

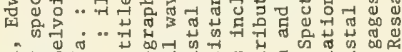
हो $>$. म

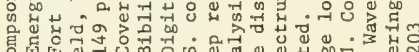

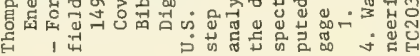

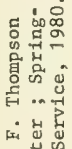

चु

忽专范

소웡

-

is

兘

3

곡

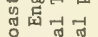

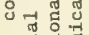

is

उ

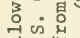

刃्ट

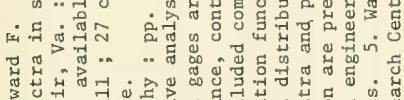

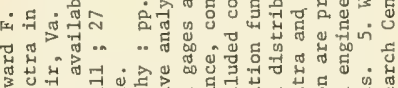

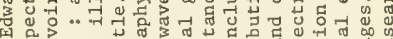
की

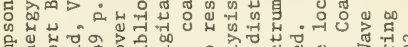

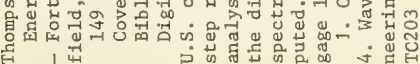

क्. $\ldots$

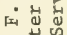

ซु

谣它苝

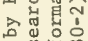

-

कूष

身然

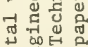

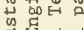

त्र

ช

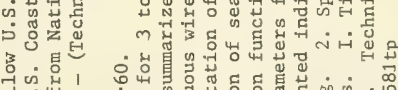

नुम

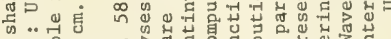

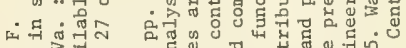

。

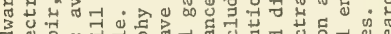

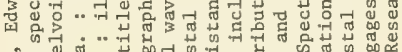

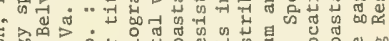

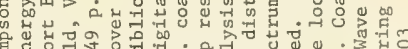

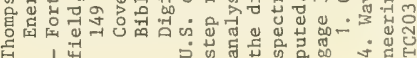





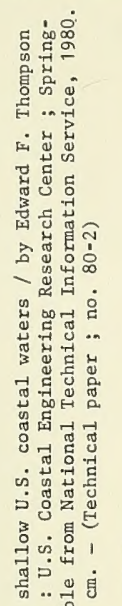

व

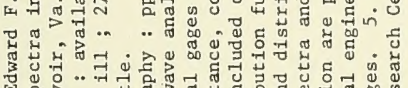

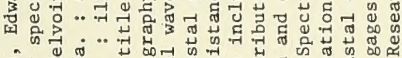

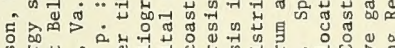

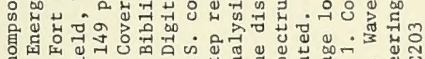

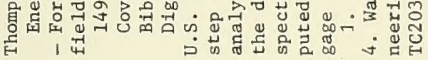

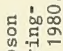

言路 ब

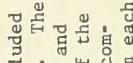

.

4.

ชั

起落

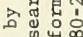

-

का

म्ञ

उ

भु)

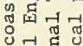

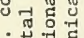

is

的最

䠉..

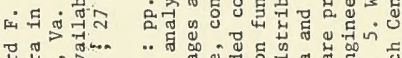

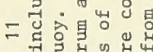

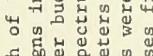

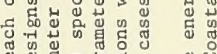

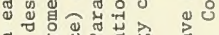

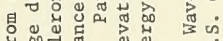

出

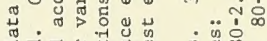

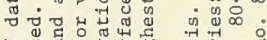

出

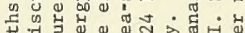

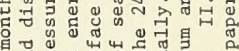

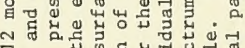

(구 की

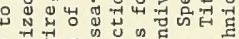

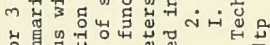

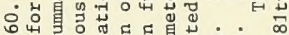

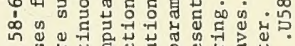

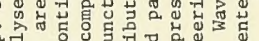

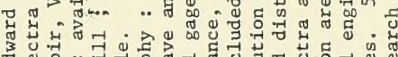

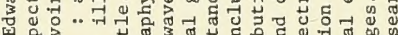
की

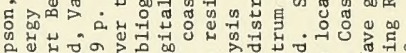

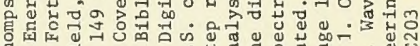

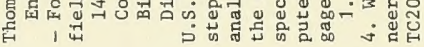

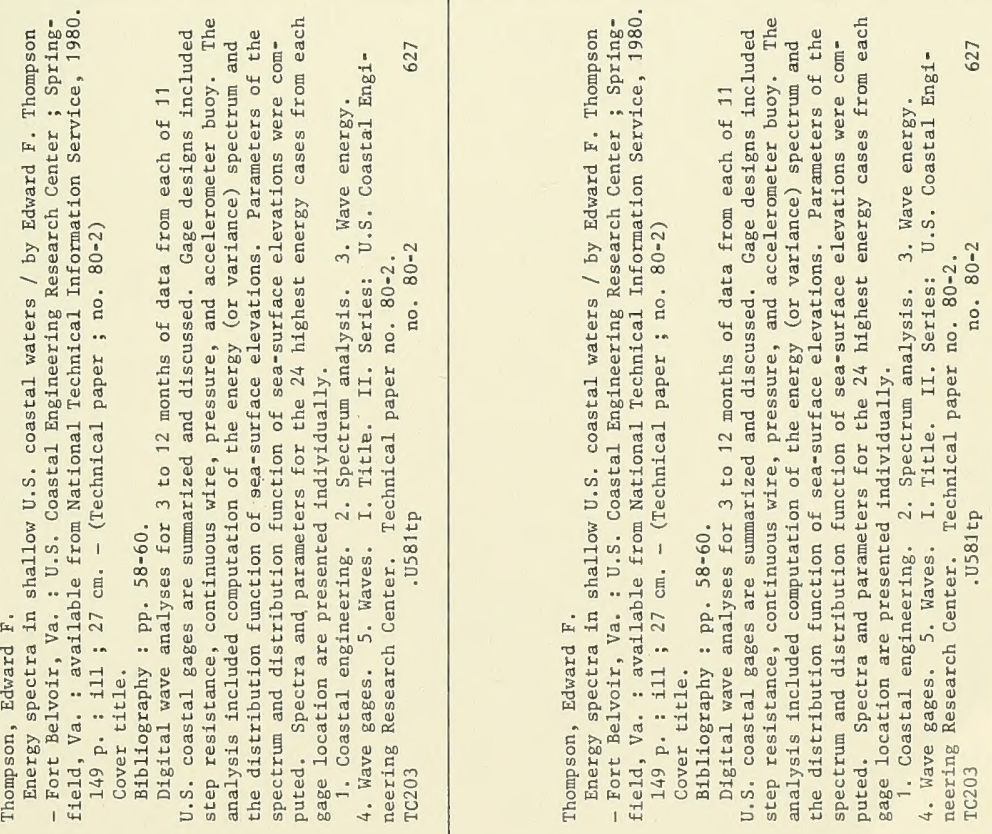




